Universidad de Lima

Facultad de Derecho

Carrera de Derecho

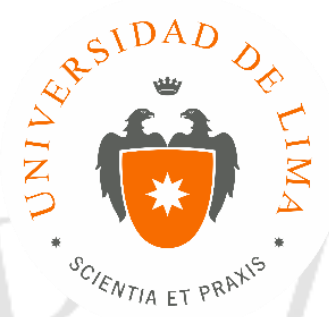

\title{
MARCAS NO TRADICIONALES NO VISIBLES: ANÁLISIS DE LA NORMATIVA LEGAL VIGENTE EN EL PERÚ. UNA GRAN OPORTUNIDAD PARA LAS MARCAS OLFATIVAS
}

Tesis para optar el Título Profesional de Abogado

Marlenny Fernanda Zevallos Labrin Código 20092681

Asesor

Luis Alonso García Muñoz-Najar

Lima - Perú

Julio de 2018 


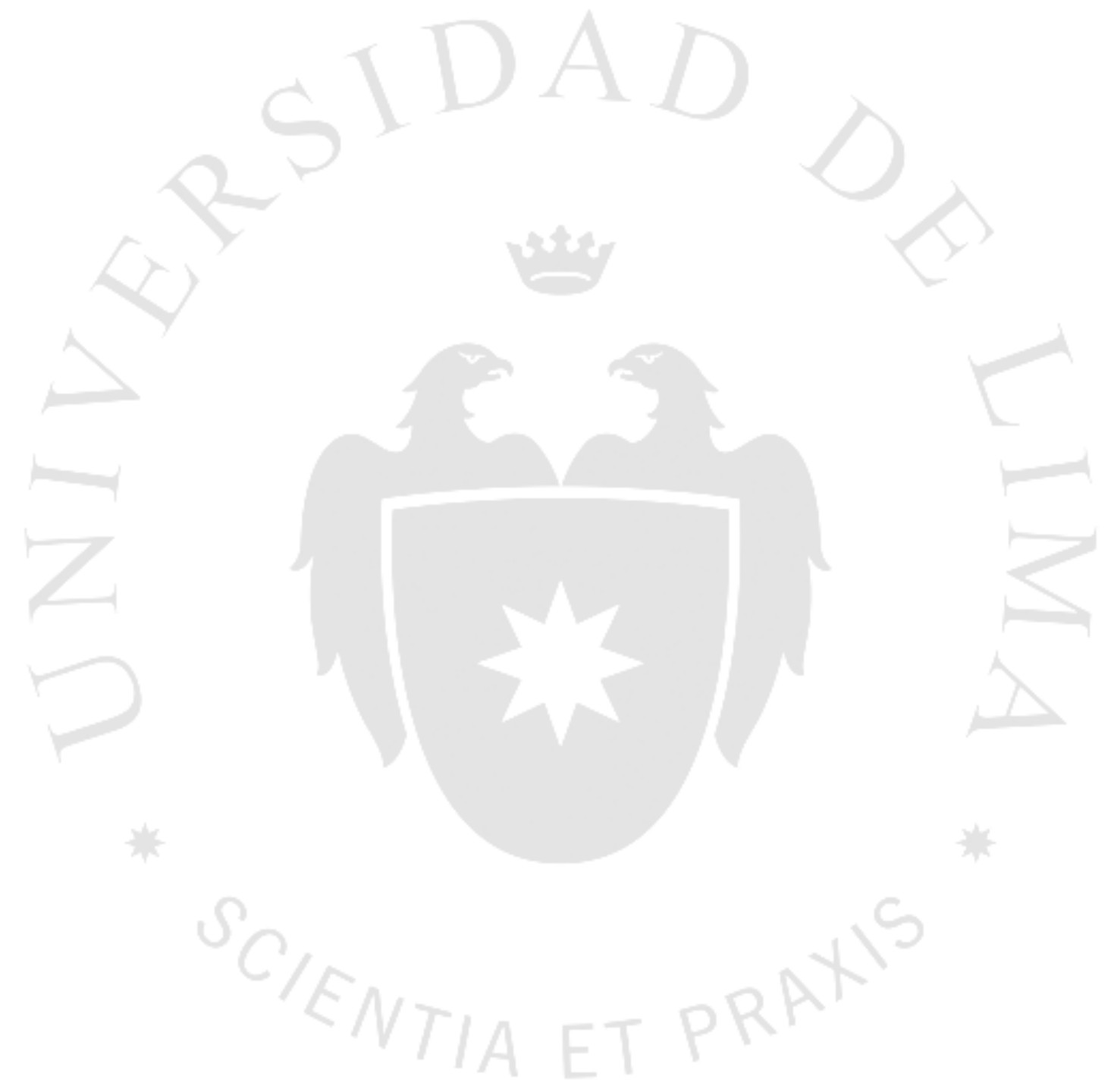




\section{DEDICATORIA}

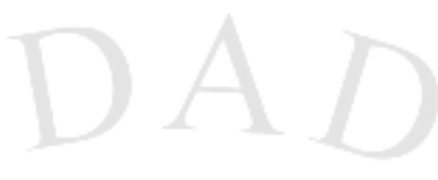

A Dios mi creador, y a los familiares, colegas, profesores y tutores que me acompañaron en este gran proceso de formación. 


\section{MARCAS NO TRADICIONALES NO VISIBLES: ANÁLISIS DE LA NORMATIVA LEGAL VIGENTE EN EL PERÚ. UNA GRAN OPORTUNIDAD PARA LAS MARCAS OLFATIVAS}




\section{TABLA DE CONTENIDO}

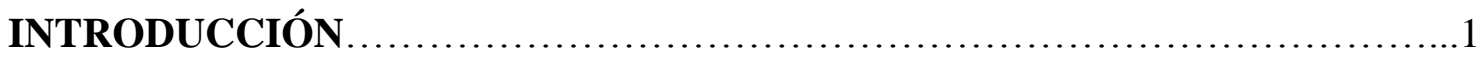

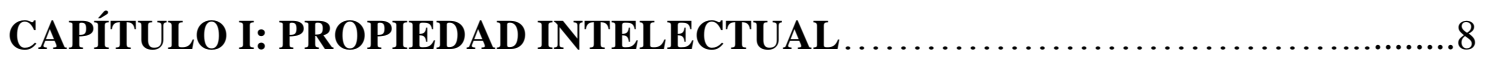

1.1 Definición..................................................................... 8

1.2 Antecedentes históricos.............................................11

1.2.1 En el ámbito internacional......................................11

1.2.2 En el ámbito subregional....................................17

1.3 Derechos de autor y derechos conexos.............................. 18

1.4 Derechos de propiedad industrial....................................... 21

1.4.1 Sistemas de las nuevas creaciones..............................21

a) Patentes de invención.......................................21

b) Modelos de utilidad..........................................23

c) Diseños industriales.....................................24

1.4.2 Signos distintivos.......................................24

a) Marcas..................................................25

b) Lemas comerciales....................................27

c) Nombres comerciales....................................27

d) Indicaciones geográficas..................................27

$1.5 \mathrm{El}$ alcance de los derechos de propiedad intelectual.......................28

CAPÍTULO II: DERECHO MARCARIO .....................................

2.1 Concepto de marca............................................... 30

2.2 Funciones de la marca.................................................. 34

2.2.1 Función distintiva y diferenciadora.............................34

2.2.2 Función de identificación del origen empresarial..................35

2.2.3 Función de recolección de prestigio o calidad....................36

2.2.4 Otras funciones de la marca...................................36

a) Función publicitaria e informativa............................36

b) Función competitiva......................................37

c) Función de protección del titular de la marca....................39

d) Función de protección al consumidor...........................39 
e) Función de la marca en el mundo empresarial. .39

2.3 Principios Marcarios

2.3.1 Principio de registrabilidad....................................41

2.3.2 Principio de territorialidad..................................41

2.3.3 Principio de especialidad......................................42

2.3.4 Principio de temporalidad...................................43

2.4 Tipos de marcas...................................................... 44

2.4.1 Marca de producto y marca de servicio..........................44

2.4.2 Marcas denominativas, figurativas y mixtas.....................44

2.4.3 Marcas evocativas, arbitrarias y de fantasía.......................45

2.4.4 Marcas bidimensionales y tridimensionales.....................45

2.4.5 Marcas colectivas y marcas de certificación.......................45

2.4.6 Marcas de reserva y marcas defensivas..........................46

2.4.7 Marcas tradicionales y no tradicionales.........................46

2.5 Requisitos para el registro de marcas................................47

2.6 Prohibiciones al registro de marcas........................................48

\section{CAPÍTULO III: PROTECCIÓN A LAS MARCAS NO TRADICIONALES NO}

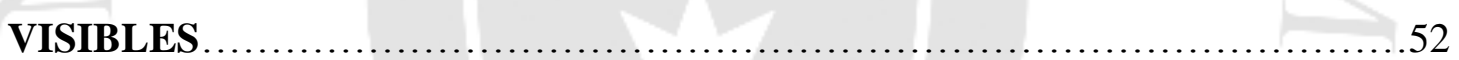

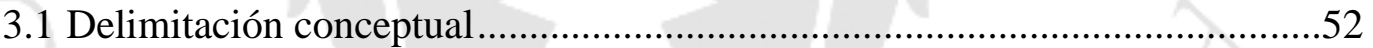

3.2 Decisión 486 - Régimen Común sobre Propiedad Industrial de la Comunidad Andina, y las marcas no tradicionales no visibles..........................55

3.2.1 Requisito de la distintividad................................59

a) La aptitud distintiva de un signo sonoro......................61

b) La aptitud distintiva de un signo táctil........................64

c) La aptitud distintiva de un signo gustativo....................65

d) La aptitud distintiva de un signo olfativo....................67

3.2.2 Requisito de la representación gráfica........................75

a) La represetación gráfica de un signo sonoro.....................78

b) La representación gráfica de un signo táctil....................87

c) La representación gráfica de un signo gustativo.................89

d) La representación gráfica de un signo olfativo...................90

3.2.3 Prohibiciones al registro de marcas no tradicionales no visibles.....97 
3.3 Decreto Legislativo 1075: examen comparativo entre signos distintivos, y las marcas no tradicionales no visibles

3.4 Tratados Internacionales de los que el Perú es parte en materia de Propiedad Intelectual concernientes al Derecho de Marcas, y las marcas no tradicionales no visibles. 102

3.4.1 Convenio de Paris 102

3.4.2 Acuerdos sobre los Aspectos de los Derechos de Propiedad Intelectual relacionados con el Comercio (ADPIC)........................104

3.4.3 Acuerdo de Promoción Comercial Perú - EEUU....................105

3.4.4 Tratado sobre el derecho de marcas (TLT)........................106

3.4.5 Acuerdo Comercial entre el Perú y la Unión Europea..............107

3.4.6 Otros tratados internacionales..............................108

a) Acuerdo de Asociación Transpacífico (TPP)..................108

b) Tratado de Singapur sobre el Derecho de Marcas...............109

3.5 Derecho comparado en el tratamiento de las marcas no tradicionales no visibles

3.5.1 Colombia ................................................112

a) Casos prácticos.....................................113

- Marcas sonoras..........................................113

- Marcas táctiles..........................................121

- Marcas olfativas..........................................125

3.5.2 Ecuador.................................................... 137

a) Casos prácticos........................................138

- Marcas táctiles.........................................138

3.5.3 Estados Unidos de América....................................139

a) Casos prácticos.........................................142

- Marcas gustativas......................................142

- Marcas táctiles..........................................142

- Marcas sonoras...........................................144

- Marcas olfativas..........................................145

3.5.4 Unión Europea..............................................148

a) Casos prácticos.......................................... 162

- Marcas gustativas..........................................162 
- Marcas táctiles..........................................162

- Marcas sonoras............................................162

- Marcas olfativas..........................................166

3.6 Casos prácticos de marcas no tradicionales no visibles en el Perú............186

3.6.1 Marcas sonoras...............................................186

3.7 Interpretaciones Prejudiciales del Tribunal de Justicia de la Comunidad Andina sobre marcas no tradicionales no visible...........................194

3.8 Una gran oportunidad para las marcas olfativas........................201

3.8.1 El uso de los aromas como iniciativa empresarial...................201

CAPÍTULO IV: APORTES. .208

4.1 Criterios para determinar la distintividad de las marcas no tradicionales no visibles, sobre la base de la función fundamental y más importante de la marca: su función identificadora y diferenciadora ....................................208

4.2 La eliminación del requisito de la representación gráfica para el registro de marcas no tradicionales no visibles y la adminisión de muestras y/o reproducciones como representaciones indispensables para registrar estos nuevos tipos de marcas................................................229

4.3 La Decisión 486 y el Decreto Legislativo 1075 deben regular el tema de marcas teniendo en consideración el registro de marcas no tradicionales no visibles...

1. Conclusiones generales............................................247

2. Conclusiones específicas.........................................253

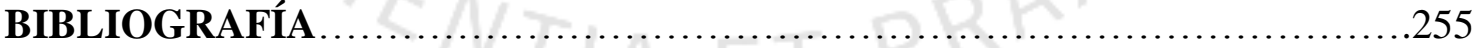




\section{INTRODUCCIÓN}

Los derechos de propiedad intelectual alrededor del mundo se han convertido en figuras jurídicas claves para el desarrollo social y económico de los países. Estos derechos son de fundamental relevancia para cualquier relación comercial entre los distintos agentes económicos que interactúan en el mercado.

Dentro de los derechos de propiedad intelectual se encuentra la figura de la marca, la cual ha tenido desde sus orígenes gran importancia en el mundo comercial. Esta figura ha tenido que enmarcarse a las situaciones sociales y económicas del momento para su funcionamiento como signo distintivo.

Por mucho tiempo, las marcas han estado compuestas por elementos figurativos, denominativos y mixtos, pero debido al gran desarrollo económico internacional, y con esto, el progresivo aumento de la competencia, los empresarios se han visto en la necesidad de componer las marcas con elementos distintos con el fin de captar más la atención de los consumidores.

En efecto, han surgido marcas compuestas de distintos elementos, algunas de las cuales serán objeto de estudio en el presente trabajo de investigación, estas son: las marcas sonoras, táctiles, gustativas y olfativas, conocidas en doctrina como "marcas no tradicionales no visibles".

Cabe recalcar que si bien la Decisión 486 (norma subregional que tiene supremacía sobre cualquier norma nacional) admite expresamente el registro de signos no visibles como marcas, como los signos olfativos y sonoros - no estando claro si se permite el registro de signos táctiles y gustativos en dicha norma - hay gran debate en doctrina acerca de la distintividad de estos signos, así como de la posibilidad de ser representados gráficamente, siendo estos dos requisitos indispensables para que puedan acceder a registro. 
Asimismo, debe mencionarse que en el Perú hay ya gran número de marcas sonoras registradas, pero no hay hasta la fecha solicitudes de los otros tipos de marcas no tradicionales no visibles, siendo preocupante en mayor medida sobre la falta de marcas olfativas, las cuales se consideran beneficiosas para nuestros empresarios dado su gran poder evocador.

Vale precisar que este debate sobre la distintividad y el requisito de la representación gráfica de las marcas no tradicionales no visibles también se ha observado en los demás países miembros de la Comunidad Andina, en la Unión Europea, y en los Estados Unidos de América; incluso, en diversas reuniones del Comité Permanente sobre el Derecho de Marcas, Diseños Industriales e Indicaciones Geográficas de la Organización Mundial de la Propiedad Intelectual (OMPI) se ha expuesto esta discusión.

Planteamiento del problema:

Con el gran desarrollo de la economía a nivel internacional se puede apreciar que cada día las empresas buscan implementar nuevos métodos para competir y ganar más posición en el mercado, y de esta manera lograr persuadir a los consumidores de comprar los productos y servicios que ofrecen. En ese sentido, el sistema marcario ha sido clave para que los empresarios puedan darle valor agregado a sus bienes, pues una marca, además de permitir al consumidor identificar sus productos y servicios, lleva consigo la reputación y prestigio que a lo largo del tiempo ha adquirido.

En este orden de ideas, debido al progresivo aumento de la competencia, las empresas se han visto en la necesidad de captar la atención del público consumidor de una manera más innovadora, ya no solamente utilizando el sentido de la vista (que ha sido a lo largo del tiempo la manera más usual de marketing), sino aprovechando otros sentidos del ser humano como el olor, el tacto, el gusto y el oído, lo que en el Derecho Marcario se denomina como Marcas No Tradicionales No Visibles.

Pese a que estos avances son de gran ayuda para los empresarios, los Estados - y en nuestro caso, el Perú, así como los demás países miembros de la CAN- no están avanzando al mismo ritmo en el tratamiento legal de estos nuevos tipos de marcas, lo 
que está generando grandes trabas en su desarrollo y, al mismo tiempo, no dando respuesta a muchas de las interrogantes que se han generado sobre la distintividad de estos signos y sobre la posibilidad de ser representados gráficamente para que puedan ser registrados como marcas.

En efecto, sobre la aptitud distintiva de las marcas no tradicionales no visibles, se han manifestado distintas posiciones como: i) los consumidores no las apreciarían como signos distintivos, pues solo estarían acostumbrados a las marcas visibles; ii) los consumidores no podrían percibirlas antes de elegir el producto, no pudiendo cumplir la función principal de la marca; iii) deberían mostrar mayormente distintividad sobrevenida para que puedan acceder al registro; iv) no podrían separarse del producto que distinguen, siendo dañino para la libre competencia y no permitiendo al signo cumplir con la función principal de la marca; v) serían percibidas de manera subjetiva por parte de los consumidores, no teniendo claro el objeto de protección; vi) el signo no visible tendría que ser novedoso para que pudiera acceder a registro; vii) se verían como signos meramente funcionales; entre otros argumentos, que han obstaculizado el registro de marcas no tradicionales no visibles, sin tener en cuenta la finalidad del sistema marcario, y no teniendo claras muchas de las instituciones del mismo.

Asimismo, sobre el requisito de la representación gráfica se han presentado y propuesto distintos medios para satisfacer este requisito, cabiendo preguntarse cómo podrían representarse gráficamente signos no visibles. En efecto, de los casos prácticos expuestos y, sobre todo, del caso Sieckmann, se verá que este requisito ha constituido un obstáculo para el registro de estos signos; es por ello que es necesario estudiar la figura de la representación gráfica en relación a estos nuevos tipos de marcas, y determinar qué medio es más idóneo para el correcto funcionamiento del sistema marcario.

Debe recalcarse que la Oficina de Propiedad Intelectual del Perú; es decir, el Instituto Nacional de Defensa de la Competencia y de la Protección de la Propiedad Intelectual - INDECOPI - tiene poca experiencia en el análisis y estudio de registro de marcas no tradicionales no visibles, pues hasta la fecha no cuenta con marcas no tradicionales no visibles registradas (ni solicitudes) a excepción de las marcas sonoras. 
Asimismo, si bien nuestra norma andina - la Decisión 486 - se considera una norma avanzada en cuanto al tratamiento legal de las marcas no tradicionales no visibles (a comparación de las legislaciones de otros países), los demás países miembros tampoco tienen experiencia sobre el tema; a excepción de Colombia (aunque no mucha), que es el país miembro de la CAN con más solicitudes y registros de estos tipos de marcas.

Por este motivo, hemos recopilado la experiencia de la Unión Europea y los Estados Unidos de América por ser los más avanzados en la materia; sin embargo, debe precisarse que todas las posiciones de estos países sobre ambos requisitos han tenido mucha influencia en las distintas Oficinas de Propiedad Intelectual alrededor del mundo, generando muchas veces trabas en el desarrollo de las marcas no tradicionales no visibles, pese a ser estos nuevos tipos de marcas, figuras legales que han llamado la atención de los grandes empresarios.

Justificación:

El Perú, como un país en vías de desarrollo, necesita proteger a los diversos agentes económicos que interactúan en el mercado para lograr desarrollar cada día más su economía. En ese sentido, el Estado debe proteger las iniciativas empresariales que puedan hacer más competitivo y eficaz el proceso de consumo; caso contrario, estos agentes no se verían incentivados a innovar sus productos, lo que haría imposible hacer al país más competitivo.

En este orden de ideas, siendo que las marcas no tradicionales no visibles están surgiendo como iniciativas innovadoras por parte de los agentes económicos a nivel internacional, el Perú no puede hacer caso omiso a este tema, pues de no darle el debido tratamiento legal las empresas no se verán incentivadas ni protegidas para poder desarrollarlas, no aprovechando una oportunidad que quizá nos permita ser más competitivos internacionalmente. Asimismo, el desarrollar este tema nos permitirá analizar el funcionamiento de nuestro sistema marcario y su eficacia con relación a las demandas actuales del mercado.

Hipótesis: 
- Los solicitantes deberán demostrar en mayor medida que los signos no visibles han adquirido distintividad sobrevenida para que puedan ser registrados como marcas, pues los consumidores, en principio, no podrán identificarlas como tales.

- El requisito de la representación gráfica ya no responde a las nuevas demandas del mercado, pues hace imposible el registro de las marcas no tradicionales no visibles y, en consecuencia, debe ser eliminado.

- Es necesario que se modifiquen algunos artículos de la Decisión 486 de la Comunidad Andina y del Decreto Legislativo 1075 para que puedan registrarse sin inconvenientes los signos no visibles como marcas.

Objetivos:

1. General:

Analizar y dar solución a los problemas de la distintividad y del requisito de la representación gráfica de los signos no visibles para su acceso al registro como marcas $\mathrm{y}$, en consecuencia, puedan ser debidamente protegidas por el sistema marcario.

\section{Específicos:}

- Analizar la aptitud distintiva de un signo no visible, y sus distintas posiciones.

- Analizar si el requisito de la representación gráfica es indispensable para que un signo pueda constituirse como marca, en especial, en el caso de los signos no visibles.

- Evaluar las distintas formas de representación de los signos no visibles como marcas, para determinar cuál es la más adecuada.

- Analizar los criterios de registrabilidad de las marcas no tradicionales no visibles bajo la Decisión 486 de la Comunidad Andina, y otras leyes a las que el Perú está sujeto en materia de Propiedad Intelectual.

- Evaluar posibles alternativas de cambio de la normativa vigente para el registro de las marcas no tradicionales no visibles. 
Metodología a emplear:

El método a emplearse en el presente trabajo de investigación es el inductivo, pues a raíz de premisas particulares de toda la información recogida de los diferentes países en el tratamiento legal de las marcas no tradicionales no visibles, así como de los tratados internacionales en la materia, y casos prácticos, se llegarán a resultados generales para su posible implementación en el sistema marcario peruano.

Asimismo, en algunas partes de la investigación se utilizará un enfoque funcionalista; es decir, vamos analizar los distintos conceptos e instituciones que se encuentran en el Derecho Marcario y corroborar si estos son viables para el registro de estos nuevos tipos de marcas.

Estructura de la investigación:

En el Capítulo I se hace un breve repaso de la Propiedad Intelectual en general, en donde se abordan temas básicos como su definición, antecedentes históricos, derechos de autor y derechos conexos, derechos de propiedad industrial y los alcances de estos derechos, con el fin de visualizar el tema en cuestión: las marcas, y poder conceptualizarlas mejor, saber en qué extremo del derecho se encuentran situadas y poder diferenciarlas con figuras afines.

En el Capítulo II, con el fin de poder tener un panorama general sobre el Derecho Marcario, y poder estudiar a las marcas no tradicionales no visibles de manera adecuada, abordamos el concepto de marca, sus funciones, principios, tipos de marcas, los requisitos y prohibiciones para su registro.

En el Capítulo III se estudia de manera profunda a las marcas no tradicionales no visibles: marcas sonoras, táctiles, gustativas y olfativas, en concordancia con las normas nacionales, andinas, tratados internacionales, derecho comparado (países miembros de la Comunidad Andina, Unión Europea y los Estados Unidos de América), casos prácticos en el Perú y en el seno del Tribunal de Justicia de la Comunidad Andina, y explicamos la importancia que el mundo empresarial le ha dado a las marcas olfativas. 
En el Capítulo IV, en base a lo expuesto en los capítulos precedentes, se exponen los aportes del presente trabajo de investigación, respecto a la distintividad y requisito de representación gráfica de las marcas no tradicionales no visibles.

Finalmente, en el apartado final se exponen las conclusiones generales y específicas de la presente tesis, a partir de los resultados obtenidos de la investigación.

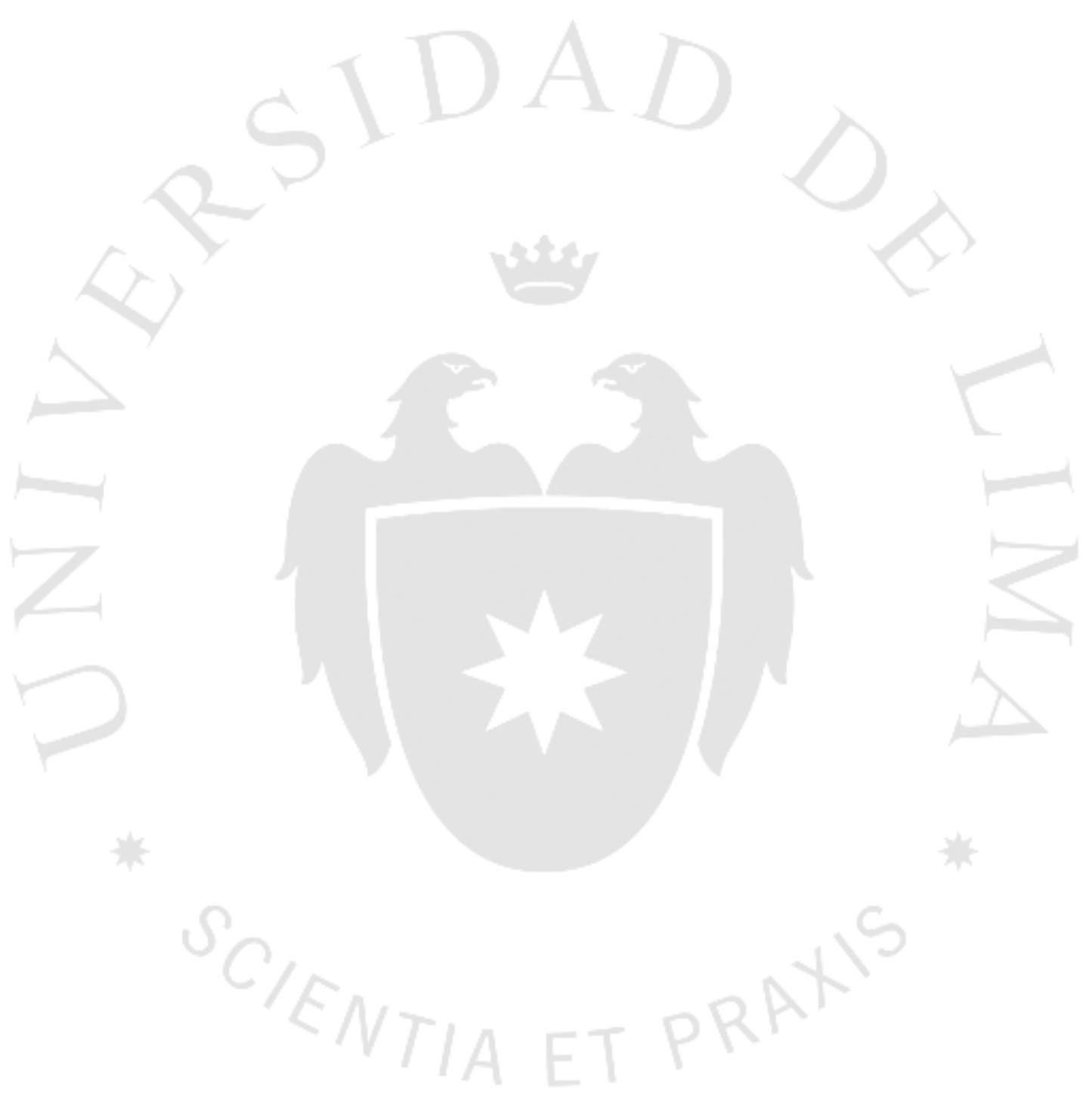




\section{CAPÍTULO I: PROPIEDAD INTELECTUAL}

\subsection{Definición}

La Propiedad Intelectual ha presentado variaciones a lo largo del tiempo, desde la edad moderna en que su necesidad se hizo evidente hasta la actualidad.

Pese a lo expuesto, las normas peruanas muestran que han adoptado a la Propiedad Intelectual como un tipo especial de propiedad. Sobre este aspecto, es necesario mostrar los siguientes artículos del Código Civil (1984), los cuales, sobre la materia, expresan lo establecido a continuación:

Art. 18.- Los derechos del autor o del inventor, cualquiera sea la forma o modo de expresión de su obra, gozan de protección jurídica de conformidad con la ley de la materia.

Art. 884.- Las propiedades incorporales se rigen por su legislación especial.

Art. 886.- Son muebles:

$(\ldots)$

6.- Los derechos patrimoniales del autor, inventor, de patentes, nombres, marcas y otros similares.

Art. 923.- La propiedad es el poder jurídico que permite usar, disfrutar, disponer y reivindicar un bien.

Art. 2093.- La existencia y los alcances de los derechos reales relativos a obras intelectuales, artísticas o industriales se rigen por lo dispuesto en los tratados y leyes especiales; y si éstos no fueran aplicables, por la ley del lugar donde dichos derechos hayan sido registrados

La ley local establece los requisitos para el reconocimiento y ejercicios de tales derechos. 
Adicionalmente a lo expuesto, el artículo 2 de la Constitución Política del Perú (1993) señala en concordancia con su numeral 8) que toda persona tiene derecho a la libertad de creación intelectual, artística, técnica y científica, así como a la propiedad sobre dichas creaciones y a su producto.

Cabe recalcar, con el fin de poder definir de manera más concisa a la Propiedad Intelectual, que el diccionario de la Real Academia Española (2014) define al término Intelectual como "perteneciente o relativo al entendimiento".

En este orden de ideas, puede decirse que para nuestra legislación la Propiedad Intelectual es la propiedad sobre un bien mueble incorporal, consistente en todo lo perteneciente o relativo al entendimiento humano, como las creaciones e invenciones (derechos de autor, marcas, patentes, entre otros), teniendo estos derechos expresamente protección constitucional ${ }^{1}$. Asimismo, en concordancia a la definición de Propiedad señalada en el artículo 923 expuesto anteriormente, los titulares tienen el poder jurídico para usar, disfrutar, disponer y reivindicar, en este caso, sus inventos o creaciones, rigiéndose esta protección por tratados y leyes especiales, y si estos no fueran aplicables por la ley del lugar donde dichos derechos hayan sido registrados.

Para un mejor entendimiento de la materia, debe precisarse que usualmente se utiliza el término "Propiedad Intelectual" para referirse tanto al tipo especial de propiedad (tal como lo hemos definido) como a la disciplina normativa encargada de regular este tipo especial de propiedad, siendo correcto referirnos a esta última como "Derechos de Propiedad Intelectual".

Por otro lado, es menester precisar que el tratamiento legal de esta materia no se limita sólo al ámbito nacional, sino tanto al subregional como internacional (tal como puede inferirse del artículo 2093 anteriormente expuesto).

\footnotetext{
${ }^{1}$ Debe recalcarse que en el tema de marcas, el Tribunal Constitucional del Perú estableció en su sentencia del 10 de noviembre de 2015 (Exp. 08506-2013-PA/TC) que la marca no tiene sustento constitucional directo.
} 
En efecto, cabe señalar que el Perú en el año 1969 con los países vecinos de Bolivia, Colombia, Chile y Ecuador (sumándose posteriormente Venezuela) ${ }^{2}$ suscribieron el Acuerdo de Cartagena - acuerdo de creación de la Comunidad Andina decidiéndose en dicho acuerdo tratar y regular, entre otros temas, a la Propiedad Intelectual de forma comunitaria, aprobando normas legales de rango supranacional. Estas normas comunitarias son denominadas "decisiones", las cuales no necesitan aprobación previa de los Congresos o Asambleas de sus países miembros para que deban aplicarse, sino que son vinculantes de forma inmediata.

Por otra parte, en el ámbito internacional, la Propiedad Intelectual se ha considerado una materia clave para el desarrollo de los países, tratando éstos de negociar y llegar a acuerdos sobre su tratamiento legal mediante tratados multilaterales y bilaterales. Así, el Perú (al igual que la mayoría de los países del mundo) forma parte de la Organización Mundial de la Propiedad Intelectual (en adelante, OMPI) organismo especializado de las Naciones Unidas - que ha generado diversos tratados sobre la materia, los cuales muchos de ellos han sido ratificados por el Perú. De la misma manera, nuestro país ha suscrito acuerdos bilaterales con muchos países regulando este tema.

Por lo expuesto, la definición de Propiedad Intelectual y sus diversos conceptos deben analizarse no solamente en base a las normas y tratamientos legales existentes en el plano nacional, sino también desde el ámbito subregional e internacional.

Cabe mencionar que la Comunidad Andina no ha señalado una definición de Propiedad Intelectual de manera expresa dentro de sus normas. Por su parte, la Organización Mundial de la Propiedad Intelectual (OMPI, 2002) ha establecido que "la propiedad intelectual se relaciona con las creaciones de la mente: invenciones, obras literarias y artísticas, así como símbolos, nombres e imágenes utilizados en el comercio” (p.2), y que la Propiedad Intelectual se divide en dos categorías: i) La propiedad industrial, y ii) el derecho de autor (p.2).

\footnotetext{
${ }^{2}$ Actualmente la Comunidad Andina está conformada por los países de Bolivia, Colombia, Ecuador y el Perú.
} 


\subsection{Antecedentes históricos}

\subsubsection{En el ámbito internacional}

Tal como se mencionó en el subcapítulo anterior, la Propiedad Intelectual comenzó a tomar importancia desde la Edad Moderna, precisamente desde el siglo XV con la invención de la imprenta por Johannes Gutenberg. Anteriormente a ello, puede decirse que no hubo lo que denominamos Propiedad Intelectual con características similares a como la conocemos hoy en día. Sin embargo, hubieron ciertos indicios.

En la época griega ${ }^{3}$ tanto las obras de los escritores como sus reproducciones eran escritas a mano; por ello la adquisición de ejemplares tenía un costo elevado y solo podían ser adquiridas por una clase privilegiada. En esta época si bien hubieron pequeños intereses por parte de los autores en proteger la paternidad de sus obras, no hubieron intereses económicos de su parte.

En efecto, el Instituto Autor de España (2010) nos explica que:

Podemos remontarnos a la antigua Grecia para encontrar los primeros reconocimientos al intelecto humano. En el año 330 ac, una ley ateniense ordenó que se depositaran en los archivos de la ciudad copias exactas de las obras de los grandes clásicos. En ese entonces, los libros eran copiados en forma manuscrita; por consiguiente, el costo de las copias era muy alto y su número total era limitado. Este hecho, sumado a la escasez de personas capacitadas para leer y en condiciones de poder adquirirlas, determinó el nacimiento de un interés jurídico específico que proteger (párr.1).

Esta situación se mantuvo hasta a mediados de la Edad Media, periodo que se caracterizó por la fuerte influencia del cristianismo, siendo para los ciudadanos del momento el mundo espiritual más importante que cualquier valor material o económico. En este periodo tampoco se podía hablar de Propiedad Intelectual como actualmente la conocemos, pues se pensaba que la creatividad de los hombres venía de Dios, por lo que las obras eran consideradas de la sociedad y no de su autor. Asimismo, según Salvador Ruíz (2011), al igual que en el mundo antiguo, se entendía que al transmitir el dominio de la obra, el autor perdía todo derecho futuro sobre la misma. Por lo que no

\footnotetext{
${ }^{3}$ Debe recalcarse que en este tiempo no se diferenciaba la obra del soporte material que la contenía.
} 
podía reclamar derechos de obra, edición, etc. Eran reglas más de carácter moral que de orden jurídico (p.43, 44).

Por estas mismas razones, en este tiempo había pocos intercambios comerciales $\mathrm{y}$, por ello, ausencia de normas jurídicas que los regulara, bastando solamente los usos y costumbres del derecho romano.

Esta situación fue cambiando entre los siglos XI y XII. Las ciudades comenzaron a crecer, y con ellas, los intercambios comerciales. En esta época la obtención de dinero ya se veía como un medio de subsistencia. De esta manera, fueron surgiendo los artesanos y grandes comerciantes, así como la aparición de la Lex Mercatoria, la cual fue el sistema jurídico creado por los propios comerciantes para regular sus relaciones de acuerdo a sus usos y costumbres.

Debe recalcarse que en esta época no existía una economía de mercado, pues no había libertad de concurrencia y competencia, y, por ello, las leyes estaban hechas a favor de los comerciantes, quienes eran un grupo privilegiado que podía realizar actos de comercio.

Es menester recalcar que es en este periodo de la historia, con el desarrollo de los intercambios comerciales, con la aparición de los comerciantes, y con la creación de la Lex Mercatoria, donde comenzaron haber indicios de la figura más tratada de la Propiedad Intelectual: la marca ${ }^{4}$.

Sobre el particular, es importante indicar lo expresado por Carlos Cornejo (2000) a continuación:

La marca es una expresión de la transformación de la sociedad, pero también parte constitutiva de ella, característica que comparte con todo el derecho comercial, con la Lex Mercatoria. Específicamente, la marca surge como una de las respuestas a las

\footnotetext{
${ }^{4}$ La figura de la marca en este tiempo, además de no tener la misma función principal que ahora posee, no era una figura legal de gran relevancia, pues tal como lo explica María Baylos Morales (2009): "Puede comprenderse el escaso valor de los signos mercantiles en una sociedad en la que sólo existe un pequeño margen de competencia económica". (p.263).
} 
múltiples exigencias del comercio, en una época en que el cambio de la sociedad era proclive a este desarrollo (...).

La institución jurídica de la marca nace a finales del siglo XI y durante el siglo XII, como parte de la Lex Mercatoria o cuerpo de derecho mercantil. (...)

(...) Es así que en esta época la marca existe como institución jurídica que acota ciertos derechos y obligaciones asociados a un aspecto de las relaciones comerciales, como era la identificación del origen de los productos, a las que se añadían según circunstancias sociales especificas una serie de otras funciones. (...) Podemos ver que la marca no era un ente aislado, sino más bien, parte de un sistema de derecho que había nacido para

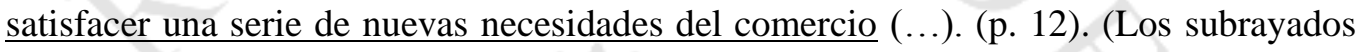
son míos).

Debe enfatizarse que si bien en esta época las marcas no eran usadas como signos para distinguir productos o servicios en el mercado, estos signos eran usados para identificar el origen de los productos, para garantizar su calidad, y para fiscalizar que las personas que no tenían el privilegio de concurrir en el mercado no realicen actividad comercial.

En el siglo XIII aumentaron los intercambios comerciales formándose el comercio internacional. En esta época surgieron las marcas de los maestros (las cuales eran obligatorias) unidas a las marcas de las corporaciones, a las cuales se le añadieron las funciones de brindar seguridad y evitar fraudes.

Es fundamental mencionar que el siglo XV fue una época muy importante para la Propiedad Intelectual, pues la imprenta fue inventada por Johannes Gutenberg. Fue a raíz de este suceso que comenzaron a surgir necesidades que requerían resolverse por medio de los derechos de autor, marcas y patentes.

En ese sentido, la invención de la imprenta propició, en primer lugar, que el contenido de las obras de los autores (sus opiniones, creencias e ideas) se comenzaran a difundir con mayor velocidad, pudiendo las personas tener más acceso a ellas y aumentando el número de lectores y, por otra parte, la obra se independizó de su 
soporte material, pues su contenido fue lo que se convirtió en lo importante. Por este motivo, surgió la necesidad política de regular su reproducción, otorgando las autoridades a los libreros e impresores del momento el monopolio de explotación de las obras, a cambio de que pudieran censurar las que fueran en contra de sus ideales e intereses.

Por otro lado, siendo que las personas podían ilustrarse y educarse más, así como acceder más rápido a la información, los desarrollos científicos y tecnológicos aumentaron, y con esto la necesidad de las patentes y de las marcas. Estas últimas debido a que estos desarrollos permitieron potenciar los procesos productivos, y con esto, expandir el comercio a gran velocidad, surgiendo diversos problemas que hicieron necesario atribuirle a las marcas (conforme transcurría el tiempo) nuevas funciones, tales como: controlar que no se vendieran productos prohibidos, recolectora de prestigio del dueño de la marca, asegurar el pago de impuestos, entre otros.

Al respecto, María Baylos Morales (2009) sobre las distintas funciones otorgadas a las marcas hasta antes de la época de la revolución industrial, nos indica:

(...) convendrá partir de la diferenciación entre las siguientes funciones posibles del signo: como indicador de la propiedad del objeto, como equivalente a firma artística, como elemento de individualización de responsabilidades inherentes al proceso de producción y finalmente, como medio de diferenciación del empresario o de sus productos ante la clientela. Cada una de estas modalidades constituyen figuras totalmente diversas, algunas de las cuales no tiene relación de ningún género con el moderno concepto del signo distintivo de carácter mercantil. (p.262)

En el siglo XVII nos situamos en la época de la Ilustración o también llamado "Siglo de las Luces", aquí surgieron los primeros filósofos liberales, siendo las figuras más importantes para el tema Thomas Hobbes y John Locke, sentándose las primeras bases para el establecimiento de una economía de mercado.

De acuerdo a lo explicado por Carlos Cornejo (2000), John Locke manifestaba que el derecho de propiedad era el derecho más importante que tenía el ser humano; tanto es así que en uno de sus textos señaló que las obras del cuerpo y el trabajo de las manos de un individuo eran propiamente de él, por lo que los derechos intelectuales 
eran una manifestación externa de la persona, refiriéndose a que se tratarían de derechos de la personalidad. Indicó además que la creación intelectual era un patrimonio económico que solo pertenecía a su propio creador. Por su gran influencia, fue Inglaterra el primer país que reconoció los derechos patrimoniales de los autores, y de esta manera, los derechos intelectuales se fueron convirtiendo de ser una institución del derecho mercantil a una del derecho civil, específicamente como un derecho de propiedad. (p. 65- 66, 71-72).

En el siglo XVIII es cuando los problemas que necesitaron de los derechos de propiedad intelectual se hicieron más evidentes. En esta época ya las obras de los autores se diferenciaban del soporte que las contenía, convirtiéndose el autor en el propietario de los derechos morales y económicos de la obra. A finales de este siglo las ideas liberales se expandieron con más fuerza, habiendo una fuerte posición a favor de la libertad de imprenta. Es por este motivo que en el año 1710 se promulgó en Inglaterra el Estatuto de la Reina Ana que eliminó los monopolios para la reproducción y venta de las obras literarias. De la misma manera, en 1763 en España el Rey Carlos III estableció en una ordenanza real que el derecho exclusivo de imprimir una obra solo podía otorgarse a su autor; y en Francia en 1777 Luis XVI reconoció los derechos a los autores de editar y vender sus obras. Cabe recalcar que es a partir de estos acontecimientos que muchos países reconocieron dentro de sus legislaciones nacionales el derecho de autor.

Por otro lado, con respecto a la marca, el abogado Carlos Cornejo (2000) explica que por estos tiempos surgieron dos importantes pensadores que influenciaron mucho en su formación: Adam Smith y Jeremías Bentham. El primero es conocido hasta nuestros tiempos por su famosa obra "La riqueza de las naciones" en la que explicó cómo funcionaba la economía de mercado. Fue en ese entonces que la marca comenzó a desarrollarse como un instrumento que serviría luego para competir en el mercado ante la necesidad de los comerciantes de diferenciar las diversas mercancías que comercializaban. De la misma manera, Jeremías Bentham también influyó fuertemente sobre la materia. Para él las leyes debían elaborarse dependiendo el grado de felicidad que generaba a la mayoría de personas, poniendo a la seguridad como un principio 
fundamental, y ligándola expresamente al derecho de propiedad, incluyendo a los derechos de autor, marcas, patentes, entre otros. (p. $72-77$; 77-87)

Luego de la Revolución Francesa la difusión de las ideas liberales provocó que se extinga la figura de la marca como era conocida en aquel tiempo, así como la figura de los maestros, corporaciones y cualquier tipo de privilegio en el comercio, enalteciéndose como principio fundamental la libre concurrencia al mercado. Sin embargo, debido a que hubieron casos de usurpaciones y falsificaciones, se restableció la figura de la marca.

Principalmente, con el transcurso de la Revolución Industrial el concepto de marca fue tomando forma hasta convertirse en un signo distintivo cuya función principal es distinguir productos o servicios en el mercado, función que solo puede desenvolverse en una economía de mercado en el que los competidores necesitan usar estrategias para captar clientela, y la única manera de hacerlo es que estos puedan diferenciar sus productos o servicios.

Así lo explica María Baylos Morales (2009) cuando establece que:

La verdadera estimación autónoma del signo no llega hasta el momento en que se proclama y vive una libertad de industria y comercio y un régimen de libre competencia y de libertad de mercado. Es la posibilidad de diferenciarse de los demás, de ofrecer aquello que los demás no tienen, de presentarse ante el consumidor con una apariencia y utilizando unos medios diversos de los que emplean los otros lo que promueve ese interés especialísimo representado por la posesión de medios exclusivos que distingan y diversifiquen, que identifiquen los productos de una empresa y los separen y diferencien de los competidores, que fijen el prestigio acumulado por el esfuerzo comercial, que en definitiva actúen como verdaderos vehículos por los que se canaliza la corriente de elección de los consumidores(...) (p.262).

Cabe recalcar que en esta época hubieron importantes acontecimientos de índole internacional para el desarrollo de la Propiedad Intelectual. De acuerdo a lo expuesto en 
la reseña histórica de la página web de la $\mathrm{OMPI}^{5}$, en 1883 varios países desarrollados firmaron el Convenio de Paris para la protección de la Propiedad Industrial. Este fue el primer instrumento internacional de Propiedad Intelectual. Otro acontecimiento importante fue la adopción del Convenio de Berna en 1886 para la protección de las obras literarias y artísticas. Más adelante en 1893 la Secretaría encargada de administrar el Convenio de Paris y la Secretaria encargada de administrar el Convenio de Berna se fusionaron creando la BIRPI, lo que es hoy en día la Organización Mundial de la Propiedad Intelectual - OMPI - convirtiéndose en organismo especializado de las Naciones Unidas en $1974^{6}$.

En efecto, puede resumirse que la propiedad intelectual y, en particular, la figura de la marca, ha sido consecuencia, hasta el día de hoy, de las situaciones sociales, económicas y comerciales del momento.

\subsubsection{En el ámbito subregional}

Ya se ha indicado como se ha venido desarrollando la Propiedad Intelectual en el transcurso del tiempo en el ámbito internacional, ahora para entender el tratamiento de la Propiedad Intelectual dentro de la Comunidad Andina, es importante saber que después de la Segunda Guerra Mundial la idea de los procesos de integración y de la industrialización tuvo gran acogida por parte de los países de América Latina, considerándolos materias claves para su progreso, pues traería consigo la obtención y el desarrollo de la ciencia y tecnología de los países más avanzados. Así, según Baldo Kresalja (2004), luego de la Segunda Guerra Mundial, la Comisión Económica para la América Latina de las Naciones Unidas (CEPAL) representó la hegemonía de un nuevo paradigma cuyo concepto clave era la industrialización; inclusive, se llegó a pensar que América Latina debía intensificar sus propios esfuerzos de superación haciendo uso de la ciencia y la tecnología más moderna, debiendo intensificar el comercio en la región y la ayuda mutua con miras a crear un mercado común. (p.16, 17)

\footnotetext{
${ }^{5}$ Véase. http://www.wipo.int/about-wipo/es/history.html .

${ }^{6}$ Debe resaltarse que previamente, ya habiendo varios países en el mundo adoptado en su legislación interna los derechos de Propiedad Intelectual, en 1948 el derecho de autor es universalmente reconocido en la Declaración Universal de los Derechos Humanos.
} 
De esta manera, en 1969 los países de Bolivia, Colombia, Ecuador, el Perú y Chile (quien actualmente ya no forma parte de este acuerdo de integración) suscribieron el Acuerdo de Cartagena, habiendo adoptado desde esta fecha varias decisiones en materia de Propiedad Intelectual, siendo, las más importantes para el desarrollo del presente trabajo de investigación, las siguientes:

- Decisión 85 (1974): "Reglamento para la aplicación de las normas sobre propiedad industrial". (Derogada)

- Decisión 311(1991): “Régimen común sobre propiedad industrial”. (Derogada)

- Decisión 313(1992): “Régimen común sobre propiedad industrial”. (Derogada)

- Decisión 344(1993): “Régimen común sobre propiedad industrial”. (Derogada)

- Decisión 486(2000): “Régimen común sobre propiedad industrial”. (Vigente)

Es necesario recalcar que todas estas normas se formaron de acuerdo a la forma de pensamiento y acontecimientos del momento. En ese sentido, debe precisarse que tanto la suscripción del Convenio de Paris y del Acuerdo sobre los aspectos de los derechos de propiedad intelectual relacionados con el comercio - ADPIC (Anexo 1C del Convenio por el que se crea la OMC) por parte de los Países Miembros influenciaron en la elaboración de las decisiones 311 en adelante, hasta elaborarse la actual Decisión 486.

En efecto, puede decirse que la Decisión 486 ha sido el resultado de la persistencia de los Países Miembros de adecuar las normas del régimen andino a estos tratados, principalmente, a los artículos del ADPIC.

\subsection{Derechos de autor $y$ derechos conexos}

Los derechos de autor son una rama de los derechos de Propiedad Intelectual que protegen las obras intelectuales de los autores. Estos derechos pueden ser morales como patrimoniales, y son protegidas desde su creación.

Para entender un poco más lo que significan los derechos de autor en el mundo de la Propiedad Intelectual comentaremos brevemente el Decreto legislativo 822 - Ley sobre el derecho de autor. 
La ley sobre el derecho de autor (1996) en su artículo 18 establece que "el autor de una obra tiene por el solo hecho de la creación la titularidad originaria de un derecho exclusivo y oponible a terceros, que comprende a su vez los derechos de orden moral y patrimonial determinado en la presente ley”. Sin embargo, para entender un poco más este extremo de la Propiedad Intelectual, es necesario saber qué significa autor y qué se entiende por obras.

En efecto, el artículo 2 del mismo decreto establece que autor es toda persona natural que realiza una obra intelectual; asimismo, define al término obra como "toda creación intelectual personal y original, susceptible de ser divulgada o reproducida en cualquier forma, conocida o por conocerse". (Decreto legislativo 822, 1996)

En ese sentido, el derecho otorga a las personas que realizan una creación intelectual con estas características la titularidad sobre la misma; es decir, un derecho exclusivo y oponible a terceros.

Sobre el particular es necesario señalar lo establecido en el artículo 5 del referido Decreto legislativo:

Art. 5.- Están comprendidas entre las obras protegidas las siguientes:

a. Las obras literarias expresadas en forma escrita, a través de libros, revistas, folletos u otros escritos.

b. Las obras literarias expresadas en forma oral, tales como las conferencias, alocuciones y sermones o las explicaciones didácticas.

c. Las composiciones musicales con letra o sin ella.

d. Las obras dramáticas, dramático-musicales, coreográficas, pantomímicas y escénicas en general.

e. Las obras audiovisuales.

f. Las obras de artes plásticas, sean o no aplicadas, incluidos los bocetos, dibujos, pinturas, esculturas, grabados y litografías. 
g. Las obras de arquitectura.

h. Las obras fotográficas y las expresadas por un procedimiento análogo a la fotografía.

i. Las ilustraciones, mapas, croquis, planos, bosquejos y obras plásticas relativas a la geografía, la topografía, la arquitectura o las ciencias.

j. Los lemas y frases en la medida que tengan una forma de expresión literaria o artística, con características de originalidad.

k. Los programas de ordenador

1. Las antologías o compilaciones de obras diversas o de expresiones del folklore, y las bases de datos, siempre que dichas colecciones sean originales en razón de la selección, coordinación o disposición de su contenido.

m. Los artículos periodísticos, sean o no sucesos de actualidad, los reportajes, editoriales y comentarios.

n. En general, toda otra producción del intelecto en el dominio literario y artístico, que tenga características de originalidad y sea susceptible de ser divulgada o reproducida por cualquier medio o procedimiento, conocido o por conocerse. (Decreto legislativo 822, 1996)

En ese sentido, puede decirse que por el solo hecho de ser un autor el creador de una obra, el derecho le concederá la titularidad de la misma, pudiendo consistir ésta en cualquiera de las obras señaladas en el artículo 5 arriba indicado.

Por otra parte, si bien el derecho otorga protección al autor en cuanto a la creación de sus obras, el derecho también protege a aquellas personas que intervienen en el procedimiento de su difusión, tales como a los artistas intérpretes o ejecutantes, los productores de fonogramas y a los organismos de radiodifusión. Esta protección es lo que se denomina como Derechos Conexos.

En ese sentido, los derechos conexos protegen a las siguientes personas:

Artista intérprete o ejecutante: persona que representa, canta, lee, recita, interpreta o ejecuta en cualquier forma una obra literaria o artística o una expresión del folklore, así como el artista de variedades y de circo. 
Organismo de radiodifusión: la persona natural o jurídica que decide las emisiones y que determina el programa así como el día y la hora de la emisión.

Productor de fonogramas: persona natural o jurídica bajo cuya iniciativa, responsabilidad y coordinación se fijan por primera vez los sonidos de una interpretación o ejecución u otros sonidos, o representaciones digitales de los mismos. (Decreto legislativo 822, 1996)

\subsection{Derechos de Propiedad Industrial}

Los derechos de propiedad industrial son una rama de los derechos de Propiedad Intelectual que a diferencia de los derechos de autor tienen una incidencia directa en la actividad empresarial. Los derechos de propiedad industrial se dividen en dos ramas: sistema de las nuevas creaciones y signos distintivos. Estos derechos están regulados por la Decisión 486 - Régimen Común sobre Propiedad Industrial - y el Decreto Legislativo $1075^{7}$ - Decreto Legislativo que aprueba Disposiciones Complementarias a la Decisión 486 de la Comisión de la Comunidad Andina que establece el Régimen Común sobre Propiedad Industrial.

\subsubsection{Sistema de las nuevas creaciones}

En el sistema de las nuevas creaciones se encuentran las patentes de invención, modelos de utilidad y diseños industriales, los cuales revisaremos a continuación:

a) Patentes de invención:

Una patente es un derecho de uso exclusivo otorgado a una persona natural o jurídica sobre una invención, siempre que esta cumpla con los siguientes requisitos:

\footnotetext{
${ }^{7}$ Debe precisarse que mediante el Decreto Legislativo 1309 se modificaron algunos artículos del Decreto Legislativo 1075.
} 
- Novedad: se considera que una invención cumple con el requisito de novedad cuando consiste en un producto o procedimiento que no haya estado comprendido en el estado de la técnica ${ }^{8}$.

- Nivel inventivo: se considera que una invención cumple con el requisito de nivel inventivo si para una persona del oficio normalmente versada en la materia técnica esa invención no hubiera resultado obvia ni se hubiera derivado de manera evidente del estado de la técnica.

- Susceptible de aplicación industrial: se considera que una invención cumple con este requisito cuando su objeto pueda ser producido o utilizado en cualquier tipo de industria.

Debe enfatizarse que se podrán otorgar patentes de invención tanto para productos como para procedimientos.

En este orden de ideas, siempre que las invenciones cumplan con estos requisitos se podrán otorgar a los titulares derechos patrimoniales sobre las mismas; sin perjuicio de lo expuesto, no basta con la mera invención para que se constituya esta protección, sino que es necesario que la invención se registre en la Oficina de Propiedad Industrial correspondiente, circunscribiéndose su protección al territorio de la oficina del país donde ha sido registrada, por el plazo de veinte (20) años.

Para una mejor ilustración de la figura de las patentes de invención, señalaremos los derechos de sus titulares, para lo cual indicaremos expresamente el artículo 52 de la Decisión 486 (2000):

Artículo 52.- La patente confiere a su titular el derecho de impedir a terceras personas que no tengan su consentimiento, realizar cualquiera de los siguientes actos:

a) cuando en la patente se reivindica un producto:
i) fabricar el producto;
ii) ofrecer en venta, vender o usar el producto; o

b) cuando en la patente se reivindica un procedimiento:

i) emplear el procedimiento; o

\footnotetext{
${ }^{8}$ De acuerdo al segundo párrafo del artículo 16 de la Decisión 486 (2000), "el estado de la técnica comprenderá todo lo que haya sido accesible al público por una descripción escrita u oral, utilización, comercialización o cualquier otro medio antes de la fecha de presentación de la solicitud de patente o, en su caso, de la prioridad reconocida".
} 
Vale precisar que el autor tendrá la obligación de explotar este invento. Asimismo, una vez vencido el plazo de veinte (20) años de protección de la invención por medio de la patente, el invento será objeto de dominio público.

b) Modelos de utilidad:

Los modelos de utilidad son aquellas invenciones menores o pequeñas que son protegidas a través del sistema de patentes. A diferencia de la patente de invención, las patentes de modelo de utilidad solo protegen las invenciones menores de productos y no procedimientos.

De esta manera, el artículo 81 de la Decisión 486 (2000) define al modelo de utilidad de la siguiente manera:

Artículo 81.- Se considera modelo de utilidad, a toda nueva forma, configuración o disposición de elementos, de algún artefacto, herramienta, instrumento, mecanismo u otro objeto o de alguna parte del mismo, que permita un mejor o diferente funcionamiento, utilización o fabricación del objeto que le incorpore o que le proporcione alguna utilidad, ventaja o efecto técnico que antes no tenía.

Asimismo, establece en el artículo 82 de la misma norma que "no se considerarán como modelos de utilidad: las obras plásticas, las de arquitectura, ni los objetos que tuvieran carácter estético" (Decisión 486, 2000), recalcando en el párrafo siguiente que "no podrán ser objeto de una patente de modelo de utilidad, los procedimientos y las materias excluidas de la protección por la patente de invención". (Decisión 486, 2000)

Vale precisar que la duración de protección de la patente de modelo de utilidad es de diez (10) años, y le confiere al titular los mismos derechos y obligaciones expuestos anteriormente para las patentes de invención, sólo necesitando cumplir como requisitos que esta invención menor cuente con novedad y que presente alguna utilidad, ventaja o efecto técnico que antes no tenía. 
c) Diseños industriales:

Los diseños industriales son aquellas características ornamentales o estéticas de un producto que son protegidas por los derechos de Propiedad Intelectual.

En efecto, la Decisión 486 (2000) establece que:

Artículo 113.- Se considerará como diseño industrial la apariencia particular de un producto que resulte de cualquier reunión de líneas o combinación de colores, o de cualquier forma externa bidimensional o tridimensional, línea, contorno, configuración, textura o material, sin que cambie el destino o finalidad de dicho producto.

Bajo este orden de ideas, se protegerá el derecho de uso exclusivo sobre los diseños industriales siempre que sean diseños nuevos de acuerdo a lo establecido en el artículo $115^{9}$ de la norma antedicha. Para su protección es necesario el registro del diseño industrial cuya protección durará diez (10) años.

Para un mejor entendimiento es necesario señalar que el artículo 129 de la Decisión 486 (2000) establece que:

Artículo 129.- El registro de un diseño industrial conferirá a su titular el derecho a excluir a terceros de la explotación del correspondiente diseño. En tal virtud, el titular del registro tendrá derecho a actuar contra cualquier tercero que sin su consentimiento fabrique, importe, ofrezca, introduzca en el comercio o utilice comercialmente productos que incorporen o reproduzcan el diseño industrial.

\subsubsection{Signos distintivos}

Al igual que el sistema de nuevas creaciones, en el Perú los signos distintivos son regulados por la Decisión 486 - Régimen común sobre propiedad industrial- y el Decreto Legislativo 1075 - Decreto Legislativo que aprueba disposiciones

\footnotetext{
${ }^{9}$ Artículo 115.- Serán registrables diseños industriales que sean nuevos.

Un diseño industrial no es nuevo si antes de la fecha de la solicitud o de la fecha de prioridad válidamente invocada, se hubiere hecho accesible al público, en cualquier lugar o momento, mediante su descripción, utilización, comercialización o por cualquier otro medio.
}

Un diseño industrial no es nuevo por el mero hecho que presente diferencias secundarias con respecto a realizaciones anteriores o porque se refiera a otra clase de productos distintos a dichas realizaciones. (Decisión 486, 2000) 
complementarias a la Decisión 486 de la Comunidad Andina que establece el Régimen común sobre propiedad industrial.

Dentro del sistema de los signos distintivos se encuentran las marcas, los lemas comerciales, los nombres comerciales, las indicaciones geográficas y las denominaciones de origen.

Tal como vimos en los antecedentes históricos de la Propiedad Intelectual, la figura de la marca tal como la conocemos hoy en día surgió a raíz del nacimiento de una economía de mercado, en donde existe libertad de concurrencia y competencia. Todas las demás figuras de los signos distintivos fueron surgiendo de la misma manera.

Los signos distintivos son, como su mismo nombre lo indica, signos que se utilizan para distinguir productos, servicios, establecimientos, actividades, entre otros, por parte de los diversos agentes económicos. Asimismo, es necesario precisar que el signo distintivo por excelencia es la marca, pues en base a esta figura (la cual es la más utilizada por los empresarios) se han podido diseñar los mecanismos de protección para los otros signos distintivos.

En efecto, según Dante Vilches (2013):

Especial complejidad presenta la búsqueda de una determinación concreta de lo que la doctrina y legislación en sus inicios han querido establecer al regular los signos distintivos. Así, los operadores jurídicos han optado por esbozar la teoría de los signos distintivos a partir del desarrollo teórico de las marcas, paradigma por excelencia de los signos distintivos, desatendiendo la búsqueda de una teoría continental que permita entender la figura en su espectro más general. (p.23)

a) Marcas:

De acuerdo a lo establecido en el artículo 134 de la Decisión 486, una marca es cualquier signo que es apto para distinguir productos o servicios en el mercado. Este signo, como se ha manifestado, es muy importante en una economía de mercado pues los competidores necesitan que los consumidores puedan identificar sus productos o servicios de acuerdo a las características que estas revisten. Asimismo, una marca 
proporciona información al consumidor de que el producto o servicio es proporcionado por un origen empresarial determinado, distinguiéndolos de los otros, y dotándolos de una reputación en el transcurso del tiempo. Es por una marca que los consumidores pueden escoger qué producto o servicio es más idóneo para sus fines.

Cabe recalcar que el artículo en mención señala que podrán registrarse como marcas los signos susceptibles de representación gráfica. Este extremo de la norma será analizado más adelante de manera más detallada, por ser un tema medular en el estudio del presente trabajo de investigación.

Por otro lado, la protección de una marca dura diez (10) años y puede renovarse por un plazo igual de manera indefinida. En este lapso de tiempo el titular de la marca tendrá derecho al uso exclusivo de la misma y de impedir que un tercero la utilice sin su consentimiento; asimismo, podrá otorgar licencias para su uso, y podrá ceder este derecho.

A la vez, según Christian Northcote (2013), el titular tendrá las siguientes obligaciones: i) Obligación al uso de la marca: si bien la Decisión 486 no menciona expresamente esta obligación existe la figura de cancelación de marca por falta de uso; ii) se deberá utilizar la marca tal cual fue registrada, pudiendo variar solo características secundarias y no medulares del signo (esto es para su protección); iii) en caso de licencias el titular del registro responderá por su idoneidad. (p.22)

Otras características importantes de la marca es que esta sólo será protegida dentro del territorio de la Oficina de Propiedad Intelectual en la cual fue registrada, y su protección será limitada a los productos o servicios para los que han sido registrados.

Adicionalmente, es menester recalcar que hay tres artículos que tratan sobre el tema de marcas que son de vital importancia para su entendimiento, así como para el desarrollo del presente trabajo, estos son los artículos 134, 135 y 136 de la Decisión 486. Por este motivo, estos artículos se revisarán en los próximos capítulos. 
b) Lemas comerciales:

De acuerdo al segundo párrafo del artículo 175 de la Decisión 486 (2000) "Se entiende por lema comercial a la palabra, frase o leyenda utilizada como complemento de una marca".

Cabe recalcar que un lema comercial deberá registrarse para que tenga protección. Asimismo, su registro siempre dependerá del registro de una marca.

c) Nombres comerciales:

Son signos distintivos encargados de identificar y distinguir actividades económicas, una empresa o establecimiento mercantil, y no productos y/o servicios como las marcas. A diferencia de estas, los nombres comerciales no necesitan ser registrados para obtener protección, sino que basta con su uso. En ese sentido, la protección de un nombre comercial comienza con su primer uso, siendo en este caso el registro declarativo y no constitutivo de derechos. Asimismo, para su registro y protección el titular deberá tener en cuenta lo establecido en el artículo 194 de la Decisión 486 ${ }^{10}$.

En este orden de ideas, el derecho otorga al titular de un nombre comercial la facultad de impedir que un tercero lo utilice sin su consentimiento o de utilizar un signo similar que pueda generar confusión o asociación en el público consumidor.

d) Indicaciones geográficas

Si se revisa la Decisión 486 puede apreciarse que se ha considerado a las indicaciones geográficas como un género, y a las denominaciones de origen e indicaciones de procedencia como las especies. Esto puede comprobarse incluso con la técnica legislativa utilizada para desarrollar cada una de estas materias, esto es, que el Titulo

${ }^{10}$ Art. 194 de la Decisión 486 (2000). -

No podrá registrarse como nombre comercial un signo que esté comprendido en alguno de los casos siguientes:

a) cuando consista, total o parcialmente, en un signo contrario a la moral o al orden público;

b)cuando su uso sea susceptible de causar confusión en los medios comerciales o en el público sobre la identidad, la naturaleza, las actividades, el giro comercial o cualquier otro aspecto de la empresa o establecimiento designado con ese nombre;

c) cuando su uso sea susceptible de causar confusión en los medios comerciales o en el público sobre la procedencia empresarial, el origen u otras características de los productos o servicios que la empresa produzca o comercialice; o,

d)cuando exista una solicitud o registro de nombre comercial anterior. 
XII "De las Indicaciones Geográficas", se subdivide en los Capítulos I y II "De las Denominaciones de Origen" y "De las Indicaciones de Procedencia" respectivamente. Sin embargo, no hay una definición expresa sobre lo que significa el término “Indicaciones Geográficas”, señalando la Decisión 486 (2000) solo la definición de “Denominación de Origen” en el artículo 201, tal como se muestra a continuación:

Artículo 201.- Se entenderá por denominación de origen, una indicación geográfica constituida por la denominación de un país, de una región o de un lugar determinado, o constituida por una denominación que sin ser la de un país, de una región o de un lugar determinado se refiere a una zona geográfica determinada, utilizada para designar un producto originario de ellos y cuya calidad, reputación u otras características se deban exclusiva o esencialmente al medio geográfico en el cual se produce, incluido los factores naturales y humanos. (Decisión 486, 2000).

Por otra parte, el artículo 221 de la antedicha Decisión 486 (2000) señala que "se entenderá por indicación de procedencia un nombre, expresión, imagen o signo que designe o evoque un país, región, localidad o lugar determinado".

\subsection{El alcance de los derechos de Propiedad Intelectual}

Los derechos de Propiedad Intelectual se dividen, por una parte, en derechos de autor y derechos conexos, y por otra, en derechos de propiedad industrial. Sin embargo, en la actualidad se está tratando dentro de esta materia a los derechos de los obtentores vegetales (de manera sui generis) ${ }^{11}$, expandiéndose cada día más los derechos de propiedad intelectual a las nuevas demandas del mercado ${ }^{12}$.

${ }^{11}$ Artículo 27 del ADPIC (1994):

(..)

3. Los Miembros podrán excluir asimismo de la patentabilidad:

a) los métodos de diagnóstico, terapéuticos y quirúrgicos para el tratamiento de personas o animales;

b) las plantas y los animales excepto los microorganismos, y los procedimientos esencialmente biológicos para la producción de plantas o animales, que no sean procedimientos no biológicos o microbiológicos. Sin embargo, los Miembros otorgarán protección a todas las obtenciones vegetales mediante patentes, mediante un sistema eficaz sui generis o mediante una combinación de aquéllas y éste. Las disposiciones del presente apartado serán objeto de examen cuatro años después de la entrada en vigor del Acuerdo sobre la OMC. (Los subrayados son míos).

${ }^{12}$ Cabe recalcar que según el artículo 3 del Decreto legislativo 1075, letra f), los esquemas de trazados de circuitos integrados también forman parte de la propiedad industrial. 
En ese sentido, debe recalcarse que tal como hemos visto en los antecedentes históricos del presente trabajo de investigación, la propiedad intelectual y los derechos que la protegen han ido evolucionando de acuerdo a las situaciones sociales y económicas del momento, habiéndose expandido su alcance y acoplándose a las condiciones del comercio de cada época, por lo que, en el presente trabajo de investigación debe visualizarse los actuales usos que los empresarios están poniendo en práctica respecto a la propiedad intelectual, en el caso en concreto, sobre la figura de la marca, pudiéndose constatar su notable interés en utilizar marcas no tradicionales no visibles para distinguir los productos o servicios que comercializan en el mercado. 


\section{CAPÍTULO II: DERECHO MARCARIO}

Tal como vimos en el apartado de Antecedentes Históricos del capítulo I, las marcas tal como las conocemos hoy en día surgieron a raíz de la aparición de una economía de mercado, en la cual hay libertad de concurrencia y competencia, donde se necesita que los consumidores puedan elegir libremente el producto o servicio más idóneo a sus necesidades, siendo para tal tarea necesario el uso de signos distintivos como las marcas.

Asimismo, en el subcapítulo de Signos Distintivos del capítulo anterior expresamos una breve introducción al sistema marcario que rige en nuestro país; sin embargo, por ser el entendimiento de este sistema medular para el presente trabajo de investigación pasaremos a analizarlo con más detenimiento.

\subsection{Concepto de marca}

Tal como se mencionó anteriormente, el artículo 134 de la Decisión 486 (2000) establece que "A efectos de este régimen constituirá marca cualquier signo que sea apto para distinguir productos o servicios en el mercado"; sin embargo, para poder entender exactamente la definición de lo que se considera como marca, es necesario inmiscuirnos en lo que dice la doctrina al respecto.

\section{Para Carlos Fernández - Nóvoa (2004):}

La marca es un bien inmaterial; esto es, un bien que no tiene una existencia sensible, sino que, por el contrario, necesita materializarse en cosas tangibles (corpus mechanichum) para ser percibido por los sentidos, siendo, además, susceptible de ser reproducido ilimitadamente y de modo simultaneo en diversos lugares. (p.27) (El subrayado es mío).

Asimismo, este autor nos indica que a diferencia de las invenciones o creaciones, la marca no posee una fisonomía tan definida, toda vez que el titular de una patente de invención, por ejemplo, tendrá la propiedad exclusiva de la invención, mientras que el titular de una marca solo tendrá la propiedad exclusiva de ésta para 
determinadas clases de productos o servicios (principio de especialidad), pudiendo coexistir dos o más derechos sobre una misma marca para clases diferentes. Sin embargo, este autor es claro en manifestar que este concepto de marca consistente en la unión entre el signo y las distintas clases es una de las facetas de la figura de la marca; es decir, una marca en potencia, faltándole el ingrediente básico que consiste en la unión entre el signo y el producto en cuanto tal unión es aprehendida por el público consumidor (p.28).

En efecto, para Carlos Fernández - Nóvoa (2004) la marca presenta perfiles muy variados, no debiéndola solo identificar con un signo, pues este sólo sería un componente más de la misma. Así lo aclara cuando establece que:

Hemos visto como no cabe identificar la marca con un signo porque el signo es tan solo uno de los componentes de la marca: esta consiste, ante todo, en la unión entre un signo y un producto. A su vez, la unión entre signo y el producto constituye una marca únicamente en tanto que la unión es captada por los consumidores (...) (p.29).

En ese sentido, puede apreciarse que para este autor el bien inmaterial que se protege con el derecho de marcas no se encuentra bien definido, como sí sucede en el caso de las patentes de invención.

Por otro lado, Ignacio de Medrano Caballero (2009) nos explica que lo que se protege con el derecho marcario no es la creación o labor intelectual del signo (por más creativo, novedoso y atractivo que este sea), sino que se protegen como meros medios identificadores, discrepando con la doctrina que considera a la marca como una creación intelectual (p.1233)

Por otra parte, damos alcance a las siguientes definiciones que diversos autores sobre la materia han expuesto:

a) Dentro de la doctrina argentina, Breuer Moreno define a la marca como "el signo característico con que el industrial, comerciante o agricultor distingue los productos de su industria, comercio o explotación agrícola"

(...) 
c) Ledesma dice de las marcas que "son símbolos denominativos emblemáticos que distinguen los artefactos de una fábrica, los objetos de un comercio o los productos de la tierra y de las industrias agrícolas."

( ...)

f) Etcheverry, siguiendo a Halperín, define la marca como "el signo distintivo impreso o aplicado a los productos para distinguirlos de sus similares".

(...)

j) McCarthy sigue la definición de la Ley Lanham, vigente en los Estados Unidos, que caracteriza a la marca como "cualquier palabra, nombre, símbolo o dispositivo o cualquier combinación de los mismos adoptados o utilizados por un fabricante o comerciante para identificar sus bienes y distinguirlos de los fabricantes o vendidos por otros".

k) En un importante trabajo de la UNCTAD se expresa que "las marcas son universalmente reconocidas como un dispositivo utilizado por un productor o distribuidor para identificar los bienes que fabrica o vende. A través de tal identificación es generalmente posible distinguir los bienes de acuerdo a su fuente $\mathrm{u}$ origen, o sea, distinguir, los bienes de una empresa de los de otras (...)" (como se citó en Bertone y Cabanellas, 2003, p.17-18) (los subrayados son míos).

Asimismo, para Jorge Otamendi (2010) "la marca es el signo que distingue un producto de otro o un servicio de otro". (p.1).

Por su parte, el Tribunal de Justicia de la CAN ha señalado sobre la definición de marca lo siguiente:

La Decisión 486, en su artículo 134, define a la marca como "cualquier signo que sea apto para distinguir productos o servicios en el mercado. Podrán registrarse como marcas los signos susceptibles de representación gráfica".

La marca es un bien inmaterial constituido por un signo conformado por palabras o combinación de palabras, imágenes, figuras, símbolos, gráficos, etc., que, susceptibles de representación gráfica, sirvan para distinguir en el mercado productos o servicios, a fin de que el consumidor o usuario medio los identifique, valore, diferencie y seleccione $\underline{\text { sin riesgo de confusión o error acerca del origen o la calidad del producto o del servicio. }}$. 
La doctrina ha reconocido, en atención a la estructura del signo, algunas clases de marcas, como las denominativas, las gráficas y las mixtas. En el marco de la Decisión 486 se puede, sin embargo, constatar la existencia de otras clases de signos, $\underline{\text { diferentes a }}$ los enunciados, como los sonidos, los olores, los colores, la forma de los productos, sus envases o envolturas, etc., según consta detallado en el artículo 134 de la mencionada Decisión (Proceso 70-IP-2013,2013) (Los subrayados son míos).

En efecto, en el seno de la Comunidad Andina (lo cual es aplicable para el Perú como país miembro), puede apreciarse que al igual que Carlos Fernández -Nóvoa, se considera a la marca como un bien inmaterial; sin embargo, y pese a que la legislación andina sí contempla el principio de especialidad - como lo veremos más adelante delimita el objeto de protección a cualquier signo que sea apto para distinguir productos o servicios en el mercado. Asimismo, de lo expresado en el Proceso 70-IP- 2013 puede desprenderse que la marca no se protege por ser considerada como una creación intelectual - coincidiendo con la posición de Ignacio de Medrano Caballero.

Por otra parte, de las definiciones expuestas por Luis Eduardo Bertone y Guillermo Cabanellas de las Cuevas, en primer lugar, respecto a lo citado por Ledesma, nuestra norma andina no define a la marca como "símbolos denominativos", pues queda claro de lo expresado por el Tribunal de Justicia de la CAN, así como veremos en el presente trabajo de investigación, que las marcas pueden conformarse por signos denominativos, figurativos o mixtos, y como expresa este Tribunal, por sonidos, olores, colores, entre otros signos.

En ese sentido, el Tribunal de Justicia de la CAN parece haber adoptado como concepto de marca, los siguientes elementos:

- Es un bien inmaterial

- Es un signo

- Es apto para distinguir productos o servicios en el mercado

- Es susceptible de representación gráfica

En efecto, de la lectura de la antedicha interpretación prejudicial queda claro que una marca es un bien inmaterial, consistente en un signo apto para distinguir productos 
o servicios en el mercado; sin embargo, genera duda el extremo que indica la susceptibilidad de representación gráfica como parte integrante de la definición de marca, sobre todo si en el último párrafo de la cita antedicha establece que en el marco de la Decisión 486 se puede, sin embargo, constatar la existencia de otras clases de signos como los olores y sonidos, cabiendo preguntarse cómo representar gráficamente estos signos no visibles. Debe tenerse en consideración, además, que ninguno de los autores antedichos incluye dentro de la definición de marca a la susceptibilidad de representación gráfica del signo.

Vale precisar, por otro lado, que el concepto de marca que la Comunidad Andina ha adoptado se asemeja al indicado por Jorge Otamendi, con la diferencia de que no se necesita que un signo, en un principio, distinga productos o servicios, sino que tenga la aptitud para efectuar esta función. Asimismo, la norma andina no establece que sea un signo para identificar los productos o servicios de un competidor del de los otros - tal como lo establecen algunos de los autores citados por Luis Eduardo Bertone y Guillermo Cabanellas de las Cuevas - sino que la marca es un signo que es apto para distinguir productos o servicios en el mercado.

Para un mejor entendimiento de la figura de la marca analizaremos sus funciones en el siguiente apartado.

\subsection{Funciones de la marca}

Si bien del artículo 134 expuesto anteriormente se desprende que la función de la marca es distinguir productos o servicios en el mercado, es necesario precisar que no es su única función; por el contrario, con el desarrollo continuo del mercado se considera que esta institución jurídica ha ido desempeñando cada día más funciones.

\subsubsection{Función distintiva y diferenciadora}

De acuerdo a lo establecido por la Real Academia Española (2014) un signo es un “objeto, fenómeno o acción material que, por naturaleza o convención, representa o sustituye a otro". En ese sentido, en nuestra vida cotidiana frecuentamos con un sinnúmero de signos: el nombre (representa parte de la identidad de una persona), los números (representan una cantidad), las letras (representan lo que queremos decir), el 
sonido de un celular (representa que alguien quiere comunicarse con nosotros), y así podríamos dar innumerables ejemplos. Sin embargo, no todos los signos pueden constituirse como marcas; estas deben ser aptas para identificar y distinguir productos o servicios en el mercado.

Tal como vimos en los antecedentes históricos, la construcción jurídica de la marca tal como la conocemos hoy en día se desarrolló con la función principal de identificar y distinguir productos o servicios en el mercado, siendo esta función indispensable para cualquier economía de mercado, o en el caso peruano, para una economía social de mercado (tal como establece nuestra Constitución Política ${ }^{13}$ )

$\mathrm{Al}$ respecto, es necesario aclarar que tanto una economía de mercado como una economía social de mercado se caracterizan por la libertad de concurrencia y competencia. La libertad de concurrencia quiere decir que cada individuo es libre de poder acceder al mercado y realizar actividad empresarial, y, siendo que cada concurrente accede al mercado con el fin de obtener ganancias y maximizar sus intereses, se crea la necesidad de competir entre ellos, pues de los muchos productos o servicios que ofrecen en el mercado, el consumidor elegirá los que más satisfagan sus intereses.

En ese sentido, los consumidores, del gran número de bienes que se les oferta en el mercado, tienen que identificar los que más les satisfaga; es decir, individualizar el bien dentro de la gran variedad de la misma clase, y distinguirlos de los otros productos o servicios ofertados, para de esta manera realizar una elección eficiente de los bienes que van a adquirir. Sin la existencia de la marca esta elección sería imposible, pues los consumidores no podrían identificar y diferenciar los distintos productos o servicios.

Es por todo lo expuesto que la función distintiva y diferenciadora es la función principal de la marca y, por lo tanto, es la cualidad que todo signo debe poseer para que pueda ser considerado como marca.

\subsubsection{Función de identificación del origen empresarial}

\footnotetext{
${ }^{13}$ Constitución Política del Perú (1993): “Artículo 58. - La iniciativa privada es libre. Se ejerce en una economía social de Mercado. (...)".
} 
Otra de las funciones de la marca consiste en identificar cuál es el origen empresarial del producto o servicio; es decir, identificar quién es la persona natural o jurídica que lo elaboró o prestó, respectivamente.

Debe precisarse que esta función es una consecuencia común e importante de la función principal de la marca, pero no necesaria.

\subsubsection{Función de recolección de prestigio o calidad}

De la función principal de la marca - la cual es identificar y distinguir productos o servicios en el mercado - unidos con otros factores, se deriva la función de recolección de prestigio o calidad de la marca. En otras palabras, de acuerdo a la publicidad que se le haga a la marca, la calidad de productos que ella diferencie, su grado de originalidad y su frecuente uso en el mercado por parte de sus titulares hará que obtenga en el transcurso del tiempo una buena reputación. Esta buena reputación de la que llega a gozar una marca es lo que se llama "Good Will", el cual se convierte en un activo fijo de un empresario. Por el "Good Will" de una marca esta puede llegar a ser un activo fijo valorizado por mucho dinero.

Lo que sucede es que en virtud a la función distintiva y diferenciadora de la marca, los consumidores pueden identificar y diferenciar un producto o servicio en el mercado. En base a la experiencia que obtengan los consumidores en la utilización de estos bienes, y en base a una buena publicidad de la marca, los consumidores relacionarán la marca con la calidad del producto o servicio que identifica, pudiendo recolectar esta marca con el transcurso del tiempo buena reputación. Es por ello que esta función (al igual que la función identificadora de origen empresarial y las otras funciones que veremos a continuación) son funciones que se derivan de esta función principal, siendo consecuencias comunes más no necesarias. "Las restantes funciones de la marca, si bien son significativas y de gran trascendencia económica, se encuentran subordinadas a la función distintiva, tanto desde el punto de vista lógico como del jurídico.” (Bertone y Cabanellas, 2003, p. 30).

\subsubsection{Otras funciones de la marca}

a) Función publicitaria e informativa 
Como ya se sabe, la función publicitaria e informativa de la marca se deriva de la función principal de la marca. Lo que sucede es que al ser la marca un signo que distingue productos o servicios en el mercado, resulta un mecanismo idóneo por parte de los empresarios para captar la atención del público consumidor, y publicitar los bienes que identifica la marca. "Es claro que la marca, debido a su conformación particular que la hace distintiva, es un instrumento indispensable para que se dé una efectiva publicidad" (Carlos Cornejo, 2014 , p.62).

Asimismo, la marca también cumple una función informativa, debiéndose ésto a la experiencia del consumidor en la utilización del producto o servicio que distingue la marca. De acuerdo a esta experiencia, la marca puede informar al consumidor sobre la calidad de los bienes, el origen empresarial, hasta sobre su precio.

En ese sentido, según Luis Eduardo Berlone y Guillermo Cabanellas de las Cuevas (2003):

La utilización de las marcas permite informar al publico que productos exteriormente iguales, o cuyas cualidades no son inmediatamente distinguibles, han sido identificados en forma diferente a fin de que se distingan sus respectivas calidades y condiciones. Asimismo, mediante la función de identificación de origen, la marca informa al público sobre la procedencia de los bienes y servicios, con las limitaciones señaladas.(...). Las marcas proporcionan un signo que relaciona la información adquirida por experiencia, por otros medios, al producto, facilitando asi los juicios de calidad. (...). Las marcas permiten acumular información sobre las experiencias propias y de terceros habidas respecto de los productos así identificados (p.54).

Esta función es importante pues en base a la función informativa y publicitaria de la marca, los consumidores podrán elegir dentro de los distintintos productos o servicios de una clase cuáles bienes escoger, otorgándoles valores a las marcas.

b) Función competitiva

Si bien la función competitiva de la marca también se deriva de su función distintiva y diferenciadora, puede decirse que es una de las funciones más importantes y que le da sentido al funcionamiento del sistema marcario, pues los concurrentes al mercado con 
el fin de ganar más clientela necesitan ofertar sus productos y servicios con la mejor calidad, precio, imagen y prestigio, a comparación de sus competidores, con el fin de que los consumidores decidan elegir los bienes que aquellos ofrecen en el mercado, y de esta manera obtener más ganancias.

En ese sentido, y de acuerdo a lo mencionado lineas arriba, los consumidores necesitan elegir los bienes que son más idóneos para sus intereses, y para que realicen esta elección necesitan identificarlos y diferenciarlos de los otros (función principal que realiza la marca). A raíz de esta elección, los consumidores por la experiencia en la utilización de los productos o servicios identificados con una marca, podrán relacionarla con las condiciones de precio, calidad, reputación e imagen. En otras palabras, los esfuerzos que los empresarios realizan para tener el mejor producto o servicio posible para ofertar a los consumidores y ganar más clientela, es representado por la marca.

Es por este motivo que la marca cumple una función competitiva, que es vital en una economía de mercado. Asimismo, de las normas sobre la materia puede apreciarse que muchas de estas son elaboradas a raiz de los casos de competencia desleal, pues se sanciona que una persona natural o jurídica utilice una marca igual o similar a otra ya registrada, pues lo que no se quiere es que una persona se apropie del esfuerzo, trabajo y dedicación en la elaboración y/o prestación del producto o servicio que es representado por una marca. Asi lo indica McCarthy:

El derecho de marcas no es sino una rama de un área más amplia llamada Competencia Desleal (Unfair Competition) o Practicas Comerciales Desleales (Unfair Trade Practices). (...) Ésta no es sino el género del que la violación de marcas es una de las especies. (...) Todas las infracciones marcarias son casos de competencia desleal y suponen el mismo ilícito (como se citó en Berlone y Caballenas, 2003, p.66)

Asimismo, los mismos autores indican que el sistema marcario:

forma parte del conjunto de normas destinadas a asegurar el correcto funcionamiento del sistema concurrencial. (...) Como, desde el punto de vista concurrencial, el sistema marcario está destinado a evitar que ciertos comerciantes confundan al público haciendo pasar sus bienes y servicios por los de otros, o aprovechen el esfuerzo y gastos ajenos, imitando los signos 
identificatorios de los productos comercializados por otros comerciantes (Luis Eduardo Berlone y Guillermo Cabanellas, 2003, p.68).

Por lo expuesto, puede decirse que si bien esta función no es la principal de la marca, la función competitiva es el fundamento del sistema marcario.

c) Función de protección del titular de la marca

La función de protección del titular de la marca también es una función que se deriva de su principal. Tal como se sostuvo anteriormente, los empresarios para competir en el mercado realizan muchos esfuerzos para ofertar los bienes que más satisfagan los intereses de los consumidores, con la finalidad de captar más clientela; después de varios esfuerzos, debido a la constante elección del producto o servicio por parte de los consumidores, la marca llega a tener buena reputación. En ese sentido, este signo distintivo le da la protección y seguridad al titular de la marca de que ese esfuerzo será distinguido y diferenciado de los demás bienes comercializados en el mercado.

d) Función de protección al consumidor

La función de protección al consumidor también se desprende de la función principal de la marca, pues como se ha mencionado, el consumidor, a través de esta, podrá elegir de la gran variedad de productos o servicios que son ofertados en el mercado, los que más se ajusten a sus intereses. Asimismo, y de acuerdo a las demás funciones que hemos estudiado, mediante la experiencia que el consumidor adquiera con la elección de los bienes que son distinguidos con la marca, esta le brindará información sobre sus condiciones de calidad, precio, imagen y prestigio.

e) Función de la marca en el mundo empresarial

Con el transcurso del tiempo hemos podido corroborar que las marcas se han convertido en un mecanismo importante y estratégico de los empresarios para poder captar más clientela, dándole un valor agregado a los productos y servicios que con ella se distinguen. Hasta puede afirmarse que en muchos casos, el valor de una marca (por el goodwill generado) puede llegar a costar una suma considerablemente mayor que cualquiera de los otros activos de una empresa. 
En nuestra vida cotidiana podemos percibir que los ambientes que nos rodean estan llenos de marcas como Apple, Google, Coca - Cola, Microsoft, Toyota, IBM , Samsung, Amazon, Mercedes - Benz, entre otros. Es muy complicado encontrar a una persona que vea estas marcas y no las relacione con los productos o servicios que ellas distinguen.

Para tener una idea de cuánto valor se le puede dar a una marca, es necesario mencionar el informe denominado "Best Global Brands 2016" publicado por la consultora Interbrand (firma pionera en valoración de marcas), en la cual se aprecia que por cuarto año consecutivo Apple encabeza la lista con un valor de US\$ 178.119 millones, seguido por Google con un valor de US\$133.252 millones (El Comercio, 2016). Cabe preguntarse cuánto valor tendrían las computadores de Apple sin su marca; o cuánto valor tendrían las bebidas gaseosas de Coca- Cola sin este signo distintivo; ¿tendrían el mismo valor? Muy convencidamente se responde a esta pregunta de forma negativa.

En efecto, las marcas han llegado a ser herramientas legales muy importantes para el mundo empresarial. Además de su función identificadora y diferenciadora, de identificación del origen empresarial, condensadora de reputación y prestigio, de protección a los titulares de marcas y de los consumidores, de la función informativa y publicitaria, y de competitividad, una marca le da valor agregado a los productos y servicios en el mercado, sirviendo como estrategias en la captación de clientes.

Es por este motivo, que el sistema marcario debe estar regulado de manera que ningún competidor pueda aprovecharse del esfuerzo ajeno de otro representado en una marca, debiendo este sistema actualizarse de acuerdo al continuo desarrollo del mercado, en la medida que los nuevos tipos de marcas utilizados por los empresarios, como estrategias para captar más clientela, puedan ser protegidas por el derecho.

\subsection{Principios marcarios}

Para que el derecho marcario pueda proteger debidamente a las marcas se necesitan parámetros que puedan fijar cómo se van a proteger estos signos distintivos y cuáles son 
los alcances de esta protección, teniendo en cuenta el variado número de productos y servicios que se comercializan en el mercado.

Estos parametros se denominan en doctrina "Principios marcarios", y son los que veremos a continuación.

\subsubsection{Principio de Registrabilidad}

El Principio de Registrabilidad consiste en que la protección de la marca sólo se activará con el registro; es decir, los Países Miembros de la CAN han adoptado el sistema atributivo, mediante el cual por el registro se constituyen los derechos sobre la marca. Sin embargo, debe precisarse que algunos países han adoptado el sistema declarativo, en el cual el nacimiento de protección de la marca nace con su uso, y el registro solo es declarativo de derechos. Asimismo, hay países que han adoptado un sistema mixto, en el cual el registro al principio es declarativo de derechos, y con el transcurso del tiempo se vuelve constitutivo.

En efecto, los Paises Miembros de la CAN han adoptado el sistema atributivo, y esto puede constatarse con lo establecido en los artículos 154 y 155 de la Decisión 486 (2000), los cuales presentamos a continuación:

Art.154.- El derecho al uso exclusivo de una marca se adquirirá por el registro de la misma ante la respectiva oficina nacional competente.

Art. 155.- El registro de una marca confiere a su titular el derecho de impedir a cualquier tercero realizar, sin su consentimiento, los siguientes actos: (...).

\subsubsection{Principio de Territorialidad}

El Principio de Territorialidad establece que la protección de la marca por parte de las

Oficinas Nacionales Competentes solo se limitará al territorio del país donde ha sido registrada. Asimismo, en virtud al mismo principio, la protección de la marca se regirá de acuerdo a las normas nacionales e internacionales aplicables en ese país. 
En efecto, en el caso peruano, si una marca ha sido registrada en el Perú, el Instituto nacional de Defensa de la Competencia y de la Propiedad Intelectual INDECOPI - no podrá protegerla en otros países, sólo en el territorio del Perú. De la misma manera, si una marca ha sido registrada en Chile, Argentina, o en cualquier otro país diferente al Perú, el INDECOPI no podrá protegerla dentro del territorio peruano.

Pese a lo expuesto, hay dos excepciones a este principio en virtud a la normativa comunitaria. La primera es la oposición andina, tal como se muestra en el artículo 147 de la Decisión 486 (2000) a continuación:

Art 147.- (...) se entenderá que tiene legítimo interés para presentar oposiciones en los demás Países Miembros, tanto el titular de una marca idéntica o similar para productos o servicios, respecto de los cuales el uso de la marca pueda inducir al público a error, como quien primero solicitó el registro de esa marca en cualquiera de los Países Miembros (...).

La segunda excepción se da cuando se trata de un signo notoriamente conocido ${ }^{14}$ registrado en otro país, que no necesariamente es de un País Miembro de la CAN; en este caso el INDECOPI protegerá esta marca, no otorgando el registro sobre la misma a los interesados.

\subsubsection{Principio de Especialidad}

El Principio de Especialidad limita el alcance de protección de la marca a los productos o servicios para los cuales ha sido registrada, o para los bienes con los cuales pueda tener una conexión competitiva.

Para la explicación de este principio es necesario señalar lo establecido en el artículo 151 de la Decisión 486 (2000) el cual indicaremos a continuación:

Art. 151.- Para clasificar los productos o los servicios a los cuales se aplican las marcas, los Países Miembros utilizarán la Clasificación Internacional de Productos y Servicios para el Registro de las Marcas, establecida por el Arreglo de Niza del 15 de junio de 1957, con sus modificaciones vigentes.

\footnotetext{
${ }^{14}$ Véase el Título XIII de la Decisión 486 que regula el tema de Signos Distintivos Notoriamente Conocidos.
} 
Las clases de la Clasificación Internacional referida en el párrafo anterior no determinarán la similitud ni la disimilitud de los productos o servicios indicados expresamente.

En ese sentido, para la protección de la marca en relación a los bienes que quiere distinguir, los Países Miembros utilizan la Clasificación Internacional de Productos o Servicios para el Registro de Marcas, establecida por el Arreglo de Niza ${ }^{15}$ del 15 de junio de 1957 (revisado en Estocolmo el 14 de julio de 1967 y en Ginebra el 13 de mayo de 1977 y modificado el 28 de septiembre de 1979), en la cual se clasifican los bienes por 45 clases, siendo las 34 primeras para productos, y de la 35 hacia adelante para servicios. Sin perjuicio de lo expuesto, es necesario resaltar lo establecido en el último parrafo del artículo expuesto el cual manifiesta que "las clases de la Clasificación Internacional referida en el párrafo anterior no determinarán la similitud ni la disimilitud de los productos o servicios indicados expresamemente" (Decisión 486, 2000). Es decir, esta clasificación internacional sólo será utilizada como referencia para la protección de la marca y no de manera estricta.

En este orden de ideas, por el principio de especialidad, la protección de la marca se otorgará de acuerdo a los productos o servicios que la misma distingue, y esta protección se activará cuando otra marca (la cual se solicita registrar) pueda generar riesgo de confusión o asociación con otra ya existente en el mercado (o en trámite).

Asimismo, es necesario aclarar que en los casos de signos distintivos notoriamente conocidos, los alcances de protección de la marca sobrepasan los parámetros establecidos por este principio.

\subsubsection{Principio de temporalidad}

Este principio establece que la protección de las marcas tendrán un plazo limitado; en efecto, el artículo 152 de la Decisión 486 (2000) establece que "El registro de una

\footnotetext{
${ }^{15}$ Es necesario precisar que los Países Miembros no son parte del Arreglo de Niza; sin embargo, han establecido en el artículo 151 de la Decisión 486 utilizar esta clasificación para el registro de marcas.

Véase http://www.wipo.int/treaties/es/ShowResults.jsp?lang=es\&treaty_id=12, http://www.wipo.int/treaties/es/ActResults.jsp?act_id=19, http://www.wipo.int/treaties/es/ActResults.jsp?act_id=22.
} 
marca tendrá una duración de diez años contados a partir de la fecha de su concesión y podrá renovarse por periodos sucesivos de diez años”.

Asimismo, y tal como se muestra en el artículo expuesto, este plazo podrá ser renovado por el mismo periodo ilimitadamente.

\subsection{Tipos de marcas}

Luis Eduardo Bertone y Guillermo Cabanellas de las Cuevas (2003) nos comentan que "El Derecho, a través de la legislación, la jurisprudencia y la doctrina, ha elaborado una serie de categorías marcarias, jurídicamente significativas (...)” (p.293), y los Países Miembros de la Comunidad Andina no han sido la excepción. En efecto, estas categorias marcarias son las que pasaremos a revisar a continuación:

2.4.1 Marca de producto y marca de servicio ${ }^{16}$ :

La marca de producto es aquel signo distintivo que sirve para distinguir un producto en el mercado. Con la misma lógica, una marca de servicio es aquella que distingue un servicio en el mercado. Estos dos tipos de marcas reciben el mismo tratamiento jurídico, sólo diferenciándose en el bien que se identifica con la marca.

2.4.2 Marcas denominativas, figurativas $y \operatorname{mixtas}^{17}$ :

Estos tipos de marcas se diferencian por los elementos que las conforman. En efecto, una marca denominativa es aquella compuesta por una o más palabras; una marca figurativa es aquella compuesta por dibujos y figuras, sin ningun elemento denominativo; y, la marca mixta es una marca compuesta tanto por elementos denominativos y figurativos o una marca compuesta por elementos de distintos tipos.

\footnotetext{
${ }^{16}$ Otamendi (2010) nos explica que: "Un instituto relativamente nuevo en el sistema marcario es la marca de servicio. Así como la marca tradicional distingue un producto de otro, la marca de servicio diferencia un servicio de otro" (p.12). En efecto, este autor nos explica que originariamente la marca era concebida para identificar productos, y más adelante se extendió para distinguir servicios.

${ }^{17}$ Diego Chijane (2007) indica que:

Las marcas denominativas o verbales son aquellas que se componen exclusivamente por signos pronunciables. Las marcas gráficas son las constituidas por líneas, formas, colores, dibujos, grafías en general que representen una imagen, la que en sí misma no resulta expresable verbalmente (...) (p.380).

Asimismo, según Chijane (2007) las marcas mixtas son las que se forman por elementos gráficos y denominativos (p. 381).
} 


\subsubsection{Marcas evocativas, arbitrarias y de fantasía ${ }^{18}$ :}

Estos tipos de marcas se diferencian por su grado de protección. Las marcas evocativas son aquellas que tienen una relación con las características del producto o servicio que se distingue con la marca; es decir, basta con usar un poco la imaginación para relacionarla con el bien que distingue. Este tipo de marcas tienen un grado de protección menor pues no puede prohibirse a los competidores que dejen de mencionar las cualidades y/o características de los bienes que comercializan en el mercado.

Las marcas arbitrarias son aquellas que si bien tienen algún significado no están relacionadas con el producto o servicio a distinguir; por el contrario, las marcas de fantasía son aquellas que están compuestas por elementos que pueden inclusive no tener significado real, siendo este tipo de marcas las que tienen mayor grado de protección.

\subsubsection{Marcas bidimensionales y tridimensionales:}

Las marcas bidimensionales son aquellas que buscan proteger la marca en sus dos dimensiones, como las denominativas, figurativas o mixtas. Estas marcas son normalmente planas; en cambio, las marcas tridimensionales son aquellas que buscan proteger las marcas en sus tres dimensiones; es decir, en su sentido ancho, alto y profundo; como por ejemplo, los envases, empaques y recipientes. Estas marcas están dentro de la tipología de las marcas no tradicionales, tal como lo explicaremos más adelante.

\subsubsection{Marcas colectivas y marcas de certificación:}

La marca colectiva es aquella que busca identificar los productos y servicios de un grupo de personas, asociaciones, grupo de fabricantes, sea por su origen o por cualquier otra característica común. Este tipo de marcas se diferencian del resto (a excepción de las marcas de certificación) en que es necesario la existencia de un reglamento de uso

\footnotetext{
${ }^{18}$ Fernández - Novoa (2004) señala que:

Las denominaciones carentes de significado propio constituyen las marcas denominativas, caprichosas o de fantasía. Las denominaciones dotadas de significado propio pueden constituir marcas sugestivas que aluden indirectamente a la naturaleza o a las características del producto; o bien marcas arbitrarias cuyo significado no guarda relación alguna con la naturaleza o las características del correspondiente producto (p.293).
} 
en el cual se establezcan los términos y condiciones para que sus integrantes utilicen de manera conjunta una marca.

En efecto, el artículo 180 de la Decisión 486 (2000) establece que "se entenderá por marca colectiva todo signo que sirva para distinguir el origen o cualquier otra característica común de productos o servicios pertenecientes a empresas diferentes y que lo utilicen bajo el control de un titular".

En cuanto a las marcas de certificación, al igual que las marcas colectivas, se diferencian del resto por la necesidad legal de contar con un reglamento de uso. Estas marcas son aquellas que se utilizan para que su titular pueda certificar ciertas características o calidad de los productos o servicios que ofrece un conjunto de empresarios en el mercado. En ese sentido, el artículo 185 de la antedicha Decisión 486 (2009) establece que "se entenderá por marca de certificación un signo destinado a ser aplicado a productos o servicios cuya calidad $\mathrm{u}$ otras características han sido certificadas por el titular de la marca".

\subsubsection{Marcas de reserva y marcas defensivas ${ }^{19}$ :}

Lo que caracteriza a este tipo de marcas es que en ambas no hay utilización de las mismas. En el caso de las marcas de reserva estas son registradas con la finalidad de que ninguna persona pueda apropiarse de ellas. Usualmente se da cuando una marca es muy creativa y no puede ser explotada por un periodo de tiempo.

Por otra parte, las marcas defensivas son aquellas que tienen por finalidad que ninguna persona pueda registrar alguna marca similar a una marca principal (la que sí se usa).

2.4.7 Marcas tradicionales y no tradicionales ${ }^{20}$ :

\footnotetext{
${ }^{19}$ Según Bertone y Cabanellas (2003) las marcas defensivas son aquellas que son registradas no con el propósito de ser utilizadas para distinguir productos o servicios en el mercado, sino que son registradas con el fin de proteger una marca que sí es utilizada en el mercado (p.321).

Asimismo, para Bertone y Cabanellas (2003) las marcas de reserva son aquellas que son registradas con el fin de ser utilizadas en un plazo posterior al registro (p.323).
} 
Como se mencionó anteriormente, las marcas pueden componerse por solo denominaciones (marcas denominativas), por figuras (marcas figurativas) o por una combinación de ambas (marcas mixtas). Estos elementos son los que a lo largo del tiempo ya han sido reconocidos como aptos para conformar una marca y obtener la protección que se deriva con su registro. Estos tipos de marcas son denominadas "marcas tradicionales". Por otro lado, a lo largo del tiempo, los comerciantes, con la finalidad de captar más clientela y volver más atractiva su marca, han utilizado nuevos elementos para conformarlas, a este tipo de marcas con elementos nuevos son las que se denominan en doctrina "marcas no tradicionales" o "nuevos tipos de marcas".

Asimismo, debe precisarse que las marcas pertenecientes a esta tipología varían a lo largo del tiempo, pues lo que actualmente consideramos marcas tradicionales en el pasado pudieron ser consideradas como no tradicionales; y las marcas que hoy en día consideramos marcas no tradicionales es probable que en el futuro estén incluidas dentro del tipo de marcas tradicionales ${ }^{21}$.

Estos tipos de marcas las analizaremos con más detalle en el siguiente capítulo por ser el tema principal del presente trabajo de investigación.

\subsection{Requisitos para el registro de marcas}

De acuerdo a lo establecido en el artículo 134 de la Decisión 486 (2000) que señala que “A efectos de este régimen constituirá marca cualquier signo que sea apto para distinguir productos o servicios en el mercado. Podrán registrarse como marcas los signos susceptibles de representación gráfica. (...)", se desprende que la normativa andina exige dos requisitos para que un signo pueda constituirse como marca: i) que el

\footnotetext{
${ }^{20}$ Según Castro (2012) la definición de "marcas no tradicionales" se entiende por oposición a lo que se denomina por "marcas tradicionales"; es decir, "aquellas que se expresan a través de letras, números, palabras, dibujos o símbolos, y que son apreciadas por el sentido de la vista" (p.297).

${ }^{21}$ Esto también puede deducirse de la diferenciación entre marca de producto y marca de servicio expuesto por Otamendi (2010) en la que establece que: "Un instituto relativamente nuevo en el sistema marcario es la marca de servicio. Así como la marca tradicional distingue un producto de otro, la marca de servicio diferencia un servicio de otro." (p.12) (el subrayado es mío). En efecto, la marca de servicio en su momento fue considerada como una marca no tradicional, considerándose ahora una marca tradicional.
} 
signo sea apto para distinguir productos o servicios en el mercado; es decir, que posea aptitud distintiva; y ii) que el signo sea susceptible de representación gráfica.

Sobre el particular, es necesario adelantar que estos dos requisitos son de gran debate doctrinal en cuanto al registro de marcas no tradicionales no visibles; sobre todo, hay muchas dudas de si estos tipos de marcas pueden cumplir con el requisito de la representación gráfica.

Por este motivo, siendo que el análisis de dicho artículo es medular para el presente trabajo de investigación, se tratará con más detenimiento en el siguiente capítulo.

\subsection{Prohibiciones al registro de marcas}

Las prohibiciones al registro de marcas se regulan en los artículos 135 y 136 de la Decisión 486. En el primer artículo mencionado se señalan las denominadas "prohibiciones absolutas", las cuales vienen a ser las prohibiciones que se derivan por las caracteristicas que presenta una marca por si misma; es decir, caracteristicas que componen un signo que si se protegiera como marca no podría cumplir su función principal: la de identificar y distinguir productos o servicios en el mercado. Por otro lado, el artículo 136 señala las denominadas "prohibiciones relativas", cuyas prohibiciones se derivan sobre la base de que su coexistencia con otras marcas u otros derechos de propiedad intelectual, afectaría el derecho de un tercero.

En efecto, los artículos 135 y 136 de la Decisión 486 (2000) establecen lo siguiente:

Art. 135.- No podrán registrarse como marcas los signos que:

a) no puedan constituir marca conforme al primer parrafo del artículo anterior;

b) carezcan de distintividad;

c) consistan exclusivamente en formas usuales de los productos o de sus envases, o en formas y características impuestas por la naturaleza o función de dicho producto o del servicio de que se trate;

d) consistan exclusivamente en formas u otros elementos que den una ventaja funcional o técnica al producto o al servicio al cual se aplican; 
e) consistan exclusivamente en un signo o indicación que pueda servir en el comercio para describir la calidad, la cantidad, el destino, el valor, la procedencia geográfica, la época de producción u otros datos, características o informaciones de los productos o de los servicios para los cuales ha de usarse dicho signo o indicación, incluidas las expresiones laudatorias referidas a esos productos o servicios;

f) consistan exclusivamente en un signo o indicación que sea el nombre genérico o técnico del producto o servicio de que se trate;

g) consistan exclusivamente o se hubieran convertido en una designación común o usual del producto o servicio de que se trate en el lenguaje corriente o en la usanza del país;

h) consistan en un color aisladamente considerado, sin que se encuentre delimitado por una forma especifica;

i) puedan engañar a los medios comerciales o al público, en particular sobre la procedencia geográfica, la naturaleza, el modo de fabricación, las caracteristicas, cualidades o aptitud para el empleo de los productos o servicios de que se trate;

j) reproduzcan, imiten o contengan una denominación de origen protegida para los mismos productos o para productos diferentes, cuando su uso pudiera causar un riesgo de confusión o de asociación con la denominación; o implicase un aprovechamiento injusto de su notoriedad;

k) contengan una denominación de origen protegida para vino y bebidas espirituosas;

1) consistan en una indicación geográfica nacional o extranjera susceptible de inducir a confusión respecto a los productos y servicios a los cuales se aplique;

m) reproduzcan o imiten, sin permiso de las autoridades competentes, bien sea como marcas, bien como elementos de las referidas marcas, los escudos de armas, banderas, emblemas, signos y punzones oficionales de control y de garantía de los Estados y toda imitación desde el punto de vista heráldico, así como los escudos de armas, banderas y otros emblemas, siglas o denominaciones de cualquier organización internacional;

n) reproduzcan o imiten signos de conformidad con normas técnicas, a menos que su registro sea solicitado por el organismo nacional competente en normas y calidades de los Países Miembros;

o) reproduzcan, imiten o incluyan la denominación de una variedad vegetal protegida en un País Miembro o en el extranjero, si el signo de destinara a 
productos o servicios relativos a esa variedad o su uso fuere susceptible de causar confusión o asociación con la variedad;o

p) sean contrarios a la ley, a la moral, al orden público o a las buenas costumbres;

No obstante lo previsto en los literales b), e), f), g) y h), un signo podrá ser registrado como marca si quien solicita el registro o su causante lo hubiese estado usando constantemente en el País Miembro y, por efecto de tal uso, el signo ha adquirido aptitud distintiva respecto de los productos o servicios a los cuales se aplica.

Art. 136.- No podrán registrase como marcas aquellos signos cuyo uso en el comercio afectara indebidamente un derecho de tercero, en particular cuando:

a) sean idénticos o se asemejen a una marca anteriormente solicitada para registro o registrada por un tercero, para los mismos productos o servicios, o para productos o servicios respecto de los cuales el uso de la marca pueda causar un riesgo de confusión o de asociación;

b) sean identicos o se asemejen a un nombre comercial protegido o, de ser el caso, a un rótulo o enseña, siempre que dadas las circunstancias, su uso pudiera originar un riesgo de confusión o de asociación;

c) sean idénticos o se asemejen a un lema comercial solicitado o registrado, siempre que dada las circunstancias, su uso pudiera originar un riesgo de confusión o de asociación;

d) sean identicos o se asemejen a un signo distintivo de un tercero, siempre que dada las circunstancias su uso pudiera originar un riesgo de confusión o de asociación, cuando el solicitante sea o haya sido un representante, un distribuidor o una persona expresamente autorizada por el titular del signos protegido en el País Miembro o en el extranjero;

e) consistan en un signo que afecte a identidad o prestigio de personas jurídicas con o sin fines de lucro, o personas naturales, en especial, tratándose del nombre, apellido, firma, título, hipocorístico, seudónimo, imagen, retrato, caricatura de una persona distinta del solicitante, salvo que se acredite el consentimiento de esa persona o, si hubiese fallecido, el de quienes fueran declarados sus herederos;

f) consistan en un signo que infrinja el derecho de propiedad industrial o el derecho de autor de un tercero, salvo que medie el consentimiento de éste;

g) consistan en el nombre de las comunidades indigenas, afroamericanas o locales, o las denominaciones, las palabras, letras, caracteres o signos utilizados para 
distinguir sus productos, servicios o la forma de procesarlos, o que constituyan la expresión de su cultura o práctica, salvo que la solicitud sea presentada por la propia comunidad o con su consentimiento expreso;y,

h) constituyan una reproducción, imitación, traducción, transliteración o transcripción, total o parcial, de un signo distintivo notoriamente conocido cuyo titular sea un tercero, cualesquiera que sean los productos o servicios a los que se aplique el signo, cuando su uso fuese susceptible de causar un riesgo de confusión o de asociación con ese tercero o con sus productos o servicios; un aprovechamiento injutos del prestigio del signo; o la dilución de su fuerza distintiva o de su valor comercial o publicitario. 


\section{CAPÍTULO III: PROTECCIÓN A LAS MARCAS NO TRADICIONALES NO VISIBLES}

Habiendo revisado en el capítulo anterior nuestro sistema marcario, es pertinente analizar de acuerdo a las normas vigentes, cuál es la regulación y tratamiento legal que se le da a las marcas no tradicionales no visibles, para lo cuál, además de relacionarlas con las normas vistas anteriormente, veremos su tratamiento y regulación en otros países.

En efecto, para poder entender su tratamiento legal, es necesario primero delimitar conceptualmente este tipo de marcas, tal como veremos en el siguiente apartado.

\subsection{Delimitación conceptual}

Tal como se indicó en el capítulo anterior, usualmente las marcas estan compuestas por elementos denominativos, figurativos o mixtos; sin embargo, con el gran desarrollo de la economía tanto a nivel nacional como internacional los empresarios han visto atractivo el uso de nuevos elementos para conformar sus marcas. En ese sentido, esas marcas conformadas con esos nuevos elementos en doctrina se denominan "nuevos tipos de marcas" o "marcas no tradicionales" en contraposición a lo que se denomina como "marcas tradicionales".

En efecto, Juan David Castro García (2012) expresa que:

Para abordar el objeto en estudio resulta imprescindible delimitar conceptualmente la noción de "marca no tradicional", definición que no es difícil de precisar ya que se entiende por oposición a lo que se consideran las marcas "tradicionales", es decir, aquellas que se expresan a través de letras, números, palabras, dibujos o símbolos, y que son apreciadas por el sentido de la vista. De esta manera, una marca no tradicional es aquella que es percibida por cualquiera de los cinco sentidos y cuya representación debe ser hecha a través de métodos de representación no tradicionales (p.297). 
En la misma linea, Juan José Arías (2015) indica que: "Por lo general, la doctrina ha considerado como marcas tradicionales aquellas constituidas por los signos denominativos, mixtos y gráficos - principalmente los isotipos-, siendo los demás considerados como marcas no tradicionales" (p.7).

Por su parte, José Alexander Ávila Vallecillo (2016) señala que:

(...) no existe un concepto unificado tendiente a definir con exactitud a las marcas no tradicionales (...) podríamos establecer que las marcas no tradicionales consisten en cualquier signo distintivo útil para diferenciar bienes, productos y servicios de entre otros de su misma clase o especie, pudiendo ser distinguidos y percibidos mediante cualquier sentido del cuerpo humano (vista, tacto, olfato, gusto, oído) y sean por ende, susceptibles de representación gráfica (p.14).

Asimismo, en el Manual Armonizado en Materia de Criterios de Marcas de las Oficinas de Propiedad Industrial de los Países Centroamericanos y la República Dominicana (2016), en colaboración con varios organismos de propiedad industrial, entre ellos la OMPI, establecieron que "Marcas tradicionales son las que "tradicionalmente" han sido reconocidas en la doctrina, y en las legislaciones, e incluyen a las marcas denominativas, figurativas y mixtas (combinación de elementos denominativos y figurativos)" (p.16), y establecieron a las marcas no tradicionales de la siguiente manera:

Con el desarrollo de la tecnología y el surgimiento de nuevos métodos publicitarios para atraer la atención de los consumidores, los empresarios empezaron a recurrir a otros elementos -distintos de los tradicionales signos denominativos, figurativos o mixtos- para identificar sus productos o servicios. Ante tal fenómeno, el derecho marcario ha tenido que evolucionar para incluir dentro del concepto de marca, no sólo a aquellos que tradicionalmente eran reconocidos en las legislaciones, sino a todo signo capaz de identificar productos y servicios. Surgen así las llamadas marcas no tradicionales. (Manual Armonizado en Materia de Criterios de Marcas de las Oficinas de Propiedad Industrial de los Países Centroamericanos y la República Dominicana, 2016, p.17)

Por otro lado, José Daniel Liévano Mejía (2011) diferencia a las marcas tradicionales de las marcas no tradicionales de la siguiente manera: 
Como ya lo habíamos mencionado, la marca tradicionalmente se ha asociado con imágenes en dos dimensiones, compuestas por una forma, una combinación de colores y un texto. Pero, existen otro tipo de signos diferentes a las imágenes, bien sean visibles o no visibles, que podrían llegar a considerarse como marcas, como lo son los sonidos, los olores o aromas, la textura, el sabor o la forma, entre otras opciones. Estas que acabamos de mencionar son las marcas no tradicionales, y su nombre se debe a que no es usual que los productos o servicios en el mercado se identifiquen y diferencien por medio del uso de este tipo de signos distintivos. Es su carácter de novedosas y diferentes lo que las hace opuestas a lo tradicional y por este motivo se ha decidido denominarlas marcas no tradicionales (p.3).

En este orden de ideas puede decirse que las marcas no tradicionales son aquellos nuevos tipos de marcas compuestos por elementos pocos usuales o tradicionales por parte de los empresarios; es decir, estarían compuestos por elementos diferentes a los denominativos, figurativos o mixtos.

Vale recalcar que en las sesiones del Comité Permanente sobre el Derecho de Marcas, Diseños Industriales e Indicaciones Geográficas se han referido a estos tipos de marcas, en sus inicios como "nuevos tipos de marcas", y luego como "marcas no tradicionales". A su vez, específicamente en la Decimosexta Sesión, se establecieron dos subcategorias de las marcas no tradicionales, las compuestas por signos visibles y no visibles, siendo estos últimos materia del presente trabajo de investigación.

En efecto, en la Decimosexta Sesión de este Comité (OMPI, 2006) se estableció lo siguiente:

Actualmente, los tipos de signos que se consideran aptos para constituir una marca ya no son sólo las palabras y los elementos figurativos. En el comercio se utilizan signos perceptibles visualmente junto con otros que, no siendo visualmente perceptibles, tienen la capacidad de distinguir bienes y servicios. Hay también otros signos que son visibles, pero se apartan del concepto tradicional de signo constitutivo de marca en uno o varios de sus rasgos característicos. Con la intención de clasificar los diversos signos capaces de constituir una marca, en este documento los signos se agrupan según puedan ser percibidos por la vista o por algún otro de los sentidos. 
En este orden de ideas, de la lectura del documento de esta sesión puede desprenderse que las marcas no tradicionales visibles estan compuestas por las marcas tridimensionales, marcas de color, hologramas, lemas publicitarios, titulos de películas y libros, signos animados o de multimedia, marcas de posición y marcas gestuales; mientras que las marcas no tradicionales no visibles estan compuestas por las marcas sonoras, olfativas, gustativas y táctiles.

Así también lo explica José Alexander Ávila Vallecillo (2016) cuando indica que:

En la Decimosexta sesión, a través del Comité Permanente, La OMPI ( 2007) efectuó una clasificación exhaustiva en cuanto al tema de marcas no tradicionales, encasillándolas en dos grandes grupos marcarios (Ver figura \#1) : a) Signos visibles: i) Marcas tridimensionales; ii) Marcas de color; iii) Hologramas; iv) Lemas publicitarios; v) Títulos de películas y libros; vi) Signos animados o de multimedia; vii) Marcas de posición; y viii) Marcas gestuales; b) Signos no visibles: i) Marcas sonoras, ii)Marcas olfativas, iii) Marcas gustativas, y iv) Marcas de textura o táctiles(p. 2-8)" (como se citó en Ávila, 2016, p.15).

De la misma manera, Juan David Castro García (2012) señala que:

Las marcas no tradicionales son de dos tipos principalmente, las visuales (colores, formas, hologramas, imágenes en movimiento y marcas de posición) y las no visuales (sonidos, olores, sabores y texturas) que son percibidas por alguno o varios de los sentidos del ser humano (p.297).

En este orden de ideas, en el presente capítulo se tratarán las marcas no tradicionales no visibles; estas son: las marcas sonoras, olfativas, gustativas y táctiles, y su tratamiento legal y sus inconvenientes para cumplir con los requisitos de distintividad y de representación gráfica para que puedan acceder al registro.

\subsection{Decisión 486 - Régimen Común sobre Propiedad Industrial - de la Comunidad Andina, y las marcas no tradicionales no visibles}

En este apartado es necesario analizar de manera profunda el artículo 134 de la Decisión 486 mencionado anteriormente, pues es en este artículo donde podremos 
visualizar si una marca no tradicional no visible podría constituirse como tal de acuerdo a los requisitos esenciales que esta norma nos dicta.

Para un mejor análisis lo volveremos a citar a continuación:

Art.134.- A efectos de este régimen constituirá marca cualquier signo que sea apto para distinguir productos o servicios en el mercado. Podrán registrarse como marcas los signos susceptibles de representación gráfica. La naturaleza del producto o servicio al cual se ha de aplicar una marca en ningún caso será obstáculo para su registro.

Podrán constituir marcas, entre otros, los siguientes signos:

a) Las palabras o combinación de palabras;

b) Las imágenes, figuras, símbolos, gráficos, logotipos, monogramas, retratos, etiquetas, emblemas y escudos;

c) Los sonidos y los olores;

d) Las letras y los números;

e) Un color delimitado por una forma, o una combinación de colores;

f) Las forma de los productos, sus envases o envoltura;

g) Cualquier combinación de los signos o medios indicados en los apartados anteriores. (Decisión 486, 2000) (Los subrayados son mios).

Como puede apreciarse, el literal c) del artículo mencionado señala de manera expresa que los sonidos y los olores sí pueden constituirse como marcas. Asimismo, este artículo no menciona expresamente si los signos táctiles o gustativos pueden constituirse como tal; sin embargo, consideramos que la lista comentada es de numerus apertus, pues comienza expresando que: "Podrán constituir marcas,_entre otros, los siguientes signos: (...)" (Decisión 486, 2000) (El subrayado es mio); por lo que puede inferirse que estos signos sí podrían constituirse como marcas en virtud a esta decisión andina.

Pese a lo expuesto, es necesario indicar que el primer párrafo incluye dos requisitos: i) que el signo sea apto para distinguir productos o servicios en el mercado, y ii) que el signo sea susceptible de representación gráfica. 
En ese sentido, es acertado preguntarse si estos signos no tradicionales son aptos para cumplir con la función identificadora y distintiva de la marca, la cual es su función principal. Asímismo, es necesario cuestionarse cómo un signo no visible, como el olor, el sonido, el tácto o el gusto pueden representarse gráficamente.

Debe aclararse que de la lectura del primer párrafo del artículo 134 puede concluirse que la definición que la norma andina le otorga a la marca es la de "cualquier signo que sea apto para distinguir productos o servicios en el mercado"; por lo que el carácter distintivo del signo viene a ser la parte medular en la definición de la marca, por ser este fundamental para cumplir con su función principal. Es por este motivo que la distintividad debe ser un requisito obligatorio para que se constituya cualquier derecho sobre una marca.

Sobre el requisito de la representación gráfica, del primer párrafo del artículo en mención puede observarse que el mismo no pareciera formar parte de la definición de marca ${ }^{22}$; sin embargo, es un requisito esencial que la norma ha establecido para que un signo pueda constituirse como tal; por este motivo, es necesario determinar si este requisito es indispensable o no para que la marca pueda cumplir con su función principal, que es la de identificar y diferenciar productos o servicios en el mercado.

Debe precisarse que originalmente en la Decisión 85 se establecía, en su artículo 56, que podían registrarse como marcas los signos que fueran novedosos, visibles y suficientemente distintivos. Es decir, bajo el régimen de esta decisión (que data de

\footnotetext{
${ }^{22}$ No obstante, debe recordarse que el Tribunal de Justicia de la CAN estableció que:

La marca es un bien inmaterial constituido por un signo conformado por palabras o combinación de palabras, imágenes, figuras, símbolos, gráficos, etc., que, susceptibles de representación gráfica, sirvan para distinguir en el mercado productos o servicios, a fin de que el consumidor o usuario medio los identifique, valore, diferencie y seleccione sin riesgo de confusión o error acerca del origen o la calidad del producto o del servicio (Proceso 70-IP-2013, 2013) (El subrayado es mío).
}

En efecto, queda la duda de si para el Tribunal de Justicia de la CAN la susceptibilidad de representación gráfica del signo sea parte de la definición de marca, o solo sea un requisito para su registro. 
1974) era imposible que los sonidos, las texturas, los olores o los sabores pudieran registrarse como marcas, pues se señalaba expresamente que el signo debía ser visible. Esta decisión no establecía una definición exacta de lo que se consideraba como marca, limitándose a establecer los requisitos para que un signo se constituyera como tal. Asimismo, no exigía que el signo fuese susceptible de representación gráfica. En ese sentido, es necesario señalar que en el literal b) del artículo 60 y literal d) del artículo 61, se establecía que a la solicitud debia acompañarse y/o indicarse la descripción clara y completa de la marca que se pretendía registrar, y las reproducciones de la marca si fuera el caso.

Posteriormente, la Decisión 85 se derogó por la Decisión 311 (1991), cuyo artículo 71 establecía lo siguiente:

Podrán registrarse como marcas los signos que sean perceptibles, suficientemente distintivos y susceptibles de representación gráfica.

Se entenderá por marca todo signo perceptible capaz de distinguir en el mercado, los productos o servicios producidos o comercializados por una persona de los productos o servicios idénticos o similares de otra persona.

Como puede apreciarse, desde la Decisión 311 ya no se exigía que un signo sea visible para que pudiera registrarse como marca, bastaba con que el signo sea perceptible (pudiendo serlo a través de otros sentidos). Asimismo, es a partir de esta decisión que se incorporó el requisito de la representación gráfica; sin embargo, hay duda sobre si bajo el régimen de esta decisión un signo no visible podía constituirse como marca; pues si bien se eliminó el requisito de la visibilidad, no había una lista enunciativa que estableciera si algún signo no visible podía constituirse como tal (como sí sucede en la decisión actual) y tampoco quedaba claro cómo un signo no visible podía ser representado gráficamente.

Es importante observar que el segundo párrafo del artículo comentado sí definía a la marca, la cual tampoco incluía a la representación gráfica como parte integrante de su concepto, sino que en dicho artículo se mencionaba sólo como un requisito para su registro. 
Asimismo, es necesario indicar que el literal b) del artículo 76 (bajo apercibimiento de no ser admitida a trámite) y los literales b) y d) del artículo 77 de la misma decisión, establecía que a la solicitud debía acompañarse y/o indicarse la descripción clara y completa de la marca que se pretendía registrar para objeto de su publicación, y la reproducción de la marca cuando tuviera elementos gráficos.

La Decisión 311 tuvo corta duración, y fue derogada por la Decisión 313 en 1992. Esta última decisión no tuvo modificaciones sobre los artículos comentados. De la misma manera, esta decisión fue derogada en 1993 por la Decisión 344 (la cual tampoco tuvo modificaciones sobre las disposiciones comentadas), y fue también posteriormente derogada por la actual Decisión 486.

\subsubsection{Requisito de la distintividad}

Dado que la función principal de la marca es la de identificar y distinguir productos o servicios en el mercado, el requisito de la distintividad es el más importante de todo el sistema marcario. "La distintividad es la cualidad insoslayable que debe presentar todo signo que pretenda acceder legalmente al registro"( Diego Chijane, 2007, p.29). Asimismo, esta distintividad debe determinarse según los bienes que se desea distinguir.

La distintividad se clasifica en "distintividad intrínseca" y "distintividad extrínseca". La primera se relaciona con los elementos que conforman la marca de acuerdo con los productos o servicios que se buscan distinguir, esto es el signo en sí mismo considerado en relación con los bienes para los cuales se va a utilizar; en cambio, la distintividad extrínseca se relaciona con la distintividad que debe tener una marca en comparación con otros signos distintivos ya existentes, para no generar riesgo de confusión o de asociación en el consumidor al momento de elegir un producto o servicio en el mercado.

Vale precisar que muchas de las prohibiciones absolutas contenidas en el artículo 135 de la Decisión 486 se refieren a supuestos en los cuales un signo adolecería de distintividad intrínseca; es decir, los signos descriptivos, las formas usuales de los 
productos, los nombres genéricos o técnicos de un producto o servicio, su designación común o usual son supuestos de distintividad intrínseca. De la misma manera, muchas de las prohibiciones relativas contenidas en el artículo 136 de la misma norma adolecerían de distintividad extrínseca.

Asimismo, de acuerdo al artículo 134, el signo para constituirse como marca deberá ser apto para distinguir productos o servicios en el mercado. Al respecto, debe aclararse que si bien una marca al momento de solicitar su registro muchas veces no es usada en el mercado (pues no es necesario el uso de la marca para que un signo sea registrado, a diferencia de otras legislaciones), y por lo tanto, no distingue ningún producto o servicio aún, el signo debe tener la potencialidad de poder cumplir con esta función.

Por otro lado, es interesante exponer la diferenciación que Christian Schmitz Vaccaro hace sobre el tema. Él explica que la distintividad se asocia más al medio; esto es, a la marca; mientras que la diferenciación se enfocaría en el objeto mismo, al producto. La distintividad poseería una connotación jurídica mientras que la diferenciación sería un concepto más vinculado al campo del marketing y publicidad (Schmitz, 2012).

En ese sentido, los competidores buscan diferenciar sus productos y servicios frente a los de los otros competidores, pero es con la marca que logran ser distinguidos. Un producto, puediendo ser diferente de los otros ofertados por un competidor, puede ser copiado por otro, pero la marca es única en relación al producto o servicio para el cual se utiliza, pues el registro de una marca, como se ha explicado anteriormente, da el derecho exclusivo a su titular de utilizar la marca, impidiendo que terceros puedan usarla sin su consentimiento.

Asimismo, este autor nos comenta que esta necesidad de distinción emerge en los tiempos actuales con una fuerza nunca antes vista, pues el comercio ha incrementado de manera considerable, teniendo en el mercado un sinúmero de productos idénticos o similares. Por estas razones, los competidores deben hacer que su marca, como signo distintivo, tenga éxito en el mercado, debiendo quedar plasmada en 
la mente del consumidor para que lo pueda relacionar al bien que distingue (Schmitz, 2012)

En este orden de ideas, los consumidores actualmente se ven invadidos de infinidad de marcas para poductos y servicios similares, por lo que los competidores deben utilizar estrategias para que estos signos puedan cumplir con su función principal, y las otras funciones vistas en el capítulo anterior. Las marcas no tradicionales no visibles, como los sonidos, olores, las texturas y los sabores, son signos que actualmente se estan utilizando como una forma innovadora de distinguir los distintos bienes en el mercado; los empresarios ya no solo utilizan los signos visibles que son los que tradicionalmente se han usado a lo largo del tiempo para poder distinguir bienes y servicios en el mercado.

En ese sentido, cabe preguntarse si estos signos no visibles poseen aptitud distintiva para constituirse como marcas, tal como veremos a continuación:

a) La aptitud distintiva de un signo sonoro

Hay discusión en doctrina de si los sonidos por si solos pueden cumplir con el requisito de la distintividad. Tal como nos explica Diego Chijane (2007), los autores en contra usualmente manifiestan que los consumidores no estarían acostumbrados a percibir los signos sonoros como marcas, y que éstos solo serían percibidos luego de efectuarse la compra del producto o servicio; es decir, no cumpliendo con su función de informar al consumidor sobre el origen empresarial del bien ofertado, y no permitiéndole individualizarlo para que realice una elección eficiente (función identificadora y diferenciadora de la marca), por lo que ante cualquier solicitud debería probarse su distintividad sobrevenida primero; asimismo, se dice que el signo sonoro para que sea distintivo debe estar siempre acompañado de algún elemento visual, y así poder acceder a registro (p.490).

Por otro lado, algunos autores argumentan que al solicitarse que un signo acceda a registro no es necesario que el mismo sea distintivo, sino que tenga aptitud para serlo. Sobre lo indicado, es menester enfatizar la posición de Diego Chijane (2007): 
(...) al solicitarse un signo no es necesario que el mismo sea distintivo, sino que tenga aptitud para serlo. Así, es como pensar que una breve expresión musical no tendrá aptitud para individualizar un programa de radio o televisión o la actividad radiotelevisiva en sí (p.490).

Asimismo, Alberto Casado Cerviño (2009) nos comenta que gran sector de la doctrina ha acogido el criterio de exigir, además de los requisitos establecidos para registrar marcas tradicionales, un requisito adicional, que sería la prueba de que el signo no visual es percibido por los consumidores como medio adecuado para distinguir bienes en el mercado.

Adicionalmente, es indispensable mencionar que en el Comité Permanente sobre el Derecho de Marcas, Diseños Industriales e Indicaciones Geográficas de la OMPI, se ha discutido el tema sobre la distintividad de las marcas sonoras, en la Decimosexta y Decimoseptima sesión.

Sobre el particular, en la Decimosexta Sesión, en virtud a la información proporcionada por las Oficinas de Propiedad Industrial de varios de los Estados Parte, la Secretaría elaboró un documento sobre el tratamiento que se le estuvo dando a las marcas no tradicionales bajo las distintas legislaciones. Con respecto a los signos sonoros, se indicó que éstos podían ser de dos tipos: i) los musicales y, ii) los no musicales. Con respecto a los primeros, se explicó que estos consisten en sonidos creados para el fin específico o bien en sonidos tomados de partituras ya existentes. Para un mejor entendimiento, es necesario precisar que estos sonidos consisten en melodías, como por ejemplo, un fragmento de una canción ya existente, o como bien se indicó, una melodía creada para usarse como marca. Con respecto a los sonidos no musicales, se señaló que estos consisten en sonidos creados o bien consistentes en reproducciones de sonidos que se encuentran en la naturaleza o ruidos, como por ejemplo, el sonido de un trueno o el rugido de un león (Comité Permanente sobre el Derecho de Marcas, Diseños Industriales e Indicaciones Geográficas de la OMPI, 2006). 
Asimismo, un dato importante es que en el cuestionario elaborado por la OMPI (Comité Permanente sobre el Derecho de Marcas, Diseños Industriales e Indicaciones Geográficas de la OMPI, 2010), 38 de 76 Oficinas de Propiedad Industrial respondieron que admitían los sonidos musicales; mientras que 28 de 73 oficinas respondieron que admitian el registro de sonidos no musicales; es decir, menos de la mitad admitía estos últimos.

Por otra parte, es importante señalar expresamente lo que se dijo también en esta sesión:

$\underline{\text { Si bien no puede descartarse la posibilidad de que los sonidos tengan una capacidad }}$ intrínseca para distinguir bienes y servicios, posiblemente sea más frecuente que adquieran su carácter distintivo con el uso y que se empleen en combinación con otros tipos de marcas, tales como las marcas verbales o figurativas. En tal caso, ambos tipos de signos deben ser capaces de operar como marcas (Comité Permanente sobre el Derecho de Marcas, Diseños Industriales e Indicaciones Geográficas de la OMPI, 2006). (El subrayado es mío).

En cuanto a la Decimoséptima Sesión (Comité Permanente sobre el Derecho de Marcas, Diseños Industriales e Indicaciones Geográficas de la OMPI, 2007) se analizaron los principios existentes en el derecho de marcas con relación a los nuevos tipos de marcas, y se señaló que tanto un tono único como sonido cualquiera, y las obras musicales o teatrales de larga duración no suelen percibirse como signos distintivos. Asimismo, se manifiestó que en virtud al Principio de la Disponibilidad, los sonidos que se consideran habituales en una rama comercial no pueden registrarse como marcas. Asi se estableció cuando se señaló que:

(...) De acuerdo con el principio de la disponibilidad, los sonidos que se consideran habituales en una rama comercial y cuya utilización es reivindicada por los comerciantes no se pueden registrar como marcas, como ocurriría con el sonido de cristales rotos en el sector de los "servicios de reparación de parabrisas" o con obras musicales clásicas notoriamente conocidas en el sector de los servicios de "clases de danza". Sin embargo, muchos sonidos sin relación descriptiva particular con los productos o servicios ofrecidos podrían considerarse aceptables prima facie, como podría ser el caso del aullido de un lobo en relación con las bebidas alcohólicas (OMPI, 2007) (El subrayado es mío). 
En cuanto al regimen comunitario de la Comunidad Andina, que es el que nos concierne, Baldo Kresalja (2000) manifiesta que no estaría en discusión su capacidad de distinguir, siendo admitidas por la Decisión 486. Así lo indica cuando señala que:

A diferencia de lo que ocurre con las marcas olfativas, prácticamente no existe discusión en Doctrina respecto de la capacidad de los sonidos para distinguir productos y servicios. A la indudable capacidad evocativa de que están dotados los sonidos, se suma el extraordinario desarrollo moderno de las comunicaciones que hacen posible su reproducción a distancia; ello hace que las empresas lo usen frecuentemente para distinguir productos y servicios. Así, es una realidad innegable y comprobable por todos que muchas veces nos encontramos frente a melodías, jingles o simples sonidos que, inconscientemente, nuestras mentes asocian con algún producto o servicio en particular. Estamos frente a verdaderas marcas. (...). (p.176). (los subrayados son mios).

Pese a lo expuesto, es necesario recalcar que la mayor parte de la doctrina, tanto nacional, regional como internacional, ya ha admitido que el sonido posee aptitud distintiva inherente, y que el ser humano es capaz de distinguir infinidad de sonidos a lo largo de sus vidas, pudiendo diferenciarlos y relacionarlos con ciertos bienes, muy independientemente a cómo estén utilizadose usualmente en el comercio. Esto puede apreciarse en virtud a que actualmente ya existe un número considerable de registros de marcas sonoras en las diversas oficinas de Propiedad Industrial, incluido en el Perú.

b) La aptitud distintiva de un signo táctil

"En este tipo de marcas es la superficie del producto lo que puede dar lugar a su reconocimiento, por ejemplo por tener la superficie tocada una estructura o textura específicas y reconocibles (...)" (Decimosexta Sesión del Comité Permanente sobre Derechos de Marcas, Diseños Industriales e Indicaciones Geográficas, 2006); asimismo, se dice que por su naturaleza, el signo táctil no podrá ser separado del bien que identifica y distingue, pues el consumidor solo puede percibirlo al tocar el producto o envase; por lo que su difusión en el mercado sólo podrá realizarse cuando los consumidores puedan estar en contacto directo con el producto. 
Si bien han habido marcas táctiles registradas en diversas Oficinas de Propiedad Intelectual, no hay muchas posiciones a favor de que los signos táctiles cuenten con distintividad inherente; muy por el contrario, en la USPTO, que es la Oficina de Propiedad Industrial que ha tenido más solicitudes y registros de estos nuevos tipos de marcas, muchos de estos signos han sido denegados alegando su funcionalidad. Asimismo, lo que usualmente se ha manifestado es que el signo táctil sólo podría obtener distintividad sobrevenida, pues la textura de los productos no sería visto como marca por los consumidores, sino como parte del producto o envase. Adicionalmente, se dice que el tacto como signo es muy subjetivo, y lo que para el solicitante se considere distintivo, para otras personas podría no apreciarse de manera similar.

No obstante a lo expuesto, si bien en el Perú no han habido solicitudes ni registros de estos tipos de marcas, sí han habido marcas táctiles registradas dentro de los Países Miembros de la CAN, tal como lo veremos más adelante.

c) La aptitud distintiva de un signo gustativo

Las marcas gustativas son las marcas no tradicionales no visibles menos aceptadas por parte de las Oficinas de Propiedad Industrial. Si bien los consumidores, mediante su uso prologando y constante en el tiempo pueden relacionar el sabor con un producto especifico, se dice que el gusto por sí mismo no posee distintividad inherente, pues es imposible disociar el sabor con el bien que pretende distinguir, pudiendo solo con su uso diferenciarse el producto del signo.

Asimismo, se dice que la percepción de los sabores es subjetiva y variable. Según Diego Chijane (2007):

(... ) se indica que la percepción subjetiva y variable de los sabores imposibilita que sean registrados como marca. No es posible determinar objetivamente qué es lo que se reivindica como signo, ya que su aprehensión sensorial dependerá de distintos factores, a saber: edad, temperatura, medio ambiente e incluso varía la percepción de un mismo sabor a medida que en forma continuada se lo va percibiendo (p.496).

Es interesante señalar que el sector que se ha visto más interesado en el registro de estos tipos de signos es el sector farmacéutico para identificar y distinguir 
medicamentos. Sin embargo, para estos productos (y como para la mayoria de los que se han solicitado) las Oficinas de Propiedad Industrial argumentan como motivo de rechazo la funcionalidad del signo. En ese sentido, la USPTO en varias oportunidades ha señalado que el consumidor no relacionaría el sabor como marca del producto, sino como un elemento funcional de este, el cual sería mejorar los sabores desagradables de los productos farmacéuticos.

La USPTO, sobre la solicitud de registro de un signo gustativo - solicitud $\mathrm{N}^{\circ}$ 76467774 - ha señalado que "El sabor agradable da una ventaja comparativa al solicitante respecto de los otros competidores, ya que incrementa la voluntad y habilidad de los pacientes a la hora de tomarse el fármaco" (como se citó en Lizano y Pal, 2013 p.122).

En la misma linea, la USPTO en el 2008 rechazó el registro de una marca gustativa que consistía en "el sabor a lavanda, menta, zacate de limón y tomillo" para distinguir bebidas no alcohólicas toda vez que el signo funcionaría para mejorar el sabor de estas bebidas, y permitiría obtener beneficios en la salud de quienes las toman, otorgándose así una ventaja competitiva en caso se hubiera concedido el registro del signo gustativo (como se citó en Lizano y Pal, 2013, p.122).

Por otro lado, el Circuito Federal de los Estados Unidos en el caso Brunswick Corp.v. British Seagul Ltd. manifestó que "como con cualquier marca el análisis de funcionalidad de jure depende si el registro de una característica entorpece o no a la competencia, y no tanto si la característica contribuye al éxito del producto" (como se citó en Lizano y Pal, 2013, p.126). (El subrayado es mío).

Adicionalmente, es menester mencionar que la Junta de Juicios y Apelaciones sobre Marcas de los Estados Unidos (TTAB) ha establecido en diversas oportunidades cuáles serían los criterios utilizados para evaluar si un signo tiene un rol funcional o no en relación con el producto que se busca distinguir. En ese sentido, los factores para determinar la funcionalidad de un signo serían los siguientes: i) la existencia de una patente de utilidad evidenciando sus ventajas utilitarias; ii) la existencia de materiales publicitarios en el cual el solicitante del signo promociona sus ventajas utilitarias; iii) la 
disponibilidad del producto con la misma función para los competidores y; iv) la existencia de evidencia que demuestre que el signo comparativamente es un método más simple o más barato para producir el producto. La TTAB hace hincapié en que basta con que uno de estos factores se produzca para determinar la efectiva funcionalidad del signo (como se citó en Lizano y Pal, 2013, p.126).

Por otra parte, según Liévano (2013), se dice que la única posibilidad para que un signo gustativo pueda acceder al registro es que el sabor vaya acompañado de un signo visual, o que adquiera distintividad sobrevenida, debiéndose exigir para ambos casos que el sabor sea completamente novedoso y diferente al que habitualmente tienen los productos para los cuales se desea registrar. (p.33 - 34).

En ese sentido, es necesario precisar que en el Perú no han habido solicitudes ni registros de estos tipo de marcas; asímismo, tampoco hay indicios de que se hayan registrado en los demás Países Miembros de la CAN.

d) La aptitud distintiva de un signo olfativo

Si bien hay posiciones en contra al registro de los olores como marcas en virtud a su aptitud distintiva, la posición que predomina es la contraria. Si se echa un vistazo a la doctrina puede corroborarse que no se discute a menudo la distintividad de este tipo de marcas, sino que las discusiones principalmente se han centrado en el requisito de la representación gráfica del signo olfativo.

En efecto, Gonzalo Ferrero (2009) manifiesta que:

Afortunadamente, hoy por hoy está muy difundida y aceptada en el mundo (salvo probablemente en Asia) la noción de que ciertos olores son perfectamente registrables (aun cuando la figura genera posiciones encontradas en la doctrina especializada), y deben gozar de protección legal dada su indiscutible capacidad distintiva. (Ferrero, 2009, p.131-132) (El subrayado es mío).

Asimismo, José Daniel Liévano Mejía (2013) también nos comenta que "el requisito de la distintividad no ha sido discutido de manera profunda, debido a que el 
debate jurídico en torno a este tipo de signos se ha centrado en el requisito de la representación gráfica.” (p.28).

Sin perjuicio de lo expuesto, señalaremos las opiniones que sobre la distintividad de los signos olfativos se han expresado en doctrina.

En principio, se ha manifestado que el olfato del ser humano no estaría lo suficientemente desarrollado para distinguir gran cantidad de aromas y, por ello, solo podría diferenciar un número muy limitado, hecho que perjudicaría a la libre competencia en caso se permitiera el registro de signos olfativos como marcas.

En efecto, Diego Chijane (2007) nos explica la denominada Teoría del Agotamiento, como sigue:

Para determinados productos el olor resulta esencial, por tanto, si un competidor registrara diversos aromas podría restringirse indebidamente a la competencia. Además, existe una preferencia universal por determinadas fragancias, las que serían rápidamente apropiadas con los consecuentes perjuicios a la competencia. Asimismo, como antes se expresara, resulta difícil admitir que el consumidor distinga los finos matices diferenciales de dos fragancias similares, por ello, el registro de un aroma implicaría la monopolización de fragancias próximas, reduciéndose considerablemente la cantidad de aromas disponibles. (Chijane, 2007, p.484 - 485) (El subrayado es mío).

Gonzalo Ferrero (2009), en esta línea, agrega que si partiéramos del hecho de que la raza humana no tuviera el sentido del olfato completamente desarrollado y solo pudiera diferenciar un número limitado de aromas, el consumidor no podría diferenciar dos fragancias similares y, ocasionaría, además de perjudicar la libre competencia, presentaciones de acciones por infracción en grandes cantidades (p.333).

Asimismo, este autor también nos explica que para cierto sector de la doctrina, los signos olfativos no serían considerados como marcas por parte de los consumidores, pues para que el olor pudiera cumplir su función principal el consumidor debería tener acceso al signo antes de realizar la compra, posición con la que coincide (Ferrero, 2009, p.334). 
En la misma línea, Diego Chijane (2017) indica que como posición en contra al registro de este tipo de signos, se ha manifestado que los olores no serían el medio de comunicación habitual de los seres humanos, ni tampoco el medio habitual de identificación empleado por los comerciantes, por lo que, el consumidor, a la hora de identificar productos o servicios, siempre buscará signos denominativos o figurativos. Además, señala que para ciertos autores sería poco probable que el consumidor pueda acceder al olor previamente a la compra del producto como consecuencia de su embalaje, por lo que solo podrían percibir el olor si se les proporcionara una muestra (p. 482).

Asimismo, según Diego Chijane (2007), en doctrina muchas veces se ha dicho que:

(...)los seres humanos tienen una capacidad muy baja para reconocer los olores e identificarlos. Dado que para la memoria olfativa "recordar" un olor puede ser posible, sin embargo, muy poco probable que un aroma sea reconocido e identificado invariablemente con un producto determinado. Asimismo, se señala que, a diferencia del recuerdo visual, la memoria derivada de la percepción de olores resulta poco fiable.

También se argumenta que el público en general sólo se encuentra capacitado para distinguir unos pocos básicos aromas que, al igual que en materia de colores, podrían catalogarse de primarios. Por este motivo, en la mayoría de los casos el consumidor incurriría en confusión al ser difícil, o quizás imposible, que pueda distinguir con claridad las finas gamas y gradaciones de aroma (p.483).

Por otro lado, Gonzalo Ferrero (2009) también nos comenta sobre la denominada "Doctrina de la Funcionalidad", según la cual los signos funcionales no podrían registrase como marcas, aún en el supuesto de que dichos signos hubieran adquirido significado secundario, pues los efectos competitivos serían perjudiciales (p.333-334).

Al respecto, Diego Chijane (2007) señala que para ciertos autores los signos olfativos serían percibidos como elementos ornamentales para hacer más atractivo el producto (función decorativa). En ese sentido, nos señala que la antes OAMI - llamada antes así a la Oficina de Propiedad Intelectual de la Unión Europea - sobre la solicitud 
de registro del "aroma de la frambuesa" como marca, indicó que el consumidor percibiría este olor como un elemento decorativo destinado a mejorar la presencia del producto (p. 483).

Por otra parte, el antedicho autor Gonzalo Ferrero (2009) nos habla también sobre el concepto de genericidad, concepto por el cual no está permitido registrar una marca sobre signos frecuentemente utilizados para fabricar un determinado producto (p.344).

En la misma línea, José Daniel Liévano Mejía (2013) señala que:

Con relación al requisito de la distintividad, no se evidencia mayor problema, pues como se mencionó previamente en este capítulo, simplemente se debe exigir que el olor del producto sea completamente novedoso, arbitrario, y difiera de manera significativa al que habitualmente se acostumbra a usar en los productos de la misma categoría en el mercado ( p.31) (Los subrayados son míos).

De lo expuesto debe resaltarse que para este autor el signo olfativo debe ser novedoso; sin embargo, es pertinente recordar que de acuerdo al artículo 134 de la Decisión 486, expuesto líneas arriba, no se exige que el signo deba ser novedoso para que sea registrado como marca, solo que posea aptitud distintiva, y que pueda ser representado gráficamente, a diferencia de lo que se establecía en la derogada Decisión 85 .

Sobre los conceptos de genericidad del signo, la doctrina de la funcionalidad, y otras prohibiciones, Diego Chijane (2007) también nos explica que:

Ahora bien, de admitirse el registro de los signos in examine, no será posible la apropiación individual de aromas que pudieran reputarse genéricos, descriptivos, funcionales o de uso común. Así, por tratarse del aroma natural del producto, el olor a chocolate debería reputarse "genérico" para chocolates. Tampoco han de registrarse fragancias "descriptivas", tal es el caso del olor a menta para identificar caramelos de menta. Deberá rechazarse la inscripción de fragancias funcionales, como aquellas destinadas a enmascarar el mal olor natural del producto en cuestión. Y, en último término, tampoco se deberán inscribir aquellos aromas catalogables de uso común por 
su generalizada utilización en el mercado, como lo es el olor a limón en detergentes para plato (p. 482).

Asimismo, este autor nos explica, coincidiendo con Carlos Fernández - Novoa, que en doctrina se encuentra una clasificación de aromas en relación a los productos para los cuales son aplicados, con la finalidad de determinar si podrían ser registrados como marcas o no. Esta clasificación está dividida en tres categorías:

- Primary scents marks: Estos aromas son aplicados a productos cuya función principal es producir dichos aromas. Este es el caso de los perfumes o los desodorantes (Chijane, 2017, p.488).

Hay discusión en doctrina de si los aromas de estos productos pueden registrarse como marcas o no, pues como hemos visto $\mathrm{y}$, veremos particularmente en el caso Chanel $\mathrm{N}^{\circ} 5$, se dice que el olor no debe derivarse de la propia naturaleza del producto.

Secondary scents marks: Estos aromas son aplicados a productos cuya función principal es enmascarar el olor original de los productos. Este es el caso de los detergentes o jabones. En estos supuestos se estaría en presencia de olores que cumplirían un rol funcional (Chijane, 2017, p.488).

En ese sentido, de acuerdo a la doctrina de la funcionalidad vista líneas arriba, es muy probable que estos signos olfativos no puedan registrase como marcas.

- Unique scents marks: Estos aromas son aplicados a productos a los cuales no interesa si tienen olor o no (Chijane, 2017, p.488). Este es el caso, como veremos más adelante, del "aroma a hierba recién cortada para pelotas de tenis".

Sobre este aspecto, es necesario referirnos a la posición de Isabel Ramos (2014). Ella es una de las autoras cuya posición es que los olores pueden ser distintivos siempre que no sean inherentes o características naturales de los bienes que pretenden distinguirse, sino que consistan en elementos añadidos. Sin embargo, en el caso de los 
"secondary scents marks" y "primary scents marks", ella considera que sí podrían llegar a tener la distintividad necesaria para poder constituirse como marcas dependiendo del grado de originalidad del olor. Así lo explica cuando establece que:

(...) un olor puede tener carácter distintivo si no es inherente o una característica natural del producto o servicio, sino que lo añade para identificarlos y es reconocido por el público como indicador del origen empresarial.

\section{$(\ldots)$}

De tal manera que, en la línea que indicábamos previamente, el olor propio de un producto no puede atribuirse en exclusiva, por no concurrir carácter distintivo; pero los perfumes o jabones de forma destacable dentro de los productos en los que es inherente el aroma, separándonos del derecho norteamericano, pueden constituir el olor objeto de protección, por la posibilidad (indicada en líneas precedentes) de innovar y crear aromas lo suficientemente distintivos como para ser registrados como marcas (Ramos, 2014, p.179 y 181) (Los subrayados son míos).

Por otro lado, Maylee Cheilan también señala que el olor no debe consistir en un atributo inherente u olor natural del producto, coincidiendo con Isabel Ramos en que el olor debe consistir en un elemento extra que se le agrega al producto, debiendo ser un olor tan característico y peculiar que no pueda ser confundido o relacionado con otro. Así lo manifiesta cuando dice que:

Las marcas olfativas son aquellas que están constituidas por un olor suficientemente distintivo, el cual debe ser tan característico y particular que no pueda confundirse ni asociarse con otro.

Son aromas que van más allá de ser una característica intrínseca del producto o servicio y para que se consideren como tal, inexorablemente, tienen que añadirle un valor extra a lo que representen (Cheilan, 2014, p.6). (Los subrayados son míos).

En otro orden de ideas, Diego Chijane (2007) nos explica que en doctrina se ha manifestado que un signo olfativo podría poseer el grado de distintividad necesaria para poder ser registrado como marca, y recalca que se ha reconocido que en la mayoría de casos un signo olfativo puede llegar a ser distintivo como consecuencia de su constante uso en el mercado, adquiriendo distintividad sobrevenida. De esta manera, se indica que 
mientras el consumidor más acceso tenga al olor, y pueda con este identificar productos, el signo adquirirá mayor distintividad (p.479).

En línea similar, José Daniel Liévano Mejía (2003) considera que un olor no posee distintividad inherente, sólo puede poseer distintividad sobrevenida, recalcando que un olor sólo podría diferenciar un producto más no identificarlo con su origen empresarial. (p.29)

En efecto, José Daniel Liévano Mejía (2003) nos indica dos situaciones en las cuales un olor sí podría cumplir con el requisito de la distintividad para que pueda ser registrado como marca:

- Cuando el olor es completamente novedoso y su utilización no es usual al que normalmente se emplea para la comercialización de los productos que busca distinguir con el signo olfativo. Asimismo, debe estar acompañado con un elemento denominativo o figurativo, pues el olor sólo permitirá al consumidor diferenciar los productos en el mercado, mientras que el signo denominativo o figurativo permitirá a los consumidores identificar a los productos con su origen empresarial.

- Cuando el olor adquiere distintividad sobrevenida, configurándose el significado secundario o "secondary meaning". En este supuesto, el olor del producto también debe ser novedoso y diferir del olor que normalmente se usa para dichos productos (p.29).

En este mismo orden de ideas, la Trademark Trial and Appeal Board (TTAB) de los Estados Unidos de América, que conoció el recurso de apelación contra una resolución expedida por la USPTO, determinó que la solicitante había demostrado que el signo olfativo que pretendía registrar como marca había adquirido distintividad, pues era la única que comercializaba dichos productos con aroma en el mercado, y el olor no era inherente o natural a los productos que comercializaba; asimismo, en la publicidad, la solicitante había recalcado esta característica aportada a los productos, indicando que los consumidores y distribuidores habían llegado a conocerla por distribuir dichos productos con determinado aroma (como se citó en Ramos, 2014, p.176). 
Bajo otros argumentos, Diego Chijane (2007) señala que para cierta parte de la doctrina un olor para que sea distintivo debe ser objetivo; es decir, tener sus características completamente definidas para saber su ámbito de protección por el sistema marcario (p. 483). En ese sentido, indica que “(..) no podrá mutar por factores extrínsecos a él, porque de no ser percibido establemente, mal podría grabarse en la mente del consumidor y así desempeñar la función distintiva" (Chijane, 2007, p.483).

En efecto, el citado autor Chijane (2007) señala que para los autores en contra al registro de marcas olfativas, los olores variarían a lo largo del tiempo y su percepción sería muy subjetiva, toda vez que estos cambiarían dependiendo de la salud, estado psicológico, cultura del ser humano, medio ambiente, temperatura, nivel de humedad, mayor o menor ventilación, etc. (p.484). En ese sentido, expresa que "debido a sus moléculas gaseosas, un olor es muy fácilmente modificable por la existencia de otros aromas cercanos o por su interacción con el propio medio ambiente." (Chijane, 2007, p.484).

Por otra parte, Rafael Giménez Camacho (2010) indica que el admitir el registro de marcas olfativas sería un acto tendiente a la apropiación de uno de los cinco sentidos humanos, contrarios a los principios de competencia económica (párr.3).

Ahora que ya hemos visto las distintas posiciones en doctrina, es importante saber cómo se ha tratado este tema en el seno de la OMPI.

En la Decimosexta Sesión del Comité Permanente sobre Derecho de Marcas, Diseños Industriales e Indicaciones Geográficas (OMPI, 2006) se explicó que en un Estado Miembro, para realizar los exámenes de distintividad de los signos olfativos se establecieron los siguientes criterios:

- Si el solicitante es la única persona que comercializa los bienes afectados;

- Si la fragancia no es un atributo inherente o una característica natural de los bienes, sino, por el contrario, una característica aportada;

- Si el solicitante ha puesto de relieve y ha dado a conocer la marca olfativa en su publicidad; 
- Si el solicitante ha demostrado que los clientes, comerciantes y distribuidores de sus productos han llegado a conocer al solicitante como origen de dichos bienes.

Asimismo, en esta sesión del Comité (OMPI, 2006) se resaltó que en la Oficina de Marcas de otro Estado Miembro se estableció que el requisito de distintividad del signo olfativo debía evaluarse como si se tratara de cualquier otra marca y, se indicó que los aromas naturales, de enmascaramiento, los funcionales y comunes de los productos se habían declarado no aptos para distinguir bienes en el mercado.

En la Decimoséptima sesión del mismo Comité (OMPI, 2007) también se señaló que los olores naturales o habituales de los productos, que son necesarios que los otros comerciantes utilicen, son difíciles de registrar, como el caso del olor a vainilla para productos de pastelería o cualquier olor de enmascaramiento. Asimismo, en esta sesión también se indicó que:

(...) la aplicación de un aroma a un producto que no lo suele tener ofrece muchas más posibilidades de ser registrada. Probablemente no sería sencillo registrar este tipo de marcas y posiblemente se exigirían pruebas de su carácter distintivo adquirido. Se ha observado que puede ser necesario un número considerable de pruebas para determinar que un aroma funciona como marca (OMPI, 2007).

Asimismo, en este Comité (OMPI, 2007) se hizo referencia a la imposibilidad de registrar signos funcionales, explicando que éstos serán considerados como tales cuando sean fundamentales para el uso o el fin al que está destinado el producto, o si afecta su costo o calidad.

En efecto, se señaló que queda excluido el registro de perfumes, jabones, detergentes, lociones, y sus similares.

\subsubsection{Requisito de la representación gráfica}

El requisito de la representación gráfica, tal como se mencionó anteriormente, si bien pareciera no formar parte de la definición de marca, el artículo 134 de la Decisión 486 lo exije como requisito para que el signo pueda acceder al registro. En ese sentido, para un mejor entendimiento del tema, es necesario esclarecer qué significa que un signo sea susceptible de representación gráfica. 
Sobre el particular, la Real Academia Española (2014) define estos términos de la siguiente manera:

- Susceptible: "1. adj. Capaz de recibir la acción o el efecto que se expresan a continuación. (...)".

- Representación: “1.f. Acción o efecto de representar. 2.f. Imagen o idea que sustituye a la realidad. (...)".

- Gráfico: "1.adj. Perteneciente o relativo a la escritura y a la imprenta. 2.adj. Dicho de una descripción, de una operación o de una demostración: Que se representa por medio de figuras o signos".

De lo expuesto puede decirse que para que un signo cumpla con el requisito de ser susceptible de representación gráfica, debe ser capaz de representarse por medio de figuras y signos; es decir, de manera escrita o imprensa.

Así también lo explicó el abogado General Ruiz - Jaramo Coloms, cuando el Tribunal Federal Alemán de Patentes planteó ante el Tribunal de Justicia de las Comunidades Europeas cuestiones sobre la representación gráfica de los signos no visibles, tal como se indica:

Representar gráficamente es describir algo usando simbolos susceptibles de ser dibujados. Quiere esto decir que a la aptitud originaria de un signo cualquiera para distinguir debe añadirse su capacidad para ser "llevado al papel"; y por consiguiente, para ser visualmente percibido (como se citó en Fernández - Novoa, 2004, p.45).

En ese sentido, un signo para poder constituirse como marca, además de contar con aptitud distintiva, deberá ser apto para ser graficado mediante lineas, figuras, sea de manera escrita o impresa; es decir, la representación gráfica deberá ser visualmente perceptible.

Por lo expuesto, cabe preguntarse: ¿si la función principal de la marca es distinguir productos o servicios en el mercado, entonces por qué diversas legislaciones, incluida la Decisión 486, exigen como un requisito esencial, además de la distintividad, que el signo sea susceptible de representación gráfica? 
Según Diego Chijane (2007), este requisito es importante para efectos registrales, pues es una condición necesaria que facilita la actividad de registración para el examen, publicación e inscripción del signo que desea constituirse como marca. Asimismo, señala que el sustento de la exigencia de este requisito es el Principio de Seguridad Jurídica del Sistema Marcario, pues si la marca registrada otorga el derecho de uso exclusivo a su titular, los terceros deben conocer con precisión los limites de ese derecho, teniendo certeza cuál es el signo que se ha registrado para saber si es apropiable o no, y no violar los derechos del titular de la marca (p.472-473).

En efecto, se dice que el requisito de la represención gráfica en el proceso de registro de una marca permite que los terceros que vean afectados sus derechos puedan oponerse a esa solicitud de registro, asi como también permite que las autoridades competentes puedan realizar el examen de registrabilidad, y determinar si el signo esta incurso en algunas de las prohibiciones relativas o absolutas contempladas en las normas, y para esto necesitan saber específicamente cómo es el signo.

En ese sentido, el Tribunal de Justicia de las Comunidades Europeas, en el caso Sieckmann (el cual analizaremos con detenimiento más adelante) expresó que:

El sistema de registro de marca constituye un elemento esencial de la protección de las mismas que contribuye a la seguridad jurídica y a la buena administración, tanto en el ámbito del Derecho Comunitario como en los diferentes derechos nacionales (Tribunal de Justicia de las Comunidades Europeas, 2002).

Asimismo, Diego Chijane (2007), coincidiendo con Carlos Fernandez - Nóvoa, explica que para que el requisito de la representación gráfica cumpla con sus finalidades principales (la cual es brindar seguridad jurídica a los distintos actores), la representación gráfica deberá reunir las siguientes cualidades: i) deberá ser gráfica; ii) deberá ser completa, clara y precisa, para saber lo que se está monopolizando; y iii) deberá ser facilmente inteligible, para que lo puedan visualizar los que consulten el registro del signo. Además, el mismo autor manifiesta que en los textos legales no se exige que la comprensión del signo deba ser inmediata (poniendo el ejemplo del pentagrama, que muchas veces los solicitantes de marcas sonoras presentan a las 
oficinas nacionales competentes para cumplir con el requisito de la representación gráfica, y que no se pueden comprender inmediatamente) (p.473).

Es importante mencionar que tanto este autor, como Carlos Fernandez - Novoa (2004), nos cuentan que en la Unión Europea han habido dos clases de interpretaciones en cuanto al requisito de la representación gráfica; uno en sentido estricto, y otro en sentido amplio. En el primero se dice que para que el signo cumpla con ser susceptible de representación gráfica debe ser autosuficiente; esto es, que por si solo proporcione de manera directa y precisa la identidad del signo, no bastando con la descripción verbal, pues esta no sería una representación gráfica del signo, sino una mera explicación de los elementos que lo conforman. En cuanto a la interpretación en sentido amplio, se dice que el signo cumple con ser susceptible de representación gráfica bastando presentar una representación indirecta, acompañada de otros medios que la complementen, como una muestra del olor (en caso de marcas olfativas), o la reproducción del sonido (en caso de las marcas sonoras), no formando parte de la solicitud, ni de las publicaciones oficiales (p.43-44).

Ahora que ya hemos visto cuáles son los argumentos para la exigencia del requisito de la representación gráfica, veremos cuál ha sido el tratamiento legal de este requisito en cuanto al registro de marcas no tradicionales no visibles.

\section{a) La representación gráfica de un signo sonoro}

Cuando se trató la distintividad del signo sonoro se indicó que en la Decimosexta sesión del Comité Permanente sobre Derecho de Marcas, Diseños Industriales e Indicaciones Geográficas (OMPI, 2006)/se había manifestado (de acuerdo a la información proporcionada por las Oficinas de Propiedad Industrial de los Estados Parte,) que estos signos son de dos clases: los musicales y los no musicales. Esta clasificación ha tenido mucha importancia para el registro de estos signos, pues en algunos paises los signos sonoros no musicales son considerados insuceptibles de representación gráfica, no habiéndose hasta el momento encontrado una forma adecuada de cumplir con este requisito. En realidad la diferencia de estos dos signos es que los sonidos musicales, a 
diferencia de los no musicales, son susceptibles de ser representados mediante pentagrama.

Para una mejor expocisión, procederemos a detallar lo que se ha manifestado en el Comité Permanente sobre Derecho de Marcas, Diseños Industriales e Indicaciones Geogragráficas de la OMPI sobre el tratamiento de la representación gráfica de los signos sonoros.

En la Decimosexta Sesión del Comité Permamente sobre Derecho de Marcas, Diseños Industriales e Indicaciones Geográficas (OMPI, 2006) se indicó que el signo sonoro tenía que representarse gráficamente o mediante notación musical, o bien descrito con palabras. Asimismo, se manifestó que se podía aportar casetes y discos compactos.

En cuanto a los signos sonoros no musicales, como el "mugido de una vaca" o el "sonido de una bocina de automóvil" se señaló que en la solicitud debía indicarse las características del sonido o su diagrama de frecuencias, y que la banda de sonido debía registarse en una banda magnetofónica.

Adicionalmente, en este Comité se indicó que en una resolución judicial se había señalado que el requisito de la representación gráfica para un signo sonoro no se satisfacía por medio de una descripción escrita, mediante una onomatopeya (en el caso de los signos sonoros no musicales), o identificándolo con una mera secuencia de notas musicales; sin embargo, se consideró que el pentagrama dividido en compases que contuviera, en concreto, una clave, notas musicales y silencios cuya forma indicara su valor relativo, asi como sus accidentes, sí satisfacía el requisito de la representación gráfica.

Sin perjuicio de lo expuesto, es menester señalar que en esta sesión se indicó, de acuerdo a la información proporcionada por los Estados Parte, que era posible que no hubiera un método preferido para satisfacer el requisito de la representación gráfica de los signos sonoros, y que se siguían diversos procedimientos en los distintos sistemas marcarios. 
En la Decimoséptima Sesión del Comité Permanente sobre Derechos de Marcas, Diseños Industriales e Indicaciones Geográficas (OMPI, 2007) se manifestó que para cumplir con el requisito de la representación gráfica de los signos sonoros musicales se exigía la notación musical; asimismo, a diferencia de la sesión anterior, se indicó que en una comunicación se había señalado que los solicitantes de estos signos sonoros debian certificar la exactitud de la notación musical ante una organización competente. En esta sesión se volvió a reiterar que el sonido debía representarse con un pentagrama dividido en compases que contuviera, en concreto, una clave, notas musicales y silencios cuya forma indicara su valor relativo, así como sus accidentes, cuando sea necesario.

Cabe recalcar que pese a que en la sesión anterior se había manifestado que la descripción escrita no satisfaría el requisito de la representación gráfica, en este Comité se señaló lo siguiente:

Además de las notas musicales o de una muestra del sonido a veces deberá presentarse una descripción escrita del sonido. A fin de ayudar al público a entender la naturaleza del signo, la descripción deberá indicar, en la medida de lo posible, las notas, los instrumentos, la duración del sonido, el compás/tiempo el volumen y demás características del sonido. Podrá exigirse al solicitante que presente una descripción escrita del sonido que contenga los detalles de la designación reivindicada (OMPI, 2007).

Como se expone, en esta sesión indican la necesidad de una descripción escrita del sonido, pese a la presentación de notas musicales o de alguna muestra de sonido.

También, se señaló que para los sonidos no musicales se exigía la descripción escrita del sonido; y en algunos casos los sonogramas. No obstante, se manifestó que en la Comunidad Europea ya no se admitían los sonogramas, señalándose además que otros medios técnicos, como los oscilogramas, espectrogramas o sonogramas podrían considerarse inadecuados para representar signos sonoros ya que no resultaban facilmente accesibles o comprensibles por el público en general. 
Otro dato importante que se manifestó es que algunas Oficinas de Propiedad Industrial no admitían la grabación del sonido como medio para satisfacer el requisito de la representación gráfica.

Sobre las publicaciones de las marcas sonoras se indicó lo siguiente:

En cuanto a la publicación de las marcas sonoras, en dos comunicaciones se sugiere que, a efectos de la publicación de la reproducción del signo, se coloque en el sitio Web de la Oficina un icono sonoro que ponga a disposición del público la melodía o el sonido de que se trate (OMPI, 2007).

Este punto es importante pues muchos de los conflictos en cuanto a la aceptación de la representación gráfica del signo sonoro se sustenta en que para muchos especialistas, el público interesado no podría tener una idea clara, completa e inteligible sobre el signo sonoro registrado o a registrarse, y el hecho de que en las publicaciones pueda reproducirse el sonido, otorga seguridad tanto a los diversos agentes económicos como a las autoridades competentes.

En la Décimoctava Sesión del Comité Permanente sobre Derecho de Marcas, Diseños Industriales e Indicaciones Geográficas (OMPI, 2007) se manifestó que para los sonidos musicales, por lo general, para satisfacer el requisito de la representación gráfica, se solía indicar en la solicitud el tipo de marca, y adjuntar las notas musicales en un pentagrama, complementándose muchas veces con una descripción escrita del sonido. Se precisó también que en muchos países exigían la grabación del sonido en un casete o CD.

Asimismo, se volvió a precisar que la representación gráfica podía satisfacerse mediante un pentagrama dividido en compases que contuviera una clave, notas musicales y silencios cuya forma indicara su valor relativo y, de ser el caso, los accidentes, determinando el tono y la duración de las notas, resaltándose que si bien esta forma de representación no permitiría percibir el sonido de forma inmediata, otorgaba la posibilidad de comprender fácilmente el sonido.

Vale precisar que en esta sesión se manifestó que: 
(...) Cuando la representación "gráfica" no es un requisito absoluto, se considera que una grabación del sonido constituye una representación adecuada de la marca. De hecho, se observa que cuando la marca consiste exclusivamente en un sonido, una fragancia, $u$ otro elemento que no se perciba con la vista, no se exige al solicitante que presente un dibujo (OMPI, 2007).

En ese sentido, puede apreciarse que en algunos países no se exige necesariamente que la representación sea gráfica cuando se trata de una marca no tradicional no visible, bastando con la reproducción del signo, como una grabación en el caso de signos sonoros.

Por otro lado, sobre los sonidos no musicales se estableció que el requisito podía satisfacerse mediante una onomatopeya, una descripción escrita, una grabación sonora, una grabación digital puesta a disposición en internet o una combinación de todos estos métodos.

En la Décimonovena Sesión del Comité Permanente sobre Derecho de Marcas, Diseños Industriales e Indicaciones Geográficas (OMPI, 2008) se indicó que habitualmente para representar los sonidos musicales, en la solicitud debía indicarse el tipo de marca y presentar las notas musicales en un pentagrama; y sólo como complemento a esta solicitud podía mostrarse una descripción escrita del sonido. Asimismo, para los sonidos no musicales se manifestó que el requisito de la representación gráfica podía quedar satisfecho por la onomatopeya, la descripción escrita, una grabación sonora en formato análogico o digital adjunto al formulario de la solicitud o presentada electrónicamente, o una combinación de esos métodos.

Además, se señaló que otras alternativas que se había utilizado para representar gráficamente el sonido era con los oscilogramas, espectrogramas o sonogramas, surgiendo el debate de si estos medios de representación gráfica eran suficientes para cumplir con esta exigencia.

Un dato importante es que en este Comité, en virtud a la información proporcionada por las distintas Oficinas de Propiedad Industrial de los Estados Parte, la 
Secretaría indicó un posible ambito de convergencia entre éstos, el cual se detalla de la siguiente manera:

Posible ámbito de convergencia $\mathrm{N}^{\mathrm{o}} 7$

Con respecto a la solicitud de registro de una marca sonora, la representación de ese tipo de marca consistente en un sonido musical comprenderá una notación musical en un pentagrama junto con una descripción escrita de la marca, en la que se pueda indicar los instrumentos utilizados, sus notas, su longitud y toda otra característica del sonido en cuestión. Las Oficinas podrán exigir una grabación analógica o digital del sonido en un formato de sonido de uso corriente. Cuando se contemple la presentación electrónica, se podrá presentar con la solicitud un archivo electrónico de sonido.

La representación de una marca sonora consistente en un sonido no musical consistirá en una onomatopeya del sonido, una descripción de palabras o una grabación sonora analógica o digital presentada junto con la solicitud. Cuando se contemple la presentación electrónica, se podrá presentar con la solicitud un archivo electrónico del sonido (OMPI, 2008) (El subrayado es mío).

Por otra parte, tanto en la Vigésima Sesión del Comité Permanente sobre Derecho de Marcas, Diseños Industriales e Indicaciones Geográficas (OMPI, 2008) y en el documento de trabajo elaborado por la Secretaria WIPO/S Trad/INF/3 (OMPI, 2009), se estableció lo mismo que en las sesiones indicadas anteriormente, adicionándose que en algunas jurisdicciones se consideraría únicamente a la notación musical en un pentagrama como representación gráfica adecuada de la marca sonora.

En resumen, en diversas sesiones del Comité Permanente sobre Derecho de Marcas, Diseños Industriales e Indicaciones Geográficas de la OMPI se ha indicado que el requisito de la representación gráfica de una marca sonora musical se satisfaría por medio de un pentagrama. Es discutible si la descripción escrita de un signo o si su reproducción, mediante un casete, cd o algún otro soporte material por sí solos podrían satisfacer este requisito (pues ha quedado claro que puede adjuntarse como complemento en una solicitud). Asimismo, en cuanto a la representación gráfica de las marcas sonoras no musicales puede desprenderse que no hay posiciones firmes sobre su representación, pudiéndose apreciar que en muchas ocasiones se ha querido representar por una onomatopeya, una descripción escrita, un sonograma, un espectrograma, un 
oscilograma, o una combinación de estos medios, discutiéndose su idoneidad para cumplir con este requisito, y no aceptándose muchas veces el registro de los signos sonoros no musicales por no poder cumplir con el requisito de la representación gráfica.

Para una mejor apreciación de las posiciones sobre el requisito de la representación gráfica de una marca sonora, vamos a señalar los comentarios de diversos autores al respecto.

Diego Chijane (2007), citando al Tribunal de Justicia de la Unión Europea, señala que si bien podría facilmente representarse trozos de música mediante notas musicales - una mera sucesión de notas sin ninguna otra precisión - no sería una representación clara y precisa, pues no permitirían determinar la tonalidad ni la duración de los sonidos que conforman la melodía. Asimismo, sobre la discripción escrita, el autor considera que ésta no sería una representación gráfica, pues solo permitiría a los interesados formarse una idea del sonido, siendo muy subjetiva su apreciación (p.491-492).

Adicionalmente, sobre las onomatopeyas este autor nos señala que “(...) se considera que entre el sonido real que se pretende imitar fonéticamente y la onomatopeya tal como se pronuncia, existe un desfasaje, y ello debido a que, a través del lenguaje humano no se pretende imitar un sonido" (Chijane, 2007, p.492). En ese sentido, Chijane (2007) nos explica que la onomatopeya variará dependiendo del idioma, y señala como ejemplo el sonido del canto de un gallo, cuya onomatopeya sería kikeriki, en aleman, kukkokiekuu, en español, kokoriko, en frances, chichirichi, en ingles, kukeleku, en italiano y en portugués cocorocócó (p.492).

En efecto, de acuerdo a lo señalado por el antedicho autor, el uso de la onomatopeya no cumpliría el requisito de la representación gráfica por no otorgar una idea clara y precisa sobre el signo a registrarse.

Por otro lado, en el asunto Shield Mark (el cuál veremos más adelante), el Tribunal de Justicia de la Unión Europea estableció que para que se cumpliera el requisito de la representación gráfica, la representación debía ser clara, precisa, 
completa en sí misma, facilmente accesible, inteligible, duradera y objetiva, de acuerdo a los criterios establecidos por el propio Tribunal en el asunto Sieckmaan (como se citó en Casado, 2009).

Sobre la descripción escrita, el antedicho autor nos explica que en la Unión Europea los Organos Competentes han mantenido siempre la posición, como principio general, de que ésta no sería una alternativa adecuada para satisfacer el requisito de la representación gráfica, y recalca que de acuerdo a lo que el Tribunal de Justicia de la Unión Europea expuso en el caso Shield Mark, la descripción escrita de un sonido, un olor y, en general, la de los signos no figurativos, están llena de subjetividad, condición que es enemiga de la precisión y de la claridad (como citó Casado, 2009).

Asimismo, sobre las marcas sonoras musicales, tal como se explicó anteriormente, este autor indica que el Tribunal de Justicia de la Unión Europea ha considerado que el pentagrama es adecuado para representar gráficamente el sonido, y precisa que para el Tribunal de Justicia de la Unión Europea, un pentagrama dividido en compases y en el que figuran, una clave (sol, fa, do, etc), algunas notas musicales y silencios cuya forma (redonda, blanca, negra, corchea, semicorchea, etc) indica el valor relativo y las alteraciones (sostenido, bemol, becuadro) puede constituir una representación adecuada de las marcas sonoras, pues cumpliría los requisitos que se derivan de la jurisprudencia del Tribunal; esto es, que la representación de la marca debe ser clara, precisa, completa en sí misma, fácilmente accesible, inteligible, duradera y objetiva (como se citó Casado, 2009).

En ese sentido, para la Unión Europea la presentación del pentagrama, con las caracteristicas mencionadas, era suficiente para cumplir con el requisito de la representación gráfica de las marcas sonoras musicales. Vale recalcar que este autor también señaló que para este derecho comunitario no era necesario presentar un archivo sonoro, como un cd o casete, u otro medio, para cumplir con este requisito.

Sobre las marcas sonoras no musicales, este autor nos comenta, coincidiendo con Chijane, que para el Tribunal de Justicia de la Unión Europea la onomatopeya no sería suficiente para cumplir con el requisito de la representación gráfica, e indica que 
podrían percibirse de forma diferente en función de los individuos y paises. Además, señala que para este organo el sonograma tampoco sería adecuado para satisfacer este requisito, pues solo lo haría accesible a quienes tuviesen una formación musical. Sobre el espectrograma, se indicó lo mismo, pues estas representaciones, por si solas, y sin utilizar otro medios técnicos, no permitirían saber el signo sonoro que se desea registrar (a diferencia del pentagrama, que no necesita de otros medios técnicos) (como se citó en Casado, 2009)

Por su parte, Carlos Fernández - Nóvoa (2004) - tal como nos explicó Diego Chijane - nos comenta que el Abogado General Ruíz - Jarabo Colomer si bien manifestó que el pentagrama era una representación que no era inteligible por todos, también recalcó que no había motivo para exigir que la percepción sea inmediata (como se citó en Fernández- Nóvoa, 2004, p.171).

En efecto, el Abogado General Ruíz - Jarabo Colomer señaló que el solfeo técnica destinada a cantar los textos musicales, no es dominado por la generalidad de los destinatarios del signo, pero permite que, con la lectura de la partitura por una persona versada, los legos lleguen a aprehender el signo sonoro sin riesgo de confusión sobre su identidad (Como se citó en Fernández- Nóvoa, 2004, p.171).

En otra linea, es indispensable mencionar que sobre la Decisión 486, Baldo Kresalja (2001) manifiesta que el desarrollo de las comunicaciones hace posible la reproducción de los sonidos a larga distancia.

Asimismo, es importante saber que:

Nos adscribimos a la denominada "protección indirecta o marca sonora por conversión" la conversión del signo sonoro a un signo distinto para que pueda ser registrado, en contraposición a protección directa o marca sonora pura, que consiste en utilizar y registrar el sonido mismo, es decir, sin representación gráfica. A veces el pentagrama no es de utilidad (Kresalja, 2001, p. 176) (los subrayados son míos).

En la misma línea, Gonzalo Ferrero (2009) nos explica que con el desarrollo de la tecnología surgieron nuevos tipos de marcas; comenzando a escucharse desde los 
años 90 de dos tipos de ordenamientos legales: i) el sistema de representación descriptivo, y ii) el sistema de representación gráfica. Sobre el particular, señaló que el primero fue adoptado por los Estados Unidos bajo el argumento de que las marcas distinguen e identifican un producto o servicio a través del audio y no por medios visuales y, en ese sentido, no requería presentarse un dibujo en la solicitud de registro de marca, bastando un simple espécimen del signo y la prueba de su uso (p.329 - 330).

En este orden de ideas, nuestro sistema de marcas se ha acogido al sistema de representación gráfica, o tal como lo expone Baldo Kresalja, a la protección indirecta o marca sonora por conversión. En ese sentido, no bastaría con la reproducción del sonido en un casete, $\mathrm{CD}$ u otro soporte material para cumplir el requisito de la representación gráfica, sino con una representación que pueda ser escrita o expresada en papel; es decir, que necesariamente sea gráfica y, por ende, visible.

b) La representación gráfica de un signo táctil

Como se explicó anteriormente, la marca táctil es aquel signo que buscar distinguir productos o servicios a través del sentido del tacto. Hay muchas posiciones a favor y en contra de si estos nuevos tipos de marcas pueden registrase o no como tal. En ese sentido, la discusión de la representación gráfica del signo táctil no ha hecho esperarse desde su aparición.

Sobre el particular, el Comité Permanente sobre Derecho de Marcas, Diseños Industriales e Indicaciones Geográficas de la OMPI, en sus diversas sesiones, ha señalado lo siguiente:

- En la Decimosexta Sesión de este Comité (OMPI, 2006) se señaló que para cumplir el requisito de la representación gráfica se necesitaba la impresión del signo en relieve, siguiendo el procedimiento de escritura del sistema braille. Asimismo, se indicó que en una solicitud de registro de marca, el solicitante además de adjuntar la reproducción del signo, señaló el tipo y la descripción detallada de la marca.

- En la Decimoséptima Sesión del mismo Comité (OMPI, 2007) se manifestó que los Estados Partes que permiten el registro de marcas táctiles han adoptado vías 
ligeramente distintas para cumplir con el requisito de la representación gráfica. En efecto, en un caso, el solicitante además de representar el signo como se indicó en la sesión Decimosexta, tuvo que adjuntar un dibujo de la marca, así como describirla en la solicitud. Asimismo, al igual que en el caso de las marcas sonoras, se señaló que los Estados Partes de la Unión Europea aplicaban los criterios del caso Sieckmann para analizar si determinada representación cumplía con el requisito de la representación gráfica o no.

- En la Decimonovena Sesión del Comité (OMPI, 2008) la Secretaría, de acuerdo a la información proporcionada por los Estados Partes, manifestó que el posible ámbito de convergencia entre estos sobre el requisito de la representación gráfica de la marca fue el siguiente:

Posible ámbito de convergencia $\mathrm{N}^{\circ} 10$

Con respecto a la solicitud de registro de una marca de textura o táctil, la representación de ese tipo de marcas consistirá en una descripción detallada por escrito de la marca. Cabe considerar si la Oficina debería exigir alguna forma de representación gráfica si los elementos proporcionados no son suficientes para determinar la naturaleza y las características de la marca (OMPI, 2008).

- Asimismo, tanto en la Vigésima Sesión del Comité (OMPI, 2008) y en el Documento OMPI WIPO/STrad/INF/3 (OMPI, 2009) la Secretaría indicó que no pudo hallar un ámbito de convergencia respecto al requisito de la representación gráfica del signo táctil. Asimismo, se señaló que en algunos Estados consideraban a la descripción escrita un medio apto para representar gráficamente este tipo de signos, y que otros, por el contrario, habían establecido que este medio no era adecuado para cumplir con el requisito de la representación gráfica.

En este orden de ideas, se encuentra latente la discusión sobre cuál sería el medio idóneo para cumplir con el requisito de la representación gráfica de una marca táctil, no habiendo uniformidad en doctrina si es mediante una descripción escrita, su reproducción mediante el sistema braille y/o adjuntando un dibujo de la marca que desea registrarse. 
c) La representación gráfica de un signo gustativo

Sobre el requisito de la representación gráfica de una marca gustativa también se ha discutido mucho si puede o no cumplir con este requisito. Asimismo, a las marcas gustativas se le ha tratado de dar un tratamiento similar a las marcas olfativas (como lo trataremos en el siguiente apartado).

En efecto, es necesario señalar que el Comité Permanente sobre Derecho de Marcas, Diseños Industriales e Indicaciones Geográficas (OMPI, 2006) también ha tratado este tema en su Decimosexta Sesión. Al respecto, en dicha sesión se comentó que en un caso el requisito de la representación gráfica del signo gustativo se había satisfecho mediante una descripción escrita, indicando el tipo de marca en la solicitud. Asimismo, es en esta primera sesión sobre el tema de marcas no tradicionales que se dijo que los exámenes de registrabilidad de las marcas gustativas podían realizarse siguiendo los mismos criterios utilizados para los signos olfativos, señalando además que este tipo de marcas solo podían corresponder a productos y no a servicios.

En la Decimoséptima Sesión del mismo Comité (OMPI, 2007) se estableció que para evaluar si el signo gustativo cumplía o no con el requisito de la representación gráfica, al igual que en el caso de otros signos no visibles, los Órganos Competentes de la Unión Europea utilizaban los criterios establecidos en el caso Sieckmann (caso que por su importancia, analizaremos más adelante). Por otro lado, se indicó que un Tribunal Nacional había dictaminado que: "si bien una indicación como "la marca consiste en el siguiente sabor: el sabor artificial de fresa" puede considerarse una representación gráfica accesible e inteligible para el público, dicha indicación no cumpliría los criterios de precisión y de objetividad". También, es importante señalar que una descripción, de acuerdo a una de las comunicaciones enviadas por los Estados Parte a la Secretaría, sí podría admitirse.

Es importante señalar que en la Decimonovena Sesión del presente Comité (OMPI, 2008) se indicó un posible ámbito de convergencia entre los Estados Partes que presentaron información a la Secretaría, señalando que la representación gráfica de una 
marca gustativa podría consistir en una descripción del gusto, debiendo considerarse si la Oficina Competente debía exigir o no la presentación del espécimen del producto. Sin embargo, en la Vigésima Sesión del mismo Comité (OMPI, 2008) y en el documento elaborado por la Secretaría WIPO/S Trad/Inf/3 (2009)- que fueron las últimas dos reuniones sobre el tema - no se pudo hallar un posible ámbito de convergencia respecto a la representación gráfica de estos signos.

d) La representación gráfica de un signo olfativo

Como se señaló anteriormente, la discusión sobre el registro de signos olfativos, así como de las marcas no tradicionales no visibles en general, se ha centrado principalmente en el requisito de la representación gráfica, pues es difícil pensarse cómo puede representarse gráficamente un signo no perceptible visualmente.

Sobre el particular, Diego Chijane (2007) nos comenta que parte de la doctrina estaría a favor de interpretar el requisito de la representación gráfica en sentido amplio, bajo el argumento de que “(...) el mismo debe interpretarse conforme a la concepción moderna de marca, en la que se incluyen diversos tipos de nuevos signos, entre ellos: colores, sonidos, hologramas, olores y otros capaces de desempeñar la función de marca en el mercado" (Chijane, 2007, p.479 - 480) (El subrayado es mío).

Asimismo, Chijane (2007) nos explica que para cierto sector de la doctrina a favor del registro de signos olfativos, la descripción escrita sí permitiría cumplir con el requisito de la representación gráfica, al igual que las técnicas de fraccionamiento en las que se separan los componentes volátiles del olor para identificar cada uno de ellos, comparándolos con compuestos conocidos, como la cromatografía de gases y la cromatografía líquida de alto rendimiento (p.480).

Adicionalmente, en doctrina también se ha indicado que: “(...) en la industria del perfume, desde largo tiempo, se viene utilizando un léxico profesional que permite distinguir matices de un aroma por ligeras variaciones en la descripción verbal" (Chijane, 2007, p.481) (El subrayado es mío) 
En ese sentido, puede decirse que hay cierta parte de la doctrina que considera posible representar gráficamente el olor mediante la descripción verbal; sin embargo, debe precisarse que muchos son de la opinión que a este medio de identificación debería acompañarse con la muestra física del olor, a efectos de una mejor identificación del signo que pretende distinguirse, pudiendo esta muestra renovarse periódicamente.

Por otra parte, este autor también nos explica que otro sector de la doctrina vería imposible que estos signos cumplan el requisito de la representación gráfica, señalando que: "El principal obstáculo contra el registro de signos olfativos, consiste en la imposibilidad de ser representados gráficamente, no existiendo al día de hoy medios idóneos que cumplan fehacientemente dicho requisito formal”' (Chijane, 2007, p.485) (el subrayado es mío).

Sobre las técnicas de fraccionamiento, Diego Chijane (2007) nos comenta que este sector en contra considera que este medio no sería fiable para representar gráficamente el olor, pues muchos de sus componentes, al estar presentes en cantidades mínimas, no serían detectados, y la presencia de cualquier compuesto podría variar la percepción global del olor (p.485).

Por otro lado, en la revista de la OMPI de febrero 2009 (OMPI, 2009), se indicó que el aroma debía representarse gráficamente, porque la muestra física perdería sus propiedades con el transcurso del tiempo. Asimismo, sobre adjuntar la fórmula química del olor como medio para satisfacer el requisito de la representación gráfica, se manifestó que ésta solo representaría la sustancia mas no el olor y, por otro lado, se indicó que la descripción verbal debía ser exacta, sin generar confusión. Es decir, se repitió lo manifestado por el Tribunal de Justicia de la Unión Europea en el caso Sieckmann (caso que veremos con mayor detenimiento más adelante).

Además, sobre el antedicho caso Sieckmann, Majumdar y Al han manifestado que la percepción de las marcas olfativas y gustativas puede variar, produciendo confusión entre los consumidores, y han precisado que se trata de una dificultad práctica y no jurídica (como se citó en Ramos, 2014, p.168). 
Por su parte, Isabel Ramos (2014) considera que el signo olfativo podría renovarse cada cierto tiempo, en caso se presentara como muestra física para satisfacer el requisito de la representación gráfica. Asimismo, sobre la formula química, admite que no todo el que acceda a ella podrá identificar el aroma; sin embargo, compara esta situación con la complicada información que se acompaña en las solicitudes y registros de patentes de invención, manifestando que de la misma manera no todos los usuarios entienden y no es obstáculo para su registro (p.170).

Como puede apreciarse, son más las dificultades que se generan sobre la representación gráfica de las marcas olfativas, que por su aptitud distintiva. Asimismo, la doctrina que estaría en contra desdeñaría todo lo manifestado por la doctrina a favor. Sin embargo, se han propuesto alternativas para que un signo olfativo pueda llegar a representarse gráficamente.

En efecto, Isabel Ramos (2014) nos señala algunas alternativas. En primer lugar, nos comenta sobre la posibilidad de representar gráficamente el aroma mediante sensores de olfato, mediante el instrumento fox 4000, que al analizar el aroma generaría un archivo digital. Asimismo, precisa que este sistema debería ir acompañado de un análisis sensorial; es decir, examen de las propiedades organolépticas de un producto para los órganos sensoriales. En segundo lugar, esta autora nos señala también, de acuerdo al Trademark Manual of Examining Procedure de la USPTO, la posibilidad de representar gráficamente el olor mediante un producto que permita rascar y oler, así como un papel hermenéuticamente cerrado como formas de muestras admisibles. Adicionalmente, también nos habla de la posibilidad de reemplazar el espécimen cada cinco años (p.170, 177, 178).

En ese sentido, puede mostrarse que esta autora sería partidaria de representar gráficamente el olor a través de su depósito, inclusive del aroma conjuntamente con el producto que distingue. Esto se confirma cuando manifiesta que:

(...) incluso puede depositarse en el registro de marcas el propio producto con el fin de que en origen sea supervisado por el registrador (o examinador) en orden a decidir si concede la marca, y, a su vez, para que pueda ser estudiado por cualquier tercero y 
analizar así el objeto de protección de la marca olfativa (Ramos, Isabel, 2014, p.182). (El subrayado es mío).

Por otra parte, Luca Escoffier y Arnold Jin (2010), haciendo referencia al Sistema Marcario Comunitario de la Unión Europea, consideran que la única forma de lograr la representación gráfica de un olor es con los progresos tecnológicos que habrá en el futuro (p.8) Sin embargo, manifiestan que "mientras pueda ser posible obtener 1) una muestra duradera y estable que pueda 2) ser fácil y objetivamente perceptible por el público mediante la consulta de la base de datos pública de la OAMI, no habría razón para denegar el registro" (Escoffier y Jin, 2010, p.8).

En este orden de ideas, ellos nos comentan que ya existen varias patentes relacionadas con la emisión y almacenamiento en forma electrónica de muestras de olores o fragancias, y consideran que estos progresos tecnológicos, para que puedan adecuadamente representar gráficamente un signo olfativo, deben cumplir tres condiciones:

1) la creación y amplia difusión de computadoras con dispositivos de emisión de olores o fragancias incorporados;

2) la adopción de una clasificación internacional (con categorías bien definidas) de olores o fragancias con muestras duraderas y estables que sean accesibles en línea:

3) la adopción por la OAMI de una base de datos donde esas muestras puedan presentarse junto con la solicitud, almacenarse y ponerse a disposición del público para futuras búsquedas (Escoffier y Jin, 2010, p.8).

Luego de haber visto las distintas posiciones sobre el requisito de la representación gráfica de los signos olfativos, es necesario remitirnos a lo que en el Comité Permanente sobre Derecho de Marcas, Diseños Industriales e Indicaciones Geográficas se ha manifestado al respecto.

Sobre el particular, en la Decimosexta sesión (OMPI, 2006) se señaló que dependiendo de las distintas legislaciones nacionales y regionales, el medio para satisfacer el requisito de la representación gráfica varía. 
En efecto, se manifestó que en un Estado Miembro no se requería el dibujo del signo cuando consistía en un signo no visible, sino que debía presentarse una descripción clara y detallada de la marca no visual.

Asimismo, en esta sesión también se indicaron los criterios establecidos en el caso Sieckmann sobre los medios para representar gráficamente un olor, los cuales no serían mediante una formula química, una descripción, un depósito del signo olfativo, o una combinación de estos elementos.

Adicionalmente, se señaló que no existiría actualmente ninguna clasificación de las fragancias aceptadas internacionalmente que permita identificar de modo objetivo y preciso el aroma por medio de la atribución de un nombre o códigos específicos, como los códigos de colores internacionales o con la notación musical.

En la Decimoséptima sesión del Comité Permanente sobre Derecho de Marcas, Diseños Industriales e Indicaciones Geográficas (OMPI, 2007) también se hizo referencia a los criterios del caso Sieckmann, recalcando en particular que:

(...) el tribunal competente estableció los siguientes criterios para la representación gráfica en el caso de las fragancias: a) debe ser "precisa" a fin de definir la marca y de determinar el alcance de protección; b) debe ser "clara" tanto para las autoridades como para el público; c) debe ser "completa, fácilmente accesible e inteligible" en el registro; d) debe ser "duradera" a lo largo del periodo de vigencia del registro y e) debe ser "objetiva" a fin de evitar cualquier duda en la identificación del signo (como se citó en OMPI, 2007) (Los subrayados son míos).

Asimismo, un dato importante que nos da este Comité es que los criterios recogidos por el caso Sieckmann ha tenido vinculación para al menos veintisiete (27) países y una oficina regional.

Debe precisarse también que en este Comité se señaló que a consecuencia de los criterios Sieckmann, se han dejado de registrar marcas olfativas o éstas han sido denegadas, siendo que hasta la fecha no se ha encontrado un medio adecuado para cumplir con el requisito de la representación gráfica. 
Adicionalmente, en esta sesión también se hizo referencia a que en un país miembro se presentó una descripción verbal del signo olfativo, y posteriormente el espécimen del mismo. Además, se dijo que "Existe la tendencia a evitar toda referencia a técnicas cromatográficas y otros métodos altamente especializados para la identificación de olores ya que resultarían incomprensibles para una persona normal y corriente" (OMPI, 2007).

En este orden de ideas, en esta sesión se concluyó que si bien en algunas legislaciones se permitía el registro de marcas olfativas, o no se excluían expresamente, hasta ahora no se admitían el registro de estos signos, y tampoco se sabía si en el futuro se podrían reproducir estas marcas por medios electrónicos.

En la Decimonovena Sesión del Comité Permanente sobre el Derecho de Marcas, Diseños Industriales e Indicaciones Geográficas (OMPI, 2008) se estableció que la representación gráfica del olor sí podría consistir en una descripción escrita, precisándose que ésta debía proporcionar la información necesaria a una persona normal y corriente para que logre identificar la marca, debiéndose incluir, por lo general, la indicación del tipo de marca.

Asimismo, sobre el depósito del espécimen de la marca, se dijo que su registro podía variar dependiendo de si solo se necesitaba para registrar la marca, o si es que formaba parte de la solicitud.

Adicionalmente, en esta sesión también se manifestó que "se tiende a evitar las referencias a los métodos altamente especializados para la identificación de olores ya que resultarían incomprensibles para una persona normal y corriente” (OMPI, 2008).

Debe precisarse que en esta sesión se llegó al siguiente posible ámbito de convergencia entre los Estados participantes:

Posible ámbito de convergencia $\mathrm{N}^{\circ} 8$

Con respecto a la solicitud de registro de una marca olfativa, la representación de este tipo de marca consistirá en una descripción del olor. Cabe considerar si la Oficina 
debería exigir, en el curso del examen, la representación de un espécimen del producto al que se aplica el olor (OMPI, 2008) (El subrayado es mío).

Pese a que en esta sesión se llegó a este posible ámbito de convergencia respecto a la representación gráfica del signo olfativo, en la Vigésima sesión (OMPI, 2008), y también, tal como consta en el documento denominado "La Representación de Marcas No Tradicionales Ámbitos de Convergencia” preparado por la Secretaría (OMPI, 2009) este posible ámbito de convergencia entre los Estados miembros cambió por el siguiente:

Ámbito de Convergencia $\mathrm{N}^{\circ} 8$ Marcas Olfativas

El SCT no pudo hallar un ámbito de convergencia respecto de la representación de las marcas olfativas. Algunas jurisdicciones aceptaron que esas marcas podrán representarse mediante una descripción, mientras que otras consideran que una descripción no puede representar de forma adecuada el carácter de ese tipo de marcas. (El subrayado es mío).

En las Vigésimo primera (2009), Vigésimo segunda (2009) y Vigésimo tercera (2010) sesión no se dijo nada nuevo respecto a las otras sesiones, reiterando el criterio señalado en el caso Sieckmann de que la representación gráfica de la marca debía cumplir con ser "clara, precisa y completa por sí misma, fácilmente accesible, comprensible, duradera y objetiva"; asimismo, se informó que sesenta y ocho (68) respuestas al cuestionario elaborado por la Secretaría, y respondido por los Estados Miembros, fueron afirmativas en cuanto la falta de cumplimiento de los requisitos de percepción visual y de representación gráfica como motivos de denegación para el registro de estos tipos de marcas.

Adicionalmente, en el Grupo de Trabajo encargado del examen de los párrafos 4 a 6 de la Regla 3 del Reglamento del Tratado de Singapur sobre el Derecho de Marcas (2010) se estableció que la SCT no pudo determinar un ámbito de convergencia concerniente a la representación de este tipo de signos.

Bajo este orden de ideas puede verse que en el seno de la OMPI tampoco se ha establecido el medio adecuado de satisfacer el requisito de la representación gráfica del signo olfativo. 
Por lo expuesto, habiéndose analizado el artículo 134 de la Decisión 486, y habiéndose explicado las discusiones existentes sobre los requisitos de distintividad y de representación gráfica de las marcas no tradicionales no visibles, se considera idóneo revisar los artículos 135 y 136 de la norma andina, sobre prohibiciones absolutas y relativas al registro de marcas.

\subsubsection{Prohibiciones al registro de marcas no tradicionales no visibles}

Los signos sonoros, táctiles, gustativos y olfativos, como toda marca, no deberán incurrir en las prohibiciones absolutas y relativas de los artículos 135 y 136 de la Decisión 486 expuestos anteriormente para su registro.

Todas las prohibiciones antedichas son necesarias tener en consideración para poder registrar un signo como marca, sea este visible o no. Sin embargo, respecto a las marcas no tradicionales no visibles es necesario hacer énfasis en las siguientes:

- La letra c) del artículo 135 señala que no podrán registrarse como marcas los signos que consistan exclusivamente en formas usuales de los productos o de sus envases, o en formas y características impuestas por la naturaleza o función de dicho producto o del servicio del que se trate.

Este extremo del artículo, en principio, estaba previsto solo para las solicitudes de registro de marcas tridimensionales; sin embargo, el Tribunal de Justicia de la Comunidad Andina en el Proceso 242-IP-2015 estableció:

137. Estos criterios fueron inicialmente concebidos en el contexto de las marcas tridimensionales pero son igualmente aplicables a la mayoría de tipos de marcas. En consecuencia, la referencia a "la forma" del producto o de su envase, contenida en la precitada normativa andina, debe entenderse en sentido amplio, por el método de la ratio legis. En el caso particular de las marcas táctiles, "forma" equivale a "textura", así como en el caso de las marcas gustativas significa "sabor" y en las marcas olfativas indicará "olor", "perfume" o "fragancia", por referir algunos tipos de signos no visibles (Tribunal de Justicia de la CAN, 2015) (El subrayado es mío). 
En este orden de ideas, esta prohibición también se extiende al registro de marcas no tradicionales no visibles, no pudiendo registrarse un signo que sea: i) usual al producto o al envase que lo contiene; ii) impuesto por la naturaleza del producto o servicio que identifica, o iii) impuesto por su función.

En ese sentido, la Decisión 486, en armonía con la antedicha interpretación prejudicial del Tribunal de Justicia de la Comunidad Andina, ha acogido la posición antes vista de que los signos no visibles (incluidos los sabores y texturas) pueden ser registrados como marcas, siempre que no incurran en estos supuestos; es decir, y tal como hemos visto al estudiar cada una de las marcas no tradicionales no visibles (y en lo que se puede desprender que hay uniformidad en la doctrina), no podrán registrarse signos no visibles que sean usuales, genéricos, funcionales, impuestos por la naturaleza del producto o servicio que buscan distinguir.

- La letra d) del artículo 135 establece que no podrán registrarse como marcas los signos que consistan exclusivamente en formas $\mathrm{u}$ otros elementos que den ventaja funcional o técnica al producto o al servicio al cual se aplica.

Tal como hemos visto, la funcionalidad del signo ha sido uno de los criterios para la oposición al registro de estos signos como marcas, por lo que deberá corroborarse que los signos sonoros, táctiles, gustativos y olfativos no incurran en esta prohibición.

Vale precisar que el fundamento de esta prohibición es que el otorgamiento de un derecho exclusivo sobre un signo funcional, ocasionaria que el titular tenga una ventaja competitiva frente al resto de competidores, siendo esto dañino para la libre competencia. Asimismo, con este artículo también se pretende que los interesados no se aprovechen de la figura de la marca para extender el derecho de propiedad intelectual sobre algún producto; es decir, para que no se aprovechen de las renovaciones indefinidas que se pueden obtener en virtud al sistema marcario cuando lo correcto sería protegerlo via patente de invención o 
modelo de utilidad (de ser el caso), los cuales tienen plazos de protección menores.

- La letra f) del artículo 135 establece que no podrán registrarse como marcas los signos que consistan exclusivamente en un signo o indicación que sea el nombre genérico o técnico del producto o servicio de que se trate.

De su lectura puede desprenderse que es una prohibición absoluta que solo corresponde a los signos que esten conformados por un nombre; es decir, que sean denominativos o mixtos. No cabría la aplicación de esta prohibición para la solicitud de registro de marcas no tradicionales no visibles; pese a que en doctrina también se ha hecho referencia sobre los signos no visibles genéricos de un producto o servicio.

En efecto, se considera que para que este extremo del artículo pueda ser aplicable a los signos no visibles sin inconvenientes debería cambiarse la redacción de la terminación "nombre" por el de "signos" genéricos.

- El último párrafo del artículo 135 de la Decisión 486 (2000) señala que:

No obstante lo previsto en los literales b), e), f), g) y h), un signo podrá ser registrado como marca si quien solicita el registro o su causante lo hubiese estado usando constantemente en el País Miembro y, por efecto de tal uso, el signo ha adquirido aptitud distintiva respecto de los productos o servicios a los cuales se aplica.

Este extremo del artículo es importante revisar pues no incluye al requisito de la representación gráfica; es decir, por más que se demuestre que un signo ha adquirido distintividad sobrevenida (lo que hace que la marca pueda cumplir con su función principal), si no cumple con el requisito de la representación gráfica no puede registrarse como marca.

3.3 Decreto Legislativo 1075: Examen comparativo entre signos distintivos, y las marcas no tradicionales no visibles. 
Habiendo revisado los artículos pertinentes a la Decisión 486, es menester visualizar algunos artículos del Decreto Legislativo 1075.

Como se indicó anteriormente, la aptitud distintiva que debe tener un signo para que pueda acceder al registro se clasifica en "distintividad intrínseca" y "distintividad extrínseca", consistiendo la primera en la aptitud distintiva que debe tener una marca en virtud a los elementos que la conforman, de acuerdo a los productos o servicios para los cuales se aplican; es decir, por los componentes del signo per se, no debiendo ser descriptivo, ni genérico, entre otros analizados en el artículo 135 de la Decisión 486. Por otro lado, la distintividad extrinseca se relaciona con la aptitud distintiva que debe poseer una marca en relación con otros signos distintivos ya existentes, para no generar riesgo de confusión o asociación en el consumidor al momento de elegir un producto o servicio en el mercado.

Sobre esta última, es necesario precisar que para determinar si una marca posee distintividad extrinseca, y pueda acceder al registro, las oficinas nacionales competentes de los Países Miembros de la CAN deben hacer un examen de registrabilidad y/o en caso de oposiciones, un examen comparativo entre el signo que se desea registrar como marca y otros signos distintivos ya registrados.

En ese sentido, en el caso peruano, el Decreto Legislativo 1075 regula del artículo 45 al 49 la forma en cómo el INDECOPI debe realizar esta comparación entre signos, estableciendo disposiciones generales y específicas para su evaluación, las cuales indicaremos a continuación:

Artículo 45.- Determinación de semejanza

A efectos de establecer si dos signos son semejantes y capaces de inducir a confusión y error al consumidor, la Dirección competente tendrá en cuenta, principalmente los siguientes criterios:

a) la apreciación sucesiva de los signos considerando su aspecto de conjunto, y con mayor énfasis en las semejanzas que en las diferencias;

b) el grado de percepción del consumidor medio;

c) la naturaleza de los productos o servicios y su forma de comercialización o prestación, respectivamente; 
d) el carácter arbitrario o de fantasia del signo, su uso, publicidad y reputación en el mercado; $y$,

e) si el signo es parte de una familia de marcas

Artículo 46.- Signos denominativos

Tratándose de signos denominativos, en adición a los criterios señalados en el artículo $\underline{45}$ de este Decreto Legislativo, se tendrá en cuenta lo siguiente:

a) la semejanza gráfotecnica;

b) la semejanza conceptual; y,

c) si el signo incluye palabras genéricas y/o descriptivas, se realizará el análisis sobre la palabra o palabras de mayor fuerza distintiva.

Artículo 47.- Signos figurativos

Tratándose de signos figurativos, en adición a los criterios señalados en el artículo 45 de este Decreto Legislativo, se tendrá en cuenta lo siguiente:

a) Si las figuras son semejantes, si suscitan una impresión visual identica o parecida.

b) Si las figuras son distintas, si evocan un mismo concepto

Artículo 48.- Signos mixtos

Tratándose de signos mixtos, formados por un denominación, y un elemento figurativo, en adición a los criterios señalados en los artículos 45, 46 y 47 del presente Decreto legislativo se tendrá en cuenta lo siguiente:

a) la denominación que acompaña al elemento figurativo;

b) la semejanza conceptual;y,

c) la mayor o menor relevancia del aspecto denominativo frente al elemento gráfico, con el objeto de identificar la dimensión característica del signo

Artículo 49.- Semejanza conceptual

Tratándose de un signo denominativo y uno figurativo, se tendrá en consideración la semejanza conceptual. Tratándose de un signo denominativo y uno mixto, se tendrán en cuenta los criterios señalados en los artículos 45 y 47 de este Decreto Legislativo. Tratándose de un signo figurativo y uno mixto, se tendrán en cuenta los criterios señalados en los artículos 47 y 48 del presente Decreto Legislativo. 
En los tres supuestos serán igualmente de aplicación los criterios señalados en el artículo 45 del presente Decreto Legislativo. (Decreto legislativo 1075, 2008) (Los subrayados con mios).

En efecto, de la lectura de estos artículos puede desprenderse que la redacción y elaboración de estos criterios se ha dirigido al examen comparativo entre signos visibles y no para signos no visibles; es decir, del artículo 46 al 49 claramente se aprecia que van dirigidos al examen comparativo entre signos denominativos, signos figurativos, entre signos mixtos, y entre signos figurativos y denominativos.

Respecto al artículo 45, sobre los criterios generales, también puede desprenderse lo mismo, toda vez que la letra a) establece como criterio "la apreciación sucesiva de los signos considerando su aspecto de conjunto (...)". En efecto, se considera conveniente que para que este artículo pueda ser aplicable a las marcas no tradicionales no visibles, debería cambiarse los terminos "su aspecto en conjunto" (por referirse solamente a los signos visibles) por "el signo en conjunto".

Asimismo, se considera que a la letra d) del artículo 45 podría añadirse el término "novedoso", pues si bien la Decisión 486 no establece como requisito la novedad del signo para que pueda registrarse una marca - tal como sí lo señalaba la derogada Decisión 85 - sí le da más distintividad y, por ende más protección a una marca no tradicional no visible, al igual que una marca de fantasía a un signo visible (tal como en doctrina se ha hecho referencia).

\subsection{Tratados Internacionales de los que el Perú es parte en materia de Propiedad} Intelectual concernientes al Derecho de Marcas, y las marcas no tradicionales no visibles

\subsubsection{Convenio de París (1883)}

Este convenio ha sido uno de los instrumentos internacionales más importantes en materia de Propiedad Intelectual, pues ha sido el primer acuerdo internacional que ha permitido a los Estados Partes proteger sus derechos sobre la propiedad industrial en otros Estados Partes. Este convenio fue ratificado por el Perú en el año 1995. 
Sobre el tema que nos corresponde es necesario indicar que el Convenio de Paris (1883) señala lo siguiente:

Art.6.- Marcas: condiciones de registro, independencia de la protección de la misma marca en diferentes países:

1) Las condiciones de depósito y de registro de las marcas de fábrica o de comercio serán determinadas en cada país de la Unión por su legislación nacional.

2) Sin embargo, una marca depositada por un nacional de un país de la Unión en cualquier país de la Unión no podrá ser rehusada o invalidada por el motivo de que no haya sido depositada, registrada o renovada en el país de origen.

3) Una marca, regularmente registrada en un país de la Unión, será considerada como independiente de las marcas registradas en los demás países de la Unión, comprendiéndose en ello al país de origen. (el subrayado es mio)

Asimismo, en el letra b) del artículo 6quinquies se establece que:

b) Las marcas de fábrica o de comercio reguladas por el presente artículo no podrán ser rehusadas para su registro ni invalidadas más que en los casos siguientes:

1. cuando sean capaces de afectar a derechos adquiridos por terceros en el país donde la protección se reclama;

2. cuando estén desprovistas de todo carácter distintivo, o formadas exclusivamente por signos o indicaciones que puedan servir, en el comercio, para designar la especie, la calidad, la cantidad, el destino, el valor, el lugar de origen de los productos o la época de producción, o que hayan llegado a ser usuales en el lenguaje corriente o en las costumbres leales y constantes del comercio del país donde la protección se reclama;

3. cuando sean contrarias a la moral o al orden público y, en particular, cuando sean capaces de engañar al público. Se entiende que una marca no podrá ser considerada contraria al orden público por el solo hecho de que no esté conforme con cualquier disposición de la legislación sobre marcas, salvo en el caso de que esta disposición misma se refiera al orden público (Convenio de Paris,1883).

De la lectura al Convenio de París puede apreciarse que la norma no señala expresamente lo qué es una marca, ni mucho menos establece qué signos podrían 
constituirse como tal. Estos dos artículos que acabamos de mostrar solo nos indican, en el caso del artículo 6, que el registro de una marca en un Estado Parte es independiente al registro de la misma en otro Estado Parte, y en el caso de la letra b) del artículo 6quinquies, cuándo una marca podrá ser rehuzada o invalidada. Sobre este último, es necesario precisar que este artículo señala, entre otros, que una marca no podrá registrase cuando esté deprovista de todo carácter distintivo.

En ese sentido, puede apreciarse que esta norma no hace referencia a las marcas no tradicionales no visibles; sin embargo, tampoco puede desprenderse de su lectura que una marca no tradicional no pueda constituirse como tal, pues se reitera, no hay disposiciones que señalen qué se entiende por marca, o qué signos podrían registrarse como tal. Asimismo, debe acotarse que este tratado no hace referencia al requisito de la representación gráfica, solo destacándose la aptitud distintiva que debe tener una marca.

3.4.2 Acuerdo sobre los Aspectos de los Derechos de Propiedad Intelectual relacionados con el Comercio (ADPIC)

Este acuerdo se encuentra en el Anexo 1C del convenio por el que se crea la OMC. Este instrumento internacional fue ratificado por el Perú en 1995.

Sobre el tema que nos corresponde es necesario mostrar el numeral 1 del artículo 15 del ADPIC (1994), el cual se muestra a continuación:

Art.15 Materia objeto de protección

1. Podrá constituir una marca de fábrica o de comercio cualquier signo o combinación de signos que sean capaces de distinguir los bienes o servicios de una empresa de los de otras empresas. Tales signos podrán registrarse como marcas de fábrica o de comercio, en particular las palabras, incluidos los nombres de persona, las letras, los números, los elementos figurativos y las combinaciones de colores, así como cualquier combinación de estos signos. Cuando los signos no sean intrínsecamente capaces de distinguir los bienes o servicios pertinentes, los Miembros podrán supeditar la posibilidad de registro de los mismos al carácter distintivo que hayan adquirido mediante su uso. Los Miembros podrán exigir como condición para el registro que los signos sean perceptibles visualmente (los subrayados son míos). 
Este acuerdo sí es relevante para el correcto estudio de las marcas no tradicionles no visibles. En primer lugar, a diferencia de lo que se establece en el Convenio de Paris, en este acuerdo, si bien no se define expresamente lo que es una marca, puede inferirse su definición cuando establece que "podrá constituir una marca de fabrica o de comercio cualquier signo o combinación de signos que sean capaces de distinguir los bienes o servicios de una empresa de los de otras empresas" (ADPIC, 1994).

Asimismo, este artículo nos indica los signos que pueden registrarse como marcas, y de su lectura, puede apreciarse que los signos indicados no se encuentran en una lista taxativa, dejando abierta la posibilidad de registrar más tipos de signos (adicionalmente a las palabras y a los elementos figurativos). Esto se evidencia cuando se establece que: "Tales signos podrán registrarse como marcas de fabrica o de comercio, en particular, las palabras (...)" (ADPIC, 1994) (El subrayado es mio).

Es menester señalar el extremo final del artículo en mención: "Los Miembros podrán exigir como condición para el registro que los signos sean perceptibles visualmente" (ADPIC, 1994). En efecto, de la lectura de este extremo del artículo se desprende que no se prohibe expresamente que los signos no visibles puedan constituirse como marcas, dejando abierta la posibilidad de su registro. En otras palabras, el artículo comentado sí permite el registro de los signos no visibles, siempre y cuando las legislaciones de los Estados Partes así lo permitan.

\subsubsection{Acuerdo de Promoción Comercial Perú - EEUU (2006)}

Este acuerdo fue firmado en el 2006, y entró en vigencia el 01 de febrero de 2009.

Sobre el tema que nos corresponde es necesario indicar que este tratado tiene un artículo muy importante sobre las marcas no tradicionales no visibles, el cual se muestra a continuación:

Artículo 16.2: Marcas:

1. Ninguna Parte requerirá, como condición del registro, que los signos sean perceptibles visiblemente y ninguna Parte podrá denegar el registro de una marca con base únicamente en que el signo está compuesto por un sonido o un olor (Los subrayados son mios). 
En ese sentido, en virtud al Acuerdo Comercial con los Estados Únidos de America (muy independientemente de que en la Decisión 486 ya se había dispuesto previamente el registro de este tipo de marcas), ninguna parte puede exigir como requisito que el signo sea perceptible visualmente. Asimismo, esta norma recalca que no podrá denegarse una solicitud solo por el hecho de que un signo consista en un olor o un sonido.

En este orden de ideas, puede observarse la importancia de las marcas no tradicionales no visibles en el Acuerdo Comercial entre el Perú y los Estados Unidos.

\subsubsection{Tratado sobre el derecho de marcas - TLT (1994).}

Este tratado entró en vigor el 06 de noviembre de 2009 en virtud al Acuerdo Comercial con EEUU (2006), toda vez que en el numeral 3) del artículo 16.1 del mismo se estableció expresamente que:

3. Cada parte ratificará o adherirá a los siguientes acuerdos hasta el 01 de enero de 2008, o a la entrada en vigor de este Acuerdo, cualquiera que sea posterior:

(a) el Tratado de Cooperación en Materia de Patentes (1970), y enmendado en 1979 ;

(b) el Tratado sobre el Derecho de Marcas (1994); y

(c) el Convenio Internacional para la Protección de las Obtenciones Vegetales (Convenio UPOV) (1991) (el subrayado es mío).

En ese sentido, el Perú se adhirió a este tratado administrado por la OMPI en el 2009. Sobre el particular, es necesario indicar el numeral 1) del artículo 2 del Tratado sobre el Derecho de Marcas (1994):

Artículo 2: Marcas a las que se aplica el Tratado

1) [Naturaleza de las marcas]

a) El presente Tratado se aplicará a las marcas que consistan en signos visibles, bien entendido que sólo las Partes Contratantes que acepten el registro de marcas tridimensionales estarán obligadas a aplicar el presente Tratado a dichas marcas. 
b) El presente Tratado no se aplicará a los hologramas ni a las marcas que no consistan en signos visibles, en particular las marcas sonoras y las marcas olfativas. (Los subrayados son míos).

Del artículo indicado se desprende que este tratado no es aplicable a los signos no visibles. Sin embargo, es necesario mencionarlo pues es un antecedente importante al Tratado de Singapur, el cual veremos más adelante.

\subsubsection{Acuerdo Comercial entre el Perú y la Unión Europea (2010)}

El 01 de marzo de 2013 entró en vigencia el Acuerdo Comercial entre el Perú y la Unión Europea (2010), que sobre el tema que nos corresponde es importante indicar el artículo que mostraremos a continuación:

Art. 203.- Requisitos para el registro

Podrá constituir una marca de fábrica o de comercio en el mercado cualquier signo o combinación de signos que sean capaces de distinguir las mercancías o servicios de una empresa de aquellos de otra empresa. Tales signos podrán estar constituidos, en particular, por palabras, incluidas combinaciones de palabras, nombres de persona, letras, números, elementos figurativos, sonidos y combinaciones de colores, así como cualquier combinación de estos signos. Cuando los signos no sean intrínsecamente capaces de distinguir las mercancías o servicios pertinentes, una Parte podrá supeditar la posibilidad de registro de los mismos al carácter distintivo que hayan adquirido mediante su uso. Una Parte podrá exigir como condición para el registro que los signos sean perceptibles visualmente" (Los subrayados son míos).

Al igual que el ADPIC, de la lectura de este artículo puede inferirse que la definición de lo que es una marca en virtud a este tratado sería la de cualquier signo o combinación de signos que sean capaces de distinguir las mercancías o servicios de una empresa de las de otras. Asimismo, este artículo indica, no taxativamente, los signos que pueden constituirse como marcas, mencionándose a los signos sonoros. No se menciona expresamente sobre los demás signos no visibles, pero deja abierta la posibilidad de su registro. 
Pese a lo expuesto, en virtud al último párrafo del artículo en mención, los países podrán determinar si aceptan como condición al registro de una marca que el signo sea perceptible visualmente o no.

\subsubsection{Otros tratados internacionales}

a) Acuerdo de Asociación Transpacífico -TPP (2016)

El 04 de febrero de 2016, el Perú suscribió el Acuerdo de Asociación Transpacífico (TPP) junto con los países de Canadá, Estados Unidos de América, México, Chile, Japón, Singapur, Malasia, Vietnam, Brunei, Australia y Nueva Zelanda con el fin de construir un gran bloque económico luego de muchos años de negociación. Sin embargo, el actual presidente de los Estados Unidos de América, Donald Trump, el 23 de enero de 2017 firmó una orden para retirarse del mismo.

Pese a que las expectativas tanto de estos países, como de los medios, es que ya no se van a continuar con los planes que se tenían sobre este acuerdo, es necesario mencionar que en temas de Propiedad Intelectual hubieron capítulos de mucha controversia.

Sobre el tema que nos corresponde es importante mencionar que en el artículo 18.18 sobre Tipos de Signos Registrables como Marcas se indicó expresamente lo siguiente:

Ninguna parte requerirá, como condición para el registro, que el signo sea visualmente perceptible, ni denegará el registro de una marca solo por el motivo de que el signo del que está compuesta es un sonido. Adicionalmente, cada Parte deberá realizar los mejores esfuerzos para registrar marcas olfativas. Una Parte podrá requerir una descripción concisa y precisa, o una representación gráfica, o ambas, de la marca, según sea aplicable (Acuerdo de Asociación Transpacífico-TTP, 2016) (el subrayado es mío).

En ese sentido, de la lectura de este artículo se desprende que el mismo admite plenamente el registro de signos no visibles como marcas, estableciendo que ninguna parte requerirá como requisito que el signo sea visualmente perceptible. Asimismo, este artículo permite que no solamente pueda presentarse una representación gráfica del signo, sino también una descripción, o una combinación de dichos medios. 
Debe recalcarse que el antedicho artículo promueve el registro de signos olfativos como marcas al señalar que: “(...) cada Parte deberá realizar los mejores esfuerzos para registrar marcas olfativas" (TTP, 2016).

Cabe precisar que el numeral 2 del artículo 18.7 referido a Acuerdos Internacionales señala de manera expresa lo siguiente:

2. Cada Parte deberá ratificar o adherirse a cada uno de los siguientes acuerdos, en caso de no haberlo hecho todavía, a la fecha de entrada en vigor de este Tratado para dicha Parte:

(a) Protocolo de Madrid;

(b) Tratado de Budapest;

(c) Tratado de Singapur;

(d) UPOV 1991;

(e) TODA, y

(f) TOIEF (TTP, 2016) (El subrayado es mío).

Es necesario indicar que en la letra c) del artículo mostrado se encuentra un pie de página en el documento original en el que se señala que "una Parte podrá satisfacer las obligaciones en el párrafo 2(a) y 2(c) ratificando o adhiriéndose ya sea al Protocolo de Madrid o al Tratado de Singapur” (TTP, 2016). Es decir, el Perú podría suscribirse a cualquiera de los dos tratados para cumplir con lo dispuesto en este artículo.

No vale referirse al Sistema de Madrid en este trabajo por extralimitarse del tema estudiado; sin embargo, si es menester señalar el Tratado de Singapur, pues si bien el Perú no es parte del mismo, sí tiene indicaciones sobre las marcas no tradicionales no visibles que es importante revisar.

b) Tratado de Singapur sobre el Derecho de Marcas (2006)

El Tratado de Singapur es una versión actualizada del Tratado sobre el Derecho de Marcas expuesto líneas arriba. En su artículo 2 establece que este tratado se aplicará a los signos que puedan registrase como marcas conforme a las legislaciones de los 
países; en ese sentido, a diferencia del Tratado sobre Derecho de Marcas, este acuerdo no limita su regulación a las marcas visibles.

A continuación mostraremos expresamente los artículos que son importantes para el estudio de las marcas no tradicionales no visibles:

Artículo 3 Solicitud

1) [Indicaciones o elementos contenidos en una solicitud o que la acompañan; tasas]

a) Una Parte Contratante podrá exigir que una solicitud contenga algunas o todas las indicaciones o elementos siguientes:

$(\ldots)$

ix) al menos una representación de la marca, según lo previsto en el Reglamento;

x) cuando proceda, una declaración, según lo previsto en el Reglamento, en la que el solicitante indique el tipo de marca, así como cualquier requisito específico aplicable a ese tipo de marca;" (Los subrayados son míos).

$(\ldots)$

Artículo 5 Fecha de presentación

1) [Requisitos permitidos]

a) Con sujeción a lo dispuesto en el apartado b) y en el párrafo 2), una Parte Contratante asignará como fecha de presentación de la solicitud la fecha en que la Oficina haya recibido las siguientes indicaciones y elementos en el idioma previsto en el artículo 8.2):

iv) una representación suficientemente clara de la marca cuyo registro se solicita (El subrayado es mío).

\section{$(\ldots)$}

Artículo 13 Duración y renovación del registro

2) [Prohibición de otros requisitos] Ninguna Parte Contratante podrá exigir que se cumplan requisitos distintos de los mencionados en el párrafo 1), y en el artículo 8 respecto de la petición de renovación. En particular, no se podrá exigir: 
i) ninguna representación u otra identificación de la marca;" (El subrayado es mío)

Asimismo, por ser de gran importancia sobre el tema estudiado, y para una comprensión conjunta del Tratado de Singapur en el tratamiento de las marcas no tradicionales no visibles, es necesario indicar los numerales 9 y 10 de la Regla 3 del Reglamento del Tratado de Singapur sobre el Derecho de Marcas (2011):

9) [Marca sonora] Cuando la solicitud contenga una declaración en el sentido de que la marca es una marca sonora, la representación de la marca consistirá, a elección de la Oficina, en su notación en un pentagrama, o en una descripción del sonido que constituye la marca, o en una grabación analógica o digital de ese sonido, o toda combinación de lo anterior.

10) [Marca que consista en un signo no visible que no sea una marca sonora] Cuando la solicitud contenga una declaración en el sentido de que la marca consiste en un signo no visible que no es una marca sonora, una Parte Contratante podrá exigir una o más representaciones de la marca, una indicación del tipo de marca y detalles relativos a la marca, según lo disponga la legislación de esa Parte Contratante”. (Los subrayados son míos).

Debe apreciarse que los artículos mostrados del Tratado de Singapur se refieren, en general, a la representación que se deberá presentar para registrar una marca; mientras que los artículos mostrados del reglamento nos indican la representación que se deberá presentar para el registro de marcas no tradicionales no visibles.

En este orden de ideas, es de apreciarse que en los artículos mencionados solo se exige, sobre la representación, lo siguiente (para cualquier tipo de marca): i) al menos una representación de la marca, ii) una representación suficientemente clara ; y si se trata de una marca no visible: i) si es sonido, un pentagrama o una descripción o una grabación analógica o digital del sonido, o toda combinación de lo anterior; ii) si es otro signo no visible, diferente al sonido, una o más representaciones de la marca, una indicación del tipo de marca, y detalles relativos a la marca, según lo disponga la legislación de esa Parte Contratante.

En ese sentido, de la lectura de estos artículos puede visualizarse que ninguno exige o hace referencia a que la representación de la marca deba ser gráfica (a 
diferencia de lo que sí sucede para una marca tridimensional ${ }^{23}$ ). Asimismo, el artículo 3, numeral 1, letra a, x) del Tratado de Singapur nos señala que cuando proceda se requerirá una declaración en la que el solicitante indique el tipo de marca, así como cualquier requisito específico aplicable a este tipo de marca. Es claro que esté último artículo hace referencia a las marcas no tradicionales no visibles.

\subsection{Derecho comparado en el tratamiento de las marcas no tradicionales no visibles}

\subsubsection{Colombia}

Este país por ser miembro de la Comunidad Andina también se rige por la Decisión 486 "Regimen Comun Sobre Propiedad Industrial".

Sobre el tema que nos concierne es interesante señalar que el 03 de febrero de 2016 la Superintendencia de Industria y Comercio emitió la Resolución 3718 (2016), en la cual regulan dos tipos de marcas no tradicionales no visibles que nos interesan: las marcas sonoras y las marcas táctiles. Sobre las primeras, esta Resolución incorpora el numeral 1.2.5.13 en el Capítulo Primero del Titulo X de la Circular Única, la cual establece lo siguiente:

\subsubsection{Marcas Sonoras}

Cuando la solicitud de registro de una marca contiene la indicación de que se trata de una marca sonora, la representación gráfica de la marca consistirá en:

a) una descripción del signo por medio de pentagramas, fonogramas o cualquier otro medio que permita su identificación, y

b) deberá acompañarse un archivo de sonido que soporte la grabación digital en formato MP3 de calidad $192 \mathrm{Kbps}$ (los subrayados son mios).

Asimismo, sobre las marcas táctiles es necesario mostrar el numeral 1.2.5.15:

1.2.5.15 Marca táctil o de textura

Cuando la solicitud de registro de una marca contenga la indicación de que se trata de una marca táctil o de textura, a efectos de cumplir con el requisito de la representación gráfica, el solicitante deberá presentar:

\footnotetext{
${ }^{23}$ Regla 3 Detalles relativos a la solicitud.- 4) [Marca tridimensional] a) Cuando la solicitud contenga una declaración en el sentido de que la marca es tridimensional, la reproducción de la marca consistirá en una reproducción gráfica o fotográfica bidimensional (Reglamento del Tratado de Singapur sobre el Derecho de Marcas, 2011).
} 
i) una descripción clara, precisa y completa de la textura que conforma el signo;

ii) un dibujo tridimensional o fotografía en formato JPG de tamaño máximo de $450 \mathrm{x}$ 450 pixeles y máximo $2 \mathrm{MB} ; \mathrm{y}$,

iii) una muestra física de la textura que se reivindica, cuyo depósito y acceso a terceros seguirá las reglas establecidas por el Grupo de Gestión Documental y Recursos Físicos. Si se trata de una radicación en línea, la muestra física deberá aportarse posteriormente como complemento de información al expediente.

iv) en caso de no presentarse la muestra física, la Superintendencia de Industria y Comercio requerirá al solicitante para que la aporte". (los subrayados son mios)

En ese sentido, sobre el artículo correspondiente a las marcas sonoras, el numeral comentado deja abierta la posibilidad de representar gráficamente esta marca a traves de un pentagrama, fonograma o cualquier otro medio que permita su identificación; señalando, además, que se deberá acompañar un archivo de sonido; es decir, necesariamente tendrá que presentarse un soporte material que contenga el sonido que desea registrarse.

Sobre las marcas táctiles, el numeral correspondiente señala que para cumplir con el requisito de la representación gráfica tendrá que presentarse una descripción clara, precisa y completa, un dibujo tridimensional o fotografía, y una muestra física, siendo esta última un complemento al expediente.

Debe precisarse que esta norma no hace referencia a las marcas olfativas y gustativas.

Pese a lo expuesto, a diferencia de lo que sucede en el Perú, que hasta la fecha no han habido solicitudes de marcas táctiles, olfativas y gustativas, en Colombia sí han habido intentos fallidos de registros de marcas olfativas, y sí han logrado registrar marcas táctiles tal como veremos a continuación:

a) Casos prácticos:

- Marcas sonoras 
- La Superintendencia de Industria y Comercio, en adelante, el SIC, a través de la Resolución $N^{\circ} 82327$ de fecha 20 de octubre de 2015 denegó el registro de una marca sonora (signo VILLAVO) para distinguir "publicidad y negocios" (servicios de la clase 35), solicitada por el Instituto de Turismo de Villavicencio. Esta Autoridad señaló que el signo sonoro era tan extenso que no lograba definir una pauta de ejecución sonora específica. En ese sentido, se alegó que el signo carecía de distintividad intrinseca, ya que no lograba identificar en el comercio a ningún producto o servicio a través de la melodía de larga duración aportada (de tres minutos con cuarenta y nueve segundos).

- Mediante Resolución $N^{\circ} 030868$ de fecha 30 de octubre de 2013 la Superintendencia de Industria y Comercio de Colombia concedió el registro de una marca sonora para distinguir servicios de la clase 38 , consistentes en servicios de comunicación, servicios que permiten a una persona comunicarse con otra, servicios de telefonía, radio, televisión, beeper, informaciones en materia de comunicaciones, transmisión de telecopias, televisión por cable, transmisión de mensajes e imágenes, transmisión vía satelite, alquiler de aparatos de fax, de telecomunicaciones, de transmisión de mensajes de modem, emisiones radiofonicas y televisadas.

En principio, el solicitante - Orbitel S.A. E.S.P - había presentado como medio para representar gráficamente el signo sonoro el siguiente pentagrama:

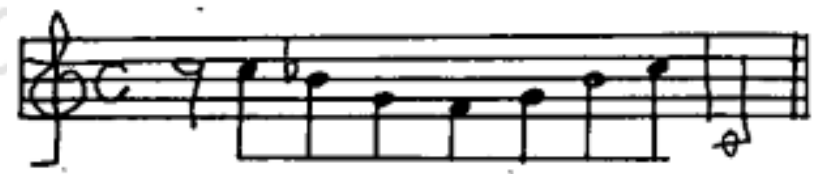

(Fuente: Resolución Nº 030868 del SIC, 2013)

Y la siguiente descripción: "Marca sonora interpretada con el instrumento marimba, cuya partitura está representada sobre el pentagrama". Adicionalmente, mediante escrito de fecha 26 de junio de 2003 se adjuntó un 
diskette con la marca sonora solicitada en formato MP3, lográndose de está manera cumplir con el requisito de la representación gráfica.

- La Superintendencia de Industria y Comercio, a través de la Resolución N 4282 de fecha 23 de febrero de 2007, resolvió conceder el registro de la marca sonora solicitada por Productos Familia S.A para distinguir productos comprendidos en la clase 5, consistentes en productos farmacéuticos, veterinarios e higiénicos, sustancias dietéticas para uso médico, alimentos para bebes, emplastados, material para apósitos, material para empastar los dientes y para moldes dentales, desinfectantes, productos para la destrucción de animales dañinos, fungicidas, herbicidas

En efecto, en el presente caso el solicitante también utilizó un pentagrama para representar gráficamente el signo sonoro que deseaba registrar, el cual se muestra a continuación:

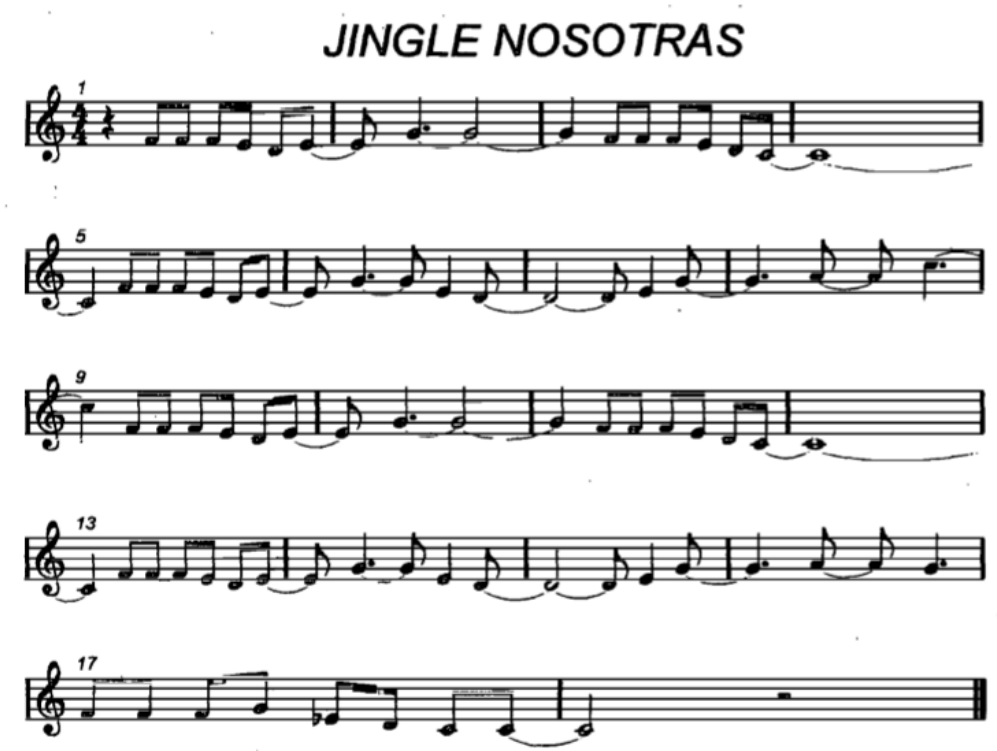

(Fuente: Resolución N 4282 del SIC, 2007)

Asimismo, también se presentó el audio del signo sonoro. 
- Mediante Resolución $N^{\circ} 7357$ de fecha 28 de marzo de 2006, la Superintendencia de Industria y Comercio concedió el registro de una marca sonora para distinguir productos farmacéuticos y veterinarios, productos higiénicos para la medicina, sustancias dietéticas para uso médico, alimentos para bebés, emplastos, material para apósitos, material para empastar los dientes y para improntas dentales, desinfectantes, productos para la destrucción de animales dañinos: fungicidas, herbicidas, de la Clase 5, solicitada por Bayer Healthcare LLC.

En el presente caso se adjuntó como representación gráfica la siguiente figura:

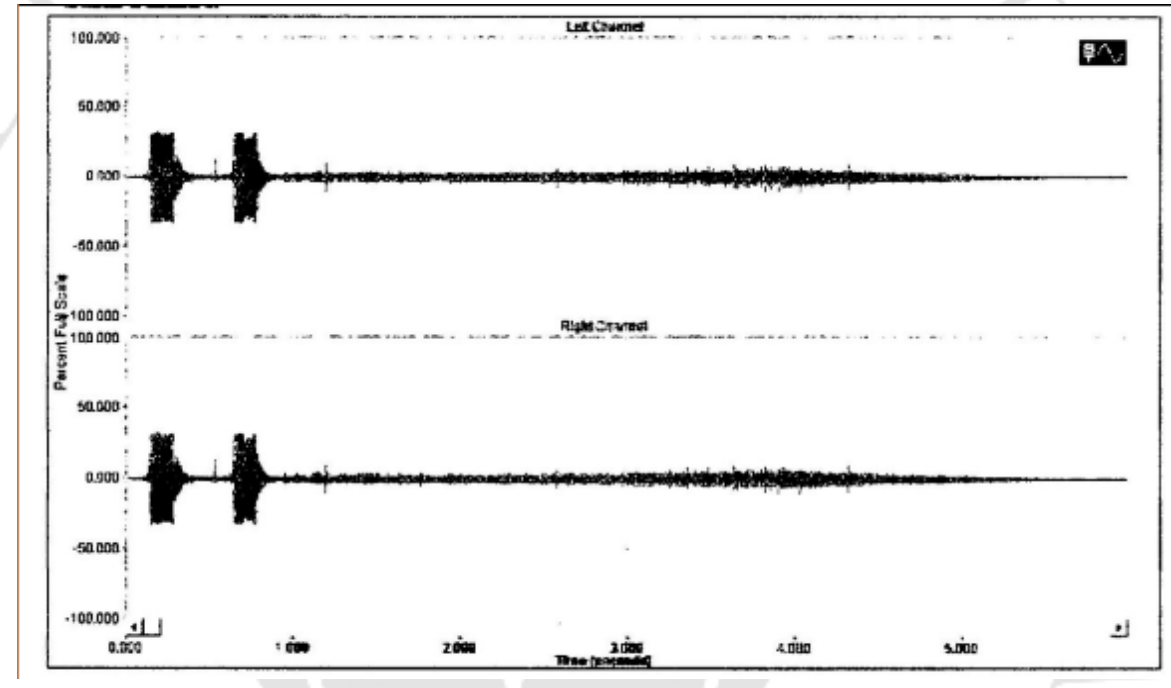

(Fuente: Resolución N 7357 del SIC, 2006)

- Por Resolución No 33397 de fecha 30 de noviembre de 2006 la Superintendencia de Industria y Comercio denegó el registro de una marca sonora para distinguir servicios comprendidos en la clase $36^{24}$, solicitada por la sociedad Allianz Aktiengesellschaft. En este caso se alegó que la información auditiva proporcionada era de tal simplicidad que no lograba definir una pauta de ejecución sonora específica. En ese sentido, se concluyó que el signo carecía de distintividad intrinseca.

24 Clase 36: Servicios de seguros; operaciones financieras; operaciones monetarias; negocios inmobiliarios. 
Vale precisar que en este caso el solicitante cumplió - según el SIC - con el requisito de la representación gráfica mediante la siguiente figura:

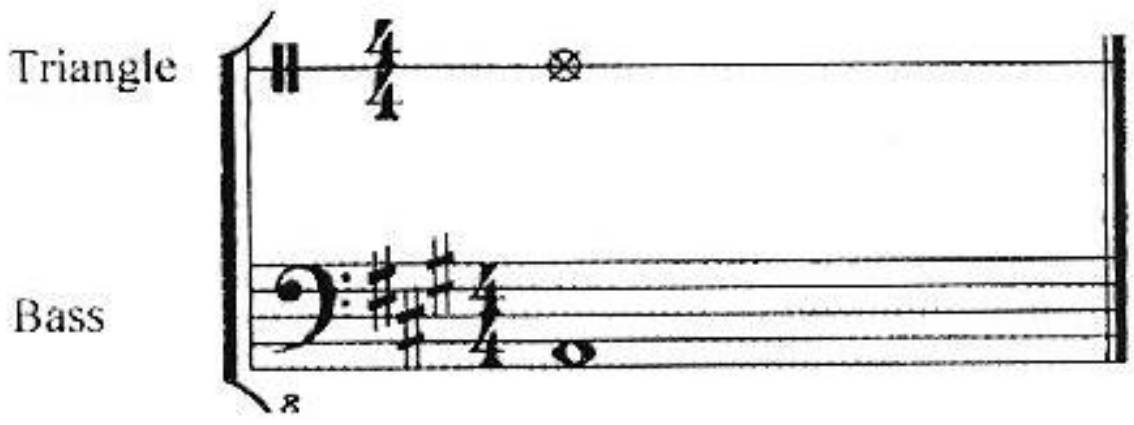

(Fuente: Resolución Nº33397 del SIC, 2006)

- Mediante Resolución $N^{\circ} 423$ de fecha 20 de enero de 2005, la Superintendencia de Industria y Comercio resolvió conceder el registro de una marca sonora para distinguir servicios de la clase 36, consistentes en negocios financieros y monetarios, seguros; solicitada por el Banco Davivienda S.A.

Para cumplir con el requisito de la representación gráfica, el solicitante adjuntó un pentagrama, tal como se muestra a continuación:
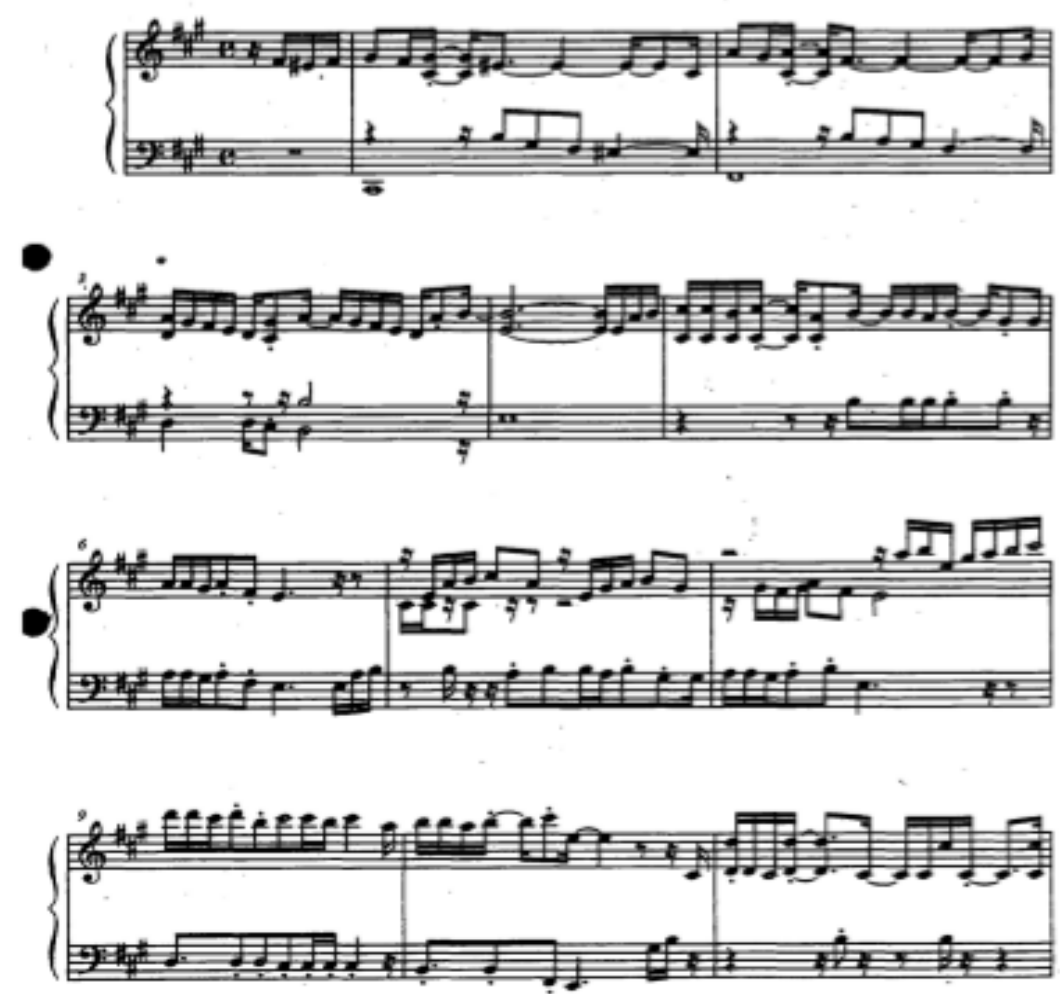

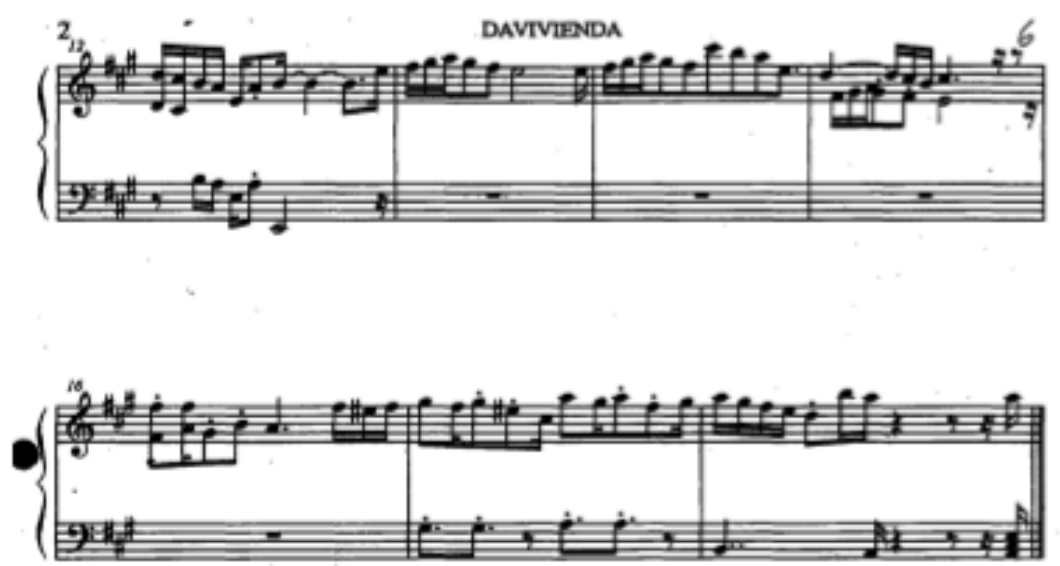

(Fuente: Resolución N 423 del SIC, 2005)

Asimismo, se adjuntó un CD con el audio del signo sonoro.

- Por medio de la Resolución $N^{\circ} 14029$ de 22 de junio de 2005, la Superintendencia de Industria y Comercio resolvió conceder el registro de una marca sonora para distinguir productos comprendidos en la clase 9, consistentes en peliculas cinematográficas, cintas de videos, cassetes de video, discos de video pregrabados, DVDs y VCDs, cintas de audio, cassetes de audio, y discos de audio pregrabados, programas de software de computador, software y video juegos de computador; solicitada por Twentienth Century Fox Film Corporation.

Para representar gráficamente el signo sonoro, el solicitante adjunto el siguiente pentagrama: 

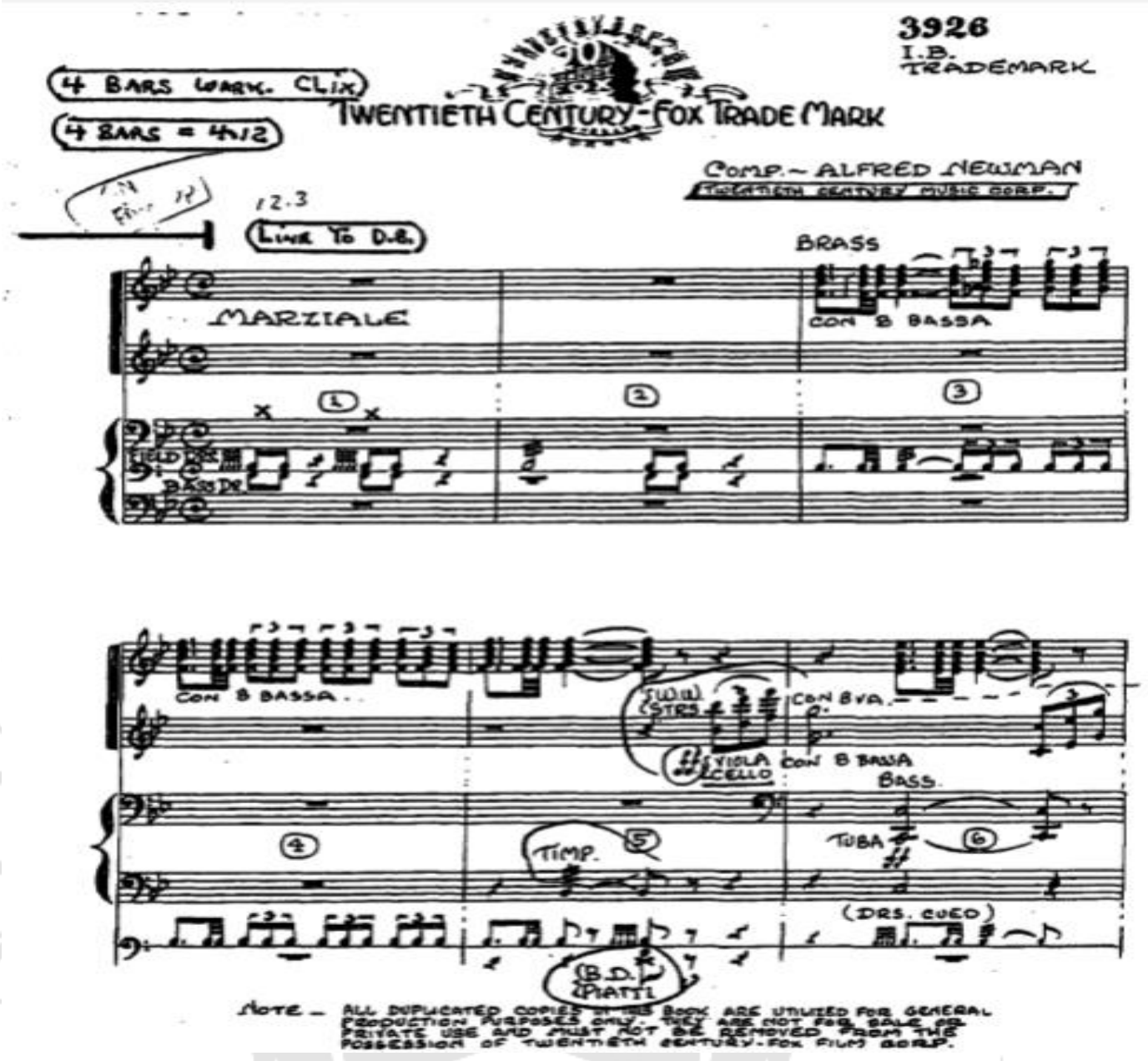

(2)

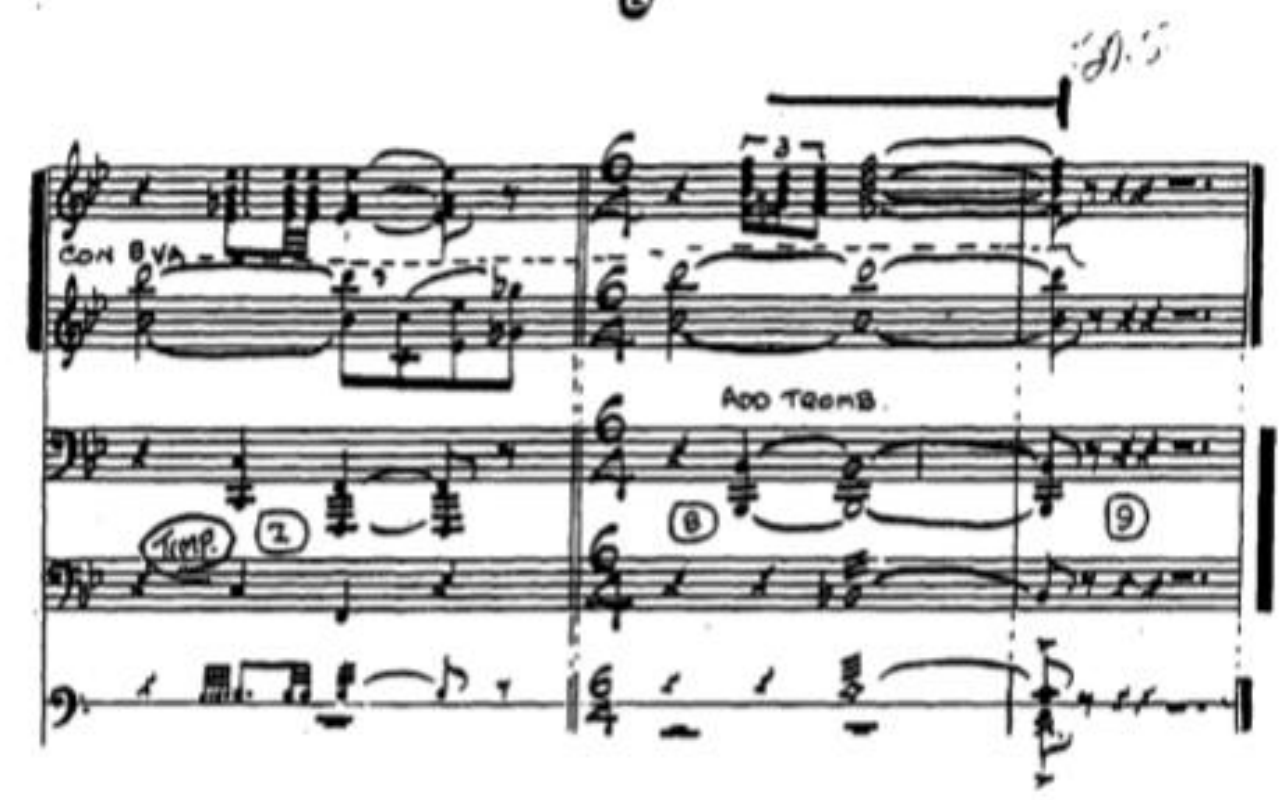

Treosinates

(Fuente: Resolución N 14029 del SIC, 2005) 
- Por medio de la Resolución $\mathrm{N}^{\circ} 42107$ del 26 de diciembre de 2002, la Superintendencia de Industria y Comercio resolvió confirmar la decisión contenida en la Resolución $N^{\circ} 23313$ de 25 de julio de 2002, en la cual se denegó el registro de una marca sonora para distinguir servicios comprendidos en la Clase 36, consistentes en servicios financieros; servicios de banca y de crédito; provisión de tarjeta de crédito, tarjeta de debito, tarjeta de cargo y servicios de tarjeta prepago, entre otros; solicitada por la sociedad Mastercard International Incorpored, por considerar que el signo auditivo se encontraba incurso en la causal de irregistrabilidad del literal b) del artículo 135 de la Decisión 486; es decir, por carecer de distintividad.

La Autoridad Nacional Competente de Colombia señaló que a pesar de que el signo cumplía con el requisito de la representación gráfica, por su simplicidad en la estructura musical no era lo suficientemente distintivo. Se alegó que el signo sonoro no contaba con elementos de naturaleza musical (poca duración) que permitiera diferenciarlo con otras melodías. Asimismo, es necesario precisar que en la resolución impugnada, el SIC manifestó que al valorar auditivamente la melodía pudo apreciar que no era distintivo, pues dicha melodía era comúnmente utilizada en las tonadas finales de muchas interpretaciones musicales.

El solicitante en el transcurso del proceso alegó que el signo debía ser distintivo, y no novedoso, argumentando que un mismo signo podía ser utilizado para productos o servicios diferentes. En ese sentido, manifestó que:

En el caso que nos ocupa, una marca sonora carece de distintividad si las notas que la conforman son iguales a las notas que conforman otra marca sonora. Es más, es necesario para hablar de carencia de distintividad que las marcas en cuestión protejan los mismos productos o servicios. (...). Es necesario que exista una marca sonora igual o similar ya registrada y que dicha marca sonora registrada proteja los mismos productos o servicios que pretende proteger la marca sonora solicitada (Resolución N² 23313 del SIC, 2002) (el subrayado es mío).

Vale recalcar que se representó gráficamente a la marca de la siguiente manera: 


\section{$J=110$}

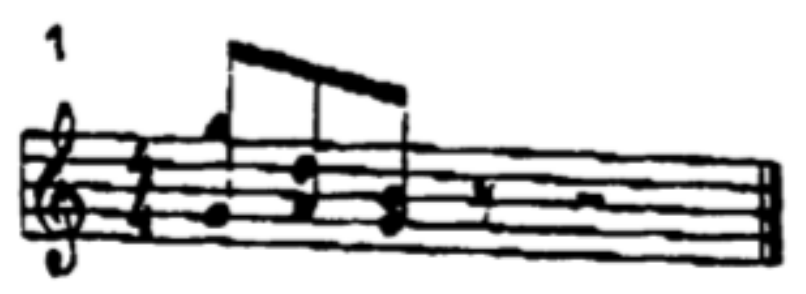

(Fuente: Resolución N² 23313 del SIC, 2002)

Además, en la solicitud se adjuntó el cassette en el cual se podía escuchar la marca auditiva.

- Marcas Táctiles

- La Superintendencia de Industria y Comercio, mediante la Resolución N 334 de fecha 6 de enero de 2017, rechazó el registro de una marca táctil, consistente en una superficie que tenía una textura gruesa, aspera, resistente y rigorosa que se asemejaba a la textura de la tela tipo jean y que se usaría como sustrato de encuadernación de diferentes productos de papelería, generalmente rectangulares. La superficie poseía costuras de hilo color amarillo o marrón, resaltando el pespunte característico de la marca que bordeaba el contorno rectangular del artículo sobre el cual se aplicaba. Esta marca táctil fue solicitada para distinguir productos comprendidos en la clase 16 de la Clasificación Internacional de Niza.

Sobre el particular, es necesario indicar que en la resolución, sobre el requisito de la distintividad en una marca táctil, se precisaron las siguientes anotaciones:

(...) la marca táctil o de textura, podría definirse esta como la constituida por una superficie plasmada en un objeto, su envase, envoltura o empaquetadura, que al ser percibida por medio del sentido del tacto es capaz de distinguir un producto e informar acerca de su origen empresarial.

La textura debe estar dotada de tal grado de distintividad, que un consumidor medio aún con los ojos cerrados pueda individualizar el producto y su origen empresarial y, por lo tanto, no puede estar conformada por una textura que 
represente ninguna funcionalidad o ventaja técnica, ni hacer referencia directa a las características esenciales de los productos que pretende identificar, so pena de estar incursa en una causal de irregistrabilidad (los subrayados son mios).

Asimismo, sobre el requisito de la representación gráfica de una marca táctil, refiriéndose al Proceso 242-IP-2015 (el cual veremos con detenimiento más adelante), se estableció lo siguiente:

“(...) En el presente caso, este Tribunal considera pertinente que la Oficina Nacional Competente exija una o más representaciones de la marca solicitada, así como la indicación del tipo de marca y otros detalles relativos a la misma.

\section{$(\ldots)$}

Cabe precisar que le atañe a la Oficina Nacional Competente verificar si la marca táctil solicitada cumple con los requisitos de susceptibilidad de representación gráfica y distintividad. Adicionalmente, como se ha explicado, ésta tiene además la facultad de exigir documentación o cualquier otro soporte material necesario para determinar con exactitud el alcance de la protección que se reivindica. En definitiva, la problemática de la representación gráfica del signo a los fines de publicación (y posibles oposiciones) atañe a la Oficina de Marcas y no al titular. En este sentido, la Oficina Nacional Competente deberá identificar los medios adecuados para hacer factible la publicación en los casos particulares de las marcas táctiles o de textura.

(...) $\underline{\text { se recomienda admitir representaciones de un signo distintas a las gráficas }}$ cuando estás sean más aptas para identificarlo, siendo suficiente que éste sea representado de una manera que permita a las autoridades competentes y al público consumidor determinar el objeto exacto de la protección conferida al titular.

(...) El Tribunal considera que se debe contar con varias representaciones de la marca, tomadas en perspectivas diferentes y según distintos métodos y modalidades. De igual manera, mientras más representaciones diferentes de una marca táctil o de textura sean publicadas, se comunicará con mayor precisión lo reivindicado y, en consecuencia, se evitarán futuras controversias relativas a dicha marca táctil. 
(...) En consecuencia, este Tribunal interpreta de una manera amplia lo que se entiende por representación gráfica, siendo necesaria la concurrencia de dos requisitos: i) la descripción clara, precisa, y completa del signo, incluyendo un dibujo tridimensional o fotografía; y ii) muestra física de la marca táctil (...) (Tribunal de Justicia de la CAN, 2015) (los subrayados son mios).

Es necesario precisar que para satisfacer el requisito de la representación gráfica, en el presente caso el solicitante, además de presentar una descripción de la marca (tal como se indicó en linas anteriores), adjuntó una fotografía y una muestra física del signo.

Sin perjuicio de lo expuesto, la Superintendencia de Industria y Comercio denegó el registro de la marca táctil, alegando que al analizar conjuntamente la muestra física con la descripción se constataba una serie de impresiciones e inconsistencias, concluyendo que este hecho implicaba que la textura aportada no se encontrara dotada de la capacidad potencial para individualizar y diferenciar los productos pretendidos de los demás productos y servicios que se ofrecen en el mercado, impidiendole de esta manera al consumidor adquirir aquel grado de discernimiento que lo lleve a asociar dichos productos con un origen empresarial determinado, careciendo la textura solicitada de distintividad extrinseca concreta.

Como puede observarse, el rechazo al registro de la marca táctil no guarda coherencia con las precisiones señaladas en el Proceso 242-IP-2015, ni con la distintividad extrinseca del signo táctil como erroneamente se señala.

Para una mejor ilustración del presente caso, mostraremos la foto que fue adjuntada por el solicitante como una forma de cumplir con el requisito de la representación gráfica (sin olvidar que adicionalmente se adjuntó la muestra del signo y su descripción): 


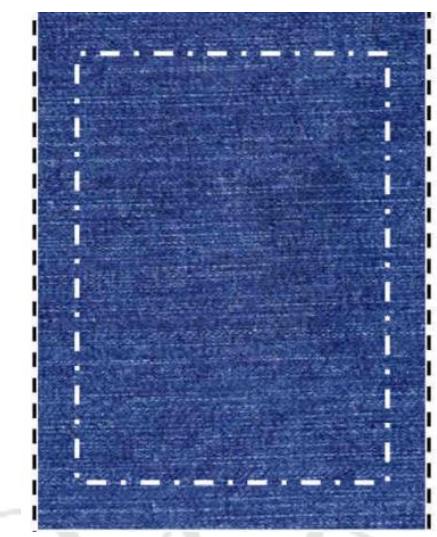

(Fuente: Resolución N`334 del SIC, 2017)

- Mediante solicitud de fecha 27 de febrero de 2015, la solicitante Diageo Brands B.V solicitó el registro de la marca táctil "Textura Superficie OLD PARR” para distinguir productos de la clase 33, para bebidas alcohólicas excepto cerverzas.

En este caso, la Superintendencia de Industria y Comercio de Colombia solicitó al Tribunal de Justicia de la Comunidad Andina interpretación prejudicial, la cual expidió dentro del Proceso 242-IP-2015, visto en el punto anterior, decisiones determinantes para el registro de marcas no tradicionales no visibles.

A raiz de lo establecido en dicho proceso, el solicitante adjuntó la siguiente descripción escrita de la marca táctil, la cual se muestra a continuación:

Consiste en una textura (superficie) grabada en relieve de apariencia craquelada, cuarteada o resquebrajada, creada a partir de la aglomeración de formas geométricas irregulares que incluyen en su mayoría, péntagonos, romboides y hexágonos, cuyos lados o segmentos de línea miden entre 3 y 6 milímetros de longitud, entre 0,08 y 0,5 milímetros de altura y entre 0,1 y 1 milímetros de grosor. Los lados/segmentos de línea y las áreas contenidas dentro de dichos segmentos de línea son lisas. El material en el que se use esta textura será vidrio de color ámbar y se usará en distintos tamaños ( El subrayado es mío).

Asimismo, a pesar de adjuntar la muestra física del signo, el solicitante adjuntó la siguiente fotografía: 


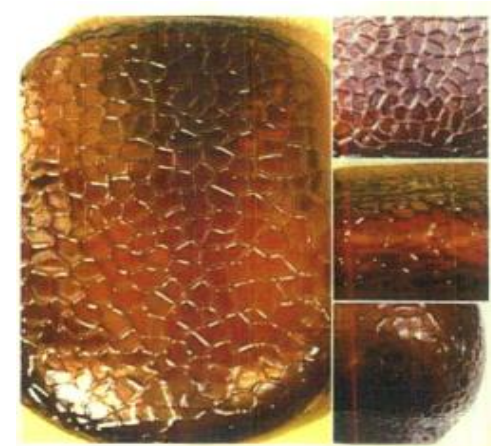

(Fuente: Solicitud Textura Superficie OLD PARR , 2015)

En ese sentido, la Superintendencia de Industria y Comercio estableció lo siguiente: i) sobre el nombre de la marca, consistente en "Textura: superficie OLD PARR, determinó que lo que se analizaría a efectos de determinar el alcance del derecho no es su nombre, sino la textura, por lo que dicha mención era irrelevante en el caso concreto; sin embargo, dicha Oficina decidió reemplazar la denominación por "Textura superficie vidrio", teniendo en cuenta tanto la descripción, imágenes y muestra física; ii) sobre la descripción presentada por el solicitante, manifestó que la referencia al color era irrelevante, pues la marca táctil es aquella que es apreciada no por el sentido de la vista, sino al tocarla; iii) sobre la funcionalidad o no del signo táctil, se indicó que el mismo no devenía en una forma necesaria dentro del mercado de bebidas alcohólicas, como tampoco tenía una ventaja tecnica o funcional, pues no influía en la capacidad de agarre, ni en las cualidades físicas ni químicas de los productos contenidos o en su empaque.

Por las razones expuestas, en este caso, la Autoridad Nacional Competente de Colombia decidió conceder el registro de la marca táctil.

- Marcas olfativas

- $\quad$ El 7 de abril de 2010, la sociedad Empresas Públicas de Medellin E.S.P. solicitó el registro de una marca olfativa para distinguir servicios de la clase 35 , consistentes en publicidad, gestión de negocios comerciales, administración comercial, trabajos de oficina. 
Para cumplir con el requisito de la representación gráfica describió al signo olfativo como "bosque fresco" y presentó la siguiente formula:

Fórmula Marca Bosque Fresco (olfativa)

\begin{tabular}{|c|c|}
\hline COMPUESTO & $\%$ \\
\hline Acido ciclopenten aceitco. 3 oxo 2 pentil metil ester & 21,113 \\
\hline Limoneno & 17,013 \\
\hline Dipropilenglicol monoetileter & 14,398 \\
\hline 2,6 octadien 1 ol 3,7 dimetil & 12,668 \\
\hline Linalil isobutirato & 7,833 \\
\hline Octanal & 6,826 \\
\hline Acido ciclopentaneacetico. 3-oxo 2-pentil metal ester & 2,864 \\
\hline ( $7^{a}$-isopropenil-4,5-dietiloctahidroinden-4-ii) metanol & 2,313 \\
\hline 1,2 dihidrolinalol & 2,203 \\
\hline 3 buten 2 on $4-(2,6,6$ trimetil 1 ciclohexen 1 ii) & 2,000 \\
\hline 2 Butanol 3,3' oxybis & 1,680 \\
\hline Dietiltalato & 1,560 \\
\hline Tonalio & 1,500 \\
\hline Acido benzene acetico. 2 -fenil etil ester & 0,861 \\
\hline 7 octen 2 ol 2,6 dimetil & 0,848 \\
\hline 2,6 octadien 1 ol 3,7 dimetil acetato & 0,646 \\
\hline 2,6 octadienal 3,7 dimetil & 0,624 \\
\hline 3 ciclohexen 1 carboxaldehido 3,4 dimetil & 0,606 \\
\hline $\begin{array}{l}\text { 2-(4a.8-Dimetil-6-oxo-1.2.3.4.4a.5.8a-octahidro naftalen } 2 \text { il) } \\
\text { propionaldéhido }\end{array}$ & 0,554 \\
\hline Mentol & 0,516 \\
\hline $1 \mathrm{H}$ indene $2,3,3$ a 4,7 a hexahidro $2,2,4,4,7,7$ hexametil & 0,485 \\
\hline a-isometil ionona & 0,464 \\
\hline Hexanol & 0,368 \\
\hline Trazas de impurezas irrelevantes en el análisis. & 0,057 \\
\hline 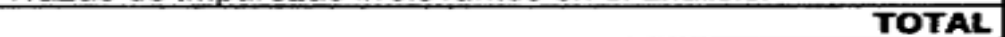 & 100,00 \\
\hline
\end{tabular}

(Fuente: Resolución N 1765 del SIC, 2011)

En este orden de ideas, en primera instancia, la Superintendencia de Industria y Comercio, mediante resolución $\mathrm{N}^{\circ} 0001765$ del 26 de enero de 2011, denegó el registro de la marca olfativa solicitada, argumentando los criterios recogidos en el caso Sieckmann, los cuales veremos más adelante.

Asimismo, esta oficina concluyó que el signo olfativo solicitado a registro carecía de distintividad intrínseca, toda vez que el olor que podía percibirse no iba más allá del común de los olores que podían llegar a producir cualquier producto que se utiliza para publicidad o comercialización de los servicios de la clase 35, manifestando además que el olor no creaba un concepto nuevo en el mercado que permitiera a los consumidores identificar su origen empresarial a partir de la formula, más aún si se tenía en cuenta que este tipo de servicios no estarían dotados de aromas. 
En ese sentido, la solicitante presentó recurso de reposición y, en subsidio, de apelación, contra la antedicha resolución $\mathrm{N}^{\circ}$ 0001765, manifestando lo siguiente:

Por lo anterior es importante reconocer, que a diferencia de la Decisión 344 del acuerdo de Cartagena, la Decisión 486 de la Comunidad Andina, introduce el reconocimiento de marcas como la olfativa, por lo que a partir de la expedición de la misma, es deber de la Superintendencia de Industria y Comercio dar protección a este tipo de signos que día a día son más comunes en el mercado, dada la importancia que representan los olores para reconocer un producto, un servicio, o un establecimiento comercial.

\section{$(\ldots)$}

-Ser Susceptible de representación gráfica: Es decir, la posibilidad de transmitir mediante trazos la descripción de la marca, por lo que el signo tiene que ser representado en forma material para que el consumidor a través de los sentidos perciba, conozca y lo solicite (...). Se debe tener en cuenta que la percepción gráfica de los signos puede ser realizada a través de diferentes medios, no solo el visual, diferente a lo mencionado por la Entidad.

$(\ldots)$

La Superintendencia de Industria y Comercio en concepto 03087905 del 17 de Diciembre de 2003, manifestó que las marcas olfativas, son "aquellas constituidas por un olor suficientemente distintivo y susceptible de representación gráfica (formula química)", haciendo referencia a que el requisito de registro que implica una representación gráfica del olor se debe hacer con la fórmula química (...)

Así mismo, en Colombia, (...) en la página web de gobierno en línea, la cual esta ligada con la Superintendencia de Industria y Comercio, se encuentra claramente que "para Registros de marca de productos y servicios o lema comercial. (...) Documentos Requeridos (...) para el registro de marca olfativa, aquella constituida por un olor suficientemente distintivo, se debe adjuntar a la solicitud la fórmula química". 
(...) En este sentido, cabe anotar que carece de toda lógica que la norma contemple un registro de marca la cual es perfectamente perceptible por el sentido del olfato para después negarla por falta de representación gráfica, sentido este que por medio de diferentes estudios se ha dicho que es uno de los que genera más recordación en el ser humano, pues "es 10,000 veces más sensible que cualquier otro de nuestros sentidos y el reconocimiento del olor es inmediato. Otros sentidos similares, como el tacto y el gusto deben viajar por el cuerpo a través de las neuronas y la espina dorsal antes de llegar al cerebro, mientras que la respuesta olfatoria es inmediata y se extiende directamente al cerebro. "Este es el único lugar donde nuestro sistema nervioso central está directamente expuesto al ambiente" (Von Have, Serene Aromatherapy)

\section{$(\ldots)$}

(...) encontramos que queda claro que para el derecho comunitario Andino, es una realidad la protección de los olores como marca y se encuentra expresamente establecido tal como se puede apreciar en el Proceso $\mathrm{N}^{\circ} 32$-IP96, en el cual se manifiesta:

"La representación gráfica: El Tribunal y la doctrina han considerado que este requisito no es el de la esencia misma del concepto y de las funciones que el signo debe cumplir como marca y más que un requisito de fondo es un requisito formal para fines registrales.

(...) En efecto, en principio, se puede afirmar que un olor o un sabor son signos o, por mejor decir medios, que pueden diferenciar un producto de sus similares. Desde el punto de vista de su esencia, tales medios no solo pueden responder teóricamente al concepto mismo de marca, sino que pueden reunir el principal requisito exigible de marca: la aptitud diferenciadora".

De igual forma se debe tener presente que la solicitud de la marca, se hace con base en un olor que es susceptible de volverse a fabricar o generar por la fórmula química que lo compone. Es decir, que al poderse establecer cuáles son sus componentes y cifrarlos en una fórmula química única, garantiza totalmente al consumidor final que la marca es irrepetible y que tiene no solo una representación gráfica sino un elemento de distintividad indiscutible. 
(...) describiendo detalladamente su fórmula química, la composición exacta de esta, la cantidad, de tal manera que de reproducir esta fórmula el olor que se obtiene siempre será el mismo, no abra cambios (...)

$(\ldots)$

(...) Adicionalmente, si la superintendencia considera que el signo solicitado a registro no anexo dentro de la solicitud la representación gráfica, debió requerir su presentación y no esperar a negar el signo. Si un solicitante pretende una marca mixta y así lo menciona y no anexa el logo, la Superintendencia de Industria y Comercio en su estudio de forma requiere para aclaración y para que se anexe el logo respectivo, asimismo, si una marca olfativa se presenta sin su representación gráfica, se debe requerir para que se subsane presentándola.

La Superintedencia de Industria y Comercio, mediante resolución $N^{\circ} 20096$ del 15 de abril de 2011, denegó nuevamente el registro de la marca olfativa, alegando reiteradamente los criterios recogidos en el caso Sieckmann y, además, manifestando que “(...) La descripción del olor: Bosque Fresco (...), dado su generalización en el mercado, no logra referir un origen empresarial determinado, en tanto que puede ser utilizado por múltiples empresarios al hacer referencias a aromas relacionados con ambientes naturales y frescos" (Resolución N²0096 del SIC, 2011).

En ese sentido, el Superintendente Delegado para la Propiedad Industrial resolvió, mediante resolución $\mathrm{N}^{\circ} 00014655$ del 3 de marzo de 2014, el recurso de apelación interpuesto por la solicitante, decidiendo revocar la resolución impugnada, indicando que “(...) si bien cumple con el requisito de la representación gráfica a través de una formula química, no resulta ser lo suficientemente clara y precisa que permita determinar el tipo de olor que se pretende proteger" (Resolución $\mathrm{N}^{\circ} 14655$ del SIC, 2014); asimismo, concluyó 
que el signo solicitado no estaba incurso en ninguna causal de registrabilidad del artículo 135, letras a) y b), de la Decisión 486 de la Comunidad Andina.

En efecto, el antedicho despacho otorgó el plazo de sesenta (60) días a la solicitante para que cumpla en representar gráficamente el signo olfativo, mediante una descripción detallada, clara y precisa.

$\mathrm{Al}$ respecto, la solicitante, mediante escrito de fecha 9 de abril de 2015, cumplió con lo solicitado, describiendo el signo olfativo que pretendía registrar de la siguiente manera:

Olor compuesto por (a) un fondo predominante de carácter cítrico, integrado con (b) un toque destacado de aroma a jazmín y, c) de manera complementaria, notas ligeras consistentes en mezclas de: jazmín con limón, eucalipto con menta y limoncillo. Evoca un ambiente campestre relacionado con lugares cercanos a fuentes de agua natural; igualmente, brinda recordación sobre elementos de naturaleza pura y viva, generando sensaciones de vitalidad, confort, tranquilidad y frescura (Resolución $\left.\mathrm{N}^{\circ} 90525,2016\right)$.

La Superintendencia de Industria y Comercio, mediante resolución $\mathrm{N}^{\circ} 90525$ del 29 de diciembre de 2016, denegó el registro de la marca olfativa solicitada, alegando nuevamente los criterios recogidos en el caso Sieckmann y, manifestando además que:

La carencia de objetividad se evidencia debido a que la descripción aludida genera una serie de ambigüedades e indeterminaciones respecto a la fragancia que se pretende registrar. A ciencia cierta, no es posible determinar de una manera inequívoca cuál es el olor compuesto que se constituye a partir de la fusión de los aromas cítricos, con el jazmín, el limón, el eucalipto, la menta y el limoncillo.

Por otro lado, la descripción aportada habla de la evocación de un ambiente campestre relacionado con lugares cercanos a fuentes de agua natural, brindando recordación sobre elementos de naturaleza pura y viva, generando sensaciones de vitalidad, confort, tranquilidad y frescura. Todos estos elementos que se dice evocar la mencionada fragancia, en realidad no gozan de la claridad requerida para que esta Dirección, como autoridad competente en 
materia de Signos Distintivos, conciba cuál es realmente el aroma del que se está hablando. La descripción de dicha evocación se encuentra plagada de apreciaciones totalmente subjetivas, ya que las sensaciones de vitalidad, confort, tranquilidad y frescura vienen a ser producto de percepciones relativas que varían de una persona a otra, dependiendo de la sensibilidad particular de cada uno de los receptores de la fragancia (...).

(...) esta Dirección tampoco logra discernir el verdadero alcance de la protección del olor que se pretende, lo que impide definir realmente el alcance del eventual derecho que se solicita (Resolución N$\left.{ }^{\circ} 90525,2016\right)$.

En ese sentido, puede apreciarse que en el presente caso también fueron utilizados cabalmente los criterios recogidos en el caso Sieckmann, denegándose el registro de la marca olfativa solicitada por no cumplir con el requisito de la representación gráfica.

Asimismo, debe resaltarse que se evidencia una contradicción en los argumentos expuestos en primera instancia por la Superintendencia de Industria y Comercio de Colombia para referirse a la falta de distintividad intrínseca de la marca olfativa solicitada para registro, pues si bien en un extremo señaló que “(...) el olor que se pueda percibir no va más allá del común de los olores que pueden llegar a producir cualquier producto que se utilice para publicidad o comercialización (...) por lo que no crea un concepto nuevo (...)”, en el otro manifestó que “(...) más aún si se tiene en cuenta que este tipo de servicios no están dotados de aromas".

Es decir, cabe preguntarse cómo ciertos servicios que no están dotados de ningún aroma, a la vez, resultan ser producidos comúnmente con el signo olfativo solicitado. Es evidente la incongruencia del antedicho despacho al momento de evaluar la distintividad de la marca olfativa solicitada.

Por otro lado, vale precisar que no hemos podido ubicar la referencia sobre el registro de signos olfativos de la página web "gobierno en línea", indicada por la solicitante; y, sobre el concepto $\mathrm{N}^{\circ} 03087905$ del 17 de diciembre de 2003, 
puede inferirse que a pesar de tener fecha posterior al caso Sieckmann, parece que la Superintendencia de Industria y Comercio hubiere adoptado estos criterios posteriormente, al no admitir la formula química como forma de representación gráfica de los signos olfativos (tal y como se indicaba en el concepto $\mathrm{N}^{\circ}$ 03087905).

- El 17 de mayo de 2005, Laboratorios Cero S.A. solicitó ante la Superintendencia de Industria y Comercio de Colombia el registro de la marca olfativa "fragancia crema cero" para distinguir productos de la clase 3, consistentes en cremas antipañalíticas no medicadas, geles, champús, vaselinas, aceites corporales, protectores labiales, removedores, talcos, así como preparaciones para blanquear y otras sustancias para la colada; preparaciones para limpiar, pulir, desengrasar y raspar; (preparaciones abrasivas) jabones; perfumería, aceites esenciales, cosméticos, lociones para el cabello y dentífricos.

Para cumplir el requisito de la representación gráfica, la solicitante adjuntó a la solicitud información sobre i) el método de elaboración, ii) la descripción olfativa, iii) un cromatograma y, iv) una muestra física del olor.

Al respecto, sobre el método de elaboración, indicó lo que se muestra a continuación:

\section{FORMULACIÓN}

\section{FRAGANCIA CREMA CERO}

La fragancia se describe olfativamente como Floriental, Rosa, Violeta, polvoso, Vainilla, almizclado (soluble en aceite).

Preparación:

Se coloca en un tanque de maceración con propilenglicol, en proporciones iguales las notas de fondo, de corazón y de salida, en el siguiente orden: 
a. Adicionar las notas de fondo vainilla Madagascar y almizcle blanco, mezclar hasta aspecto homogéneo.

b. Adicionar las notas de corazón rosa Bulgaria, violeta, Acorde Jazmín, Heliotropo, mezclando bien.

c. Adicionar las notas de salida bouquet de anís, bouquet de almendras, bouquet de durazno. Mezclar.

d. Completar volumen con propilenglicol.

e. Filtrar.

f. Envasar. (...)

Asimismo, como descripción olfativa presentó el siguiente gráfico:

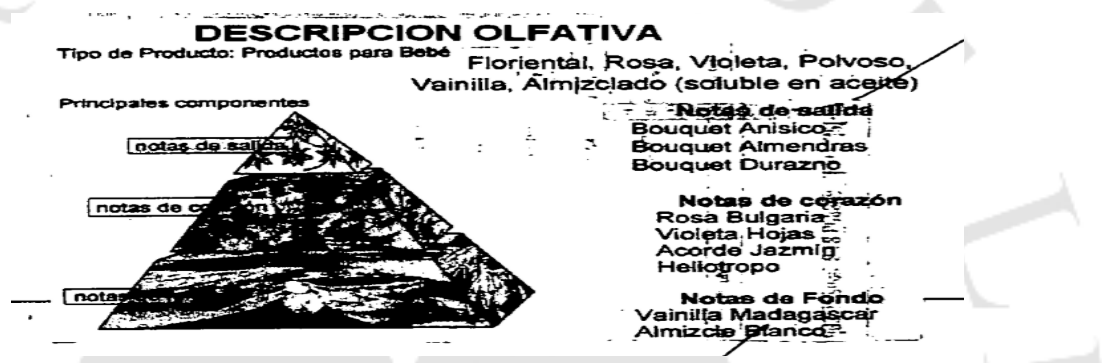

(Fuente: Resolución $\mathrm{N}^{\circ} 11956$ del SIC, 2005)

Y el siguiente Cromatograma:

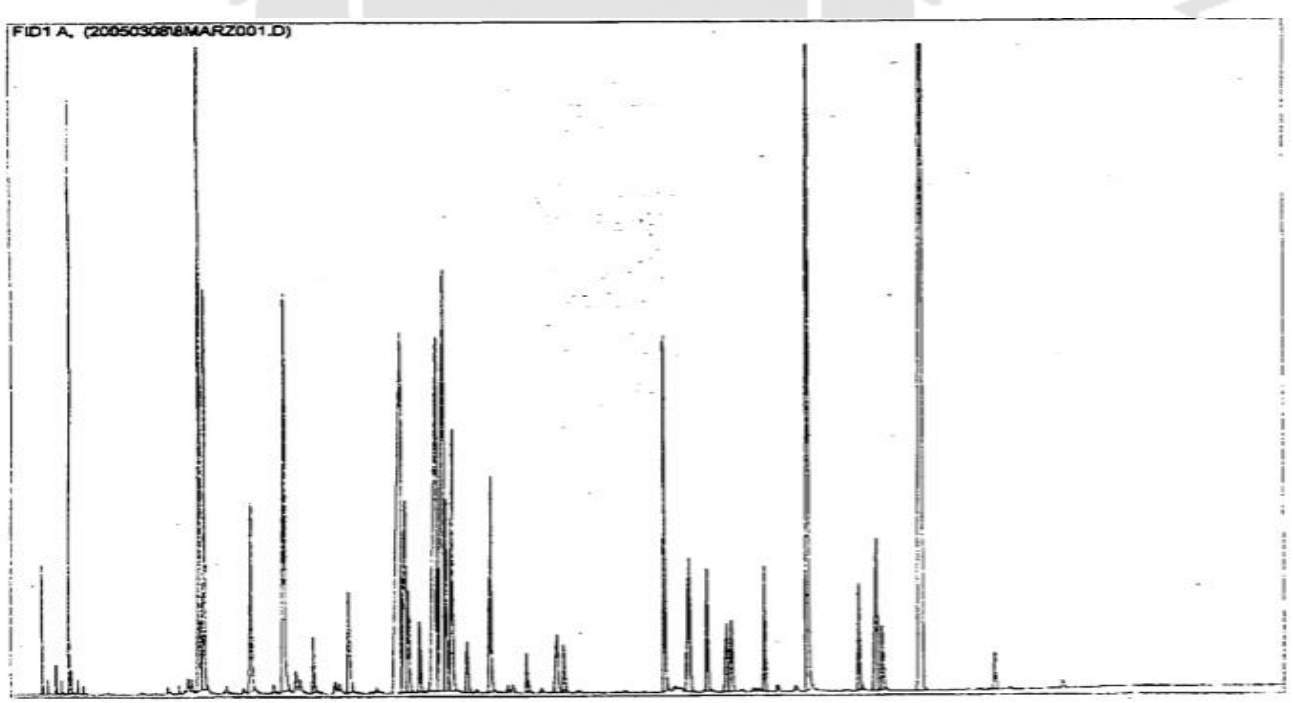

(Expediente 05 -47625 del SIC, 2005)

En ese sentido, en primera instancia la División de Signos Distintivos denegó el registro de la marca olfativa solicitada, precisando en la Resolución Nº 011956 (2007) del 30 de abril de 2007 lo siguiente:

(...) es necesario que susceptible de representación gráfica. 
Requisito impuesto por seguridad jurídica, pues el titular de la marca registrada adquiere como derecho el uso exclusivo de los signos que la forman. Una vez protegida la marca por la oficina nacional competente, se obtiene el registro marcario, el cual permite conocer la naturaleza y alcance de los signos, de las indicaciones y de los símbolos inscritos como marcas, motivos por los cuales se exige de manera tajante su representación gráfica.

Decir que un signo es susceptible de representación gráfica, significa que puede describirse mediante el empleo de símbolos que permiten ser plasmados en papel mediante dibujos, lo cual admite su percepción visual

La representación gráfica debe ser comprensible (...) ser completa, clara y precisa $(\ldots)$.

(...) la formula química no representa el olor de la sustancia sino la propia sustancia (...) pues de solicitarse la formula, lo que realmente se desea proteger es un producto específico compuesto por químicos y determinadas cantidades de componentes y no un olor determinado. Por su complejidad, se deduce que pocos serían capaces de descifrar un olor partiendo de la fórmula que representa el producto del cual emana.

(...) un producto es capaz de emitir olores diversos según su concentración, temperatura ambiental o soporte en el que se encuentre, lo que no permite que sea identificado siempre de la misma manera.

El objetivo de la marca es que el consumidor distinga su origen empresarial, esta finalidad puede cumplirse por cualquiera de los sentidos del ser humano: vista, oído, tacto, olfato y gusto. Sin embargo, debe tenerse en cuenta que aunque todo mensaje susceptible de aprehensión por cualquier sentido puede llegar a ser un signo apto para identificar ya sea bienes y servicios, la percepción no es la misma con todos los sentidos, pues cada uno de ellos identificará o percibirá el signo de acuerdo a la función que tenga. Igualmente tal percepción es relativa pues depende del receptor y de su sensibilidad. 
Un signo que en sí mismo no permite su percepción visual puede constituirse como marca, siempre que pueda ser objeto de representación gráfica, en particular por medio de figuras, líneas o caracteres, que sea clara, precisa, completa en sí misma, fácilmente accesible, inteligible, duradera y objetiva.

El requisito de la representación gráfica aplicado a los signos olfativos no se cumple mediante una formula química, una descripción con palabras, el depósito de una muestra del olor en cuestión ni una combinación de las anteriores posibilidades.

(...) aún de admitirse una muestra de olor que se pretende registrar se encuentran inconvenientes relativos a su claridad y precisión por factores tales como el paso del tiempo y la volatilidad de sus componentes.

No puede negarse sin embargo que en un momento dado un signo olfativo pueda ser susceptible de representación gráfica, ya que la tecnología ha venido desarrollando diversos sistemas para dibujar olores, pero en la actualidad estos avances presentan dificultades en la expresión visual del signo.

$\underline{\text { Las anteriores apreciaciones sobre marca olfativa se desarrollaron gracias a las }}$ conclusiones presentadas el 6 de noviembre de 2001 por el Abogado General, Dr. Dámaso Ruiz - Jarabe Colomer, en el asunto C-273/00 (Caso Sieckmann)

(...) el signo solicitado carece de representación gráfica, pues la descripción que adjunta el solicitante en el expediente para la producción de la fragancia es realmente la formula como se crea o fabrica el producto y debe tenerse en cuenta que el aroma que éste genera es parte del producto mismo.

(...) aunque en un momento dado sea susceptible de ser representado gráficamente el signo, este por sí mismo carece de la distintividad intrínseca que se espera de las marcas, pues el olor que se pueda percibir no vas más allá del común de los olores que puede llegar a producir cualquier producto cosmético o higiénico comprendido en la clase $3^{\circ}$ Internacional, por lo que no crea un concepto nuevo en el mercado que permita a los consumidores identificar su origen empresarial a partir de su fragancia, más aún si se tiene en cuenta que este tipo de productos usualmente están dotados de aromas. 
De lo expuesto, debe destacarse que la Superintendencia de Industria y Comercio en este caso utilizó los criterios recogidos en el caso Sieckmann (el que veremos más adelante) para denegar el registro del signo olfativo solicitado. Asimismo, puede observarse que acogió las teorías i) de que el aroma no puede ser el producto mismo (tal como lo veremos en el caso Chanel), y que ii) los denominados "primary scents marks " y "secondary scents marks" no pueden ser registrados como marcas.

Posteriormente, Laboratorios Cero S.A presentó recurso de reposición y/o apelación contra la antedicha resolución, y citando a Alejandro García Urdaneta, manifestó lo siguiente:

Aunque sea excusable la ignorancia o incapacidad del "fallador", no puede tornarse en 'prueba' o argumento para negar el registro de una marca olfativa o sonora. En estos eventos, el operario de registro de propiedad industrial o debe acceder a lo pedido de plano o debe apoyar su decisión en el concepto de experto o perito. Tal ignorancia o incapacidad no debe convertirse en un medio para enervar la aplicación de la ley. Una "alegre opinión" no es prueba (como se citó en Expediente 05 -47625 del SIC, 2007)

En ese sentido, tal como consta en el Expediente 05 -47625 del SIC (2007), la solicitante manifestó que habían cumplido con representar gráficamente el olor al presentar un cromatograma y la descripción olfativa (aunque no sea entendible por el común de los consumidores ni para los operarios administrativos), y requirió que si el despacho conocía de otra escritura para representar los olores, se la comunicaran para presentarla.

Asimismo, sobre la posición del despacho de que "(...) el olor que se puede percibir no va más allá del común de los olores que puede llegar a producir cualquier producto cosmético o higiénico comprendido en la Clase $3^{\mathrm{a}}$ Internacional (...)", la solicitante indicó que el despacho debía enunciar algunos productos comunes que necesaria o usualmente se identifiquen con el aroma que pretendía registrar. Adicionalmente, la solicitante manifestó que los productos de la clase 3 son con los que más se competiría en relación a los olores, por ser 
la clase donde se ubican los perfumes y cosméticos, siendo necesaria su protección.

Sobre los criterios del caso Sieckmann, la solicitante indicó que si bien los argumentos son respetables, no tienen la fuerza suficiente para derogar o neutralizar la voluntad del legislador; por lo que correspondía al despacho acatar dicha voluntad y no la del doctrinante Dr. Dámaso Ruiz - Jarabe Colomer.

Además, la solicitante señaló que “(...) no por ser un olor "supuesta y erradamente carente de representación gráfica", deja de tener el carácter esencial de una marca LA DISTINTIVIDAD (...)".

En este orden de ideas, tanto la División de Signos Distintivos (mediante resolución $\mathrm{N}^{\circ} 26779$ del 28 de agosto de 2007) como el Superintendente Delegado de la Propiedad Industrial (por resolución $N^{\circ} 17152$ del 4 abril 2009) confirmaron la decisión contenida en la resolución $\mathrm{N}^{\circ} 11956$ de 30 de abril de 2007.

\subsubsection{Ecuador}

Este país por ser también miembro de la Comunidad Andina se rige por la Desición 486 - Regimen Comun sobre Propiedad Industrial.

En diciembre de 2016 se aprobó el Código Orgánico de la Economía Social de los Conocimientos, conocido por el Código Ingenios, el cual regula, entre otros, a la Propiedad Intelectual. Sobre el derecho marcario, a comparación de la Decisión 486 (en la cual solo puede inferirse una definición), define a la marca como cualquier signo que sea apto para distinguir productos o servicios en el mercado. Asimismo, también señala que sólo podrán registrase como marcas los signos que sean susceptibles de representación gráfica.

En efecto, el artículo 359 de la norma comentada señala que:

\section{(...)}

Podrán constituir marcas, entre otros, los siguientes signos o medios: 
1. Las palabras o combinación de palabras;

2. Las imágenes, figuras, símbolos, gráficos, logotipos, monogramas, retratos, etiquetas, emblemas y escudos;

3. Los sonidos, olores y sabores;

4. Las letras y los números;

5. Un color delimitado por una forma o una combinación de colores;

6. La forma de los productos, sus envases o envolturas;

7. Los relieves y texturas perceptibles por el sentido del tacto;

8. Las animaciones, gestos y secuencias de movimientos;

9. Los hologramas; y,

10. Cualquier combinación de los signos o medios indicados en los apartados anteriores (Código Orgánico de la Economía Social de los Conocimientos, 2016) (los subrayados son míos).

De la lectura de este artículo se muestra que a diferencia de la Decisión 486, se establece que tanto los sabores como los signos táctiles, entre otros, podrán registrarse como marcas.

a) Casos Prácticos

- Marca Táctiles

- En relación al caso de registro de la marca táctil para la botella de whisky de Old Parr en Colombia (analizado en el apartado anterior), es necesario indicar que la empresa Diageo Brands B.V solicitó el registro de la misma previamente en el Instituto Ecuatoriano de Propiedad Intelectual (IEPI), para distinguir productos de la clase 33 (bebidas alcohólicas excepto cervezas).

La derogada Ley de Propiedad Intelectual de Ecuador también exigía como requisitos para el registro de marcas que el signo sea distintivo y que cumpla con ser susceptible de representación gráfica, sin indicar cómo éstos se satisfarían en el caso de los signos no visibles. Sin embargo, en el presente caso, el IEPI determinó que mediante una impresión en relieve, a través de un proceso de doble impresión, se cumplía con representar graficamente el signo táctil. 
En efecto, con este medio pudo cumplirse con el requisito de la representación gráfica y, de manera idónea, con la publicación de la marca táctil. En ese sentido, esta impresión en relieve de vidrio craqueado fue publicada en el Diario Oficial Ecuatoriano.

Sobre el requisito de la distintividad, la Autoridad Nacional Competente no dudó en que este signo táctil cumplía cabalmente con ser apto para distinguir estos productos en el mercado.

\subsubsection{Estados Unidos de América}

El sistema marcario de los Estados Unidos de América es diferente al establecido en la Decisión 486 por diferentes razones; en primer lugar, el registro no es constitutivo de derechos; es decir, la protección de la marca no nace con el registro del signo, sino que el requisito fundamental para otorgarle protección a una marca es con su uso en el comercio. En segundo lugar, si bien no es necesario registrar una marca para que nazca su protección, la Oficina de Patentes y Marcas de los Estados Unidos - USPTO (por sus siglas en ingles)- sí mantiene categorias de registros. Se cuenta con un Registro Federal, que protege a las marcas a escala nacional, y un Registro Estatal, que protege a las marcas al interior de cada estado. Asimismo, se cuenta con un Registro Principal y un Registro Suplementario; en el primero se registran los signos que cuentan con todos los requisitos para constituirse como marcas, y en el segundo, se registran los signos que teniendo la capacidad de cumplir con todos los requisitos, aún, por diversas circunstancias, no han logrado cumplir totalmente con alguno. En este último registro, se incluyen los signos que tienen la capacidad de ser distintivos, pero aún no lo logran completamente. En este sentido, el registro de un signo en el Registro Suplementario no otorga los mismos derechos que los inscritos en el Registro Principal ( siendo estos más amplios). La protección que otorga el Registro Suplementario son derechos limitados y, recien cuando el signo haya cumplido con todos los requisitos podrá registrarse en el Registro Principal. 
Sobre las marcas no tradicionales no visibles, debe recalcarse que es en este país en donde se ha tenido más éxito en el desarrollo y registro de estas marcas, debido a que se han desarrollado conceptos como el trade dress ${ }^{25}$, la distintividad sobrevenida y la teoría de la funcionalidad; asimismo, la definición de marca establecida en el Capitulo 15 Sección 1127 (Lanham Act) del Código de los Estados Unidos se ha redactado de manera amplia, tal como se muestra a continuación:

El termino marca incluye cualquier palabra, nombre, símbolo, dispositivo, así como cualquier combinación de estos utilizado por una persona que tiene la intención bona fide de utilizar en el comercio y aplica para registrarlo en el registro principal establecido en este capítulo, para identificar y distinguir sus bienes, incluyendo un producto único, de aquellos producidos o vendidos por otros, y para indicar el origen de estos bienes, incluso si es desconocido (como se citó en Lizano y Pal, 2013, p.49-50) (el subrayado es mío).

De la lectura de esta definición puede apreciarse que cualquier signo puede constituirse como marca siempre que 1) la persona tenga la intención de usarla en el comercio e, 2) identifique y distinga sus bienes, de aquellos producidos o vendidos por otros.

Sobre esta definición, la Comisión de Revisión de la Asociación de Marcas de los Estados Unidos en 1987, “determinó que los términos 'símbolo, o dispositivo no debían ser borrados o restringuidos para impedir el registro de signos como un color, forma, olor, sonido o configuración que funciona como marca" (como se citó en Lizano y Pal, 2013 p.92). Por su parte, Catherine Saez, citando a Sharon Marsh (Ex Comisionada Adjunta para la politica de análisis de marcas de la Oficina de Patentes y Marcas de los Estados Unidos) nos comenta que "El derecho de marcas de EE.UU. es lo suficientemente flexible para satisfacer la mayoría de las marcas no tradicionales, y no se necesitaría ningún cambio de política para abordar un aumento de registro de marcas no tradicionales, sostuvo" (como se citó en Saez, 2018, párr. 6). Asimismo, la Corte Suprema de Justicia (1995) en el caso Qualitex indicó, citando a Landes y a Posner, que "es la habilidad de la marca de distinguir el origen- y no su estatus

${ }^{25}$ Debe destacarse que en la legislación norteamericana marcaria se protege lo que se conoce como "trade dress" y que se refiere a "la imagen total de un producto la cual puede incluir elementos como el tamaño, la forma, el color o la combinación de colores, textura, gráficos o incluso técnicas de venta." 
ontológico como color, forma, fragancia, palabras o signo- lo que permite que cumpla con esos propósitos básicos" (como se citó en Lizano y Pal, 2013, p.93).

Por otro lado, puede verse que el requisito de la distintividad también es fundamental en el Sistema Marcario Estadounidense. Sin embargo, es importante destacar que se ha considerado mayormente que las marcas no tradicionales no visibles no cuentan con distintividad inherente, siendo necesario probar distintividad adquirida mediante su constante uso en el mercado. Por este motivo, los signos no visibles son comúnmente registrados, en principio, en el Registro Suplementario, hasta que el signo no visible adquiera significado secundario y pueda inscribirse en el Registro Principal.

Respecto al registro de las marcas no tradicionales no visibles, el argumento principal por el que se han denegado son por sus caracteristicas funcionales, no siendo posible registrar esta clase de signos ni en el Registro Principal ni el Registro Suplementario, incluso cuando hayan adquirido distintividad sobrevenida.

Sobre el particular, según Lizano y Pal (2013) la Corte Suprema de los Estados Unidos estableció en el caso Qualitex, que un signo es funcional si es inherente para el producto o servicio que busca distinguir, y pusiera a los competidores en una desventaja competitiva no ligada a la reputación del bien al cual se aplica el signo (p.93)

Respecto al requisito de la representación gráfica, usualmente bastaba con presentar un dibujo de la marca para que las Autoridades Competentes pudieran evaluar su registrabilidad y reproducirla en el Diario Oficial. Con el surgimiento de las marcas no tradicionales no visibles, han tratado de acoplar la exigencia de este requisito a la naturaleza de estos nuevos tipos de marcas.

En relación a la descripción como medio de representación gráfica del signo, la doctrina en contra ha manifestado que no permitiría establecer de manera objetiva e individualizada lo que se desea registrar como marca; indicando además que no existiría ninguna normativa que especifique las características que debería cumplir una descripción para representar gráficamente a las marcas. 
Por otro lado, se ha considerado que el presentar el especimen del signo no visible en la solicitud de registro ayudaría a representar de manera objetiva el signo, solo pudiendo estar disponibles en las oficinas de la USPTO, y no pudiendo ser publicadas en el Diario Oficial.

a) Casos prácticos

- Marcas Gustativas

El registro de marcas gustativas usualmente no han sido aceptadas en los Estados Unidos de América. En la mayoria de casos se ha considerado que el sabor no posee distintividad inherente, teniendo que probarse distintividad sobrevenida para que pueda ser registrado como marca. Asimismo, se ha argumentado que el sabor en los productos (en especial, los farmacéuticos) representan una caracteristica funcional, con la finalidad de hacer más agradable su sabor, siendo perjudicial para la competencia el registro de estos signos.

Sobre el requisito de la representación gráfica, la USPTO solo ha requerido la descripción de la marca para poder registrar el sabor.

- Mediante Solicitud No 76467774 N.V. Organon solicitó registrar el sabor a naranja para distinguir productos farmacéuticos. La USPTO denegó esta solicitud, argumentando que el sabor a naranja es funcional, ya que hacia que los productos resultaran más agradables, otorgándole una ventaja competitiva al fármaco.

- Marcas Táctiles

Para el año 2013, Estados Unidos de América era el país con mayor número de marcas táctiles registradas en el mundo. Sin embargo, también han habido gran cantidad de denegaciones de solicitudes, siendo los principales fundamentos de rechazo: 1)la falta de distintividad, 2)la funcionalidad de los signos y que, 3) estos signos no serían percibidos como marcas, sino como meros elementos decorativos por parte de los consumidores. 
Sobre la distintividad de estas marcas, mayormente se ha dicho que no poseen distintividad inherente, y que solo pueden adquirir distintividad mediante su uso constante en el comercio. Asimismo, se ha establecido que lo que debe ser distintivo es la sensación del tacto que se percibe al momento de tocar el producto, y no su inspección visual. También se ha manifestado que el tacto es percibido de manera muy subjetiva por parte de los consumidores, siendo complicado determinar su aptitud distintiva.

Sin perjuicio de lo expuesto, es interesante señalar que para Arturo Ishbak González (2016) "Si las sensaciones son suficientemente distintivas, las marcas táctiles pueden ser registradas como marcas. Por lo tanto, las marcas táctiles pueden ser inherentemente distintivas". En efecto, para este autor las marcas táctiles sí pueden poseer distintividad inherente.

Respecto al requisito de la representación gráfica, la USPTO ha requerido la descripción del tacto más una fotografía del producto. Sin embargo, en un caso determinó que estos medios no eran suficientes, siendo necesario presentar la muestra física del producto en la que se pudiera percibir el signo.

- En el año 2004 la USPTO (2004) denegó el registro de tres marcas táctiles, i) la textura de cristales para botellas (solicitud $\mathrm{n}^{\circ}$ 76609609), ii) la textura de cristales para corbatas (solicitud $\mathrm{n}^{\circ}$ 78439597) y; iii) la textura de reproducciones de obras de arte igualmente para botellas (solicitud $\mathrm{n}^{\circ}$ 78402600), bajo el argumento de que el consumidor no las percibiría como marcas sino como metodos de decoración. Asimismo, sobre el requisito de la representación gráfica, se estableció que se debía describir el sentido cuyo registro se solicita, mostrar su publicidad, una fotografía de los bienes, y describir su naturaleza, finalidad y canales de comercialización.

- La UPSTO (2004) denegó el registro de la marca táctil "la textura rasguñada o

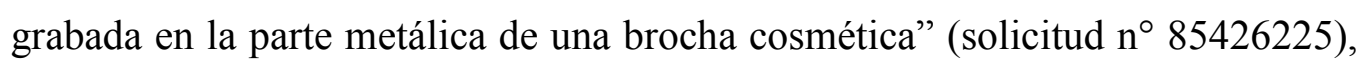
argumentando que el signo no era inherentemente distintivo, y que no parecería 
que el signo sea percibido como marca por los consumidores. Adicionalmente, sobre el requisito de la representación gráfica, estableció que la descripción no era lo suficientemente especifica sobre la naturaleza del tacto sensorial.

- Dos marcas que fueron registradas con éxito en la USPTO (2005) fueron los signos consistentes en "una cubierta de terciopelo en la superficie de una botella de vino" (Registro $N^{\circ}$ 3155702) y "una envoltura de textura de cuero alrededor de la superficie media de una botella de vino" (Registro N 3896100, 2010). La UPSTO dio la razón al solicitante cuando señalaba que era la sensación del tacto lo que debia ser distintivo y no su inspección visual, ni el examen mental semántico sobre el significado y la fabricación de la cubierta de la botella. Sobre el requisito de representación gráfica, el solicitante presentó un diagrama con un dibujo de la botella de vino y lineas punteadas destinadas a mostrar la ubicación de la marca en la superficie del producto. La UPSTO consideró que este diagrama no era suficiente, y solicitó que se presente una muestra física de la botella de vino para que el examinador pudiera sentir la textura.

Sobre la funcionalidad, en cuanto a la cubierta de terciopelo en la superficie de la botella de vino, la USPTO señaló que no era funcional respecto a lo que contenía en el interior, pues la integridad del líquido era lo mismo con o sin esa textura.

- Marcas sonoras

Sobre el requisito de la representación gráfica de las marcas sonoras, Gonzalo Ferrero (2009) nos explica que el surgimiento de este tipo de marcas se dio al principio de los 90. En esta década ya se hablaba de dos tipos de ordenamientos legales: i) el sistema de representación descriptivo y, ii) el sistema de representación gráfica. El sistema de representación descriptivo fue adoptado por los Estados Unidos, debido a que el signo que distinguia el bien era un audio, y se necesitaba la reproducción para determinar su distintividad y no un medio visual (p.329-330).

Esta explicación coincide con la manifestada por Baldo Kresalja Rosello (2001) cuando indica que la USPTO, para el registro de sonidos no musicales, solicita las 
grabaciones del ruido del signo que se pretende registrar, acompañada de una descripción escrita del mismo.

Por otro lado, sobre la distintividad de este tipo de marcas, Arturo Ishbak González (2016) señala que:

Las marcas sonoras suficientemente distintivas pueden ser registradas en el Registro Principal sin necesidad de demostrar haber adquirido distintividad, pero los sonidos que imiten o parezcan sonidos comunes o aquellos a los cuales los consumidores han sido expuestos en diferentes circunstancias, deben, con el propósito de ser registrados, estar acompañados de pruebas que demuestren que los compradores o futuros compradores reconocen el sonido y lo asocian con un solo origen.

En ese sentido, puede apreciarse que para este autor los signos sonoros sí pueden poseer distintividad inherente, salvo que imiten o parezcan sonidos comunes, debiendo los solicitantes, en estos casos, presentar las pruebas sobre su distintividad sobrevenida.

- En el año 2009, la empresa Lucafilms registró el sonido de la respiración de Darth Vader. En la solicitud se describió la marca como "ritmica respiración humana mecánica creada por la respiración a través de un regulador de tanque buceo" para distinguir juguetes, disfraces, merchandaising.

- En la USPTO tenemos el Registro N 73553567 del Rugido de un León de MGM para distinguir servicios de entretenimiento; el Registro $\mathrm{N}^{\circ} 76880750 \mathrm{del}$ "Doh" de Homero Simpson para entretenimiento; el Registro N 75332744 del tono de Intel para distinguir hardware de computadores, sistemas operativos, entre otros, y el Registro $N^{\circ} 74629287$ la fanfarria de Twentieth Century Fox para entretenimiento, entre otros.

- Marcas Olfativas

- La compañía Morrocan Oil solicitó el registro de la marca olfativa descrita como "una mezcla de almizcle, vainilla, rosa y lavanda" para distinguir productos para el cabello, siendo admitida, por considerarse que era altamente distintiva. 
En un principio la USPTO había denegado la marca olfativa solicitada por considerar que el aroma tenía un propósito utilitario, señalando que para los productos para el cabello el aroma siempre contribuye a una mejor calidad por la experiencia sensorial, y que los ingredientes para utilizar la fragancia tenía beneficios, como por ejemplo, el agua de rosas, que contiene un alto contenido de nutrientes. En ese sentido, la USPTO indicó que la funcionalidad afectaba el costo o la cualidad del producto.

Cabe resaltar que en este caso se hizo hincapié de la necesidad de analizar la fragancia como un todo y no analizar individualmente los elementos de está como criterio para determinar la funcionalidad.

Asimismo, se clasificó a la funcionalidad de dos maneras: 1) la funcionalidad de facto, y 2) la funcionalidad de iure. La primera podía registrarse y la segunda no. Tal como explican Ariana Lizano y Añusca Pal (2013):

La funcionalidad de facto por otro lado es registrable ya que es una característica de todas las marcas olfativas debido a que contribuyen a la experiencia sensorial asociada con el producto (Clarke, 2010, Solicitud número $77755814)$

Tal y como se evidencia en este caso, resulta difícil para la Oficina de Marcas y Patentes de los Estados Unidos determinar qué tan funcional debe ser una marca para considerar que es irregistrable, y más aún para el caso de las marcas olfativas, en donde está claro que la fragancia debe cumplir con un cierto grado de funcionalidad para poder identificar el origen de sus productos, así como para diferenciarlos de otros por medio del sentido del olfato (p.102).

- Se solicitó registrar ante la USPTO la marca "olor a cereza" para distinguir lubricantes sintéticos de alto rendimiento para vehículos recreativos y de carreras. Esta marca fue registrada en el Registro Principal al haberse demostrado que había adquirido distintividad sobrevenida, probando el solicitante que la marca había estado posicionada por al menos siete (7) años en 
el mercado, y que los consumidores habían llegado a identificar el antedicho olor con su producto.

- Se solicitó registrar ante la USPTO la marca olfativa descrita como "la fragancia fresca y frutal evocador a naranja" para distinguir pintura, barniz y removedor de pintura. La solicitud fue denegada por considerarse que el olor a naranja es funcional para proteger limpiadores que contienen ácido cítrico como un ingrediente activo, además del olor describir los ingredientes presentes en el producto.

- Caso In re Clarke: En 1990, Celia Clarke solicitó el registro de una marca olfativa para distinguir hilos y fibras para bordados. El aroma fue descrito como "una fragancia de alto impacto, fresca, floral, con reminiscencias de flores de plumería”.

En principio, la USPTO denegó el registro de la marca olfativa solicitada por considerar que el aroma era una característica ornamental del producto, por lo que carecía de fuerza distintiva, y habría funcionalidad en la fragancia respecto al producto; sin embargo, esta entidad, mediante resolución de la Trademark Trial and Appeal Board (TTAB) que conoció el recurso de apelación de la decisión que denegaba el registro de la marca solicitada, resolvió registrar la marca olfativa en el Registro Principal, toda vez que la solicitante había demostrado que el signo olfativo funcionaba como marca para distinguir sus hilos y fibras para bordados, además de ser la única fabricante de esos productos perfumados. Adicionalmente, se consideró que el aroma no era un atributo inherente o característica natural de los productos, sino que era un elemento aportado por ella, y que la solicitante había resaltado esta característica en su publicidad, demostrando que los consumidores, comerciantes y distribuidores habían llegado a reconocerla.

Sobre este caso, Isabel Ramos (2014) nos explica en su pie de página $\mathrm{N}^{\circ} 47$, que son pocas las marcas olfativas registradas en el Registro Principal y que a esa fecha, había más de diez (10) marcas olfativas registradas en el Registro Suplementario (p.176) 
Asimismo, esta misma autora, en su pie de página $\mathrm{N}^{\circ} 50$, citando a Hammersley, F. M, señala que "en este caso estaríamos ante los llamados unique scent marks (...), es decir, la marca identifica productos que normalmente no se caracterizan por el olor o por un olor específico que los consumidores normalmente asocian con el producto" (Ramos, 2014, p.177)

Cabe acotar que este fue el primer caso en el que se admitió el registro de una marca olfativa en los Estados Unidos de América.

\subsubsection{Unión Europea}

La legislación marcaria en la Unión Europea ha tenido recientes cambios. El 24 de diciembre de 2015 fue publicado el Reglamento (UE) $N^{\circ}$ 2015/2424 del Parlamento Europeo y del Consejo, en el que se establecieron modificaciones al Reglamento (CE) $\mathrm{N}^{\circ} 207 / 2009$ del Consejo sobre la marca comunitaria.

Sobre el tema que nos compete, es relevante señalar lo que se indica en el numeral 9 de las consideraciones del antedicho Reglamento (UE) $N^{\circ}$ 2015/2424 (2015), tal como se muestra a continuación:

(9) A fin de permitir una mayor flexibilidad y garantizar al mismo tiempo una mayor seguridad jurídica en cuanto a los medios de representación de marcas, el requisito de representación gráfica debe suprimirse de la definición de marca de la Unión. Se debe permitir que un signo se represente de cualquier forma que se considere adecuada usando la tecnología generalmente disponible, y no necesariamente por medios gráficos, siempre que la representación sea clara, precisa, autosuficiente, fácilmente accesible, inteligible, duradera y objetiva (El subrayado es mío).

De la lectura de lo expuesto, puede apreciarse que en este nuevo reglamento se ha eliminado de la definición de marca el requisito de la representación gráfica. Asimismo, se ha indicado que la representación no debe ser necesariamente gráfica para que se pueda registrar una marca, debiendo cumplir con ser clara, precisa, autosuficiente, facilmente accesible, inteligible, duradera y objetiva. 
El siguiente cuadro muestra las diferencias entre las definiciones de marca establecidas en el Reglamento (UE) N²015/2424 (Reglamento de Modificación) y el Reglamento (CE) N 207/2009:

\begin{tabular}{|c|c|}
\hline JE) $N^{\circ} 2015 / 2424$ & Reglar \\
\hline $\begin{array}{l}\text { Art.4.- Signos que pueden constituir una } \\
\text { marca de la Unión } \\
\text { Podrán constituir marcas de la Unión } \\
\text { cualesquiera signos, en particular, las } \\
\text { palabras, incluidos los nombres de personas, } \\
\text { los dibujos, las letras), las cifras, los colores, } \\
\text { la forma del producto o de su embalaje, o los } \\
\text { sonidos, con la condición de que tales signos } \\
\text { sean apropiados para: } \\
\text { a) Distinguir productos o los servicios } \\
\text { de una empresa de los de otras empresas, } \\
\text { b) Ser representados en el Registro de } \\
\text { Marcas de la Unión Europea (el "Registro") } \\
\text { de manera que permita a las autoridades } \\
\text { competentes y al público en general } \\
\text { determinar el objeto claro y preciso de la } \\
\text { protección otorgada a su titular. (Los } \\
\text { subrayados son mios) }\end{array}$ & $\begin{array}{l}\text { Art.4.- Signos que pueden constituir una } \\
\text { marca de la Unión } \\
\text { Podrán constituir marcas de la Unión todos } \\
\text { los signos que puedan ser objeto de una } \\
\text { representación gráfica y, en particular, las } \\
\text { palabras, incluidos los nombres de personas, } \\
\text { los dibujos, las letras, las cifras, la forma del } \\
\text { producto o de su presentación, con la } \\
\text { condición de que tales signos sean apropiados } \\
\text { para distinguir los productos o los servicios de } \\
\text { una empresa de los de otras empresas. (El } \\
\text { subrayado es mío) }\end{array}$ \\
\hline
\end{tabular}

En ese sentido, puede visualizarse que el nuevo reglamento ya no exige (ni incorpora dentro de la definición de marca) que el signo deba ser representado gráficamente, bastando con que la representación que se utilice permita a las autoridades y al público general determinar el signo que se va a proteger de manera clara y precisa.

Asimismo, puede apreciarse que en ambos reglamentos se establecen enunciativamente los signos que pueden constituir marcas; es decir, ambas normas establecen el término 'en particular' al momento de indicar los signos. En ese sentido, 
es de apreciarse que en la nueva norma se señala expresamente que los signos sonoros pueden constituirse como marcas, dejando con el término 'en particular' la posibilidad de que otros signos (no indicados expresamente) puedan constituirse como tal. En este orden de ideas, si bien este artículo no menciona expresamente que los signos gustativos, táctiles y olfativos pueden constituirse como marcas, tampoco lo prohibe, dejando abierta esta posibilidad. Lo que sí es un hecho es que un signo no visible, como el sonido, sí puede ser una marca dentro de la Unión Europea. En el antiguo reglamento, en cambio, no se hacía referencia a la posibilidad de que algún signo no visible pueda registrarse como marca.

Es menester precisar que muchos de los artículos del nuevo reglamento entraron en vigencia el 23 de marzo de 2016; sin embargo, sobre el artículo 4 de la definición que nos compete, y los artículos relacionados con la supresión del requisito de la representación gráfica, entraron recién en vigencia el 01 de octubre de 2017.

En este orden de ideas, a raíz de la entrada en vigencia de las antedichas disposiciones del nuevo reglamento, el 01 de octubre de 2017 también entró en vigencia el Reglamento de Ejecución (UE) 2017/1431 (2017), cuyo artículo 3 señala expresamente lo siguiente:

Artículo 3

Representación de la marca

1. La marca deberá estar representada en cualquier forma que se considere adecuada usando la tecnología generalmente disponible, siempre que pueda reproducirse en el registro de manera clara, precisa, completa en sí misma, fácilmente accesible, inteligible, duradera y objetiva, de un modo que permita a las autoridades competentes y al público en general determinar con claridad y exactitud el objeto preciso de la protección otorgada a su titular.

2. La representación de la marca definirá el objeto de registro. En los casos en que la representación vaya acompañada de una descripción con arreglo al apartado 3, letras d), e), f), inciso ii), y h), o al apartado 4, la descripción deberá concordar con la representación y no extender su ámbito de protección. 
3. Cuando la solicitud se refiera a cualquiera de los tipos de marcas enumerados en las letras a) a j), deberá contener una indicación al respecto. Sin perjuicio de lo dispuesto en los apartados 1 o 2, el tipo de la marca y su representación coincidirán entre sí, como sigue:

$(\ldots)$

g) en el caso de una marca constituida exclusivamente por un sonido o combinación de $\underline{\text { sonidos (marca sonora), la marca estará representada por la presentación de un archivo }}$ de audio que reproduzca el sonido o por una representación exacta del sonido en notación musical;

(...)

4. Cuando la marca no esté cubierta por ninguno de los tipos enumerados en el apartado $3^{26}$, su representación cumplirá las normas establecidas en el apartado 1 y podrá ir acompañada de una descripción.

$(\ldots)$

9. La presentación de una muestra o un modelo no constituirá una representación adecuada de la marca. (Los subrayados son míos).

Como puede apreciarse, en este artículo no se hace referencia a las representaciones de las marcas gustativas, táctiles y olfativas que deberán presentarse en las solicitudes para que accedan a registro, sólo hacen referencia a la representación de las marcas sonoras. Sin embargo, en cuanto a las marcas gustativas, táctiles y olfativas, este artículo da la posibilidad de poder presentar, en virtud al apartado 4, una descripción, que deberá concordar con la representación aportada de estas marcas, cabiendo preguntarse a qué medios de representación se referirá la norma para el registro de estos tipos de marcas.

\footnotetext{
${ }^{26}$ El apartado 3 del artículo 3 del Reglamento de Ejecución (UE) 2017/1431 no hace referencia a las marcas olfativas, gustativas ni táctiles.
} 
Por esta razon es que nos referiremos al tratamiento que se le han dado a las marcas no tradicionales no visibles en el marco del antiguo reglamento, y mostraremos como se dará en base al nuevo reglamento. Para esto, nos referiremos a la Decisión $\mathrm{N}^{\circ}$ EX16-7 sobre la aprobación de las Directrices relativas al examen de las marcas de la Unión Europea y los dibujos y modelos comunitarios registrados ante la Oficina de Propiedad Intelectual de la Unión Europea (EUIPO), que entró en vigor el 01 de febrero de 2017, y a la Decisión N EX17-1 sobre la aprobación de las Directrices relativas al examen de las marcas de la Unión Europea y los dibujos y modelos comunitarios registrados en la Oficina de Propiedad Intelectual de la Unión Europea, que entró en vigencia el 01 de octubre de 2017, en virtud a la entrada en vigor de las disposiciones sobre la supresión del requisito de la representación gráfica, entre otros, del nuevo reglamento. Debe precisarse que estas directrices intentan reflejar las practicas de la EUIPO en las situaciones más recientes.

\section{Marcas gustativas}

Tanto la Decisión $N^{\circ}$ EX16-7 como la Decisión $N^{\circ}$ EX17-1 asimilan el tratamiento de las marcas gustativas a las marcas olfativas, recalcando que no admiten su registro por no cumplir con el requisito de ser susceptibles de representación (debiendo ser gráfica en virtud a la primera Decisión), por no existir aún la tecnología adecuada.

En ese sentido, tanto para el antiguo y nuevo reglamento, las marcas gustativas no pueden registrarse como marcas comunitarias.

\section{Marcas sonoras}

Sobre las marcas sonoras, en el numeral 10.4 de la Decisión EX16-7 (2017) se indicó que: i) debían cumplir con representarse de forma gráfica, utilizando, particularmente, la notación musical, como el pentagrama (señalando que las notas musicales sin otra precisión, como por ejemplo, "mi, re sostenido, mi re sostenido, mi, si, re, do, la" no podían satisfacer el requisito de la representación gráfica, por no ser claras, ni precisas, ni completas en sí mismas); ii) la descripción de sonidos no era suficiente; iii) era aceptable la letra de una canción con notas musicales y el ritmo; iv) no era aceptable una sonografía si no iba acompañada de un archivo electrónico que incluyera el sonido; 
v) cuando consistiera en un signo sonoro no musical, el único medio de representación gráfica sería la sonografía junto con el archivo sonoro.

Adicionalmente a lo expuesto, es interesante señalar lo que se establecía en el numeral 10.4.1 de la antedicha Decisión sobre el archivo de sonido electrónico:

Es opcional adjuntar un archivo de sonido MP3 cuando se haya presentado una notación musical, aunque únicamente en caso de que la presentación sea electrónica (efiling). La Oficina no aceptará la presentación de un archivo de sonido electrónico por

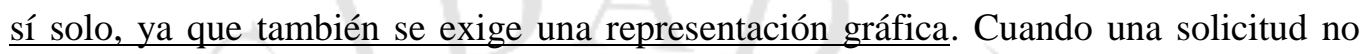
incluya una representación gráfica de la marca, se planteará una irregularidad en la fecha de presentación (los subrayados son mios). (Decisión № EX16-7, 2017, p.24 p.25)

Con lo expuesto puede apreciarse que la notación musical, por ser gráfica, prevalecía al archivo de sonido, siendo en casos opcionales, o siendo solamente considerado como un complemento, no bastando la presentación del sonido por sí solo para poder registrarlo como marca. Esto mismo también puede corroborarse cuando en el numeral 10.4.2 de la misma Decisión, sobre notas musicales, se expresaba que: "El solicitante podrá presentar una sola nota musical, lo cual cumplirá el requisito de representación gráfica de la marca. En dichos casos, podrá adjuntarse un archivo de sonido electrónico, aunque no es obligatorio" (Decisión $N^{\circ}$ EX16-7, 2017, p.25) (el subrayado es mío).

Sobre la sonografía, se establecía que este por sí solo no satisfacía el requisito de la representación gráfica pues ni la EUIPO ni los terceros interesados podrían saber el sonido exacto que este gráfico representa, debiendo necesariamente adjuntarse, junto al sonograma, el archivo sonoro.

Asimismo, sobre la onomatopeya, esta Decisión señalaba que existe un desfase en como se pronuncia el signo y los sonidos reales que se pretendían imitar fonéticamente.

Por otro lado, sobre el requisito de la representación gráfica, esta Decisión establecía que su función principal era determinar el objeto de protección. Por este 
motivo, el signo debía poder percibirse siempre de manera inequívoca y coherente (requisito de objetividad). Asimismo, se estableció que para que un signo cumpla este requisito, la representación gráfica debía consistir "en particular por medio de figuras, lineas o caracteres”, y su representación debía ser "clara, precisa, completa en sí misma, facilmente accesible, inteligible, duradera y objetiva (según el caso Sieckmann, el cual analizaremos más adelante)

Sobre el particular, esta Decisión nos da ejemplos de representaciones gráficas presentadas, y que han sido aceptadas:

\begin{tabular}{|c|c|}
\hline \multicolumn{2}{|c|}{ Ejemplos de marcas sonoras aceptables (a efectos de las formalidades) } \\
\hline MUE 8116337 & \\
Sonografía acompañada de un archivo de sonido & \\
Sonografia acompañada de un archivo de sonido & \\
\hline MUE 1637859 & 134 \\
Notación musical & \\
\hline
\end{tabular}

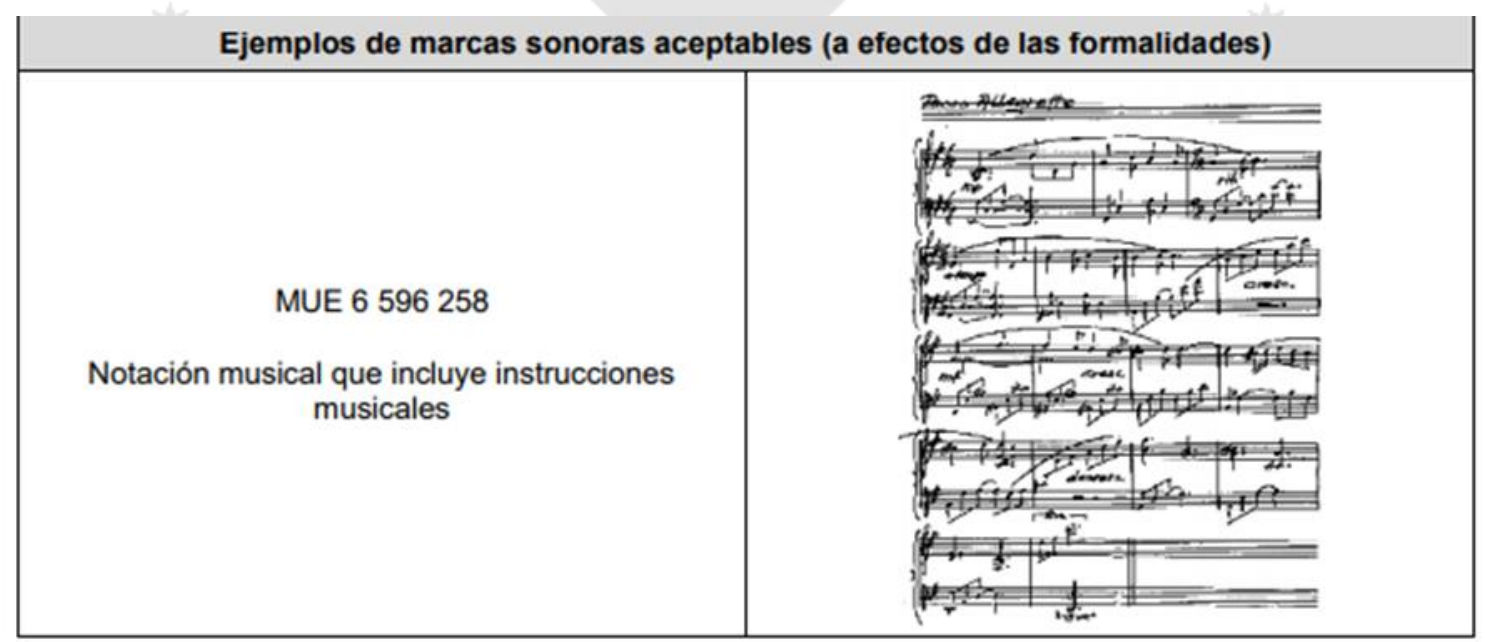

(Fuente: Decisión N EX16-7, 2017, p.25 - p.26) 
Ejemplos de representaciones gráficas aceptables:

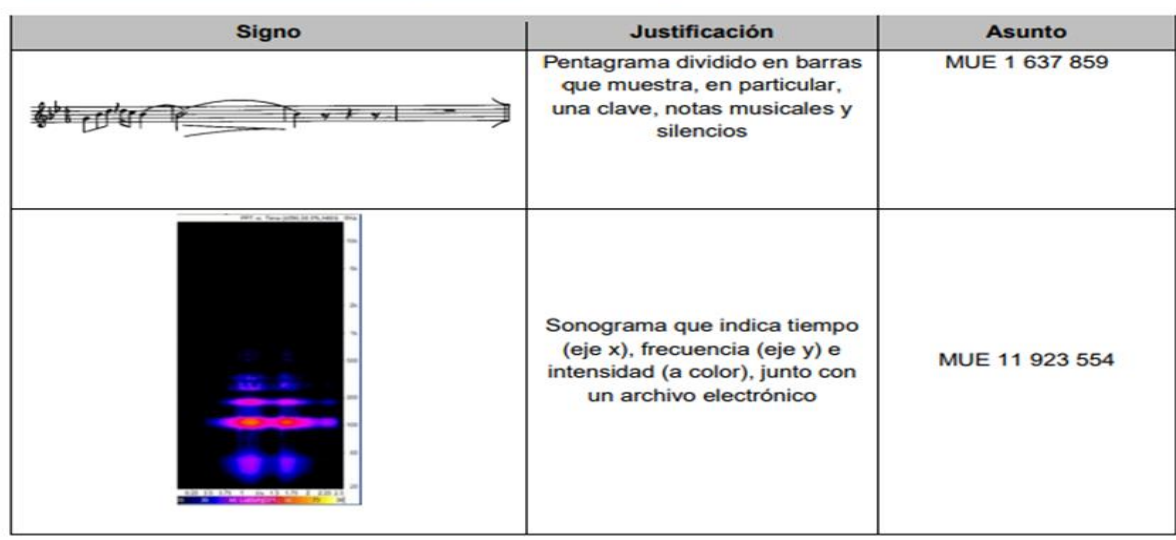

(Fuente: Decisión N EX16-7, 2017, p.7)

En la vigente Decisión $N^{\circ}$ EX17-1 (2017), en cambio, en el numeral 9.7 se establece expresamente que "Una marca sonora ${ }^{27}$ debe estar representada por la presentación de un archivo de audio que reproduzca el sonido o por una representación exacta del sonido en notación musical" (el subrayado es mío); es decir, y tal como puede apreciarse en el articulo 3, apartado 3, letra g) del Reglamento de Ejecución (UE) 2017/1431 expuesto lineas arriba, ahora el archivo de sonido puede presentarse por sí solo como medio de representación de la marca sonora, ya que esta ya no necesita ser gráfica.

Asimismo, en esta Decisión (2017) se establece que:

(...) Por «notación musical exacta» se entiende que la representación debe incluir todos los elementos necesarios para interpretar la melodía, es decir, tono, tiempo, letra (en su caso), etc.

Si el solicitante presenta tanto un archivo de audio como notaciones musicales, se le pedirá que elija cuál de los dos desea mantener. Si el solicitante presenta un archivo de audio y la representación de una sonografía, la Oficina eliminará la sonografía del expediente.

\footnotetext{
${ }^{27}$ Vale acotar que de acuerdo a la Decisión $N^{\circ}$ EX17-1 (y de lo que se puede apreciar del artículo 3 del Reglamento de Ejecución (UE) 2017/1431):

Una marca sonora se define como una marca constituida exclusivamente por un sonido o combinación de sonidos. Por tanto, las marcas que combinan sonidos con un movimiento, por ejemplo, no pueden considerarse marcas sonoras per se y deberán ser objeto de una solicitud de marca multimedia (véase el punto 9.13 infra).
} 
Desde el 1 de octubre de 2017, la Oficina no acepta descripciones de marca en relación con marcas sonoras ya que la representación de la marca define por sí sola el objeto del registro (Decisión $\mathrm{N}^{\circ}$ EX17-1, 2017, p.31) (Los subrayados son míos).

En ese sentido, esta Decisión vigente nos muestra un ejemplo de lo que sería una representación admisible de marcas sonoras en virtud al Nuevo Reglamento:

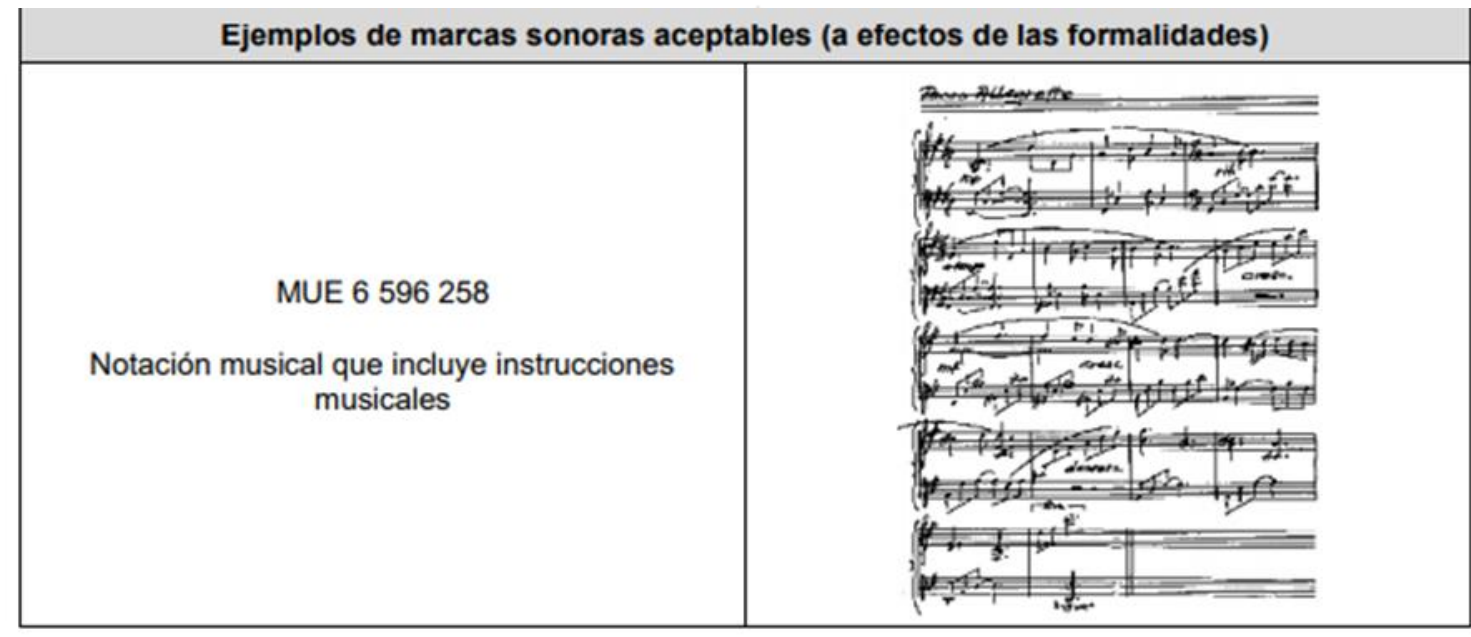

(Fuente: Decisión NºX17-1, 2017, p.32)

Por otro lado, en esta vigente Decisión, sobre la distintividad del signo sonoro para que pueda ser constituido como marca, se estableció lo siguiente:

La aceptabilidad de una marca sonora, tal como ocurre con las palabras u otros tipos de marcas, depende de si el sonido posee un carácter distintivo por sí solo, es decir, de si el consumidor medio percibiría el sonido como un sonido memorable asociado a los productos o servicios que ofrece exclusivamente una determinada empresa.

Los consumidores no suelen llegar a ninguna conclusión acerca del origen de los productos si no van acompañados de una imagen gráfica o de palabras, dado que un $\underline{\text { sonido por sí solo no se suele utilizar en las prácticas comerciales como medio de }}$ identificación.

La percepción del público destinatario no tiene por qué ser la misma en el caso de un signo formado por un sonido solo que en el caso de una marca figurativa o de palabras consistentes en un signo que no tiene relación con el aspecto de los productos a los que se aplica. Mientras que el público está acostumbrado a percibir las marcas figurativas o 
palabras como signos que identifican el origen comercial de los productos, esto no siempre resulta aplicable cuando el signo es simplemente un sonido (...). Del mismo modo, únicamente los sonidos que difieren considerablemente de la norma o de las costumbres del sector y que, de ese modo, cumple su función esencial de indicar un origen tendrán algún tipo de carácter distintivo a efectos del artículo 7, apartado 1, letra b), del RMUE (...).

Algunos tipos de marcas de sonidos con bajas probabilidades de aceptación sin pruebas de su carácter distintivo factual son:

a) fragmentos musicales muy sencillos compuestos únicamente por una o dos notas (véanse los ejemplos infra);

b) sonidos de dominio público (p. ej., La Marsellesa, Para Elisa, etc.);

c) sonidos demasiado largos para ser considerados una indicación de origen;

d) sonidos habitualmente asociados a productos o servicios específicos (véanse los ejemplos infra). Cuando el signo objeto de la solicitud esté formado por un sonido no distintivo pero incluya otros elementos distintivos, como palabras o la letra misma, se considerará en su conjunto (Decisión $\mathrm{N}^{\circ}$ EX17-1, 2017, p.37) (Los subrayados son míos)

Asimismo, esta Decisión muestra ejemplos de sonidos que serían admitidos y no admitidos para ser registrados como marcas, en virtud a su distintividad: 
Marcas denegadas:

\begin{tabular}{|c|c|c|c|c|}
\hline Signo & Descripción & \begin{tabular}{|c|}
$\begin{array}{c}\text { Productos } \\
\text { Servicios }\end{array}$ \\
\end{tabular} & Justificación & Asunto $n .^{\circ}$ \\
\hline$\hat{6}^{2-\infty}=$ & $\begin{array}{l}\text { Dos notas musicales, fa y } \\
\text { do }\end{array}$ & $\begin{array}{l}35,36,38 \\
39,41,42\end{array}$ & \begin{tabular}{|l|} 
Una $\alpha$ sintonia de dos \\
notas no influye en el \\
consumidor y solo se puede \\
percibir como un sonido \\
muy banal, por ejemplo el \\
«ding dong» de un timbre. \\
\end{tabular} & $\begin{array}{l}\text { MUE n.॰ } \\
4010336\end{array}$ \\
\hline$\square$ & $\begin{array}{l}\text { Dos pitidos } \\
\text { extremadamente cortos }\end{array}$ & 9,38 & \begin{tabular}{|l|} 
Un pitido generado por \\
máquina que suelen emitir \\
los ordenadores y otros \\
dispositivos electrónicos
\end{tabular} & $\begin{array}{l}\text { MUE n.。 } \\
9199167\end{array}$ \\
\hline & $\begin{array}{l}\text { Sonido «pings que } \\
\text { recuerda a una señal de } \\
\text { advertencia }\end{array}$ & $9,16,28$ & $\begin{array}{l}\text { Sonido que constituye una } \\
\text { sefíal de advertencia y una } \\
\text { caracteristica directa de los } \\
\text { productos objeto de la } \\
\text { solicitud }\end{array}$ & R 2444/2013-1 \\
\hline$\frac{1}{20}$ & $\begin{array}{l}\text { Sonido sintetizado } \\
\text { generado por una } \\
\text { máquina }\end{array}$ & $9,12,35$ & $\begin{array}{l}\text { Sonido tipicamente } \\
\text { asociado a los productos y } \\
\text { servicios objeto de la } \\
\text { solicitud }\end{array}$ & R $1338 / 2014-4$ \\
\hline 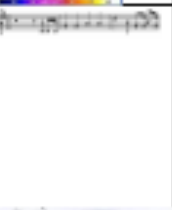 & $\begin{array}{l}\text { Las } 13 \text { primeras notas de } \\
\text { \&La Marsellesan }\end{array}$ & Cualquiera & \begin{tabular}{|l|} 
Un himno nacional es de \\
dominio público. Esto \\
implica necesariamente \\
que es un signo \\
no distintivo ya que no se \\
percibirá como indicador de \\
origen comercial.
\end{tabular} & $\begin{array}{l}\text { Ejemplo } \\
\text { inventado }\end{array}$ \\
\hline 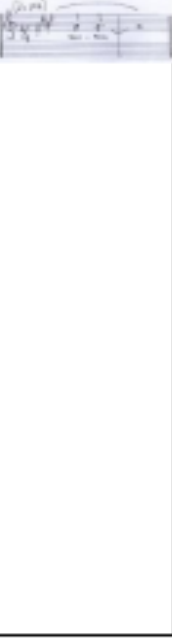 & (ninguna) & 9,38 y 41 & \begin{tabular}{|l|} 
Aunque - en lo que \\
respecta a ciertos \\
productos o servicios- un \\
sonido puede ser común \\
para identificar un producto \\
o servicio por provenir de \\
una empresa concreta, \\
dicho sonido tiene que (i) \\
no ser percibido como \\
elemento funcional (ii) ni \\
como indicador sin ninguna \\
caracteristica intrinseca. \\
En particular, un signo \\
sonoro caracterizado por \\
una excesiva sencillez no \\
se percibirá como marca. \\
En el caso que nos ocupa, \\
la marca solicitada es un \\
motivo sonoro muy simple, \\
es decir, en esencia, un \\
sonido de campanilla banal
\end{tabular} & $\begin{array}{c}\text { Sentencia de } \\
\text { 13/09/2016, } \\
\text { T-408/15 } \\
\text { EU:T:2016:468 }\end{array}$ \\
\hline
\end{tabular}




\begin{tabular}{|l|l|l|l|}
\hline & & $\begin{array}{l}\text { y común que en general } \\
\text { pasaria desapercibido y no } \\
\text { sería recordado por el } \\
\text { consumidor al que se } \\
\text { destina. }\end{array}$ & \\
\hline
\end{tabular}

Marcas aceptables:

\begin{tabular}{|c|c|c|c|c|}
\hline Signo & Descripción & \begin{tabular}{|c|} 
Productos \\
$\mathbf{y}$ \\
Servicios \\
\end{tabular} & Justificación & Asunto $\mathrm{n} .^{\circ}$ \\
\hline 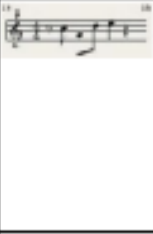 & $\begin{array}{l}\text { Secuencia de cuatro } \\
\text { tonos diferentes, } \\
\text { inicialmente } \\
\text { disminuyendo en una } \\
\text { cuarta y después } \\
\text { aumentando, para } \\
\text { finalizar en tonalidades } \\
\text { medias } \\
\end{array}$ & $16,35,42$ & $\begin{array}{l}\text { Secuencias de sonidos } \\
\text { similares a tintineos, } \\
\text { capaces de identificar } \\
\text { productos y servicios. }\end{array}$ & R 2056/2013-4 \\
\hline $31+2=+1$ & $\begin{array}{l}\text { Las dos primeras notas } \\
\text { «las más cortas suenan } \\
\text { con menos potencia que } \\
\text { la nota «do» que le sigue, } \\
\text { más larga y alta. La nota } \\
\text { «do» más larga y alta, en } \\
\text { consecuencia, se } \\
\text { acentúa a causa de su } \\
\text { tono, longitud y potencia. }\end{array}$ & $\begin{array}{l}9,16,35, \\
36,41,42\end{array}$ & \begin{tabular}{|c|} 
Según la experiencia \\
general, las secuencias de \\
sonidos similares a tintineo \\
permiten distinguir entre \\
productos y servicios.
\end{tabular} & R 87/2014-5 \\
\hline
\end{tabular}

(Fuente: Decisión N EX17-1, 2017, p.38 - p.39)

\section{Marcas táctiles}

En la Decisión $N^{\circ}$ EX16-7 no se hace referencia al registro de marcas táctiles; por el contrario, en la Decisión $N^{\circ}$ EX17-1 sí se hace referencia expresa a estos tipos de marcas; sin embargo, en esta Decisión se ha considerado que, al igual de lo que se piensa respecto al registro de marcas gustativas y olfativas, aún no existe tecnología disponible para poder representar estos tipos de marcas.

En efecto, es necesario señalar lo indicado en el numeral 9.11.3 de la Decisión $\mathrm{N}^{\circ}$ EX17-1 (2017) al respecto:

Las marcas táctiles son marcas en las que se busca protección para el efecto táctil de un determinado material o textura; por ejemplo, indicaciones en alfabeto braille o la superficie concreta de un objeto. Sin embargo, teniendo en cuenta que el artículo 4 del

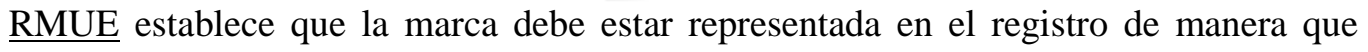
permita a las autoridades competentes y al público determinar con claridad y precisión el objeto de la protección otorgada a su titular, no es posible con la tecnología existente en la actualidad deducir con certidumbre a partir de la imagen presentada la «sensación táctil» reivindicada (...). Además, el REMUE no reconoce la presentación de muestras o especímenes como representación adecuada. Por tanto, cualquier solicitud de marca 
táctil no tendrá el tratamiento de solicitud de marca de la Unión Europea (se considerará «no presentada») (Fuente: Decisión N EX17-1, 2017, p.35).

En este orden de ideas, las marcas táctiles, en virtud a este nuevo reglamento no pueden ser registradas como marcas.

\section{Marcas olfativas}

Sobre estos tipos de marcas, la Decisión N EX16-7 (2017) establecía en el numeral 10.7 que:

Actualmente, las marcas olfativas no son aceptables, porque una representación gráfica debe ser clara, precisa, completa en sí misma, fácilmente accesible, inteligible, duradera y objetiva (...). Tal como ocurre en el resto de tipos de marcas, las descripciones de la marca no sustituirán a las representaciones gráficas. Aunque puede ser gráfica, la descripción de un olor no es clara, ni precisa, ni objetiva y, por lo tanto, no se atribuirá ninguna fecha de presentación, porque la marca no puede representarse de forma gráfica. Dichos casos (...) no serán desestimados, aunque se considerarán no presentados. En caso de que se presente una supuesta representación gráfica, se denegará la solicitud en virtud de un motivo de denegación absoluto $(\ldots)(\mathrm{p} .88,28)$.

Asimismo, el numeral 2.1 indicaba que:

El requisito de la representación gráfica no se cumple mediante la fórmula química, una descripción con palabras escritas, el depósito de una muestra del olor en cuestión ni una combinación de dichos elementos (...).

Actualmente no existe ningún medio de representar gráficamente olores de un modo satisfactorio. No existe una clasificación internacional de olores generalmente admitida que permita, al igual que en el caso de los códigos internacionales de colores o de escritura musical, identificar de manera objetiva y precisa un signo olfativo mediante la asignación de una denominación o de un código concreto e individualizado a cada olor (...).

A continuación, se ofrecen algunos ejemplos de posibles modos de representar gráficamente un olor, aunque ninguno de ellos resulta satisfactorio.

- Fórmula química 
Pocas personas serían capaces de reconocer, en una fórmula de este tipo, el olor en cuestión.

\section{- Muestra de olor}

El depósito de una muestra de un olor no constituiría una representación gráfica a efectos del artículo 4, del RMUE, puesto que una muestra de un olor no es lo suficientemente estable ni duradera.

\section{- Representación gráfica y descripción con palabras}

El requisito de la representación gráfica no se cumple mediante:

- una representación gráfica del olor,

○ una descripción del olor con palabras,

○ una combinación de ambas opciones (representación gráfica y descripción con palabras).

En efecto, no hay duda de que antes de la entrada en vigencia de las disposiciones sobre la supresión de la representación gráfica en este nuevo reglamento, las prácticas de la EUIPO en el registro de marcas mostraban que los signos olfativos no podían constituirse como marcas por no haber un medio idóneo para representarlas gráficamente. Cabe preguntarse entonces, cuál será la forma de registrar una marca olfativa a raíz de la entrada en vigencia del nuevo reglamento, ya que, como se ha visto, no se exige que el signo sea representado gráficamente, bastando con que sea representado de manera que permita a las autoridades competentes y al público en general determinar el objeto claro y preciso de la protección otorgada a su titular.

En ese sentido, debemos remitirnos a la Decisión $N^{\circ}$ EX - 17- 1 (2017), cuyo apartado 9.11.2 señala que:

Actualmente, las marcas olfativas o gustativas no son aceptables, porque $\underline{\text { la }}$ representación debe ser clara, precisa, completa en sí misma, fácilmente accesible, inteligible, duradera y objetiva (artículo 3, apartado 1, del RMUE) y el estado actual de la tecnología no permite la representación de este tipo de marcas con esas condiciones. Además, el RMUE no reconoce la presentación de muestras o especímenes como 
representación adecuada. La descripción de una marca no puede sustituir a la representación, porque la descripción de un olor o sabor no es clara, ni precisa ni objetiva (...). En consecuencia, cualquier solicitud de marca olfativa o gustativa no tendrá el tratamiento de solicitud de marca de la Unión Europea (se considerará $<<$ no presentada >). (Los subrayados son míos).

En efecto, la posición de la EUIPO sobre el registro de marcas olfativas es que no podrán registrarse como marcas por no poder se representadas de acuerdo a las condiciones exigidas: de manera clara, precisa, completa en sí misma, fácilmente accesible, inteligible, duradera y objetiva; es decir, aún los criterios recogidos en el caso Sieckmann (tal como veremos más adelante) para el registro de signos olfativos persisten.

a) Casos Prácticos:

- Marcas Gustativas:

- Dentro de los Estados Miembros de la Unión Europea se ha encontrado la marca gustativa descrita como "el sabor de un licorice para productos de papel” registrada en Benelux (encontrándose hoy en día caduca).

- Marcas Táctiles:

- No se han podido encontrar registros de marcas táctiles a nivel comunitario; sin embargo, la Oficina Alemana de Patentes y Marcas otorgó el registro de la marca táctil UNDERBERG AG para distinguir productos de las Clases 32 y 33 de la Clasificación Internacional de Niza.

- Marcas sonoras:

- Caso Grito de Tarzán: han habido tres solicitudes de registro de marca sobre "el grito de Tarzan" presentadas en la Oficina de Armonización del Mercado Interior - OAMI, ahora Oficina de Propiedad Intelectual de la Unión Europea (EUIPO). 
La primera solicitud fue denegada por no satisfacer el requisito de la representación gráfica, pues la representación presentada no cumplia con ser clara, precisa, completa en sí misma, facilmente accesible, inteligible, duradera, objetiva y concisa.

El solicitante habia presentado el siguiente sonograma para cumplir con el requisto de la representación gráfica:

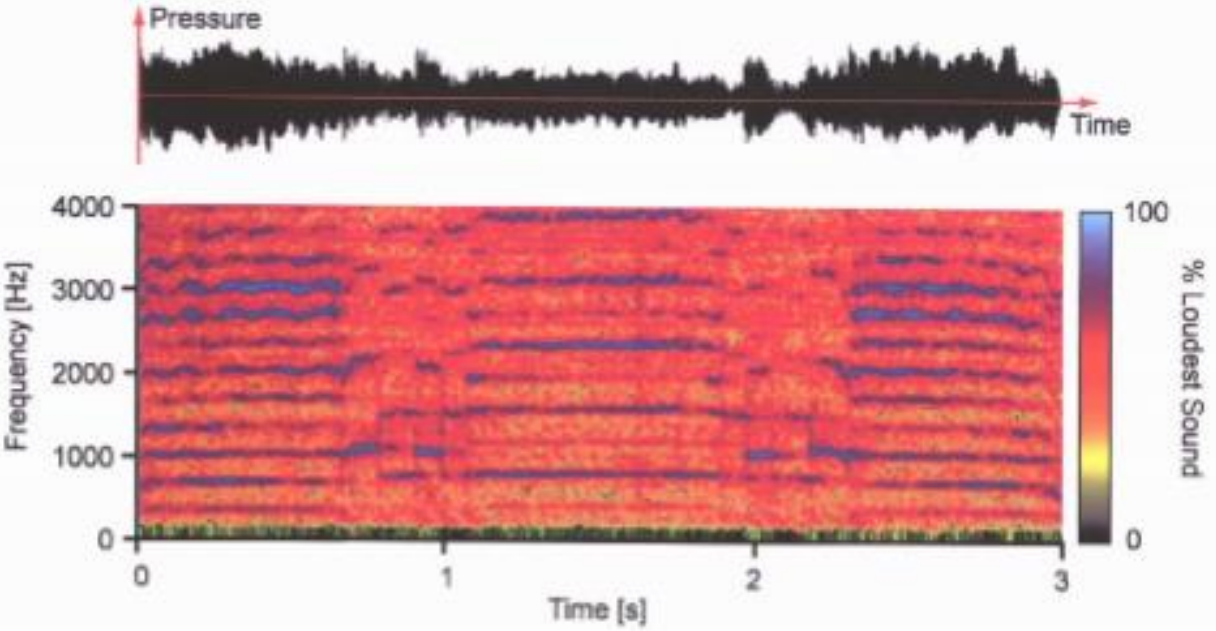

(Fuente: Oficina de Armonización del Mercado Interior - OAMI (ahora, EUIPO), 2007, p.1)

En la segunda solicitud el solicitante adjuntó el siguiente pentagrama para cumplir con el requisito de la representación gráfica, tal como se muestra a continuación:

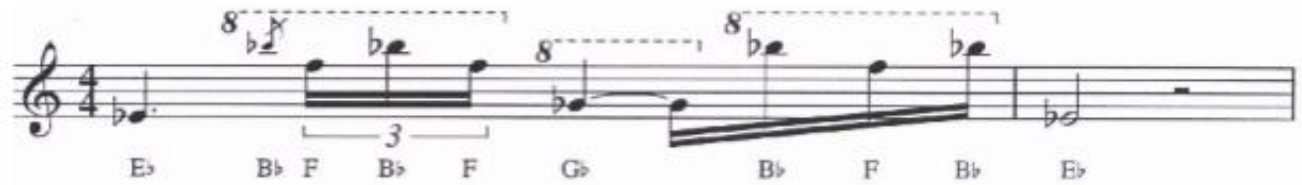

(Fuente: Oficina de Armonización del Mercado Interior - OAMI - ahora, EUIPO), 2007, p.2)

Este pentagrama fue aceptado por la OAMI, concluyendo que sí satisfacia el requisito de la representación gráfica 
En la tercera solicitud, la solicitante pudo registrar también el grito de tarzan. Gracias a un cambio de la legislación de aquel entonces, se pudo presentar un sonograma junto con un archivo sonoro MP3

- Caso Shield Mark: Este caso ha tenido mucha influencia para los examenes de registrabilidad de signos sonoros en la Unión Europea.

En el marco del conflicto entre Shield Mark BV y el Sr. Kist, el Tribunal de Justicia de la Unión Europea se pronunció sobre la distintividad y el requisito de la representación gráfica de los signos sonoros.

Sobre la distintividad, este Tribunal indicó que todos los signos que sirven para distinguir productos o servicios en el mercado pueden constituir marcas, poseyendo los signos sonoros esta cualidad. Asimismo, estableció que la distintividad que se le exigia a los signos para poder acceder al registro, no se referia a la cualidad que en concreto debía tener un signo en relación a los productos o servicios que se pretende distinguir, sino a la distintividad que un signo pueda tener en general, “(...) los sonidos y los ruidos son perceptibles por el ser humano, el cual puede memorizarlos, y permiten distinguir los productos o los servicios de una empresa de los de otras empresas" (Tribunal de Justicia de la Unión Europea, 2003, p.7).

Sin perjuicio de lo expuesto, es necesario precisar que en este caso si bien el Tribunal concluyó que un signo sonoro sí podía constituirse como marca (por poseer aptitud distintiva), lo condicionaba a que deba ser objeto de representación gráfica.

Sobre el requisito de la representación gráfica, de la lectura de la sentencia se puede apreciar que se realizaron diversos comentarios. Por una parte, se manifestó que un signo no visible podía ser registrado como marca, siempre que pueda ser representado gráficamente, en particular, 
por medio de figuras, lineas o caracteres, que sea clara, precisa, completa en sí misma, facilmente accesible, inteligible, duradera y objetiva. Asimismo, se dijo que la representación gráfica debia permitir a los usuarios determinar lo que constituye el objeto del derecho exclusivo del titular de la marca.

En ese sentido, el Tribunal de Justicia de la Unión Europea manifestó que un signo no puede ser registrado como marca sonora, si se omite precisar en la solicitud que se trata de un signo sonoro.

Asimismo, se señaló que una representación gráfica consistente en una descripción como "las nueve primeras notas de Für Elise" o "el canto de un gallo" carece de precisión y claridad. De la misma manera, manifestó que la notación musical "mi, re sostenido, mi, re sostenido, mi, si, re, do, la" no sería clara, ni precisa, ni completa en sí misma, tampoco permitia determinar la tonalidad ni la duración de los sonidos.

Sobre las onomatopeyas, este Tribunal estableció que existiría un desfase entre el pronunciamiento de la onomatopeya y el sonido o ruidos reales que se pretende emitir fonéticamente. Por este motivó, afirmó el Tribunal que la onomatopeya no permitiría que tanto las autoridades públicas como los terceros interesados determinen el signo materia de protección.

Por otro lado, el Tribunal precisó lo siguiente:

En cambio, un pentagrama dividido en compases y en el que figuran, en particular, una clave (la clave de sol, la de fa o la de do), algunas notas musicales y silencios cuya forma (para las notas: redonda, blanca, negra, corchea, semicorchea, etc.; para los silencios: silencio de redonda, silencio de blanca, silencio de negra, silencio de corchea, etc.) indica el valor relativo y, en su caso, las alteraciones (sostenido, bemol, becuadro) y dado que el conjunto de dichas notaciones determina la tonalidad y la duración de los sonidos, puede constituir una representación fiel de la sucesión de sonidos que forman la melodía cuyo registro se solicita. Este modo de representación gráfica de los 
$\underline{\text { sonidos cumple los requisitos que se derivan de la jurisprudencia del }}$ Tribunal de Justicia, según la cual dicha representación debe ser clara, precisa, completa en sí misma, fácilmente accesible, inteligible, duradera y objetiva (Tribunal de Justicia de la Unión Europea, 2003, p.11) (Los subrayados son míos).

Sobre lo indicado, el Tribunal señaló que si bien un pentagrama no es inmediatamente inteligible, puede lograr serlo con facilidad, permitiendo tanto a las autoridades competentes como a terceros interesados conocer el signo que se pretende registrar.

- Se intentó registrar "el rugido de un león", en el cual el solicitante, para cumplir con el requisito de la representación gráfica, adjuntó un sonograma, tal como se muestra a continuación:

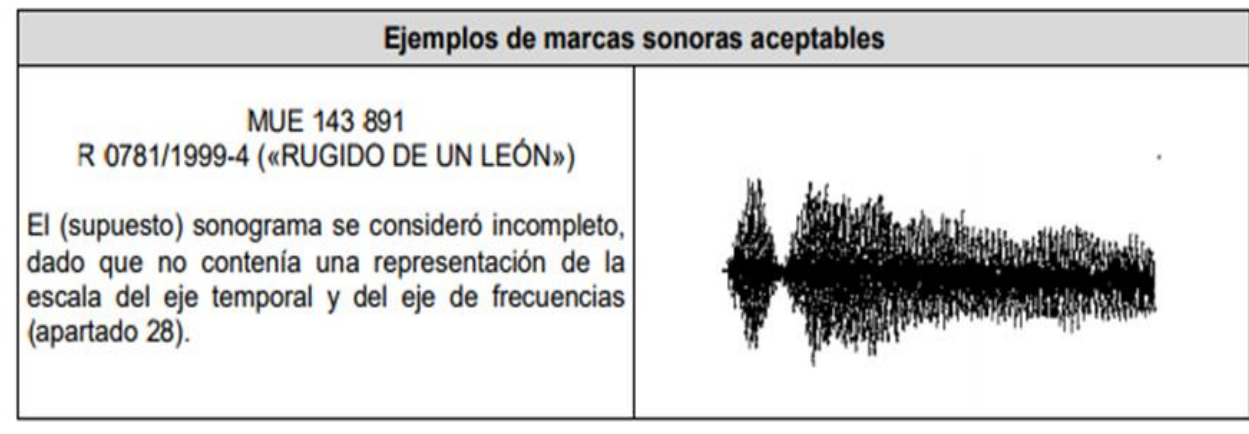

(Fuente: Decisión N EX16-7, 2017, p.6)

En ese sentido, puede apreciarse que el sonograma en el presente caso fue considerado incompleto.

\section{- Marcas olfativas:}

A lo largo del presente trabajo de investigación se ha hecho referencia al caso Sieckmann, y sobre su importancia para el registro de los signos no visibles como marcas y, en particular, del registro de signos olfativos. En este caso, se han establecido pautas para el registro de marcas no tradicionales no visibles que no solamente han influenciado en las Oficinas de Propiedad Intelectual de los Estados Miembros de la Unión Europea, sino, como se ha podido ver, en la Superintendencia de Industria y 
Comercio de Colombia, al haber utilizado estos criterios al resolver las solicitudes de registro de marcas olfativas, así como en el Tribunal de Justicia de la CAN (como veremos más adelante).

Por este motivo, vamos a hacer un resumen y estudiar el antedicho caso Sieckmann a continuación.

\section{- Caso Sieckmann:}

En el asunto C-273/00 del 12 de diciembre de 2002, conocido como el caso Sieckmann, el Tribunal de Justicia de la Unión Europea a solicitud del Bundespatentgerich (Alemania) resolvió las cuestiones prejudiciales suscitadas a raíz del recurso interpuesto por el Sr. Sieckmann contra la negativa del Deutsches Patent- und Markenamt (Oficina de Patentes y Marcas Alemana) a registrar una marca olfativa para distinguir servicios en las clases 35, 41 y 42.

Para registrar el signo olfativo, el Sr. Sieckmaan adjuntó a la solicitud de registro de marca la siguiente descripción:

Se solicita el registro de la marca olfativa depositada en la Deutsches Patent und Markenamt para la sustancia química pura cinamato de metilo (éster metílico del ácido cinámico), cuya fórmula estructural se reproduce a continuación. También se pueden obtener muestras de esta marca olfativa dirigiéndose a los laboratorios locales a través de las páginas amarillas de Deutsche Telekom AG o, por ejemplo, en la empresa E. Merk en Darmstadt (como se citó en la sentencia del Tribunal de Justicia de las Comunidades Europeas, 2003, p.3) (Los subrayados son míos)

El Sr. Sieckmann complementó la antedicha descripción, indicando que "el solicitante de la marca se declara conforme con una consulta pública de la marca olfativa depositada cinamato de metilo (...)" (como se citó en Tribunal de Justicia de las Comunidades Europeas, 2003, p.4).

Asimismo, el Sr. Sieckmann además de las indicadas descripciones, presentó junto a la solicitud, una muestra del olor en un recipiente, añadiendo que el 
aroma se describía como "balsámico-afrutado con ligeras reminiscencias de canela".

Sobre la solicitud de registro de la marca olfativa presentada, la Deutsches Patent - und Markenamt denegó su registro por considerar que la marca solicitada carecía de todo carácter distintivo, por lo que el Sr. Sieckmann interpuso recurso contra dicha decisión.

En ese sentido, a diferencia de lo dispuesto por la Deutsches Patent - und Markenamt, el Bundespatentgerich (que conoció del antedicho recurso) consideró que los olores pueden imponerse en el tráfico comercial como medio autónomo de identificación de una empresa, concluyendo que la marca solicitada resultaba idónea para distinguir los mencionados servicios, pero que, tenía dudas, de si una marca olfativa podía o no cumplir con el requisito de la representación gráfica.

Sobre el particular, es necesario recalcar lo que el Bundespatentgerich manifestó sobre el requisito de la representación gráfica, tal como se muestra a continuación:

(...) la posibilidad de representación gráfica de un signo constituye un criterio para la inscripción en el registro que, en todo caso, debe examinarse en el procedimiento de recurso con carácter prioritario a las restantes causas de denegación de registro. En efecto, en caso de imposibilidad de representación gráfica tampoco sería posible la inscripción, aún si se salva de la falta de distintividad (como se citó en la sentencia del Tribunal de Justicia de las Comunidades Europeas, 2003, p.4) (Los subrayados son míos).

En este orden de ideas, la Bundespatentgerich (2003) formuló las siguientes preguntas al Tribunal de Justicia de la Unión Europea:

1. ¿(...) el concepto de signos que puedan ser objeto de una representación gráfica sólo comprenden los que puedan representarse directamente en su configuración visible? ¿O debe entenderse también a los signos que, aunque no sean perceptibles visualmente - como por ejemplo los olores o sonidos puedan representarse indirectamente por medios auxiliares? 
2. En caso de que se responda a la primera cuestión en el sentido de una interpretación amplia, ¿se cumplen los requisitos de la posibilidad de representación gráfica (...) cuando el olor es representado

a) mediante una formula química

b) mediante una descripción (que se publicará)

c) mediante el depósito de una muestra o,

d) mediante una combinación de los medios de representación sustitutivos antes mencionados (como se citó en la sentencia del Tribunal de Justicia de las Comunidades Europeas, 2003, p.5).

En ese sentido, mostraremos lo que cada parte manifestó sobre las siguientes interrogantes:

Sobre la primera cuestión:

El Sr. Sieckmann (2003) expresó las siguientes posiciones:

-El artículo 2 de la Directiva ${ }^{28}$ no excluye que se pueda registrar una marca olfativa. Estima que una marca de este tipo está incluida en dicha disposición, al igual que las marcas sonoras, y otras marcas "no tradicionales".

-El concepto de representación gráfica debe entenderse como "representación o representación electrónica o depósito efectuado de alguna otra manera".

-En todos los casos de registro de marcas olfativas debe presentarse la fórmula química, una descripción y el depósito del signo.

${ }^{28}$ La Directiva 89/104/CEE del Consejo se encuentra derogada. Su artículo 2 establecía que: Signos que pueden constituir una marca:

"Podrán constituir marcas todos los signos que puedan ser objeto de una representación gráfica, especialmente las palabras, incluidos los nombres de personas, los dibujos, las letras, las cifras, la forma del producto o de su presentación, a condición de que tales signos sean apropiados para distinguir los productos o los servicios de una empresa de los de otras". 
-Para obtener una muestra puede acudirse a los proveedores locales de los laboratorios, o directamente a los fabricantes y a los distribuidores de productos químicos finos orgánicos.

-Mediante el conocimiento de la denominación química, que debe ser publicada, los terceros están en condiciones, tras la compra de dicho producto, y con independencia del depósito de la muestra y de la publicación de la descripción olfativa de la marca, de hacerse una idea exacta y objetiva de la misma.

Por su parte, el gobierno Austriaco consideró lo siguiente:

La posibilidad de percibir de manera visual las marcas registradas, a través de la consulta del registro, reviste una importancia considerable.

- En el caso de los signos sonoros existe una posibilidad de representación gráfica con un grado de determinación relativamente elevado del objeto que debe ser protegido. Lo que no ocurre en el caso de los signos olfativos.

El gobierno de Reino Unido (2003) manifestó que:

- El funcionamiento eficaz del sistema de marcas exige claridad y precisión de las marcas que se inscriben en registros públicos.

- Es suficiente que la marca sea representada en una forma que permita su identificación, y un grado de claridad y precisión suficiente para que el usuario del registro de marcas pueda determinar de manera exacta el signo consultando el registro.

- La representación gráfica del signo debe cumplir en: i) ser completa en sí misma, ii) poder emplearse en lugar del signo, de manera clara y precisa, y iii) ser comprensible para que las personas consulten el registro. 
Asimismo, la Comisión de las Comunidades Europeas (Sentencia del Tribunal Justicia de la Unión Europea, 2003) señaló que:

Un signo solo puede registrase como marca si el objeto de la solicitud es claro y preciso. El objeto de la representación gráfica es proporcionar una imagen clara, precisa y objetiva de la marca. El registro debe garantizar la representación gráfica integra de la marca, para que quede determinado el alcance exacto de protección, y se delimiten los derechos conferidos (p.7).

Apreciación del Tribunal de Justicia de la Unión Europea (2003) sobre la primera cuestión:

El Tribunal de Justicia de la Unión Europea, en primer lugar, señaló que el artículo 2 de la directiva debía interpretarse en el sentido de que un signo que no sea visualmente perceptible sí podía constituir marca, siempre y cuando pueda ser objeto de representación gráfica, recalcando que: "Esta representación gráfica debe hacer posible que el signo sea representado visualmente, en particular por medio de figuras, líneas o caracteres, de manera que pueda ser identificado con exactitud" (p.8).

En efecto, este Tribunal explicó que la representación gráfica de la marca era necesaria para el buen funcionamiento de registro del sistema marcario, pues la representación gráfica permite definir a la propia marca; es decir, determinar el objeto exacto de protección que se conferirá con el registro; por ello, la representación gráfica debe ser completa en sí misma, fácilmente accesible, inteligible, duradera (para poder garantizar el origen empresarial) y excluir todo carácter subjetivo al momento de identificar el signo.

Por otra parte, manifestó que el objetivo de la inscripción de la marca en un registro público es que resulte accesible a las autoridades competentes y a los operadores económicos, pues los primeros deben conocer exactamente el signo que se pretende registrar para realizar el examen de registrabilidad correspondiente $\mathrm{y}$, los segundos necesitan conocer el registro y solicitudes presentadas por sus competidores actuales o potenciales. 
En este orden de ideas, la conclusión del Tribunal de Justicia de la Unión Europea (2003) en cuanto a la primera cuestión fue la siguiente:

El artículo 2 de la Directiva 89/104/CEE del Consejo, de 21 de diciembre de 1988, Primera Directiva relativa a la aproximación de las legislaciones de los Estados miembros en materia de marcas, debe interpretarse en el sentido de que puede constituir una marca un signo que en sí mismo no pueda ser percibido visualmente, a condición de que pueda ser objeto de representación gráfica, en particular por medio de figuras, líneas o caracteres, que sea clara, precisa, completa en sí misma, fácilmente accesible, inteligible, duradera y objetiva. (p.12) (El subrayado es mío).

Sobre la segunda cuestión:

El Sr. Sieckmann señaló que debía interpretarse el requisito de la representación gráfica de manera amplia, considerando que debía consistir en una reproducción, reproducción electrónica de la marca, o en su depósito.

Con respecto a la formula química, explicó que si bien la formula química bruta en el presente caso $(\mathrm{C} 10 \mathrm{H} 10 \mathrm{O} 2)$ no mostraba el modo en que los átomos de tales elementos se imbricaban entre sí, la formula estructural química (C6H5$\mathrm{CH}=\mathrm{CHCOOCH} 3)$ y su denominación química sí permitía caracterizar una sustancia química pura.

Sobre la descripción, indicó que ya existían marcas olfativas registradas en los Estados Unidos y dentro de los países de la Unión Europea consistentes en "un aroma balsámico- afrutado con ligeras reminiscencias de canela".

Respecto al depósito, reiteró que podía consultarse la marca acudiendo a los proveedores locales de los laboratorios, fabricantes y distribuidores.

Sobre la posibilidad de utilizar la combinación de todas las maneras de representación gráfica de la marca olfativa antedichas; es decir, presentando a la solicitud de registro de la marca olfativa tanto una descripción, como la fórmula 
química, su fórmula estructural química, su denominación química, la descripción del aroma y el depósito de la muestra, resumió que:

(...) cuando se trata de la solicitud de registro de una marca olfativa sobre la base de una sustancia química pura, como en el caso de autos, la caracterización puede realizarse mediante la reproducción de la denominación química exacta, mencionada debajo de una dirección de contacto en donde pueda obtenerse el olor, completada, en su caso, con la fórmula química estructural de dicho olor, así como mediante el depósito, por ejemplo, de una muestra en la oficina de marcas que efectúe las verificaciones, añadiendo al depósito su descripción con palabras si resulta necesario (como se citó en la sentencia del Tribunal de Justicia de las Comunidades Europeas, 2003, p.10).

Por otro lado, tanto los gobiernos austriacos y el Reino Unido, conjuntamente con la Comisión, coincidieron de que en esa fase del desarrollo científico, la representación gráfica de los olores planteaba una serie de problemas, señalando que:

(...) la mera indicación de la formula química como representación gráfica de un olor no permite que éste quede determinado de un modo concreto, debido a los diferentes factores que influyen en la manera en que el olor puede percibirse efectivamente, tales como la concentración y la cantidad, la temperatura o el

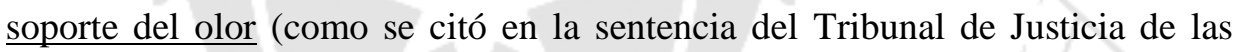
Comunidades Europeas, 2003, p.10) (El subrayado es mío).

Con respecto al depósito de la muestra del olor, el gobierno austriaco y la Comisión coincidieron en que con el transcurso del tiempo el olor experimenta transformaciones, por lo que el depósito no puede contener el olor de manera duradera como para constituir una representación de la marca.

Por su parte, la Comisión sostuvo que la descripción del olor puede interpretarse de manera subjetiva, de acuerdo a la percepción de cada persona, por lo que no sería una manera idónea de cumplir con el requisito de la representación gráfica.

El gobierno de Reino Unido hizo una serie de consideraciones. Sobre la fórmula química, consideró que: i) no representa el olor del propio producto químico, ii) 
muy pocas personas serían capaces de comprenderla y, iii) significaría una carga injustificada para quienes consultan el registro. Sobre la descripción escrita, estableció que es posible que en raras ocasiones pueda representar gráficamente el olor, pues resultaría difícil describir un olor de manera clara y precisa. Respecto al depósito de una muestra del olor, manifestó que la admisión de esta forma de representación exigiría considerables modificaciones en los registros y en los sistemas de inscripción registral de los Estados Miembros de la Unión Europea, resultando una disminución de la accesibilidad que garantiza el sistema actual de registros públicos.

Apreciación del Tribunal de Justicia de la Unión Europea (2003) sobre la segunda cuestión:

Sobre la formula química concluye lo siguiente:

- pocas personas serían capaces de reconocer el signo olfativo

- no es lo suficientemente inteligible

- no representa el olor de una sustancia, sino la sustancia en cuanto tal.

- no resulta clara ni precisa.

Sobre la descripción escrita concluye que:

- aún cuando sea gráfica no resulta lo suficientemente clara, precisa y objetiva

Sobre el depósito de una muestra del olor concluye que:

- no es suficientemente estable ni duradera.

Sobre la combinación de los antedichos tipos de representación de la marca:

- si por sí mismos no cumplen con los requisitos de la representación gráfica, tampoco la combinación de tales elementos puede cumplir con dichos requisitos, especialmente los de claridad y precisión.

En efecto, el Tribunal de Justicia de la Unión Europea (2003) resumió su conclusión sobre esta segunda cuestión de la siguiente manera: 
Habida cuenta de las precedentes consideraciones, procede responder a la segunda cuestión que, en el caso de un signo olfativo, el requisito de la representación gráfica no se cumple mediante una formula química, una descripción con palabras escritas, el depósito de una muestra del olor en cuestión ni una combinación de dichos elementos (p.11).

Comentarios sobre el caso Sieckmann:

El caso Sieckmann ha generado diversos comentarios sobre los requisitos que debe cumplir la representación gráfica de los signos que se pretenden registrar como marcas; en particular, sobre el registro de los signos olfativos y los otros signos no visibles.

En efecto, debe precisarse que gran parte de la doctrina considera que los criterios recogidos en el caso Sieckmann han generado un obstáculo para el registro de las marcas no tradicionales no visibles tratadas en el presente trabajo de investigación, no solo para los Estados Miembros de la Unión Europea, sino para los países que han aplicado estos criterios para fundamentar las denegaciones de registro de estos tipos de signos.

Según, Isabel Ramos (2014):

La interpretación de la Primera Directiva Comunitaria de Marcas dada en la relevante STJUE en el asunto Sieckmann, del 12 de diciembre de 2002, no ha hecho sino frenar la admisión de las marcas olfativas. Implica la exigencia de tantos requisitos para que una marca olfativa, $u$ otra que no pueda percibirse visualmente, sea registrada que hace prácticamente imposible, al día de hoy y a primera vista, que existan marcas olfativas protegidas tanto en la UE como marcas nacionales como comunitarias europeas (p.8). (Los subrayados son míos).

Asimismo, es importante recalcar que sobre la conclusión a la que llega el Tribunal de Justicia de la Unión Europea, sobre el depósito de la muestra del signo olfativo como medio para satisfacer el requisito de representación gráfica, esta autora no deja de reconocer que el olor puede variar con el tiempo, pero 
sostiene que el signo olfativo podría renovarse cada cierto tiempo, actualizándose de esta manera el objeto de protección.

Con respecto a la presentación de la formula química como medio para satisfacer el requisito de la representación gráfica de una marca olfativa, Isabel Ramos (2014) concuerda con el Tribunal de Justicia de la Unión Europea en que pocas personas serían capaces de comprenderla; sin embargo, sostiene que ese no es un fundamento para frenar el registro de estos tipos de signos, haciendo referencia a la información complicada que se adjunta a las solicitudes y registros de patentes de invención, las cuales tampoco pueden ser comprendidas por cualquier usuario, y esta situación no es obstáculo para no permitir su registro (p.170).

Por otra parte, la española Elisa Alonso (2016), citando la tesis francesa de Delphine Galan "La protection de la création olfactive par le droit de la propriété intellectuelle", señala que:

La dificultad reside en el hecho de que el acceso a la marca se encuentra condicionado igualmente por la actitud del signo de ser representado gráficamente. Esta exigencia podría destruir todo potencial depósito de marca olfativa (como se citó en Alonso, 2016, p.26) (el subrayado es mío).

Sin embargo, Elisa Alonzo (2016) aclara que el problema no se soluciona con eliminar el requisito de la representación gráfica, tal como ya se ha hecho en la Unión Europea, sino de la utilización de los criterios estrictos que se ha derivado del caso Sieckmann (p.26).

Por otro lado, Luca Escoffier y Arnold Jin (2010), luego de explicar los criterios recogidos en el caso Sieckmann para registrar una marca olfativa, manifiestan que "Dicho esto, parece pues imposible por ahora registrar una marca olfativa en el marco de la Comunidad, aunque ello sea factible en términos abstractos" (Escoffier, L., y Jin, A. , 2010, p.8) (el subrayado es mío). 
En este orden de ideas, puede apreciarse que los criterios del caso Sieckmann no ha hecho otra cosa más que frenar el registro de las marcas olfativas en la Unión Europea, así como impedir el registro de otros signos no visibles por no cumplir con los requisitos que una representación gráfica debería cumplir.

- Caso "olor a fresa madura":

Este caso, conocido como "el olor a fresa madura", también ha sido un importante precedente para el registro de marcas olfativas, pues el Tribunal de Primera Instancia de la Unión Europea confirmó y aplicó los criterios establecidos en la sentencia Sieckmann para resolver este caso.

Para entender mejor lo que se dijo narraremos un resumen del mismo a continuación:

El 26 de marzo de 1999, Laboratoires France Perfum S.A, ahora la empresa Eden SARL, presentó ante la anteriormente llamada Oficina de Armonización del Mercado Interior (OAMI), la solicitud de registro de marca comunitaria del signo olfativo, descrito como "olor a fresa madura", para distinguir productos de las clases 3, 16, 18 y 25. Asimismo, la solicitante adjuntó la presente imagen a colores:

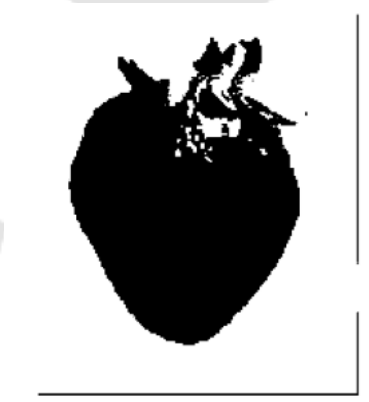

(Fuente: Tribunal de Primera Instancia de las Comunidades Europeas (Sala Tercera), 2005, II-4710)

La OAMI denegó la antedicha solicitud mediante resolución del 7 de agosto de 2003, manifestando que el signo solicitado carecía de carácter distintivo, y no cumplía con ser representado gráficamente. Sobre esta resolución, la empresa 
Eden SARL presentó un recurso, el cual fue nuevamente desestimado por la Sala Primera de Recurso de la OAMI mediante resolución de 24 de mayo de 2004, manifestando otra vez que el signo solicitado no cumplía con ser representado gráficamente. Es por este motivo que la demandante solicitó al Tribunal de Primera Instancia que anule la resolución de 24 de mayo de 2004.

La demandante en el presente caso alegó que:

- La Sala de Recurso utilizó los criterios recogidos en el caso Sieckmann sin tener en cuenta las características de la solicitud de registro de que se trata: a diferencia de la solicitud de registro que se analizó en el caso Sieckmann, en la presente solicitud no se ha presentado ni una muestra, ni fórmula química. La Sala de Recurso debió examinar si la descripción verbal y la representación gráfica en colores de una fresa madura satisfacían el requisito de la representación gráfica.

Sobre la descripción verbal: cuestionó la conclusión a la que arribó la Sala del Recurso al considerar que la descripción "olor a fresa madura" podía interpretarse de manera subjetiva. Consideró que un signo únicamente debía ser apto para distinguir los productos que designa, bastando que sea percibido como tal por el ser humano. Asimismo, refiriéndose a la sentencia Sieckmann, alegó que bastaba que la representación gráfica del signo olfativo sea "inequívoca", y que no procedía examinar si era percibida más o menos objetiva por el consumidor, pues para el registro de los demás tipos de signos no existía un criterio basado por la objetividad del signo.

- Sobra la descripción verbal: también cuestionó que la Sala del Recurso haya considerado que habría un desfase entre la descripción del signo olfativo y el olor, debido a la existencia de un gran número de tipos de fresas que podrían distinguirse por su olor. La demandante señaló que de las muestras aportadas se desprendería que el olor de las fresas es idéntico en todas sus variedades, y que únicamente el gusto es diferente en función de la variedad de que se 
trate. Bajo estos argumentos, la solicitante dedujo que el olor a fresa es estable y duradero.

Adicionalmente, consideró que la descripción era precisa, pues no se trataría de un olor a fresa cualquiera sino de fresa madura, conociendo los consumidores muy bien este olor, el cual lo han tenido grabado en su memoria desde la infancia.

En efecto, la solicitante consideró que la descripción presentada cumplía con ser clara, precisa, fácilmente accesible, duradera y objetiva y que la imagen permitiría que el signo sea en sí mismo completo.

- Sobre la representación figurativa: manifestó que la Sala del Recurso no explicó por qué la combinación de una descripción verbal y una imagen no es suficientemente precisa y clara, afirmando que la marca se debió considerar como un todo. Manifestó que la Sala del Recurso sólo habría reproducido lo manifestado por el Tribunal de Justicia de la Unión Europea en el caso Sieckmann, sin analizar de manera conjunta las representaciones aportadas.

Apreciación del Tribunal de Primera Instancia:

El Tribunal de Primera Instancia consideró que:

(...) la memoria olfativa es probablemente la más fiable de que dispone el ser humano y de que, por consiguiente, los operadores económicos tienen un interés evidente en utilizar signos olfativos para identificar sus productos, no es menos cierto que la representación gráfica de un signo debe hacer posible que éste pueda ser identificado con exactitud para garantizar el buen funcionamiento del sistema de registro de las marcas (Tribunal de Primera Instancia de las Comunidades Europeas (Sala Tercera), 2005, II-4717) (el subrayado es mío).

Como puede apreciarse, este Tribunal también consideró que el requisito de la representación gráfica es importante para garantizar el buen funcionamiento del 
sistema de registro de marcas; por este motivo, manifestó que no pueden modificarse ni flexibilizarse los requisitos para el reconocimiento de la validez de una representación gráfica con el fin de facilitar el registro de los signos cuya naturaleza haga que resulte más difícil la representación gráfica.

En ese sentido, sobre el elemento verbal, el Tribunal aclaró lo siguiente:

(...) si bien, como se desprende de la sentencia de Sieckmann, antes citada, una descripción no puede representar gráficamente signos olfativos que pueden ser objeto de multitud de descripciones, no puede excluirse, sin embargo, que un signo olfativo pueda ser objeto de una descripción que cumpla con los requisitos del artículo 4 del Reglamento $\mathrm{n}^{\circ}$ 40/9429, tal como ha sido interpretado por la jurisprudencia (Tribunal de Primer Instancia de las Comunidades Europeas (Sala Tercera), 2005, p. II-4718) (El subrayado es mío).

Asimismo, se refirió al estudio elaborado por la Cooperación Europea en el campo de la Investigación Científica y Técnica (COST), el cual fue adjuntado por el demandante, y señaló que este estudio no confirmaba la tesis expuesta por el solicitante, según la cual todas las variedades de fresas tienen el mismo olor; por el contrario, señaló que de dicho estudio se podía desprender que las diferentes variedades de fresas presentan diferencias de olor significativas. Por este motivo, concluyó que el olor a fresa no era único.

En este orden de ideas, sobre la descripción verbal concluyó que:

(...) el olor a fresa es diferente de unas variedades a otras. En consecuencia, dado que la descripción "olor a fresa madura" puede referirse a diversas variedades y, por ende, a varios olores distintos, no es unívoca ni precisa y no permite eliminar todo elemento de subjetividad en el proceso de identificación y percepción del signo solicitado (Tribunal de Primer Instancia de las Comunidades Europeas (Sala Tercera), 2005, p. II-4720)

\footnotetext{
${ }^{29}$ Reglamento derogado. El artículo 4 de dicho reglamento señalaba que:

Podrán constituir comunitarias todos los signos que puedan ser objeto de una representación gráfica, en particular las palabras, incluidos los nombres de personas, los dibujos, las letras, las cifras, la forma del producto o de su presentación, con la condición de que tales signos sean apropiados para distinguir los productos o los servicios de una empresa de los de otras empresas. Véase http://euipo.europa.eu/es/mark/aspects/reg/reg4094old.htm\#Heading8
} 
Adicionalmente a lo expuesto, este Tribunal manifestó que actualmente no existía una clasificación internacional de olores generalmente aceptada que permitiera identificar de manera objetiva y precisa los signos olfativos.

Respecto al elemento figurativo, es necesario precisar que el Tribunal manifestó que la indicación del tipo de signo en la solicitud permitía que tanto las autoridades y el público estén en condiciones de saber que se trataría de un signo olfativo, y no figurativo; sin embargo, concluyó que este no sería un medio de representación gráfica del signo, señalando que:

Pues bien, en su sentencia Sieckmann, antes citada (apartado 69), el Tribunal de Justicia declaró que para que se admita la representación gráfica de una marca olfativa, debe representar el olor cuyo registro se solicita y no el producto del que se desprende. Así, consideró que la fórmula química de la sustancia de la que se desprende dicho olor no podía considerarse una representación gráfica válida.

Por consiguiente, el Tribunal de Primera Instancia no puede sino constatar que la imagen de una fresa contenida en la solicitud de registro, al representar únicamente el fruto del que se desprende un olor supuestamente idéntico al signo olfativo de que se trata, y no el olor cuyo registro se solicita, no constituye una representación gráfica del signo olfativo (Tribunal de Primer Instancia de las Comunidades Europeas (Sala Tercera), 2005, p. II-4721).

Asimismo, este Tribunal concluyó que la combinación de los medios de representación presentados no cumplían con el requisito de la representación gráfica, pues siguiendo los criterios del caso Sieckmann, al haberse considerado que la descripción verbal y la imagen de la fresa madura, indistintamente, no cumplían con los requisitos de la representación gráfica, procedía declarar que la combinación de ambos medios no constituían una representación gráfica válida.

En este orden de ideas, el Tribunal de Primera Instancia de la Unión Europea desestimó el recurso interpuesto por la empresa demandante, y denegó el registro de la marca olfativa "olor a fresa madura". 
Comentarios sobre el caso "olor a fresa madura":

Este caso es importante pues se aplican los criterios recogidos en el caso Sieckmann para denegar el registro de la marca olfativa solicitada. En ese sentido, es necesario hacer hincapié sobre determinadas afirmaciones que el Tribunal de Primera Instancia manifestó sobre el registro de este tipo de marcas.

En primer lugar, a pesar que en el caso Sieckmann se estableció que la descripción escrita no sería un medio idóneo para representar gráficamente el olor, el Tribunal estableció que una descripción del signo olfativo sí permitiría cumplir el requisito de la representación gráfica. Lo antedicho se puede apreciar cuando el Tribunal manifestó que:

(...) si bien, como se desprende de la sentencia de Sieckmann, antes citada, una descripción no puede representar gráficamente signos olfativos que pueden ser objeto de multitud de descripciones, no puede excluirse, sin embargo, que un signo olfativo pueda ser objeto de una descripción que cumpla con los requisitos del artículo 4 del Reglamento ${ }^{\circ} 40 / 94$, tal como ha sido interpretado por la jurisprudencia (Tribunal de Primer Instancia de las Comunidades Europeas (Sala Tercera), 2005, p. II-4718).

En segundo lugar, en este caso, al igual que en el caso Sieckmann, no se dudó de la capacidad distintiva de los signos olfativos, tanto es así que el Tribunal manifestó que “(...) la memoria olfativa es probablemente la más fiable de la que dispone el ser humano (...)" (Tribunal de Primer Instancia de las Comunidades Europeas (Sala Tercera), 2005, p. II-4717).

Asimismo, en este caso también puede apreciarse que pese a que el Tribunal no dudó de la capacidad de los signos olfativos para distinguir productos o servicios en el mercado, al igual que en el caso Sieckmann, le da una vital relevancia al requisito de la representación gráfica para poder otorgar el registro de una marca olfativa. Lo antedicho se desprende cuando el Tribunal indicó que "no pueden modificarse ni flexibilizarse los requisitos para el reconocimiento de la validez de una representación gráfica con el fin de facilitar el registro de los signos cuya 
naturaleza haga que resulte más difícil la representación gráfica" (Tribunal de Primer Instancia de las Comunidades Europeas (Sala Tercera), 2005, p. II-4717).

Pese a lo expuesto, en el presente caso nos encontramos con el mismo problema de la sentencia Sieckmann, y es que si bien en ambos casos denegaron el registro de signos olfativos, y te indican qué medios no serían los adecuados para representar gráficamente este tipo de signos, no te indican cómo sí se podría representar gráficamente una marca olfativa.

En ese sentido, sobre la conclusión del caso "olor a fresa madura" compartimos la opinión de Isabel Ramos (2014), cuando indica que:

En el Asunto "olor a fresa madura" el tpi no considera adecuada la descripción realizada porque el olor puede ser diferente dependiendo del tipo de fresa; a continuación entendemos que debería haber indicado que la forma correcta de describirla es indicar detalladamente el olor a fresa de acuerdo con una o más variedades, de tal manera que ése sería el objeto de protección de la marca olfativa; en consecuencia, a nuestro juicio, una descripción de este tipo sería una manera válida de describir un olor (p.171).

En este orden de ideas, puede apreciarse que en estos casos no se han establecido los medios adecuados para representar gráficamente una marca olfativa, pese a que se ha concluido que los signos olfativos cumplen con la función principal de la marca, que es distinguir productos o servicios en el mercado.

- Caso "olor a hierba recién cortada":

Es importante señalar brevemente el caso conocido como "el olor a hierba recién cortada". Debe precisarse que el presente caso data del año 1999; es decir, antes de la sentencia Sieckmann. En este caso se solicitó el registro de la presente marca olfativa para distinguir pelotas de tenis, la cual fue admitida por la OAMI.

Sobre la descripción del signo olfativo "olor a hierba recién cortada", la OAMI consideró que cumplía con el requisito de la representación gráfica, toda vez que 
este olor sería claramente reconocido por el público en general, señalando la OAMI que "Para muchos el aroma o la fragancia de la hierba recién cortada recuerda a la primavera, el verano, campos de césped cortados, campos de deportes u otras experiencias agradables" (como se citó en Ramos, 2014, p.172).

Comentarios al caso "olor a hierba recién cortada":

Tal como puede apreciarse, antes de la Sentencia Sieckmann, la OAMI consideraba que una descripción sí sería apta para cumplir con el requisito de la representación gráfica de un signo olfativo, pese que en la Sentencia Sieckmann se estableció lo contrario. Asimismo, debemos percatarnos que el argumento de la OAMI, para admitir este medio de representación gráfica, fue que el olor a hierba recién cortada era un olor claramente conocido por los consumidores y, por ende, inequívoco.

Sin embargo, tal como lo menciona Isabel Ramos (2014):

El problema de este argumento y el que aparece en la nota a pie de página previa a estas líneas es que cuanto mayor sea el grado de conocimiento por parte del público de los consumidores (nos referimos al conocimiento del olor mucho más un olor tan común como el de "hierba recién cortada" - previo al conocimiento de la marca), la posibilidad de que el signo carezca de fuerza distintiva se eleva (p.172).

En este orden de ideas, puede apreciarse que antes de la sentencia Sieckmann se logró registrar una marca olfativa mediante la descripción escrita. Entonces, pareciera que el tratamiento de las marcas olfativas a raíz del caso Sieckmann no hubiera hecho otra cosa que frenar el registro de estos signos como marcas.

- Caso L’Oreal SA vs. Bellure:

L'Oreal SA presentó una acción por infracción de sus derechos marcarios contra Bellure por vender perfumes baratos de una fragancia aparentemente igual a la de los perfumes elaborados por la accionante, pese a no tener una marca que protegiera sus fragancias. El Juez británico de primera instancia resolvió a favor de la accionante, manifestando que existía gran similitud y equivalencia entre 
los productos, los cuales generaban en la mente de los consumidores la idea de que existía un vínculo entre L'Oreal y Bellure. La Corte de Apelaciones británica confirmó la antedicha decisión.

Sobre este caso cabe preguntarse si los perfumen podrían ser registrados cómo marcas; pues si bien en el presente caso no se registraron las fragancias de L'Oreal como marcas, se estableció que al haber dos perfumes similares, generaba la idea a los consumidores de que estas empresas tendrían un vínculo.

Al respecto, debe precisarse lo que Isabel Ramos (2014) nos comenta sobre los perfumes. Al comentar el caso visto anteriormente de "el olor a hierba recién cortada", tal como lo hemos mencionado, la autora nos explica que en el caso de los perfumes, u otros productos como los cosméticos, ambientadores, jabones, que se caracterizan por desprender un olor, carecerían de fuerza distintiva; asimismo, la autora nos comenta que sobre estos casos se dice que habría funcionalidad de los olores, y que habría agotamiento o riesgo de agotamiento del número de fragancias disponibles para identificar estos tipos de productos.

Sobre el particular, la mencionada autora no se encuentra de acuerdo con estas posiciones, argumentando que en estos productos es posible asociar determinadas fragancias, diferentes de los productos del resto de competidores, y que no suponga una ventaja competitiva ilícita. En ese sentido señala que:

Porque al igual que sucede con los perfumes la capacidad creativa puede producir un olor claramente distinguible y que sea percibido por el público de los consumidores como diferente y vinculado a un producto distinto del de los competidores como de hecho así es el caso de los perfumes (Ramos, 2014, p.173).

- Caso Chanel:

Este caso también consiste sobre el registro de perfumes como marcas. Chanel presentó la solicitud de registro de su conocido perfume $\mathrm{N}^{\circ} 5$ como marca olfativa en Reino Unido, siendo denegada bajo el argumento de que la fragancia del perfume es la esencia misma del producto. 
En ese sentido, puede apreciarse que para la Oficina de Propiedad Intelectual del Reino Unido no se puede registrar un aroma como marca olfativa si el olor deriva de la propia naturaleza del producto.

- Caso perfume Tresor:

En el presente caso, la empresa Lancome inició acciones legales contra la empresa Kecofa por comercializar un perfume más barato y tratando de imitar el olor de su perfume Tresor. Debe recalcarse que en el presente caso no se discute la protección del olor como marca, sino del olor del perfume como derecho de autor. Pese a lo expuesto, es necesario resaltar lo establecido por el Tribunal Supremo de Holanda a continuación:

(...) Tomando en cuenta esta sustancial diferencia, el Tribunal resaltó que esta diferenciación significaba que la elaboración de un perfume a partir de ingredientes distintos, pero que a su vez transmiten la misma fragancia que otro podía constituir una infracción, mientras que por el contrario, tal no sería el caso de dos perfumes que tienen fórmulas similares, pero cuya fragancia es distinta (como se citó en Ferrero, 2009, p.332) (el subrayado es mío).

Sobre este caso, debe recalcarse lo establecido por el Tribunal Supremo de Holanda, que no importa si la elaboración o formula de los aromas son iguales o diferentes, lo que importa es si los olores son iguales o similares; pudiéndose con este argumento salvar el criterio del caso Sieckmann, visto anteriormente, en denegar a la formula química, o de acuerdo al caso, a la descripción verbal, como medio para representar gráficamente los olores, pues por más que se pueda describir o adjuntar una formula química en la cual se especifique la forma de elaboración del olor, o los ingredientes con los que se elabora, lo que importa es si ese olor es igual o diferente a otro.

\subsection{Casos prácticos de marcas no tradicionales no visibles en el Perú}

\subsubsection{Marcas sonoras:}


- Con fecha 06 de enero de 2011, la empresa Arcor S.A.I.C solicitó el registro de una marca sonora para productos de la clase 30, consistentes en café, té, cacao, azucar, arroz, tapioca, sagú, sucedáneos del café, harinas y preparaciones hechas de cereales, pan, pastelería y confitería; helados comestibles; miel, jarabe de melaza; levaduras, polvos para esponjar; sal, mostaza; vinagre, salsas (condimentos); especias; hielo.

La solicitante para satisfacer el requisito de la representación gráfica, además de indicar que la marca que se pretendía registrar consistía en un signo sonoro, presentó el siguiente pentagrama:

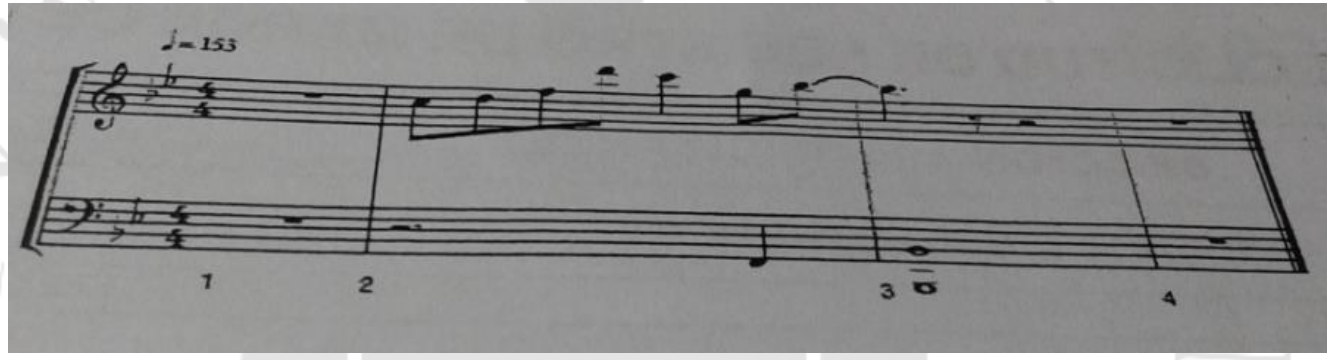

(Fuente: Resolución 1391-2014/DSD- INDECOPI/EXP. 44794-2011, 2014)

La Dirección de Signos Distintivos del INDECOPI, con fecha 21 de enero de 2011, ordenó a la solicitante presentar el soporte mágnetico (CD, DVD, u otro tipo de soporte análogo) que contuviera el audio del pentagrama que había presentado en la solicitud de registro; por lo que, el dia 07 de febrero de 2011, la solicitante presentó la pista de audio (un CD) que correspondía al pentagrama.

En ese sentido, el día 08 de febrero de 2011, la Directora de Signos Distintivos envió el Memorándum N ${ }^{\circ}$ 507-2011/DSD-Mar a la Subgerente de Logística y Control Patrimonial del INDECOPI, adjuntando el pentagrama y el CD del signo para que se emitiera un informe técnico a fin de establecer si el signo sonoro representado en el pentagrama coincidía con el contenido que se encontraba en el CD. 
El día 27 de diciembre de 2011, la Subgerente de Logística y Control Patrimonial, mediante Memorandum $\mathrm{N}^{\circ}$ 1642-2011/GAF-Sgl, indicó a la Directora de Signos Distintivos que se había remitido el audio y el pentagrama al Conservatorio Nacional de Música con la finalidad de que emitiera el informe técnico. Sin embargo, el Conservatorio Nacional de Música no atendió su solicitud, debiendo ponerse en contacto con el Laboratorio de Acústica de la Pontificia Universidad Católica del Perú para que realice el antedicho informe.

Sin perjuicio de lo expuesto, el 23 de enero de 2012 se ordenó la publicación de la solicitud de registro de la marca sonora en el Diario Oficial el Peruano ${ }^{30}$, tal como se muestra a continuación:

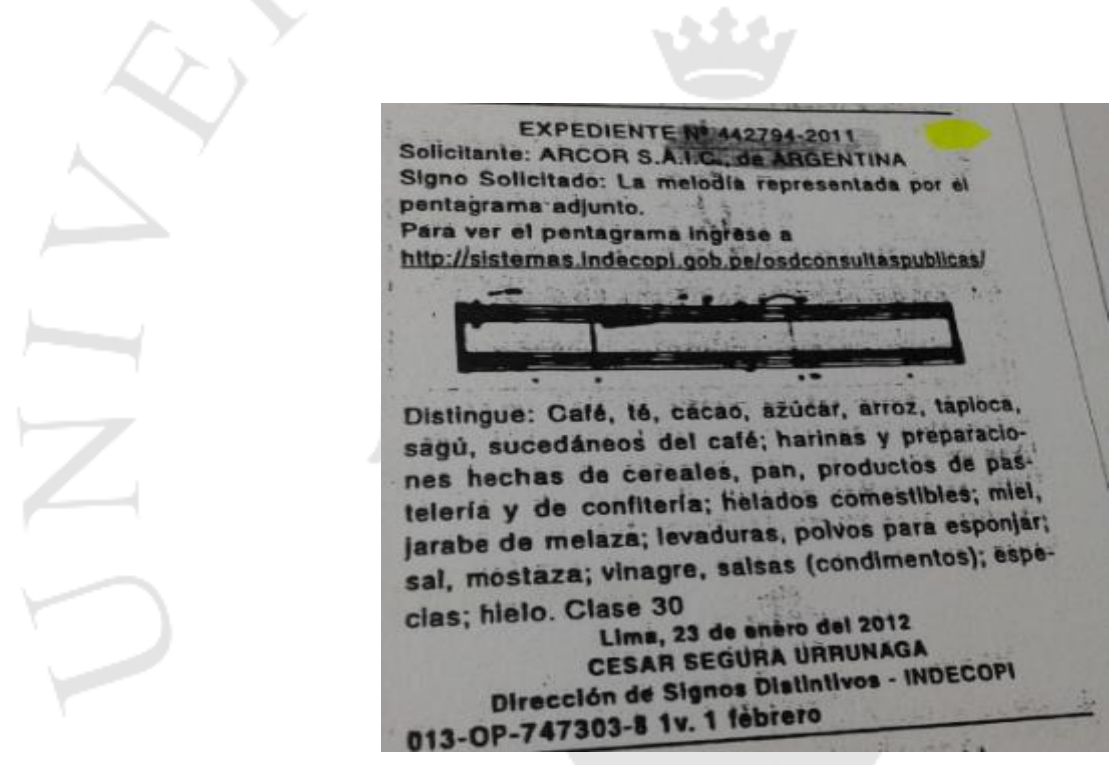

(Fuente: Diario Oficial El Peruano, 2012)

Pese a lo expuesto, mediante Cédula de Notificación de fecha 03 de junio de 2013, la Dirección de Signos Distintivos ordenó a la solicitante, que para un mejor resolver, se sirva presentar un informe emitido por una institución especializada en la materia que certifique que la representación gráfica del signo sonoro corresponde al soporte fisico que lo contiene, otorgándole un plazo de treinta (30) días hábiles para cumplir con lo solicitado.

\footnotetext{
${ }^{30}$ Debe recalcarse que en esta fecha las publicaciones de solicitudes de registro de marcas se realizaban en el Diario Oficial El Peruano. Esto cambió con el Decreto Supremo $N^{\circ}$ 071-2017-PCM: las publicaciones ahora se realizan en la Gaceta Electrónica de Propiedad Industrial del INDECOPI.
} 
En ese sentido, la solicitante pidió prorroga, la cual fue concedida por diez (10) días hábiles inprorrogables. Sin embargo, no cumplió con adjuntar el informe técnico.

Por todo lo expuesto, la Dirección de Signos Distintivos (Resolución 13912014/DSD- INDECOPI/EXP. 44794-2011, 2014) denegó el registro de la marca solicitada, argumentando lo siguiente:

La función principal de una marca, esto es, aquella que finalmente se convertirá en un elemento perceptible y susceptible de representación gráfica, en un signo con mérito marcario y posibilidad registral, es la de otorgar identidad a los productos o servicios que la emplean. (...)

La perceptibilidad del signo significa que éste pueda ser captado por cualquiera de nuestros sentidos: la vista, el oído, el gusto, el olfato o el tacto. (...)

En relación a la representación gráfica, ésta es una exigencia formal para efectos de la publicidad de la solicitud y del registro. Así en el caso de las marcas sonoras, éstas son posibles de ser representadas a través de un pentagrama, o un espectrograma. (...)

Ahora bien, de la evaluación de los medios probatorios adjuntados en el presente procedimiento esta Dirección concluye que los mismos no son suficientes a efectos de realizar el examen de registrabilidad del signo solicitado, toda vez que al no haber la solicitante presentado el Informe Técnico correspondiente no se cuenta con los medios que permitan evaluar si la melodía $\underline{\text { contenida en el CD corresponde al pentagrama consignado en la solicitud de }}$ registro que supuestamente lo gráfica por lo que no es posible realizar el examen de registrabilidad del signo solicitado (Los subrayados son míos).

Sobre lo resuelto por la Dirección de Signos Distintivos, puede apreciarse la predominancia que le otorgaron en este caso al requisito de la representación gráfica sobre la aptitud distintiva del signo sonoro. Asimismo, este signo ya estaba completamente individualizado e identificado por el archivo sonoro que se había presentado, no siendo necesario el pentagrama. Sin embargo, puede 
observarse que en este caso también se le da predominancia al pentagrama, por ser gráfica, más que al signo sonoro (expuesto en el CD) que se presentó.

Por otra parte, debe tenerse en cuenta que además de los requisitos que las normas piden para que se registre un signo (la distintividad y el requisito de la representación gráfica) en el presente caso se le estaba pidiendo al solicitante un requisito adicional, el de un informe técnico para poder realizar el examen de registrabilidad del signo. Adicionalmente, es de verse que la solicitud de registro de marca fue presentada el día 06 de enero de 2011, siendo resuelto el 24 de enero de 2014; es decir, luego de tres años de solicitar el registro del signo sonoro, lo cual, se piensa que fue un motivo desincentivante para el solicitante, cuyo ultimo escrito fue del 21 de junio de 2013.

- En fecha 27 de septiembre de 2005, la empresa Intel Corporation solicitó el registro de una marca sonora para distinguir productos de la clase 9, consistentes, entre otros, aparatos cientificos, de navegación, de medida, eléctricos, fotográficos. En ese sentido, para satisfacer el requisito de la representación gráfica, adjuntó, además del archivo de sonido, el siguiente espectograma:

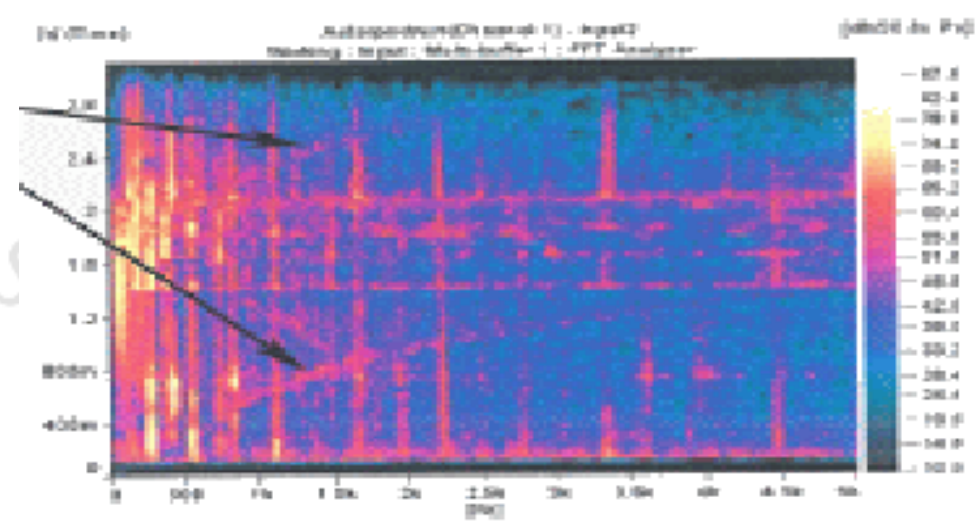

(Fuente: Resolución N 7488-2007/OSD-INDECOPI, 2007)

Al igual que en el caso anterior, el Jefe de la Oficina de Signos Distintivos mediante Memorandum $\mathrm{N}^{\circ}$ 2671-2005/ODS-Mar, solicitó remitir al Laboratorio de Sonido de la Pontificia Universidad Católica del Perú tanto el espectograma como el archivo de sonido proporcionados por la solicitante para la emisión de 
un informe técnico en el cual se determinara si el sonido representado en el espectograma coincidía o no con el contenido del archivo sonoro.

Luego de la emisión del Informe Tecnico de fecha 19 de junio de 2006, la solicitante recien pudo cumplir con publicar la solicitud de registro de la marca sonora el día 20 de julio de 2006.

En ese sentido, mediante resolución $\mathrm{N}^{\circ}$ 7488-2007/OSD-INDECOPI de 03 de mayo de 2007, la Dirección de Signos Distintivos del INDECOPI resolvió inscribir la marca sonora.

Debe acotarse que en el presente procedimiento, la solicitante tuvo que asumir los gastos del Informe Tecnico realizado por el Laboratorio de Sonido de la Pontificia Universidad Católica del Perú. Asimismo, tuvo que enviar constantes escritos para acelerar el trámite del proceso, pues es de apreciarse que desde la presentación de la solicitud, en fecha 27 de septiembre de 2005, hasta la orden de publicación, 20 de julio de 2006, transcurrieron diez (10) meses; es decir, alargando el tiempo usual del trámite de registro de una marca sin oposición.

- El 19 de enero de 2000, la Empresa Lucchetti S.A solicitó el registro de una marca sonora para distinguir café, té, cacao, azucar, arroz, tapioca, sagú, sucedáneos del café, harinas y preparaciones hechas de cereales, pan, pastelería y confitería, helados comestibles, miel, jarabe de melaza, levaduras, polvos para esponjar, sal, mostaza, vinagre, salsas (condimentos), especias y hielo, de la clase 30.

Para cumplir con el requisito de la representación gráfica, la solicitante adjuntó, además de una cinta que contenía la pista musical, un pentagrama, el cual se muestra a continuación: 


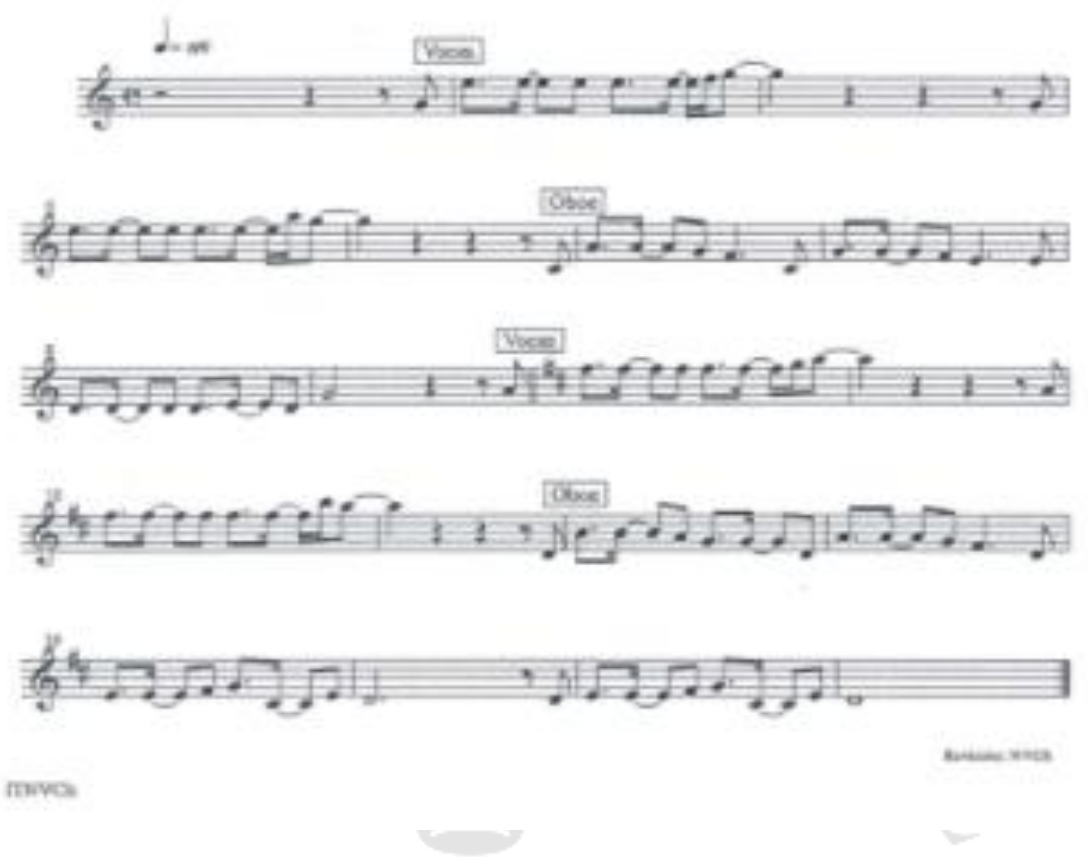

(Fuente: Resolución N 9983-2014/DSD-INDECOPI, 2014)

El 22 de mayo de 2000, la Sub-Jefa de la Oficina de Signos Distintivos, mediante Memorandum $\mathrm{N}^{\circ}$ 0800-2000/OSD envió el pentagrama y el archivo de sonido al Gerente de Administración y Finanzas del INDECOPI para remitirlos al Conservatorio Nacional de Música para la emisión de un informe técnico en el que se estableciera si la melodía representada en el pentagrama coincidía o no con la melodia que constaba en el cassette que la solicitante adjuntó.

El Conservatorio Nacional de Música manifestó lo siguiente:

La linea melódica que figura en la partitura alcanzada coincide con la versión interpretada en el cassette, salvo la última corchea del segundo compas que no coincide con la versión grabada, la cual no altera la totalidad de la linea melódica, también en el cassette se escucha un cambio de altura de la misma linea melódica.

En ese sentido, el INDECOPI requirió a la solicitante que cumpla con presentar el cassette y la partitura de manera que ambas coincidan, cumpliendo posteriormente la solicitante con dicho mandato. Asimismo, el Conservatorio Nacional de Música certificó que la partitura y el archivo de sonido ahora coincidian en su totalidad. 
Pese a lo expuesto, el INDECOPI requirió a la solicitante que presente nuevamente un pentagrama y un cassette; por lo que la solicitante cumplió con dicho mandato, adjuntando una carta emitida por el Conservatorio Nacional de Musica, precisando que el cassette coincidía con el sonido representado en el pentagrama. Posteriormente, el INDECOPI volvió a requerir a la solicitante el pentagrama y cassette de manera que coincidieran, cumpliendo nuevamente la solicitante con dicho mandato.

Mediante cédula de notificación del 28 de diciembre de 2001, la Dirección de Signos Distintivos del INDECOPI declaró en abandono el procedimiento, teniendo la solicitante que presentar recurso de reconsideración, manifestando que la demora en la emisión del informe técnico por parte del Conservatorio Nacional de Música era ya de conocimiento del INDECOPI, por ser ellos quienes habrían solicitado dicho servicio, debiendo unicamente la solicitante cancelar los gastos del informe técnico.

A través del Memorandum $\mathrm{N}^{\circ}$ 0490-2007/GAF-Log de fecha 02 de julio de 2007, el Área de Logística y Control Patrimonial del INDECOPI remitió a la Oficina de Signos Distintivos copia del Informe Tecnico $N^{\circ} 02$ (Cotización de Solicitud $N^{\circ}$ S328), el cual señalaba lo siguiente:

Al confrontar la grabación de audio del comercial de Lucchetti y la partitura recibida se puede apreciar lo siguiente:

a) La partitura no muestra la indicación de "Tempo" correspondiente de acuerdo al audio.

b) En la partitura no se especifican las entradas de las voces, solo las del instrumento con el cual dialogan, el "oboe".

c) Se ha encontrado varios errores de "figuración ritmica" y de "altura de nota" en la partitura recibida. Estos se han marcado con lápiz en la copia recibida y se encuentran corregidos en el "sketch" que damos a continuación.

$(\ldots)$ 


\section{Conclusiones:}

1. Para que la partitura sirva como dato fiable de la marca a registrarse, esta debe ser corregida según "sketch" que se adjunta.

2. En dicho "sketch" se ha puesto la indicación de "Tempo", se ha especificado las entradas de las voces e instrumentos y se han corregido los errores de "figuración ritmica" y de "altura de nota" (como se citó en Resolución Nº 9983-2014/DSD-INDECOPI, 2014).

Mediante Resolución N 9983-2014/DSD-INDECOPI de fecha 9 de junio de 2014, el INDECOPI declaró fundado el recurso de reconsideración interpuesto por la solicitante en fecha 28 de diciembre de 2001; y el día 01 de agosto de 2014 emite orden de publicación, cayendo luego en abandono el proceso.

Sobre este caso, puede percatarse que la solicitud de registro de la marca sonora fue presentada en el año 2000 y que la orden de publicación se emitió catorce (14) años después, y la demora se debió precisamente por las gestiones tanto internas del INDECOPI como de la solicitante sobre el informe técnico.

En ese sentido, puede apreciarse la importancia que le dio el INDECOPI a la representación gráfica del signo, en vez del audio que distinguía los productos en el mercado.

- Otro caso de marcas sonoras interesante es el sonido de la "cornetita" solicitada por D’onofrio Perú. En principio, la solicitante presentó un pentagrama para cumplir con el requisito de la representación gráfica; sin embargo, el INDECOPI estableció que no cumplía con dicho requisito.

En ese sentido, la solicitante presentó tres (3) gráficos del sonido: dominio del tiempo, espectro de frecuencia y gráfico tridimensional, siendo concedido el registro de dicha marca sonora por el INDECOPI. 


\subsection{Interpretaciones Prejudiciales del Tribunal de Justicia de la Comunidad Andina sobre marcas no tradicionales no visibles}

En el seno del Tribunal de Justicia de la Comunidad Andina puede encontrarse el Proceso 242-IP-2015 - Interpretación prejudicial del artículo 134 de la Decisión 486 de la Comisión de la Comunidad Andina solicitada por la Directora de Signos Distintivos de la Superintendencia de Industria y Comercio de la República de Colombia; y, de oficio, del artículo 135 literal b) de la misma normativa. Marca: TEXTURA SUPERFICIE 'OLD PARR'. Trámite: 334. Radicación 15-114096-0-0 - del 24 de agosto de 2015.

En el presente caso, el 27 de febrero de 2015 la empresa Diageo Brands B.V. solicitó el registro de la marca táctil TEXTURA SUPERFICIE “OLD PARR” para distinguir productos de la clase $33^{31}$ del Arreglo de Niza.

Para la publicación de la solicitud en la Gaceta de Propiedad Industrial de Colombia, se incluyó una etiqueta gráfica, similar a la de una marca figurativa, como representación gráfica de la marca solicitada.

En ese sentido, considerando que habían pocos precedentes de solicitudes de marcas táctiles, la Superintendencia de Industria y Comercio decidió elevar una solicitud de interpretación prejudicial ante el Tribunal de Justicia de la CAN.

En efecto, este Tribunal (2015) se manifestó sobre las marcas no tradicionales no visibles, y en particular, sobre las marcas táctiles, como sigue:

- Internacionalmente se ha considerado validar estos nuevos tipos de marcas.

- Si bien los Países Miembros de la CAN no son parte del Tratado de Singapur, es una referencia fundamental en materia de estos nuevos tipos de marcas, lo que sin duda sería una hoja de ruta para los países menos adelantados.

\footnotetext{
${ }^{31}$ Bebidas alcohólicas (excepto cervezas)
} 
- Según el caso Shield Mark BV, el Tribunal de Justicia de la Unión Europea determinó que los signos no visibles no estarian excluidos de ser considerados como marcas.

- En los Estados Unidos de América, el Lanham Act no puede ser interpretado de manera restrictiva, indicando que "un signo es todo aquello capaz de transmitir un significado usado por seres humanos"

- En el 2006, la International Trademark Association (INTA) adoptó una resolución a favor de las marcas táctiles, estableciendo que las texturas sí pueden constituirse como marcas, siempre y cuando cumplan con ser distintivas. Asimismo, se precisó que debían pasar por el test de la funcionalidad para evitar alguna posible afectación a la libre competencia con el registro de las mismas.

- Estableció ejemplos de marcas táctiles ya registradas, tal como se muestra a continuación:

59. Resulta oportuno citar algunos casos de registro de marcas táctiles o de textura, como por ejemplo el bolso o funda violeta de la botella de Crown Royal ,"la textura de terciopelo que cubre la superficie de una botella de vino" del vino Khvanchkara " "una textura de cuero que envuelve la superficie media de una botella de vino", "la textura áspera de una piedra amarilla, naranja y marrón en la parte delantera de una botella de vino", "un papel con textura de algodón” para productos de jabón, la configuración texturizada del mango de un cuchillo, un diseño utilizado como superficie para distinguir equipaje, bolsos y productos de cuero relacionados otorgado a favor de Louis Vuitton Malletier en 1996, o la textura granulada de los bolsos de Dooney \& Bourke también otorgada en 1996.

60. De igual manera, cabe mencionar algunos casos de registro de marcas táctiles que contienen caracteres Braille, como por ejemplo la otorgada a favor de Christoph Krahenmann para distinguir joyería, la marca Underberg AG para distinguir varios productos en las Clases 32 y 33 de la Clasificación Internacional de Niza, la marca MIKLI otorgada a favor del diseñador francés Alan Mikli para vestimenta y anteojos, o las marcas consistentes en las 
denominaciones "a wonder summer's night" o "Stevie Wonder" otorgadas a favor de Stevie Wonder para su vestimenta y servicios de entretenimiento. (Tribunal de Justicia de la CAN, 2015, p.18-p.19).

Por otro lado, al interpretar el artículo 134 de la Decisión 486, se estableció que para que un signo pueda constituirse como marca deberá cumplir con ser distintivo o perceptible, y ser susceptible de representación gráfica. Asimismo, recalcó que el listado establecido en dicho artículo era meramente enuciativo y no limitativo; es decir, no se trataría de un numerus clausus sino de un numerus apertus.

Sobre el requisito de la perceptibidad explicó que si bien en la Decisión 344 se encontraba expresamente establecido, en la Decisión 486 se encontraba de manera implicita dentro del concepto de distintividad, considerando que:

(...) un signo para que pueda ser captado y apreciado es necesario que pase a ser una impresión material identificable a fin de que, al ser aprehendido por medios sensoriales y asimilado por la inteligencia, penetre en la mente de los consumidores o usuarios (Tribunal de Justicia de la CAN, 2015, p.20).

Sobre el requisito de susceptibilidad de representación gráfica, explicó que es la aptitud que posee un signo de ser reproducido por palabras, imágenes, fórmulas u otros soportes, para ser captado por el publico consumidor. Asimismo, hizo recordar que la regla 3 del Tratado de Singapur establece que las partes contratantes podrán exigir una o más representaciones de la marca, una indicación del tipo de marca y detalles relativos a la marca.

Por lo expuesto, sobre el presente caso, el Tribunal de Justicia de la Comunidad Andina (2015) consideró lo siguiente:

74. En el presente caso, este Tribunal considera pertinente que la Oficina Nacional Competente exija una o más representaciones de la marca solicitada, así como la indicación del tipo de marca y otros detalles relativos a la misma. En este sentido, el Tribunal recomienda que, a la brevedad, los Países Miembros adelanten acciones para coordinar aspectos técnicos en relación al trámite, publicación y concesión de registro de marcas táctiles. 
75. Cabe precisar que le atañe a la Oficina Nacional Competente verificar si la marca táctil solicitada cumple con los requisitos de susceptibilidad de representación gráfica y distintividad. Adicionalmente, como se ha explicado, ésta tiene además la facultad de exigir documentación o cualquier otro soporte material necesario para determinar con exactitud el alcance de la protección que se reivindica. En definitiva, la problemática de la representación gráfica del signo a los fines de su publicación (y posibles oposiciones) atañe a la Oficina de marcas y no al titular. En este sentido la Oficina Nacional Competente deberá identificar los medios adecuados para hacer factible la publicación en los casos particulares de las marcas táctiles o de textura (Tribunal de Justicia de la CAN, 2015, p.22) (Los subrayados son míos).

En efecto, el Tribunal ha establecido que corresponde a la Oficina Nacional Competente verificar si una marca táctil cumple con los requisitos de distintividad y representación gráfica, y recalca que la problemática sobre este último requisito atañe a la Oficina de marcas y no a su titular, debiendo los Países Miembros adoptar acciones para hacer posible el registro de estos nuevos tipos de marcas.

Asimismo, a pesar de que la Decisión 486 establece expresamente que una marca debe ser susceptible de representación gráfica, el Tribunal de Justicia de la Comunidad Andina señaló lo siguiente:

87. Finalmente, respecto del requisito de representación gráfica, siguiendo el desarrollo reciente en la materia, se recomienda admitir representaciones de un signo distintas a las gráficas cuando éstas sean más aptas para identificarlo, siendo suficiente que éste sea representado de una manera que permita a las autoridades competentes y al público consumidor determinar el objeto exacto de la protección conferida al titular. (Tribunal de Justicia de la CAN, 2015, p.25) (El subrayado es mio).

En ese sentido, cuando una representación, por más que no sea gráfica, sea más idonea para identificar una marca (tanto para los terceros interesados, como para las Oficinas de Marcas) puede ser admitida.

Debe recalcarse que a diferencia de lo que se ha establecido en la Unión Europea, el Tribunal de Justicia de la Comunidad Andina ha considerado que mientras 
más representaciones de la marca sean presentadas y publicadas, mejor será el grado de precisión e identificación de estas.

Además, establece que:

99. En cuanto a las marcas táctiles o de textura, se debe destacar la ventaja que comporta utilizar el código Braille para la representación y publicación de este tipo de signos no visibles. Tampoco debe descartarse la posibilidad de utilizar gráficos o representaciones tridimensionales más sofisticadas y técnicas. Adicionalmente, siempre será útil la descripción simple del signo, pero no necesariamente suficiente, como sí ocurre en el caso de las marcas olfativas.

\section{( ...)}

101. En consecuencia, este Tribunal interpreta de una manera amplia lo que se entiende por representación gráfica, siendo necesaria la concurrencia de dos requisitos: i) la descripción clara, precisa y completa del signo, incluyendo un dibujo tridimensional o fotografía; $y$, ii) muestra física de la marca táctil (...) (Tribunal de Justicia de la CAN, 2015, p.28-p.29) (Los subrayados son míos).

En ese sentido, puede apreciarse que la interpretación que el Tribunal de Justicia de la CAN le da al requisito de la representación gráfica es amplia. Sobre la marca táctil, establece que la forma adecuada de representarla es mediante una descripción, una fotografía y la muestra física del signo, y, además, permite a las Oficinas Nacionales Competentes requerir otro tipo de representaciones, cuando sea más idoneo para identificar a la marca.

Con respecto a la publicación, este Tribunal ha manifestado que además de poderse publicar tanto la descripción como la fotografía, es necesario permitir el acceso a los usuarios a la muestra física del signo solicitado para que puedan conocer si el mismo vulnera o no sus derechos, y de esta manera, lograrse una publicación efectiva.

Por otra parte, en esta interpretación prejudicial, el Tribunal de Justicia de la CAN se refiere a las texturas de uso común, que al igual que las formas o signos genéricos o de uso común, no permitiría al consumidor diferenciar los productos a los 
cuales se aplica, siendo que los demás competidores del mismo rubro se verían en la necesidad de utilizar estos signos necesariamente en el mercado. Asi lo explica este Tribunal (2015) cuando establece que:

122. (...). Al igual que la prohibición de registro de signos denominativos calificados como genéricos o de uso común, la causal que impide registrar la "forma" o, por ratio legis, la "textura" de un producto o su envase con características usuales, se encamina a evitar que un empresario pueda a través del registro llegar a monopolizar una "forma" o "textura" necesaria para comercializar cierta clase de productos (p.34).

Por otro lado, el Tribunal de Justicia de la Comunidad Andina explica el caso de las texturas impuestas por una función técnica o por la naturaleza de los productos, las cuales no pueden ser registradas como marcas por afectar la libre competencia. En efecto, precisó que a diferencia de lo que sucede en la Unión Europea, que su legislación contempla como prohibición absoluta que el signo esté constituido exclusivamente por una forma impuesta por la naturaleza del propio producto, o cuando la forma del producto sea necesaria para obtener un resultado técnico, o por la forma que le dé un valor sustancial al producto que afecte su valor intrínseco, en el marco de la Comunidad Andina no se preve la prohibición de este último supuesto, contemplando solamente los dos primeros.

Asimismo, es importante destacar lo manifestado por el Tribunal (2015) sobre el literal c) del artículo 135 de la Decisión 486, tal como se muestra a continuación:

137. Estos criterios fueron inicialmente concebidos en el contexto de las marcas tridimensionales pero son igualmente aplicables a la mayoría de tipos de marcas. En consecuencia, la referencia a "la forma" del producto o de su envase, contenida en la precitada normativa andina, debe entenderse en sentido amplio, por el método de la ratio legis. En el caso particular de las marcas táctiles, "forma" equivale a "textura", así como en el caso de las marcas gustativas significa "sabor" y en las marcas olfativas indicará "olor", "perfume" o "fragancia", por referir algunos tipos de signos no visibles ( p.37) (Los subrayados son mios).

De lo expuesto se desprende que las prohibiciones absolutas, sobre signos de uso común o genéricos, y sobre las formas usuales o signos que tengan alguna función técnica, también son aplicables a las marcas no tradicionales no visibles. 


\subsection{Una gran oportunidad para las marcas olfativas}

Ahora que ya hemos estudiado el tratamiento legal de las marcas no tradicionales no visibles en el mundo de la propiedad intelectual, hemos apartado este inciso para ver la importancia que la doctrina y el mundo empresarial le ha dado a las marcas olfativas.

En efecto, consideramos que los aportes de la presente tesis permitirá el correcto registro de estos tipos de marcas, y con esto no solo el beneficio de los distintos agentes económicos que actúan en el mercado, sino que permitirá a estos diferenciar sus productos o servicios de una manera más innovadora, y con las ventajas que el olor trae consigo, tal como veremos a continuación.

\subsubsection{El uso de los aromas como iniciativa empresarial}

Con el gran desarrollo de la economía a nivel internacional puede apreciarse que cada día los comerciantes buscan implementar nuevos métodos para competir y ganar más posición en el mercado, y de esta manera lograr persuadir a los consumidores de comprar los productos y servicios que ofrecen. En ese sentido, el sistema marcario ha sido clave para que los empresarios puedan darle valor agregado a los bienes que comercializan, pues una marca, además de permitir al consumidor distinguir productos o servicios en el mercado e identificar su origen empresarial, lleva consigo la reputación y prestigio que a lo largo del tiempo ha adquirido.

En este orden de ideas, debido al progresivo aumento de la competencia, las empresas se han visto en la necesidad de captar la atención del público consumidor de una manera más innovadora, ya no solamente utilizando el sentido de la vista (que ha sido a lo largo del tiempo la manera más usual de marketing), sino aprovechando otros sentidos del ser humano como el tacto, el gusto, el oído, y el olor.

En ese sentido, el derecho de propiedad industrial no ha podido hacer caso omiso al surgimiento de estos nuevos tipos de marcas, debiendo prever su protección.

En efecto, tal como establece Gonzalo Ferrero (2009): 
Hoy por hoy ha quedado atrás el objeto de protección tradicional de las marcas que un inicio estuvo primordialmente conformados por palabras o denominaciones y figuras, diseños y logotipos de toda índole. Es así que a lo largo de estos años se ha visto cómo diversas jurisdicciones han acoplado sus ordenamientos internos y regionales, para dar cabida a una protección efectiva a este tipo de marcas nuevas no tradicionales (p.1)

Sobre el olfato, debe mencionarse que los empresarios han visto en este sentido humano un poderoso medio para identificar sus productos y servicios en el mercado, pues los resultados para captar clientela con este signo han generado diversos beneficios. Asimismo, la mayor parte de la doctrina considera que los olores tienen una fuerte capacidad evocadora, la cual permite que el consumidor pueda fácilmente recordar los productos y servicios que ha consumido relacionándolo rápidamente con el bien que identifica.

A continuación, mostraremos los comentarios, que sobre el olor, se han señalado:

Gonzalo Ferrero (2009) manifiesta que:

En mi opinión personal no hay nada que genere sensaciones más placenteras o de completo rechazo que los olores. Se dice que el olfato humano, si bien no es capaz de reconocer olores tal como algunos animales, sí es un sentido bastante desarrollado que nos permite apreciar muchos matices de olores y aromas, y que por tanto es el causante de que en ciertas ocasiones ejerzamos una decisión de consumo basados sólo y estrictamente en el olor (p.1).

Asimismo, la OMPI (2009) ha señalado: "Se dice que los recuerdos olfativos figuran entre los más evocadores, y los fabricantes están cada vez más interesados en que asociemos sus productos con aromas agradables".

Por su parte, Isabel Ramos (2014) ha manifestado: "Para diferenciarse e innovar, las marcas olfativas son un magnífico instrumento;42 el cerebro humano normalmente recuerda o asocia más fácilmente un olor, sobre todo a un producto que una o varias palabras o un dibujo.43" (p.175). 
Sin perjuicio de lo expuesto, la misma autora, en el pie de página $\mathrm{N}^{\circ} 43$, ha indicado, citando a Gippini Forunier, E., lo siguiente:

En este sentido, Gippini Forunier, E. "Las marcas olfativas...”, op. cit., p. 1, señala que varios estudios ponen de manifiesto como el olfato permite al consumidor, en ocasiones, seleccionar y recordar un producto que desea incluso en los casos en los que ha olvidado su nombre. Matizando que, sin embargo, otros estudios científicos tienden a demostrar que la capacidad de asociar aromas con objetos o de nombrar correctamente los objetos cuya aroma es percibido, es considerablemente más limitada que si se trata de percepciones visuales. Añadiendo que por ello ha de tener repercusiones jurídicas: "si el aroma es un elemento distintivo idóneo y desempeña un papel crítico en las decisiones de consumo, habría que plantearse seriamente su admisión como marca comercial (como se citó en Ramos, 2014, p.175).

También, citando a Burgett, J. M., establece que:

Burgett, J. M., “Hmm...What's That Smell?...”, op. cit., p. 1 (del formato electrónico), señala que los olores traen evocaciones a la memoria de los consumidores, por ejemplo, el olor a hierba recién cortada puede inducir a una persona a pensar en la época de primavera, y bajo determinadas circunstancias el consumidor puede asociar el olor a un producto en particular, por lo que tienen la capacidad de ser identificadores (como se citó en Ramos, 2014, p.175).

Por otro lado, Santiago Campillo (2016) señala que:

Los mamíferos tenemos una gran dependencia de nuestro olfato. Somos animales terriblemente olfativos. De hecho, los olores son capaces de evocar recuerdos, tranquilizarnos, ponernos nerviosos, excitarnos... incluso despertar viejos traumas. La información olfativa llega en primer lugar al hipotálamo y al sistema límbico, dos de los puntos más "viscerales" de nuestro sistema de procesado cognitivo. Es normal que los olores, por tanto, nos condicionen en nuestro día a día (párr.3).

Asimismo, Hernán Osorio Herrera (2014), Gerente Comercial de la empresa colombiana Dinamic Products, quienes se dedican al marketing olfativo, manifiesta que: 
(...) el $85 \%$ aproximadamente de todo lo que tenemos de publicidad está dirigido a la parte visual, y es que el sentido del olfato es el menos utilizado en temas de publicidad, y es el sentido más desarrollado del ser humano.

De acuerdo a los estudios, el 35\% de lo que olemos con relación al $1 \%$ de lo que recuerda la mente de lo que tocamos, el 15\% de lo que probamos, y solo recuerda el 5\% de lo que vemos; entonces, es el sentido que tiene una conexión directa con el cerebro, a diferencia de los otros sentidos en los que tiene que atravesar un proceso en el sistema nervioso. De hecho esto ayuda a que la memoria pueda conservarlo por más tiempo.

Esto mismo también ha sido señalado por Richard Axel y Linda B. Bucks, ambos premios Nobel de Medicina y Fisiología 2004 por su estudio sobre el olfato. Ellos señalan que:

(...) mientras que los seres humanos sólo podemos reconocer 200 colores, somos capaces de distinguir y recordar hasta 10.000 aromas distintos y que cuando nuestro bulbo olfativo detecta algún olor, la señal se envía directamente al sistema límbico, que es la zona del cerebro asociada con el procesamiento de las emociones (como se citó en Fernández, 2017, p.139)

Por su parte, Maylee Cheilan Savournin del Toro (2014):

El olfato es el único de los sentidos que está directamente conectado con el área del cerebro que procesa la emoción, el recuerdo y el aprendizaje asociado. De hecho, es cien veces más probable que recordemos algo que hemos olido que visto, oído, tocado o probado. Es por ello que, el éxito de una marca no solo se ve, se oye, se toca o se saborea, también se huele (p.3).

Como puede apreciarse de los comentarios expuestos, diversos autores señalan que la memoria olfativa es más poderosa que la memoria textual, gustativa, auditiva, incluso más poderosa que la visual. Asimismo, los autores señalados también se han referido a que el aroma de un producto o servicio tiene gran capacidad evocadora, trayendo recuerdos en la mente de las personas experiencias previamente vividas; por lo que, con la misma lógica, los olores son capaces de traer a la mente de los consumidores los bienes que han adquirido en el mercado, así como inducirlos a realizar su compra. 
A continuación, veremos cómo se han empleado los olores en el mercado, y los beneficios que ha generado:

\section{- Caso Dunkin’ Donuts:}

En Seúl, la Capital de Corea del Sur, la empresa Dunkin' Donuts tuvo la misión de persuadir al público a que consumieran el café que comercializaban, debido a la gran cantidad de competencia de venta de café por parte de otras empresas.

En efecto, aprovechando el gran tráfico vehicular de la ciudad, Dunkin's Donuts inventó pequeñas máquinas para adherirse a las radios de los transportes públicos que hacía que cuando se escuchara la publicidad del café de Dunkin's Donuts, estas máquinas esparcieran el aroma de su café. Además, pusieron anuncios y stands de Dunkin's Donuts en los paraderos de dichos transportes, lo que hacía que las personas, al salir, visualicen inmediatamente el stand o anuncio de Dunkin`Donuts.

La consecuencia de esta iniciativa fue que el número de visitantes a las tiendas de Dunkin' Donuts incrementó en 16\%, y las ventas de su café aumentó en $29 \%$.

- El olor a nuevo:

La empresa Ford quiso que los compradores de autos de segunda pudieran experimentar la sensación de encontrarse frente a un auto nuevo; por lo que crearon, con ayuda de un gran número de expertos, "el olor a nuevo". Este aroma fue impregnado dentro de estos autos, y logró producir la sensación esperada en los consumidores. El olor a nuevo fue promocionado en toda las campañas publicitarias de Ford.

La consecuencia fue que la venta de los carros de segunda aumentó de manera considerable. Hoy en día gran parte del sector automotriz utiliza este aroma.

- Caso hipermercados Bloom:

Esta empresa desarrolló una máquina que esparcía olor a filete. Esta máquina fue adherida a un anuncio gigante a las afueras de uno los hipermercados Bloom 
en Inglaterra. Este olor indujo a los consumidores a adquirir dicho filete; por lo que los consumos de dicho producto aumentaron.

Otros casos en los que se puede visualizar cómo las empresas están utilizando los aromas como estrategia de venta:

- La empresa Singapore Airlines:

Utiliza una fragancia con un toque exótico que crea la experiencia del viajero más agradable. Este olor forma parte de su identidad.

- La empresa japonesa Sumitomo Rubber Co. emplea aroma floral para neumáticos.

- La empresa Unicom Products Limited utiliza el olor a cerveza amarga, el cual es esparcido al tirar un dardo.

La empresa francesa L'Oreal utiliza fragancias frutales para envases de productos para el cabello.

- La empresa Bankiter utiliza el olor a naranja con jazmín que identifica sus sedes, oficinas, y papelería empleada en las comunicaciones que se dirigen a los clientes.

- La empresa japonesa Chaku Perfume Cía. S.A. creó una aplicación para iPhone llamada Charla Perf, la cual envía un olor acompañado de mensajes o notificaciones al correo electrónico. Para que esto sea posible se necesita que ambos móviles tengan la misma aplicación.

- En Tokio, la capital de Japón, se estuvo realizando el proyecto Ekika, el cual consistía en usar los olores para orientar a los pasajeros en relación a las zonas a las cuales iban transitando. 
De lo expuesto, puede percibirse que los aromas han llamado la atención del mundo empresarial, pues permite captar clientela en virtud a las fuertes sensaciones que pueden trasmitir, y los múltiples recuerdos que pueden traer a un consumidor. 


\section{CAPÍTULO IV: APORTES}

\subsection{Criterios para determinar la distintividad de las marcas no tradicionales no}

visibles, sobre la base de la función fundamental y más importante de la marca: su función identificadora y diferenciadora

a) A nivel andino se ha considerado que las marcas no tradicionales no visibles (incluídas las táctiles y gustativas) pueden registrarse por poder poseer aptitud distintiva y, por ende, poder cumplir con la función principal de la marca. En ese sentido, no debe denegarse el registro de una marca por el hecho del signo estar conformado por un $\underline{\text { sonido, aroma, textura o sabor, y no por algún signo visible. }}$

Luego de haber revisado el regimen subregional, nacional, y casos prácticos de los Países Miembros de la CAN en cuanto a la aptitud distintiva de los signos no visibles, es necesario acotar que de la lectura del artículo 134 de la Decisión 486 se desprende que los expertos de propiedad intelectual al momento de la elaboración de esta norma andina consideraron que los signos olfativos y sonoros, así como los demás signos señalados en la lista enunciativa expuesta en este mismo artículo, pueden poseer aptitud para distinguir productos o servicios en el mercado. Esto porque se señala que “(...) constituirá marca cualquier signo que sea apto para distinguir productos o servicios en el mercado.(...)", y luego establece que "Podrán constituir marcas, entre otros, los siguientes: (...) c) los sonidos y los olores; (...)". Es decir, los signos olfativos y sonoros no estarían incluidos en esta lista si no pudieran poseer aptitud distintiva y, por ende, cumplir con la función principal de la marca.

Asimismo, tal como Baldo Kresalja (2001) nos comenta, a partir de la elaboración de la Decisión 311 hasta la Decisión 486 puede apreciarse el esfuerzo de los Países Miembros de la CAN en querer recoger las normas de Propiedad Intelectual tanto del Convenio de París como del ADPIC, teniendo este último mucha influencia en la elaboración de la Decisión 486. En el presente trabajo, pudo apreciarse que el ADPIC (1994) fue el primer instrumento internacional en el que se hizo referencia a las marcas no tradicionales no visibles al establecer en el numeral 1 del artículo 15 que “(...)Los 
Miembros podrán exigir como condición para el registro que los signos sean perceptibles visualmente" (ADPIC, 1994).

Respecto a los signos táctiles y gustativos, no puede saberse con precisión si para estos expertos al momento de elaborar la Decisión 486 consideraron si estos signos podían constituirse como marcas y, por ende, si podían de alguna manera poseer aptitud distintiva, pues si bien no se prohiben sus registros, tampoco se admiten expresamente. Sin perjuicio de lo expuesto, debemos precisar que sobre las marcas táctiles, tanto el Tribunal de Justicia de la Comunidad Andina, en el Proceso 242-IP-2015, así como las oficinas de propiedad intelectual de Colombia y Ecuador (como hemos visto) han aceptado el registro de estas marcas y, en consecuencia, la posibilidad de ser aptas para distinguir productos o servicios, por lo que puede concluirse que a nivel andino se admite que los signos táctiles pueden cumplir con la función principal de la marca. De igual forma, sobre los signos gustativos, en el Proceso 242-IP-2015, el Tribunal de Justicia de la Comunidad Andina señaló que “(...) En el caso particular de las marcas táctiles, "forma" equivale a "textura", así como en el caso de las marcas gustativas significa "sabor" (...)", por lo que se encuentra claro que a nivel comunitario se admiten estos tipos de marcas; además, esto también puede corroborarse cuando en el mismo Proceso se establece que la lista de signos del artículo 134, que indica qué signos pueden constituirse como marcas, "no se trataría de un numeros clausus, sino de un numerus apertus, por lo que dicha lista también incluye tanto a los signos no tradicionales visibles como los no visibles" (Tribunal de Justicia de la CAN, 2015, p.20). También, debe recordarse que en la nueva normativa de Propiedad Intelectual de Ecuador, en su artículo 359, numeral 3, se señala expresamente que los sabores pueden constituirse como marcas.

En ese sentido, puede establecerse que a nivel andino las marcas no tradicionales no visibles, incluídas las táctiles y gustativas, pueden constituirse como marcas, por considerarse que pueden ser aptas para distinguir productos o servicios en el mercado; es decir, pueden cumplir con la función principal de la marca. En efecto, no debe denegarse el registro de una marca por el hecho del signo estar conformado por un sonido, aroma, textura o sabor, y no por algún signo visible. 
b) La aptitud distintiva es el requisito esencial que todo signo debe tener para poder constituirse como marca; por este motivo, este requisito debe ser incluido en cualquier concepto o definición de marca, entendiéndose por aptitud distintiva a la potencialidad que tiene un signo de distinguir productos o servicios en el mercado. Este es el requisito determinante que el INDECOPI debe evaluar al momento de conceder el registro de un signo no visible como marca.

Cuando estudiamos en el capitulo II la figura de la marca, en particular, sobre sus funciones, pudo apreciarse que la función principal de la marca es su aptitud identificadora y diferenciadora; es decir, que el signo pueda servir para identificar y distinguir productos o servicios en el mercado, siendo sus otras funciones, aunque no menos importantes, usuales pero no necesarias, tales como su función de identificación del origen empresarial, función de recolección de prestigio o calidad, función publicitaria e informativa, función competitiva, entre otras.

En ese sentido, la aptitud distintiva es el requisito esencial que todo signo ( y concepto de marca) debe tener para que pueda constituirse como tal. Es decir, tanto signos visibles como no visibles podrán constituirse como marca siempre y cuando puedan cumplir con la función principal.

Sin perjuicio de lo expuesto, debe recalcarse que el Diccionario de la Real Academia Española (2014) señala que el término aptitud significa “(...)Cualidad que hace que un objeto sea apto, adecuado o acomodado para cierto fin". En esta linea, Diego Chijane (2007) nos dice que un signo sea apto para distinguir productos o servicios en el mercado significa que el signo tenga la potencialidad de cumplir con esa función.

En este orden de ideas, es usual que cuando se solicite el registro de un signo como marca, este aún no pueda identificar o distinguir inmediatamente un producto o servicio en el mercado ${ }^{32}$, sino hasta que interactue con los consumidores; es decir, al comienzo el signo debe tener la aptitud de identificar y distinguir los productos o

\footnotetext{
32 Vale recordar que a diferencia del derecho marcario estadounidense, en el régimen andino no se necesita que el signo sea usado en el comercio para ser registrado como marca.
} 
servicios para los cuales será aplicado, pero es al momento de usarse en el comercio, e interactuar con el consumidor, que logra distinguir productos o servicios. Esto también es aplicable para el registro de signos no visibles. Estos signos al principio no podrán distinguir productos o servicios en el mercado, pero deben tener la aptitud de cumplir con esta función.

Vale recalcar que si bien se ha manifestado que los signos no visibles son considerados, a nivel andino, con aptitud para poder cumplir con la función principal de la marca, este requisito debe examinarse con relación al producto o servicio al cual el signo no visible busca distinguir, de acuerdo al Principio de Especialidad estudiado en el capítulo II.

c) Las distintas figuras de la Propiedad Intelectual y, en particular, la figura de la marca, se adecuan a las situaciones sociales, económicas y comerciales del momento, $\underline{\text { careciendo de asidero la posición de que los consumidores no estarían acostumbrados a }}$ percibir los signos no visibles como marcas.

En los antecedentes históricos expuestos en el capítulo I, hemos visto que desde la aparición de la figura de la marca (en los siglos XI y XII, con el desarrollo de los intercambios comerciales, la aparición de los artesanos y comerciantes, y con el surgimiento de la Lex Mercatoria) sus funciones y tratamientos han variado de acuerdo a las situaciones sociales, económicas y comerciales del momento (así como todas las ramas de la Propiedad Intelectual).

En ese sentido, tal como nos explica Christian Schmitz (2012), en la actualidad la necesidad de distinción de los productos o servicios emerge con una fuerza nunca antes vista, pues el comercio alrededor del mundo ha incrementado de manera considerable, teniendo los comerciantes un sinumero de productos y servicios idénticos o similares en el mercado que buscan que los consumidores los identifiquen y diferencien para que puedan ser consumidos. Es por ello que los competidores tratan de que su marca quede lo más posiblemente plasmada en la mente del consumidor. Sin embargo, con las marcas tradicionales, hoy en día, esto se torna más díficil, pues los consumidores estan invadidos de estos tipos de marcas, no quedándoles alternativa a los 
competidores de buscar estrategias para que sus marcas puedan cumplir su función principal. Es por ello que las marcas no tradicionales no visibles, como los sonidos, los olores, las texturas y los sabores, son signos que actualmente se estan utilizando como una forma innovadora de distinguir los distintos bienes en el mercado, captándo más la atención del público consumidor.

Es por esta razón que la figura de la marca esta variando a la situación tanto social, económica y comercial en la que estamos viviendo actualmente. Si anteriormente bastaba con las marcas tradicionales para distinguir productos o servicios en el mercado, ahora ya no, pues los comerciantes necesitan distinguir sus bienes de manera más atractiva, reiterándose, de manera que sus marcas queden lo más plasmadamente posible en las mentes de los consumidores. Asimismo, como vimos en el capítulo II, el concepto de marca tradicional o no tradicional varia de acuerdo a las circunstancias del momento, pues muchos de los signos que son considerados tradicionales hoy en día, en el pasado han podido ser considerados como marcas no tradicionales y, en consecuencia, es probable que los signos no visibles, que ahora los incluimos dentro del concepto de marcas no tradicionales, en el futuro sean tratados como marcas tradicionales.

En consecuencia, los usos y costumbres de los empresarios harán que los consumidores puedan percibir los signos no visibles como marcas, tal como en el pasado ha podido variar la percepción de esta figura (que identificaba en principio el lugar de origen de los productos), como los signos que se consideraban como tradicionales o no.

Adicionalmente, ya en el caso estadounidense In re Clarke, se corroboró que la solicitante de registro de una marca no tradicional no visible (una marca olfativa) para distinguir hilos y fibras para bordados, demostró que tanto los consumidores, comerciantes y distribuidores habían llegado a identificar estos productos por su aroma, con ayuda de una buena campaña publicitaria. En ese sentido, carece de asidero el argumento de que los consumidores no podrían percibir a los signos no visibles como marcas. 
d) El derecho marcario otorga el derecho de uso exclusivo de un signo a su titular, y prohibe la utilización de dicho signo por parte de terceros sin su autorización; sin embargo, el derecho marcario no regula la forma en como se utiliza dicho signo distintivo en el comercio, por lo que carece de asidero el argumento que señala que los consumidores no podrían percibir los signos no visibles como marcas antes de realizar la compra de algún producto o servicio $\mathrm{y}$, por ello, no podrían ser admitidos como $\underline{\text { marcas }}$

Debe precisarse que en el caso de las marcas sonoras, estas pueden ser rápidamente percibidas por los consumidores antes de realizar sus compras a través de medios como la televisión, la radio, las redes sociales, entre otros medios de comunicación.

Sobre las marcas táctiles y olfativas, si bien mediante los antedichos medios de comunicación no se pueden oler $^{33}$ ni percibir las texturas de los productos, estos sí pueden percibirse antes de realizar la compra, pudiendo los competidores utilizar dichos signos en los empaques de los productos, o en un establecimiento comercial antes de elegir un servicio. Sin embargo, debe recordarse que el registro de una marca otorga a su titular el derecho de uso exclusivo sobre esa marca y la protege contra los usos no autorizados en el comercio por parte de terceros, no regulando el Derecho de Propiedad Intelectual la forma de uso en el mercado de ese signo distintivo; es decir, al igual que una marca visual, si bien el registro protege que el titular tenga el uso exclusivo de dicha marca, y que nadie más en el mercado la utilice sin su autorización para realizar actos de comercio, si el titular decide utilizar la marca dentro del contenido de un empaque, de forma que el consumidor no pueda percibirla, por medio del sistema marcario o de la propiedad intelectual nada se podrá hacer, siendo quizás este tema competencia del derecho a los consumidores, en lo concerniente al derecho a la información, más no una situación vinculada al registro de signos distintivos como marcas.

Sobre las marcas gustativas, si bien puede utilizarse los mismos argumentos expuestos en el párrafo anterior, se considera que sí habría incovenientes prácticos en

\footnotetext{
${ }^{33}$ Aunque debe recordarse que ya se ha evidenciado tecnología que permite percibir olores por medio de mensajes de texto.
} 
que los consumidores puedan percibir estas marcas antes de efectuar la compra de los productos, pues la única forma de que los consumidores puedan percibirlos es probando los productos antes de comprarlos, que por la misma naturaleza del signo sería inviable. Asimismo, de lo expuesto en el capítulo III, puede observarse que se ha encontrado casos e intenciones de utilizar y/o registrar marcas gustativas principalmente para distinguir productos farmacéuticos, por lo que el consumidor solo podría percibir el signo al momento de consumir el producto mas no antes de la compra. Debe recordarse que no se ha encontrado algún caso de marcas gustativas para distinguir servicios. En ese sentido, si bien una marca gustativa en teoría puede constituirse como marca, se considera que no tiene viabilidad practica ${ }^{34}$.

e) Las marcas no tradicionales no visibles usualmente pueden poseer distintividad inherente y, dificilmente podrá aplicarse la figura del "secondary meaning" para que puedan ser registradas.

Es necesario recalcar que, sobre las marcas sonoras, la mayor parte de la doctrina considera que estos tipos de marcas pueden poseer distintividad inherente. Inclusive, Baldo Kresalja (2001) manifiesta que "no estaría en dicusión su capacidad de distinguir". Asimismo, en nuestro día a día podemos corroborar que las personas son capaces de distinguir y diferenciar gran cantidad de melodías, canciones, sonidos, ruidos, y darles diversos significados. Adicionalmente, como se ha visto, alrededor del mundo, así como dentro de los Países Miembros de la CAN, e incluso en el Perú ya tenemos registradas un gran número de marcas sonoras, y los solicitantes no han necesitado demostrar que los mismos hayan adquirido distintividad sobrevenida para que hayan sido posibles sus registros como marcas. En esta linea, puede decirse que para los países andinos y, en particular, en el Perú, se considera que los sonidos por si mismos pueden poseer distintividad inherente.

Sobre los otros tipos de marcas no tradicionales no visibles, si bien predomina la idea de que solo pueden llegar a ser distintivos por medio de su constante uso en el

\footnotetext{
34 Por otro lado, muchas veces las marcas, con el fin de que sean publicitadas, no se encuentran necesariamente junto al producto que desean distinguir, encontrándose muchas veces en llaveros, tarjetas de presentación, lapiceros, entre otros.
} 
mercado, debiendo configurarse lo que se conoce como "secondary meaning", es necesario analizar esta figura.

Sobre el particular, el Tribunal de Justicia de la Comunidad Andina, en el Proceso 388-IP-2015, sobre la distintividad adquirida o "secondary meaning” manifestó lo siguiente:

44. (...) el régimen comunitario sobre protección de la propiedad intelectual descansa principalmente en el principio de la protección al esfuerzo empresarial (...). Si un empresario (...) convierte por su uso constante, real y efectivo en el mercado, un signo

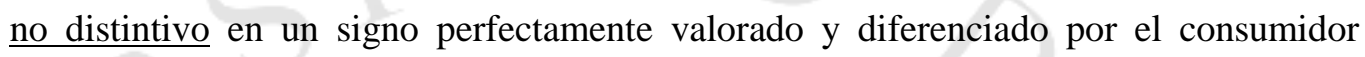
como distintivo de determinados productos o servicios; resulta natural que obtenga protección a su esfuerzo y actividad empresarial y, en consecuencia, evitar así que su solicitud sea denegada o su registro sea declarado nulo (...).

45. En el Acuerdo de Marrakech, en su anexo 1C, relativo al $<<$ Acuerdo sobre los Aspectos de los Derechos de Propiedad Intelectual Relacionados con el Comercio>> (ADPIC), establece lo siguiente:

“Artículo 15.1: (...) Cuando los signos no sean intrínsecamente capaces de distinguir los bienes o servicios pertinentes, los Miembros podrán supeditar la posibilidad de registro de los mismos al carácter distintivo que hayan adquirido mediante su uso (...)"

46. En otras palabras, signos que inicialmente no tenían aptitud para individualizar productos o servicios pueden ser protegidos por el carácter distintivo que adquieren por $\underline{\text { su uso como marca. }}$

47. (...) la distintividad adquirida flexibiliza el régimen atributivo por el registro en materia de marcas, otorgandole valor al uso previo al registro y estableciendo una importante excepción a determinadas causales de irregistrabilidad de carácter absoluto contempladas en el artículo 135 de la Decisión 486. En palabras de Carlos Correa: “(...) Según el derecho de marcas, por lo general se ha aceptado que la falta de carácter distintivo intrínseco no significa necesariamente que se excluya la protección si ha adquirido dicho carácter a través del uso.

48. En virtud de la figura para distinguir la distintividad sobrevenida, un signo que $a b$ initio no era distintivo ha cumplido tal requisito por su uso constante, real y efectivo en 
el mercado. En efecto, la Decisión 486 consagra la figura en el último párrafo del artículo 135, de la siguiente manera:

\begin{abstract}
"No obstante lo previsto en los literales b), e), f), g) y h), un signo podrá ser registrado como marca si quien solicita o su causante lo hubiese estado usando constantemente en el País Miembro y, por efecto de tal uso, el signo ha adquirido aptitud distintiva respecto de los productos o servicios a los cuales se aplica".
\end{abstract}

49. En consecuencia, la norma comunitaria contempla los siguientes presupuestos para que opere la figura estudiada, los cuales deben ser tenidos en cuenta por el Juez Consultante: El primer requisito fundamental para que opere la distintividad adquirida es que el signo que se pretende solicitar para registro o que se registró, ab initio no reúna el requisito de la distintividad. El otro requisito esencial es el uso constante, real y efectivo en el mercado sobre un territorio determinado.

(...)

51. (...) en el Proceso 92-IP-2004, el Tribunal ha indicado lo siguiente:

“(...) un signo podrá ser registrado como marca si, a pesar de no ser distintivo ab initio, o de ser descriptivo, o genérico, o común o usual, o de consistir en un color no delimitado en una forma específica, quien solicita el registro, o su causante, lo hubiese estado usando constantemente en el País Miembro y, por efecto de tal uso, el signo hubiese adquirido aptitud distintiva respecto de los productos o servicios a los cuales se aplica. En la doctrina se explica que 'un término originariamente genérico puede llegar a dejar de serlo y adquirir el carácter distintivo típico de una marca. (...) (BERCOVITZ, Alberto; ob.cit.,p.471).

52. Se advierte que la figura de la distintividad adquirida se genera sobre cualquier $\underline{\text { signo que en un principio no reunía los requisitos de registrabilidad establecidos en los }}$ literales b), e), f), g) y h), del artículo 135". (Los subrayados son míos).

En efecto, de lo expuesto por el Tribunal de Justicia de la Comunidad Andina puede apreciarse que para que se configure la distintividad sobrevenida, en nuestro régimen andino se necesita como presupuestos que: i) el signo, en principio, carezca de distintividad intrinseca, especificamente, que no reuna los requisitos de registrabilidad establecidos en las letras b), e), f), g) y h) del artículo 135 (es decir, por ser descriptivo, 
genérico, común o usual o consistir en un color no delimitado por una forma específica) $\mathrm{y}$, ii) que por su uso real, constante y efectivo en el mercado haya logrado que los consumidores distingan los servicios o productos a los cuales se aplica el signo.

Bajo la misma linea, el INDECOPI en diversas ocasiones ha indicado estos mismos presupuestos para que se configure el "secondary meaning". En efecto, en un caso más reciente, en la Resolución $\mathrm{N}^{\circ}$ 0578-2017/TPI-INDECOPI, la Sala Especializada en Propiedad Intelectual del Tribunal del INDECOPI manifestó:

Se denomina secondary meaning al fenómeno por el cual un signo originariamente desprovisto de capacidad distintiva se convierte - por consecuencia fundamentalmente del uso- en identificador de los productos o servicios de un determinado empresario.

Así, en ciertos casos, a raíz de una vasta campaña publicitaria y de un uso prolongado en el comercio, una marca que inicialmente no era distintiva, es decir que no permitía identificar los productos o servicios a los que se refería con un origen empresarial determinado, puede adquirir para el público un "significado secundario", es decir, un $\underline{\text { significado especial que va más allá del significado primario, genérico o descriptivo que }}$ normalmente tiene ese signo, el cual sirve para indicar el origen empresarial del producto o servicio particular de que se trata en relación con otros productos o servicios de la misma categoría.

De la jurisprudencia de derecho comparado puede citarse el caso de la agencia de alquiler de automóviles "Dollar-a-day” (un dólar por día) que presentó una solicitud de registro de su marca de servicio del mismo nombre en los Estados Unidos de América. $\underline{\text { Si bien en principio esta expresión resulta descriptiva de los servicios que se querían }}$ distinguir, se consideró que la marca había adquirido un significado secundario a raíz de una campaña publicitaria lanzada en todo el país y también por el hecho de que la agencia tenía oficinas en muchos lugares, que tenía millares de clientes y que la expresión "Dollar-a-day" no había sido usada para distinguir los mismos servicios por ningún otro competidor, por lo que la expresión en cuestión era reconocida por el público consumidor como un signo especial distintivo de los servicios de una empresa en particular, y no como una descripción genérica empleada por todas las empresas del mismo giro empresarial (Los subrayados son mios). 
Por lo expuesto, no cabe duda que tanto a nivel nacional como andino, la figura del "secondary meaning" es utilizada con la finalidad de que un signo, que en principio no tenía distintividad inherente (por ser descriptivo, genérico, de uso común, entre otros) y que haya adquirido distintividad a consecuencia de su uso constante, real y efectivo en el comercio, pueda registrarse como marca.

En efecto, tal como hemos indicado, a nivel andino se ha considerado que los signos no visibles, por sí mismos, pueden tener la aptitud de distinguir productos o servicios en el mercado; sin embargo, en cada caso particular, en virtud al Principio de Especialidad expuesto en el capítulo II, esta aptitud distintiva debe analizarse en relación a los productos o servicios que se buscan distinguir. Asimismo, tal como se ha establecido en el Proceso 242-IP-2015, las prohibiciones absolutas de que los signos de uso común o genéricos no podrán registrarse como marcas también son aplicables en el caso de los signos no visibles ${ }^{35}$. Adicionalmente, cabe recordar también que según la doctrina expuesta en el capítulo anterior, los signos no visibles tampoco deben ser descriptivos del producto o servicio que buscan distinguir.

En este orden de ideas, pese a que de la lectura del artículo 135 se evidencia que ha sido redactado pensándose solamente en las marcas visuales, debe concluirse que para que se configure el "secondary meaning" en relación a las marcas no visibles, estas no deben ser, en principio, inheremente distintivas en relación a los productos o servicios que pretenden distinguir; es decir, deben ser genéricas, usuales o de uso común (entre otros), pero no puede decirse que estos de plano solamente podrían adquirir distintividad sobrevenida, porque, como ya se ha expuesto, a nivel andino se ha considerado que estos signos por si mismos pueden ser aptos para distinguir productos o servicios en el mercado; además, hoy en día a la ciencia no le cabe duda que todos los sentidos del ser humano, tanto la vista, el oído ${ }^{36}$, el sabor, el tacto y olfato, son medios

\footnotetext{
${ }^{35}$ Sobre este tema, debe recordarse que en el Comité Permanente sobre el Derecho de Marcas, Diseños Industriales e Indicaciones Geográficas de la OMPI (2007) se indicó que "los sonidos que se consideran habituales en una rama comercial y cuya utilización es reivindicada por los comerciantes no se pueden registrar como marcas".

${ }^{36}$ Debe recordarse que en la décimo sexta sesión el Comité Permanente sobre el Derecho de Marcas, Diseños Industriales e Indicaciones Geográficas de la OMPI (2006) se indicó que no podía descartarse la capacidad intrínseca del olfato para distinguir.
} 
de adquisición de conocimientos de los seres humanos y, con estos, su capacidad de diferenciar y distinguir diversas cosas y situaciones, y darles diferentes significados.

En ese sentido, para que pueda configurarse el "secondary meaning", al igual que sucede en los casos de las marcas visuales, las marcas no tradicionales no visibles deberán ser, en principio, genéricos, usuales, de uso común en el mercado, descriptivos (entre otros); es decir, no poseer aptitud distintiva en relación a los productos o servicios que buscan distinguir, y, posteriormente, por medio de sus usos reales, constantes y efectivos en el mercado deberan lograr ser distintivos para los consumidores, y lograr distinguir con ellos los bienes a los cuales estos signos se aplican.

Sin embargo, a diferencia de lo que diversos autores han manifestado, se considera que es más complicado que un signo no visible (a excepción de los signos sonoros), por su misma naturaleza, pueda adquirir significado secundario. Esto en virtud a que el modo de percibir un signo táctil, gustativo u olfativo, por parte del consumidor, es usualmente mediante el contacto directo con algún producto u objeto (en el caso de los signos olfativos, también con el servicio), y en el caso de los signos visibles, no solamente pueden percibirse visualmente, sino también pueden leerse y vocalizarse, y al igual que los signos sonoros, pueden publicitarse por distintos medios de comunicación; por ejemplo, facilmente puede ser de entendimiento del público consumidor que la marca "El Periódico" para distinguir periodicos, sea una marca que identifica dichos productos, por medio de un esfuerzo y constante uso en el mercado, y gran publicidad. Es por este motivo, que tanto los signos visibles, como los signos sonoros, que sean genéricos, usuales, descriptivos, entre otros, pueden, por su uso constante, efectivo y real en el mercado, adquirir distintividad sobrevenida; pero dificilmente el olor a cacao para distinguir chocolates, va a poder adquirir distintividad sobrevenida, o el olor a menta para distinguir caramelos de menta, o el olor a limón, usualmente utilizado para distinguir productos de limpieza, pues su único medio de percepción, hasta el momento, es por medio del contacto directo con algún producto, servicio y/o el signo. Esto mismo sucede con los signos táctiles y gustativos. 
f) Las marcas no tradicionales no visibles pueden ser utilizadas separándose del producto que distinguen $\mathrm{y}$, en caso de utilizarse en el mismo producto, los signos deben darle un elemento extra al mismo, no debiendo ser un atributo inherente. Por esta razón, carece de asidero el argumento que manifiesta que algunos signos no visibles no podrán registrarse como marcas por no poder separarse de los productos que buscan distinguir

Es necesario indicar que debe diferenciarse el empaque del producto con el producto mismo, pudiendo claramente colocarse algunos de estos signos en el empaque mas no en el producto. Asimismo, en caso de colocarse estos signos en el mismo producto, debe tenerse en consideración lo manifestado por Marlee Savourin sobre los signos olfativos: "Son aromas que van más allá de ser una característica intrínseca del producto o servicio y para que se consideren como tal, inexorablemente, tienen que añadirle un valor extra a lo que representen" (Savourin, Marlee, 2014) (El subrayado es mío). Lo que de la misma manera debe aplicarse para los signos táctiles y gustativos.

En efecto, por más que los signos no visibles se encuentren en los productos, estos deben darle un valor extra, no siendo una característica intrínseca de los mismos.

g) No puede alegarse que no pueden registrarse marcas no tradicionales no visibles por $\underline{\text { ser percibidas de manera subjetiva por parte de los consumidores, pues eso equivaldría }}$ a decir que todo conocimiento adquirido por los sentidos, además del visual, es subjetivo.

Se considera que carece de asidero el argumento de que los signos no visibles, como los signos olfativos, táctiles y gustativos serían percibidos de manera subjetiva, y no objetiva, por parte de las personas. Pues no se ha encontrado algún estudio científico que determine la subjetividad en la percepción de los sentidos por parte de los seres humanos. Por el contrario, Lorenzo Vicente Burgoa (2014), ha manifestado que:

(...) se ha defendido que los colores, los sabores, olores y otras cualidades similares son algo puramente subjetivo, no algo real y objetivo. Dependerían, por tanto, del sujeto cognoscente. (...)

Frente a esto, sin embargo, tenemos: 
1) Que, como ya vimos, la naturaleza o esencia de tales cualidades no se percibe por los sentidos, sino por la razón; pero que percibimos tales cualidades justamente en cuanto son un tipo de energía de la materia, en cuanto estimulan nuestros sentidos: luego como algo de tipo objetivo, no subjetivo. Sin estimulo no hay sensación. Y por ello tampoco percibimos tales cualidades a nuestro arbitrio o según nuestros deseos. Y ello, incluso aunque el órgano de percepción sea algo del sujeto, como en los olores y sabores. Pero no es lo mismo ser "de un sujeto" que ser puramente "subjetivo". Todo conocimiento es acto de un sujeto; más no por ello es "subjetivo" en cuanto a su contenido, que es de lo que se trata.

2) De modo general, y dado que tales cualidades son los "objetos primarios y formales" de los sentidos, si ellas no fueran objetivas, nada de cuanto percibimos por los sentidos sería objetivo; no correspondería al medio objetivo. Por lo que los sentidos serían, en los animales, órganos completamente inútiles, si no ya nocivos y engañosos. (...) (p.349). (Los subrayados son míos)

Asimismo, concordamos con la posición del solicitante de la marca olfativa "olor a fresa" expuesto en el capítulo anterior, en el que para el registro de signos no visuales, como para cualquier marca, no existe un requisito o criterio basado en la objetividad del signo, sino que este debe ser distintivo en virtud a los productos o servicios a los cuales se aplica. En ese sentido, consideramos de que el hecho de que los signos no visibles no sean aun frecuentemente utilizados en el comercio, no es motivo para exigir más requisitos, pues tampoco hay certeza de que lo que percibimos mediante el sentido de la vista sea menos o más objetivo de lo que percibimos mediante los sentidos del olfato, gusto, tacto o sonido.

h) Los signos no visibles que se pretenden registrar como marcas, de acuerdo a lo establecido en el Proceso 242-IP-2015 del Tribunal de Justicia de la Comunidad Andina, en su numeral 137, con relación a las letras c) y d) del artículo 135 de la Decisión 486, no deberan consistir en olores, texturas, sabores o sonidos usuales de los productos o de sus envases, caracteristicas impuestas por su naturaleza o función, o que dichos olores, texturas, sabores o sonidos otorgen una ventaja funcional o técnica al producto o al servicio al cual se aplican. 
Sobre este aspecto, debe recordarse que en el antedicho Proceso 242-IP-2015, el Tribunal de Justicia de la Comunidad Andina precisó que a diferencia de lo que sucede en la Unión Europea, en la normativa andina no se prohibe la forma y/o signos no visibles que otorguen un valor sustancial al producto que afecte su valor intrinseco, sin embargo, se reitera, es necesario que para el registro de signos no visibles se corrobore que estos no otorgan una ventaja funcional al producto, pues como se ha visto, la funcionalidad del signo también ha sido un obstáculo para el registro de estos tipos de signos alrededor de mundo.

Debe recordarse que la Junta de Juicios y Apelaciones sobre Marcas de los Estados Unidos (TTAB) estableció que los criterios para determinar la funcionalidad de un signo son los siguientes: i) la existencia de una patente de utilidad (o, consideramos, de invención, según sea el caso) evidenciando sus ventajas utilitarias, ii) la existencia de materiales publicitarios en el cual el solicitante del signo promocione sus ventajas utilitarias, iii) la disponibilidad del producto para la misma función para los competidores $y$, iv) la existencia de evidencia que demuestre que el signo comparativamente es un método más simple o más barato para producir el producto.

Debe recalcarse que, como ya hemos visto, en Estados Unidos se necesita que el signo distintivo sea usado en el comercio para que obtenga protección, a diferencia del regimen andino, en donde solo el registro constituye los derechos sobre las marcas, por lo que si bien el punto número ii) ayudaría a determinar si un signo no visible es funcional o no, puede ser probable que la marca no esté en uso al momento de solicitar su registro, y que tampoco haya publicidad sobre ella. Sobre los demás criterios, no encontramos obstáculo o limitación para que las oficinas de propiedad intelectual de los países miembros, así como el INDECOPI utilicen estos criterios para determinar si un signo, en particular, los signos no visibles, son funcionales o no.

Asimismo, debe reiterarse, refiriendonos al Proceso 242-IP-2015, que el signo no visible demuestre que otorga un valor sustancial al producto que afecta su valor intrinseco no se encuentra contemplado como prohibición para que estos signos sean registrados como marcas, por lo que en ningún caso este deberá ser un criterio para denegar las solicitudes de registro. 
i) La denegación de un signo no visible como marca deberá sustentarse en las prohibiciones absolutas o relativas establecidas en la Decisión 486, y respetando el Principio de Especialidad. Sobre el particular, no deberá denegarse el registro de un $\underline{\text { signo sonoro bajo el sustento de que la melodía o ruido tiene corta o mucha duración, }}$ $\underline{\text { basta con que sea distintivo de acuerdo al producto o servicio que pretende distinguir }}$ para que pueda ser registrado como marca

Debe reiterarse que al momento de realizar el análisis de distintividad de un signo para que pueda ser registrado como marca, las Oficinas de Propiedad Intelectual deberán evaluarlo de acuerdo a los productos o servicios para los cuales se van a utilizar (principio de especialidad); por este motivo, consideramos que los criterios expuestos en los casos prácticos de las marcas sonoras, como de no concederse su registro por ser muy simples (como los criterios expuestos por la Superintendencia de Industria y Comercio - SIC, en las resoluciones 42107 y 33397) por tener poca duración o, por el contrario, por ser muy extensas ( como se muestra en la resolución 82327 emitida por el SIC) son errados, pues si estos criterios no se encuentran en las causales de prohibiciones absolutas y relativas no deben considerarse como obstáculos para el registro de estos tipos de signos; asimismo, no puede determinarse por el grado de duración de un sonido si tiene la potencialidad de ser distintivo o no, a menos que este no lograra percibirse por el público consumidor y, se reitera, este análisis debe realizarse de acuerdo a los productos o servicios que pretenden distinguirse. En ese sentido, consideramos errado que se haya denegado el registro del signo sonoro "ding dong" (sonido de timbre) para distinguir servicios de las clases 35, 36, 38, 39, 41 y 42, alegándose que era muy simple, pues este análisis debió realizarse dependiendo de los servicios que se pretendían distinguir, y no mediante un argumento que carece completamente de asidero. Lo más importante es si el signo tiene la potencialidad para ser distintivo, y no su grado de duración.

i)La falta de novedad de un signo no visible no debe ser un motivo para denegar su registro, pues a diferencia de la Decisión 85, la Decisión 486 no lo exige como requisito para que un signo pueda registrarse como marca 
En efecto, debe recalcarse que, a diferencia de lo establecido en la derogada Decisión 85, la Decisión 486 no exige este requisito, por lo que no debería ser un argumento de las Oficinas de Propiedad Intelectual para denegar las solicitudes de registro de marcas no tradicionales no visibles; no obstante, no puede negarse que el hecho de que el signo no visible sea novedoso aumenta sus probabilidadades de ser distintivo, al igual que para un signo visible, una marca de fantasía tiene mayor grado de distintividad y, por ende, mayor grado de protección. Por este motivo, consideramos errado lo dispuesto en el caso europeo "olor a hierba recién cortada" en cuanto la OAMI estableció que mientras más conocido sea un olor más distintiva sería la marca olfativa.

k) Para registrar marcas no tradicionales no visibles las Oficinas Nacionales Competentes deberán analizar si el sonido, olor, sabor o textura son distintivos o no y/o $\underline{\text { si son semejantes o iguales a otros ya utilizados en el mercado, y no las }}$ representaciones que se aportan para efectos de la publicidad del registro, como los pentagramas, notas musicales, formulas químicas, descripciones, dibujos, entre otras

En efecto, se dice que una marca sonora carece de distintividad si las notas que la conforman son iguales o similares a las notas de sonidos o melodias previamente registradas. Sobre el particular, cabe recalcar que en una marca sonora lo que debe ser distintivo es el sonido y no sus notas musicales; es decir, puede que las notas musicales de sonidos o melodias sean semejantes, pero si al momento de percibir los sonidos o melodías son distintas, es esta distinción la que debe prevalecer. Lo mismo ocurre en el caso de las marcas olfativas, por más que dos de este tipo de marcas esten compuestos por formulas semejantes, lo importante es que al momento de percibir dichos aromas sean distintivos.

Al respecto, consideramos acertada la posición del Tribunal Supremo de Holanda, en el caso del perfume Tresor, cuando señaló que:

(...) la elaboración de un perfume a partir de ingredientes distintos, pero que a su vez transmiten la misma fragancia que otro podría constituir una infracción, mientras que por el contrario, tal no sería el caso de dos perfumes que tienen fórmulas similares, pero cuya fragancia es distinta (como se citó en Ferrero, 2009, p.332). 
En ese sentido, lo que debe ser distitivo en las marcas no tradicionales no visibles, en el caso de los signos sonoros, es el sonido o melodía, y no sus notas musicales o los pentagramas que se presentan al momento de la solicitud; de la misma forma para los otros tipos de signos no visibles, para las marcas olfativas y gustativas, lo que debe ser distintivo son los aromas y sabores, y no los ingredientes o fórmulas presentadas; así como para las marcas táctiles, las descripciones o dibujos que se utilizan para explicar la composición de la marca no es lo relevante para determinar la distintividad de estos tipos de marcas, sino la textura del producto que se utiliza como marca.

Por otro lado, es por esta misma razón que consideramos errada la posición de que los signos táctiles serían percibidos por los consumidores como meros elementos decorativos de los productos que desean distinguir, pues el término decorar, de acuerdo al Diccionario de la Real Academía Española (2014), se define de la siguiente manera: “(...)1. tr. Adornar, intentar embellecer una cosa o un sitio. Decorar la pared, los salones.

2.tr. Servir para adornar o embellecer algo. U. t. c. intr. Las flores decoran mucho (...)" (el subrayado es mío).

Como puede apreciarse, este término se refiere al intento de embellecer una cosa o sitio; es decir, a darle un mejor aspecto visual; sin embargo, en las marcas táctiles lo que debe predominar es la aptitud distintiva del tacto que los consumidores perciben al momento de interactuar con el producto u objeto, no teniendo relevancia si el aspecto visual de esa textura otorga un embellecimiento del mismo. En esta misma linea, piénsese en una marca visual, la cual se ha elaborado con gran creatividad, que al utilizarla sobre un determinado producto, esta logre que el mismo se perciba de una forma más bella o atractiva por parte de los consumidores; sin embargo, este no es un argumento para que esta marca sea denegada para que se registre como marca, pues lo que debe predominar es su aptitud distintiva.

1)Las marcas no tradicionales no visibles no deben consistir en el producto que buscan distinguir, debiendo ser un elemento extra y, no ser parte de la función principal o complementaria de dicho producto, para que pueda ser registrada. 
Al respecto, debemos precisar que consideramos acertada esta posición, pues tal como nos explica Christian Schmitz (2012), los empresarios buscan diferenciar sus productos y/o servicios, los cuales pueden copiarse por los competidores, pero su distintividad se logra con la marca, la cual es de uso exclusivo por parte de los empresarios y, por ende, no puede copiarse. Sin embargo, en el caso peruano, la Constitución Política del Perú (1993) señala que tenemos una economía social de mercado, en la cual se busca y protege la libre competencia; por lo que, no sería concorde a nuestra constitución que en aras de expandir el derecho marcario, se permita a los empresarios obtener el monopolio sobre la comercialización de un producto o servicio. En ese sentido, al realizar el examen de registrabilidad de un signo no visible se deberá tener en cuenta que este no consista en el producto mismo. No obstante, debe enfatizarse que, como hemos señalado, debe diferenciarse en muchos casos el producto del empaque que lo contiene.

Adicionalmente, en el caso de las marcas olfativas para distinguir perfumes, desodorantes, y productos afines, este argumento se ha tornado en un gran inconveniente, cabiéndo preguntarse si podrían registrarse los aromas de estos productos como marcas.

Cabe recordar la clasificación que Diego Chijane (2007) - al igual que Carlos Fernández - Novoa - nos indican, la cual ha sido muy discutida en doctrina para la protección de los olores como marcas:

- Primary scents marks: Estos aromas son aplicados a productos cuya función principal es producir dichos aromas. Este es el caso de los perfumes o los desodorantes (p.488). Como se ha visto anteriormente, hay discusión en la doctrina de si los aromas de estos productos pueden registrase como marcas o no, pues como se ha visto, particularmente en el caso Chanel $\mathrm{N}^{\circ} 5$, se dice que el olor no debe derivarse de la propia naturaleza del producto.

- Secondary scents marks: Estos aromas son aplicados a productos cuya función principal es enmascarar el olor original de los productos. Este es el caso de los detergentes o jabones. En estos supuestos, se estaría en presencia de olores que 
cumplirían un rol funcional. En este caso, de acuerdo a la doctrina de la funcionalidad, es muy probable que no puedan registrarse como marcas (p.488)

- Unique scents marks: Estos aromas son aplicados a productos a los cuales no interesa si tienen olor o no para que puedan utilizarse. Este es el caso, como explica el antedicho autor, del "aroma a hierba recién cortada" para diferenciar pelotas de tenis (p.488).

Se considera que los Unique scents marks y, quizás, los Secondary scents marks pueden ser registrados como marcas olfativas, pues en el caso de los Primary scents marks, como los perfumes y desodorantes, los aromas son los productos mismos que se desean comercializar en el mercado, no es un elemento extra del que nos habla Marlee Savourin. Asimismo, el aroma es parte de la función principal de dichos productos. Respecto a los Secondary scents marks, como los detergentes o jabones, si bien el aroma no es parte esencial de su función $y$, son elementos extras al producto, es un aporte que se ha vuelto usual $y$, hasta podría decirse, complementario para la comercialización de estos productos, por ello, se considera que se podrán registrar signos olfativos para distinguir estos productos siempre que sean novedosos y muy creativos.

En este orden de ideas, se discrepa en parte con la posición de Isabel Ramos (2014), cuando nos dice que los olores de los perfumes o desodorantes sí podrían ser registrados como marcas si la capacidad creativa de los empresarios puede hacer que el producto se vuelva distinguible, pues es un supuesto que encontramos remoto. Sin embargo, se reitera, sí se considera viable para el caso de los Secondary scents marks. Asimismo, debemos precisar que ya en la Decimoséptima Sesión del Comité Permanente sobre Derecho de Marcas, Diseños Industriales e Indicaciones Geográficas (2007) se dijo que "(...) la aplicación de un aroma a un producto que no lo suele tener ofrece muchas más posibilidades de ser registrada". Adicionalmente, de los casos de marcas olfativas en Colombia anteriormente expuestos, puede apreciarse que el SIC ha adoptado la posición de que el aroma no puede consistir en el producto mismo, siendo Colombia, el país miembro de la CAN que más experiencia ha tenido (aunque poca) en cuanto al tratamiento legal de las marcas no tradicionales no visibles. 
Sobre las marcas gustativas, estas marcas han sido atractivas principalmente para ser aplicadas a productos farmacéuticos, cuyos sabores son inevitables para cualquier producto que deba ingerirse, por lo que se considera que estos tampoco resultan distintivos para los consumidores y, por ende, tampoco podrán ser un elemento extra al producto que buscan distinguir, a menos que el sabor se encuentre en un producto no comestible.

m) Carece completamente de asidero la posición que establece que al permitir el registro de signos olfativos se estaría permitiendo la apropiación de uno de los cinco $\underline{\text { sentidos del ser humano }}$

Sobre el particular, consideramos que esta posición no tiene fundamento pues cuando se otorga el registro de una marca visual, no se está permitiendo la apropiación de un sentido del ser humano (el sentido de la vista) sino el derecho al uso exclusivo del signo, el cual puede ser visualizado por todos, pero no utilizado en el comercio para distinguir productos con conexión competitiva (sin autorización del titular). En este orden de ideas, el registro de una marca olfativa otorga el derecho de uso exclusivo de ese aroma a su titular, pero el público en general puede oler sin restricciones ese signo, más no utilizarlo en el comercio para esos mismos productos o servicios los cuales la marca distingue, sin autorización del titular.

n) La teoría del agotamiento del registro de marcas olfativas carece completamente de asidero como para no permitir el registro de este tipo de marcas.

Respecto a esta teoria, debemos recordar que Diego Chijane(2007) nos explica que cierta doctrina manifesta que los empresarios tendrían preferencia por utilizar determinados aromas y, al permitir el registro de marcas olfativas, la competencia trataría de registrar rapidamente todos estos aromas. Sobre el particular, se considera que esta posición carece completamente de asidero, pues los olores usualmente utilizados en el comercio no pueden registrarse como marcas y, esta prohibición absoluta debe determinarse de acuerdo a los productos o servicios para los cuales desean aplicarse (Principio de Especialidad). Asimismo, debe precisarse que las 
fragancias próximas o semejantes a las ya registradas para los mismos productos o servicios tampoco pueden registrarse como marcas, por haber riesgo de confusión o asociación en los consumidores.

o)El hecho de que solo una persona del rubro comercial utilice un tipo de signo no visible no debe ser determinante para permitir su registro o no como marca

Tal como se ha manifestado en el caso estadounidense In Re Clarke, en el que se solicitó el registro de una marca olfativa para distinguir hilos y fibras para bordados, y que la Autoridad Competente Estadounidense admitió dicho registro por haberse demostrado que la solicitante era la única que comercializaba dichos productos con aroma, debe recalcarse que si bien el hecho de que solo sea un solo competidor el que utilice un signo no visible en el mercado para determinados productos o servicios, no debe ser un referente predominante para admitir el registro de una marca olfativa, pues lo que se pretende es que la mayoría de los competidores puedan utilizar estos nuevos tipos de marcas; asimismo, reiteramos, para el registro de un signo como marca debe predominar su aptitud distintiva como requisito esencial para que pueda acceder a registro.

4.2 La eliminación del requisito de la representación gráfica para el registro de marcas no tradicionales no visibles y la admisión de muestras y/o reproducciones como representaciones indispensables para registrar estos nuevos tipos de marcas

a) El requisito de la representación gráfica en el régimen andino de propiedad $\underline{\text { intelectual }}$

Tal como vimos en el capítulo III del presente trabajo de investigación, la Decisión 486 no establece una definición de marca; sin embargo, de su lectura puede concluirse que es cualquier signo que sea apto para distinguir productos o servicios en el mercado; encontrándose a la representación gráfica como un mero requisito que, aunque indispensable, no forma parte del concepto de marca.

Debe recordarse también que en la derogada Decisión 85 no se hacía referencia a la representación gráfica del signo, debiendo en las solicitudes acompañarse y/o 
indicarse la descripción clara y completa de la marca, y las reproducciones si fuera el caso. Es una ironía que en esta norma andina se haya permitido la descripción del signo cuando ningún signo no visible podía constituirse como marca (pues en esta norma se establecía que el signo debía ser visible), y que cuando posteriormente se permitió expresamente el registro de estas marcas no tradicionales no visibles se haya exigido que el signo deba ser susceptible de representación gráfica.

En efecto, en la derogada Decisión 311, al mismo tiempo que se eliminó el requisito de la visibilidad del signo, también se estableció que debía ser susceptible de representación gráfica. En esta decisión puede verse la incoherencia de la norma en cuanto se indicó que en las solicitudes debía acompañarse y/o indicarse la descripción clara y completa de la marca, y la reproducción de la marca cuando tenga elementos gráficos. Sobre este último supuesto, era claro que siempre se iba a exigir la reproducción de la marca, pues la misma norma exigía que el signo debía ser susceptible de representación gráfica; por lo que una descripción clara y completa de la marca por sí sola no iba a ser aceptada.

En este orden de ideas, pese a que el requisito de la representación gráfica del signo nunca ha formado parte del concepto de marca, y que a sus inicios tampoco fue exigido, este ha tomado gran relevancia en el registro de signos como marcas. Inclusive, esto puede evidenciarse de la lectura del último párrafo del artículo 135 de la Decisión 486, en cuanto por más que un signo haya adquirido distintividad sobrevenida, y por ende se pruebe su uso constante, real y efectivo en el mercado, si el signo no cumple el requisito de la representación gráfica, no puede registrarse como marca, pues este último párrafo no contempla la letra a) para los casos de distintividad sobrevenida.

De lo expuesto, se considera que es correcto que el requisito de representación gráfica del signo no se encuentre, ni se haya encontrado en las decisiones andinas, dentro de la definición de marca, pues tal como lo hemos explicado, la función principal de la marca es distinguir productos o servicios en el mercado, es por ello que el requisito de distintividad es fundamental para que cualquier concepto de marca sea elaborado, pero no el requisito de la representación gráfica, pues este solo ha permitido el correcto funcionamiento del sistema marcario en cuanto a seguridad jurídica y a efectos registrales. 
b) Significado del requisito de susceptibidad de signo de ser representado gráficamente

En el presente trabajo hemos visto lo que significa susceptibilidad de representación gráfica. Debemos recordar lo que para la Real Academia Española (2014) esto significa:

- Susceptible: "1.Capaz de recibir la acción o el efecto que se expresan a continuación. $(\ldots) "(\ldots)$

-Representación: "1.f. Acción o efecto de representar. 2.f. Imagen o idea que sustituye la realidad. (...)"

- Grafico: "1.adj. Perteneciente o relativo a la escritura y a la imprenta. 2. adj. Dicho de una descripción, de una operación o de una demostración: que se representa por medio de figuras o signos" (los subrayados son míos).

En efecto, según esta definición para que un signo pueda registrarse como marca debe cumplir con ser capaz de ser representado por medio de figuras o signos, pertenecientes o relativos a la escritura y a la imprenta. En esta misma línea, para el General Ruiz - Jarabo Colomer:

Representar gráficamente es describir algo usando símbolos susceptibles de ser dibujados. Quiere esto decir que a la aptitud originaria de un signo cualquiera para distinguir debe añadirse su capacidad para ser "llevado a papel"; y por consiguiente, para ser visualmente percibido (como se citó en Fernández- Nóvoa, 2004, p.171).

Asimismo, en el caso europeo Shield Mark, sobre marcas sonoras se manifestó que un signo no visible podría ser registrado como marca, siempre que pueda ser representado gráficamente, “en particular, por medio de figuras, líneas, o caracteres, que sea clara, precisa, completa en sí misma, fácilmente accesible, inteligible, duradera y objetiva" (Tribunal de Justicia de la Unión Europea, 2003); es decir, de acuerdo a los criterios establecidos también en el caso Sieckmann.

En ese sentido, queda claro que bajo las definiciones del requisito de representación gráfica expuestas, las marcas no tradicionales no visibles para que puedan acceder a registro necesitan bajo la normativa andina que puedan ser reproducidas visualmente (es decir, mediante líneas, figuras, etc); sin embargo, cabe preguntarse cómo lograr que sean representadas de manera claras, precisas, completas 
en sí mismas, fácilmente accesibles, inteligibles, duraderas y objetivas, si tienen que representarse gráficamente.

\section{c) La razón de ser del requisito de la representación gráfica}

Diego Chijane (2007) nos comenta que el requisito de la representación gráfica es importante en el sistema marcario pues facilita el examen de los signos por parte de las Oficinas Nacionales Competentes, así como de sus publicaciones e inscripciones y, también para que los terceros interesados conozcan los límites de esos derechos, teniendo certeza cuáles son los signos que se han registrado, y saber cuáles todavía se encuentran disponibles, y no violar los derechos de los titulares de marcas. Este autor enfatiza que el sustento de la importancia del requisito de la representación gráfica es el Principio de Seguridad Jurídica del Sistema Marcario.

En esta misma linea, debemos recordar lo que se dijo en el caso Sieckmann (Tribunal de Justicia de la Unión Europea, 2002) sobre el mismo: “El sistema de registro de la marca constituye un elemento esencial de la protección de las mismas que contribuye a la seguridad jurídica y a la buena administración, tanto en el Derecho Comunitario como en los diferentes Derechos Nacionales".

Asimismo, en este mismo caso el Gobierno de Reino Unido manifestó que el funcionamiento del sistema marcario requiere claridad y precisión de las marcas que se registran, siendo suficiente que la marca sea representada en una forma que permita su identificación con claridad y precisión suficiente para que el usuario del registro pueda determinar de manera exacta el signo consultándolo. Bajo el mismo argumento, el Tribunal de Justicia de la Unión Europea, en este mismo caso, señaló que las autoridades competentes deben conocer el signo exacto que pretende registrarse para realizar los examenes de registrabilidad y, por otra parte, los operados económicos también deben tener este conocimiento para saber los derechos ya registrados y, saber qué signos pueden registrarse o no.

Como puede apreciarse, el requisito de la representación gráfica es una via para que los derechos marcarios tengan seguridad jurídica; es decir; para procurar el correcto 
funcionamiento y/o protección de las marcas ya registradas, y tener certeza de que estos derechos no se vulneren, dándose esta protección a través de la publicidad registral.

d) ¿El requsito de la representación gráfica cumple su función en el caso de registros de marcas no tradicionales no visibles?

Se considera que para marcas visibles, el exigir el requisito de la representación gráfica, el cual en realidad viene a ser la reproducción del signo visible, es eficaz para otorgar seguridad jurídica al sistema marcario, pues permite reproducir la marca exactamente igual tanto en la solicitud como en las publicaciones; sin embargo, esta misma seguridad jurídica no la otorga para marcas no tradicionales no visibles, pues no permite reproducir la marca exactamente como se percibe y esto es así porque su misma naturaleza de marcas no visibles hace imposible que puedan reproducirse de manera visible, es decir, gráficamente.

Es por ello que se considera que una marca no tradicional no visible nunca va a poder ser representada de manera completa en sí misma, clara, precisa, inteligible, comprensible y duradera, con todas estas cualidades, si se exige que esta representación sea gráfica.

Adicionalmente, debe enfatizarse que lo que es distintivo en la marca no tradicional no visible no es su aspecto visual, sino el sonido, el olor, el sabor o el tacto que se va a emplear para distinguir el producto o servicio, es por ello que para que haya seguridad jurídica, lo que las autoridades competentes (para realizar el examen de registrabilidad), y los operadores económicos (para saber qué signos se están registrando, y saber cuáles pueden registrarse y cuáles no, así como para asegurarse de no infrigir derechos de terceros) necesitan saber de manera completa, clara, precisa, inteligible, comprensible y de forma duradera cuál es el sonido, el olor, el sabor o el tacto que se desea registrar, y la única forma de tener este conocimiento es accediendo a estos signos; es decir, pudiendo consultar las reproducciones y/o muestras de las marcas no tradicionales no visibles. 
En ese sentido, el requisito de la representación gráfica no puede ser un obstáculo para el registro de marcas no tradicionales no visibles, tal como erróneamente lo han hecho las autoridades competentes de los paises que hemos estudiado en el presente trabajo de investigación, pues esta seguridad jurídica que es el fundamento de la exigencia del requisito de representación gráfica no cumple su fin en el caso de estos tipos de marcas. Asimismo, debe recalcarse que es la aptitud distintiva lo que dota que un signo pueda constituirse como marca, y no su representación gráfica.

e) El acogernos a una interpretación amplia del requisito de la representación gráfica $\underline{\text { tampoco permite que este requisito cumpla con su función }}$

En efecto, tampoco sirve tratar de acogernos a lo que se denomina "una interpretación amplia del requisito de representación gráfica". Recordemos que Carlos Fernández Novoa, y Diego Chijane, nos explican que hay dos formas de entender al requisito de representación gráfica: i) en sentido estricto y, ii) en sentido amplio.

Sobre el particular, se considera que la muestra y/o reproducción debe ser la representación principal de la marcas no tradicionales no visibles porque son los únicos medios de representación que le otorgan seguridad jurídica al sistema marcario en cuanto al registro de estas marcas, pues son los únicos que permiten percibir el signo tal cual es registrado y utilizado en el mercado. Por el contrario a lo que sería una interpretación en sentido amplio del requisito de la representación gráfica, consideramos que los demás medios de representación deben ser meros complementos, que si bien pueden publicarse (pues no hay fundamento jurídico ni fáctico que lo impida), solo servirán para aproximar a los usuarios al signo que se pretende registrar o ya registrado, de ser el caso, pero solo con la muestra y/o reproducción de la marca puede percibirse el signo no visible de manera exacta.

Concordamos con la posición en doctrina explicada por Diego Chijane (2007), en que "el mismo debe interpretarse conforme a la concepción moderna de marca, en la que incluyen diversos tipos de nuevos signos, entre ellos: colores, sonidos, hologramas, olores y otros capaces de desempeñar la función de marca en el mercado". Es por este motivo, que en efecto, el signo que pretende registrarse debe ser susceptible de 
representación, pero esta no debe ser gráfica para los signos no visibles; sin embargo, el requisito de la representación gráfica debe permanecer para los signos visibles por cumplir con el objetivo de brindar seguridad jurídica al sistema marcario.

f) No debe tomarse como referencia la Regla 3 del Tratado de Singapur para representar las marcas no tradicionales no visibles

Si bien en el Tribunal de Justicia de la CAN se estableció, en el Proceso 242-IP-2015, que el Tratado de Singapur servía como referencia fundamental para el registro de signos no visibles, y que debia ser una hoja de ruta para los paises menos adelantados, no consideramos que los medios de representación indicados tanto para los signos sonoros, como para los otros signos no visibles, cumplan con otorgar al sistema marcario seguridad jurídica para este tipo de marcas.

En efecto, la Regla 3 de este tratado, indica que para representar los signos sonoros, el solicitante deberá presentar una notación en pentagrama o descripción o grabación analógica o digital de ese sonido, o todo lo anterior; sin embargo, un pentagrama o una descripción no presentará el signo sonoro que distinguirá productos o servicios en el mercado, solo la grabación analógica o digital lo mostrará. Lo mismo ocurre para el registro de los otros signos no visibles, en el caso de los signos táctiles, un dibujo, una fotografía o una descripción no permitirá al usuario saber el signo que se registrará o la marca ya registrada, solo la muestra de la textura podrá permitirlo; en el caso de los signos olfativos, la formula química, una descripción, la indicación de su elaboración no permitirán al usuario saber cuál es el aroma que identificará y diferenciará los productos o servicios que se buscan distinguir, solo la muestra de ese aroma podrá cumplir con este fin; esto mismo ocurre en el caso de los signos gustativos. No obstante, debe reiterarse que estos medios gráficos expuestos pueden servir como complemento para efectos de la públicación de la marca no tradicional no visible, para orientar a los usuarios sobre las marcas que se pretenden registrar o las que ya estan registradas, indicándose en ellas el tipo de marca; sin embargo, será por medio de la muestra de estos signos y/o reproducción que podrá saberse con precisión qué signo no visible se busca registrar o ya se encuentra registrado. 
g) Los medios adecuados para representar un signo no visible, en aras de otorgar $\underline{\text { seguridad jurídica al sistema marcario, son la muestra física y/o reproducciones, y no }}$ una representación gráfica

Sobre el particular, en concordancia con la interpretación prejudicial establecida por el Tribunal de Justicia de la CAN, en el Proceso 242-IP-2015, se considera acertado que se haya señalado que es a la Oficina Nacional Competente a quien le corresponde solucionar la problemática de la representación gráfica y no al titular, debiendo identificar los medios adecuados para su publicación, exigir una o más representaciones de la marca, asi como su indicación y detalle sobre la misma, y sobre todo, se considera acertado el extremo en el que se indica que:

Se recomienda admitir representaciones de un signo distintas a las gráficas cuando estas sean más aptas para identificarlo, siendo suficiente que permita a las autoridades y al público consumidor determinar el objeto exacto de la protección conferida al titular (Tribunal de Justicia de la CAN, 2015).

En concordancia con lo expuesto, se reitera que las Oficinas de Propiedad Intelectual deben exigir representaciones distintas a las gráficas cuando se traten de signos no visibles, los cuales, por ser los únicos que pueden satisfacer a cabalidad la seguridad jurídica del sistema marcario, deben ser las muestras y/o reproducciones de estas marcas. En efecto, deberá exigirse que la representación de la marca deba ser gráfica solo cuando se trate de signos visibles.

Respecto a la publicación, consideramos también acertado lo manifestado en este proceso al considerar que de poderse publicar tanto la descripción como la fotografía, es necesario permitir a los usuarios acceder a la muestra fisica. En ese sentido, consideramos que cualquier representación "gráfica" de la marca no visible (descripción, fórmula, entre otros) podrá publicarse, indicando el tipo de marca que pretende registrarse: si consiste en una marca táctil, sonora, olfativa o gustativa; sin embargo, en esta misma publicación puede precisarse un plazo exacto para que los terceros interesados puedan acceder al signo no visible a registrar $\mathrm{y}$, después de este lapso, los terceros interesados pueden tener plazo para oponerse a las solicitudes, si consideran que sus derechos pueden vulnerarse. 
Debe indicarse que nos sorprende que luego de que el Tribunal de Justicia de la CAN haya hecho esta interpretación prejudicial, la Superintendencia de Industria y Comercio de Colombia haya utilizado de manera estricta los criterios recogidos en el caso Sieckmann para denegar las solicitudes de registro de marcas olfativas vistos en el capítulo anterior.

En este orden de ideas, acogemos la experiencia norteamericana de solicitar para el registro de este tipo de marcas tanto una descripción, conjuntamente con la muestra y/o reproducción de la marca (la cual es la que debe prevalecer); sin embargo, debe permitirse a los terceros interesados acceder a ella.

h) La eliminación del requisito de la representación gráfica en la Unión Europea no ha $\underline{\text { significado un avance para el registro de marcas no tradicionales no visibles, con }}$ excepción de las marcas sonoras, las cuales, dentro de la categoria de las marcas no tradicionales, son las menos complejas; por lo que no es adecuado que el sistema andino tome como referencia la posición europea en el tratamiento de marcas no $\underline{\text { tradicionales no visibles }}$

Si bien en un comienzo, los medios y muchos especialistas en Propiedad Intelectual pensaron de que el eliminar el requisito de la representación gráfica en la Unión Europea era para favorecer el registro de signos no visibles, se puede concluir que en virtud al Reglamento de Ejecución (UE), apartado 4 y 9 del artículo 3, y de la Decisión EX17-1, esta supresión solo beneficia al registro de signos sonoros, pues consideran que no existe actualmente medios tecnológicos que permitan representar las marcas táctiles, gustativas y olfativas.

i) En virtud a lo expuesto, indicaremos cómo deben representarse las marcas no $\underline{\text { tradicionales no visibles para que puedan acceder a registro }}$

Ahora que hemos indicado que es la muestra y/o reproducción del signo no visible lo que permitirá otorgar al sistema marcario la seguridad jurídica que requiere para su buen funcionamiento, y que los otros medios de representación "gráfica" solo deben ser 
meros complementos para efectos de la publicación, cabenos referirnos a cada uno de estos tipos de marcas:

- Marcas sonoras:

Para registrar los signos sonoros como marcas, los solicitantes deberán presentar el archivo de sonido, permitiendo que los terceros interesandos puedan acceder a este antes y después del registro. Se considera que no es necesario solicitar otro tipo de representación, pues la tecnología hoy en día permite reproducir el sonido de manera electrónica; en efecto, ahora que las publicaciones se efectúan en la Gaceta Electrónica de Propiedad Industrial del INDECOPI, no se ve inconveniente en que puedan reproducirse los archivos de sonidos que se pretenden registrar y que en el Portal Web del INDECOPI se puedan almacenar y reproducir los signos sonoros ya registrados, tal como ya se hace en la USPTO.

Sin embargo, mientras no se implemente en estos medios la posibilidad de reproducir los archivos de sonido, se considera que deberían depositarse en la Oficina de Propiedad Intelectual (permitiendo su acceso a los terceros interesados), y para efectos de su publicación, los solicitantes podrán presentar la descripción del sonido.

Asimismo, se considera que un pentagrama para efectos de publicación del signo sonoro no es idóneo, debido a que entrariamos al mismo problema de tratar de determinar si este concuerda con exactitud con el sonido que pretende registrarse, y se dilaten y abandonen los procesos, tal y como hemos visto en los casos expuestos; en cambio, una descripción es una mera aproximación al signo y, en caso, el INDECOPI considere que la descripción no se aproxima al signo no visible, es deber de esta Oficina sugerir al titular la descripción que podría utilizarse a efectos de la publicación de la marca no tradicional no visible. Por ende, y de acuerdo al artículo 52 del Decreto Legislativo 1075, se le otorgará un plazo de sesenta (60) días para que subsane dicho requisito y no esperar a la resolución final para establecer que el signo no ha sido representado correctamente y denegar el registro de la marca. 
- Marcas táctiles

Para registrar signos táctiles, los solicitantes deberán representarlos mediante la muestra de la textura que identificará los productos o servicios en el mercado, permitiendo a los terceros interesados el acceso a esta, antes y después del registro. Asimismo, para efectos de su publicación, se considera que la manera más próxima de representar estos tipos de marcas es con la descripción de la textura y una fotografía o dibujo de la misma.

Al igual de lo que expusimos para los signos sonoros, que la descripcion y fotografia o dibujo sea adecuado o no para que se aproxime al signo táctil que pretende registrarse, dependerá de la Oficina Nacional Conpetente y, en el caso peruano, del INDECOPI, debiendo sugerirle al solicitante la representación complementaria que deberá utilizarse, en caso considere que la que presentó inicialmente no representa al signo adecuadamente para efectos de su publicación.

- Marcas olfativas y gustativas

Para registrar marcas olfativas y gustativas, los solicitantes deberán presentar las muestras del aroma o sabor que pretenden registrarse y permitir que los usuarios puedan acceder a ellas antes y después de su registro. Asimismo, sobre la base de que estas muestras pueden perecer en el tiempo - tal como lo indica Isabel Ramos (2014) y muchos otros autores en el tema - nada impide que puedan reemplazarse cada cierto tiempo.

Para efectos de la publicación de estos signos, se considera que una descripción del olor o sabor podrían ser idóneos y, en caso de no serlo a criterios de la Oficina Nacional Competente, es deber del INDECOPI asegurarse de que los solicitantes puedan describir correctamente estos signos, debiendo este organismo guiarlos y sugerirles una descripción adecuada, en caso los solicitantes no presenten la representación complementaria satisfactoriamente. 
Vale recalcar que se considera que tanto la presentación de la formula química como de la forma de elaboración de dichos olores o sabores no serviría como complemento para la publicación de estos signos no visibles, porque tendríamos el mismo problema (vistos en los casos peruanos de registros de signos sonoros) de que el INDECOPI deba cerciorarse de si estos medios corresponden a los signos olfativos o gustativos que pretenden registrarse, y se daría pie nuevamente a dilaciones y/o rechazos a la solicitudes de registro de estos tipos de marcas.

Pese a todo lo expuesto, sobre los signos olfativos, debemos recordar que es posible que en un futuro cercano ya se puedan transmitir olores vía electrónica, pues recordemos que en Japón ya se han creado Iphones con la función de poder enviar aromas mediante mensajes de texto; asímismo, tal como Isabel Ramos (2014) nos comenta, también se han estado desarrollando sensores de olfato. En efecto, se piensa que más adelante, el desarrollo de la tecnología nos permitirá percibir el aroma sin tener los usuarios que acceder a las Oficinas de Propiedad Intelectual.

Como resultado de lo expuesto en el presente apartado, puede concluirse que solo una muestra y/o reproducción del signo no visible podrá representar de manera idónea la marca a registrar, pudiendo otorgarle al sistema marcario la seguridad jurídica que necesita para su funcionamiento, por lo que, una formula química, para marcas olfativas o gustativas, un pentagrama, para los signos sonoros, un dibujo o fotografía para las marcas táctiles, ni alguna descripción sobre estos signos, u cualquiera de las formas de representación vistas en el presente trabajo de investigación, que no sea una muestra o reproducción, podrán garantizar el correcto funcionamiento del sistema marcario.

Y es que tal como se dijo en el caso Tresor expuesto en el capitulo anterior:

(...) la elaboración de un perfume a partir de ingredientes distintos, pero que a su vez trasmiten la misma fragancia que otro podría constituir una infracción, mientras que por el contrario, tal no sería el caso de dos perfumes que tienen formulas similares, pero cuya fragancia es distinta (Ferrero, G, 2009). 
No importa si dos formulas químicas, pentagramas, descripciones, entre otras, sean semejantes, pues lo que es relevante es si el signo sonoro, táctil, olfativo o gustativo son iguales a otros para distinguir los mismos productos o servicios en el mercado o con vinculación competitiva, pudiendo generar riesgo de confusión o asociación en los consumidores.

\subsection{La Decisión 486 y el Decreto Legislativo 1075 deben regular el tema de marcas teniendo en consideración el registro de las marcas no tradicionales no visibles}

En base a los aportes expuestos en los apartados anteriores sobre los criterios para determinar la distintividad y el requisito de la representación gráfica de estos signos para que puedan acceder a registro, en concordancia con los comentarios que se hicieron cuando vimos los artículos 134, 135 y 136 de la Decisión 486, y los artículos concernientes al análisis comparativo entre signos del Decreto Legislativo 1075, expuestos en el capítulo III, es necesario adecuar estas normas en la medida que pueda hacerse efectivo el registro de estos nuevos tipos de marcas.

En efecto, recordemos que la Decisión 486 (2000) establece en su artículo 134 lo siguiente:

Artículo 134.- A efectos de este régimen constituirá marca cualquier signo que sea apto para distinguir productos o servicios en el mercado. Podrán registrarse como marcas los signos susceptibles de representación gráfica. La naturaleza del producto o servicio al cual se ha de aplicar una marca en ningún caso será obstáculo para su registro.

Podrán constituir marcas, entre otros, los siguientes signos:

a) las palabras o combinación de palabras;

b) las imágenes, figuras, símbolos, gráficos, logotipos, monogramas, retratos, etiquetas, emblemas y escudos;

c) los sonidos y los olores;

d) las letras y los números; 
e) un color delimitado por una forma, o una combinación de colores;

f) la forma de los productos, sus envases o envolturas;

g) cualquier combinación de los signos o medios indicados en los apartados anteriores. (Los subrayados son míos).

Sobre este artículo se considera que, muy independientemente a que las modificaciones recientes en la Unión Europea no se hayan dirigido a permitir el registro de signos no visibles, diferentes a los sonoros, se considera apropiado acoger el extremo que establece que los signos para que puedan constituirse como marcas deberán "Ser representados en el Registro de Marcas de la Unión Europea (el "Registro") de manera que permita a las autoridades competentes y al público en general determinar el objeto claro y preciso de la protección otorgada a su titular" (Reglamento (UE) N 2015/2424, 2015), y adecuarlo a la norma andina, pudiendo quedar el primer apartado del artículo 134 de la siguiente manera:

Artículo 134.- A efectos de este régimen constituirá marca cualquier signo que sea apto para distinguir productos o servicios en el mercado. Podrán registrarse como marcas los signos que puedan ser representados de manera que permita a las autoridades competentes y al público en general determinar el objeto claro y preciso de la protección otorgada a su titular. La naturaleza del producto o servicio al cual se ha de aplicar una marca en ningún caso será obstáculo para su registro.

Adicionalmente, se considera que en la letra c) podría añadirse a las texturas y sabores, para que no haya duda en la posibilidad de registro de estos tipos de signos como marcas.

Por otra parte, recordemos lo estalecido en el artículo 135 de la Decisión 486 (2000), sobre prohibiciones absolutas:

Artículo 135.- No podrán registrarse como marcas los signos que:

a) no puedan constituir marca conforme al primer párrafo del artículo anterior;

b) carezcan de distintividad; 
c) consistan exclusivamente en formas usuales de los productos o de sus envases, o en formas o características impuestas por la naturaleza o la función de dicho producto o del servicio de que se trate;

d) consistan exclusivamente en formas u otros elementos que den una ventaja funcional o técnica al producto o al servicio al cual se aplican;

e) consistan exclusivamente en un signo o indicación que pueda servir en el comercio para describir la calidad, la cantidad, el destino, el valor, la procedencia geográfica, la época de producción u otros datos, características o informaciones de los productos o de los servicios para los cuales ha de usarse dicho signo o indicación, incluidas las expresiones laudatorias referidas a esos productos o servicios;

f) consistan exclusivamente en un signo o indicación que sea el nombre genérico o técnico del producto o servicio de que se trate;

g) consistan exclusivamente o se hubieran convertido en una designación común o usual del producto o servicio de que se trate en el lenguaje corriente o en la usanza del país;

h) consistan en un color aisladamente considerado, sin que se encuentre delimitado por una forma específica;

i) puedan engañar a los medios comerciales o al público, en particular sobre la procedencia geográfica, la naturaleza, el modo de fabricación, las características, cualidades o aptitud para el empleo de los productos o servicios de que se trate;

j) reproduzcan, imiten o contengan una denominación de origen protegida para los mismos productos o para productos diferentes, cuando su uso pudiera causar un riesgo de confusión o de asociación con la denominación; o implicase un aprovechamiento injusto de su notoriedad;

k) contengan una denominación de origen protegida para vinos y bebidas espirituosas; 
1) consistan en una indicación geográfica nacional o extranjera susceptible de inducir a confusión respecto a los productos o servicios a los cuales se aplique;

m) reproduzcan o imiten, sin permiso de las autoridades competentes, bien sea como marcas, bien como elementos de las referidas marcas, los escudos de armas, banderas, emblemas, signos y punzones oficiales de control y de garantía de los Estados y toda imitación desde el punto de vista heráldico, así como los escudos de armas, banderas y otros emblemas, siglas o denominaciones de cualquier organización internacional;

n) reproduzcan o imiten signos de conformidad con normas técnicas, a menos que su registro sea solicitado por el organismo nacional competente en normas y calidades en los Países Miembros;

o) reproduzcan, imiten o incluyan la denominación de una variedad vegetal protegida en un País Miembro o en el extranjero, si el signo se destinara a productos o servicios relativos a esa variedad o su uso fuere susceptible de causar confusión o asociación con la variedad; o

p) sean contrarios a la ley, a la moral, al orden público o a las buenas costumbres;

No obstante lo previsto en los literales b), e), f), g) y h), un signo podrá ser registrado como marca si quien solicita el registro o su causante lo hubiese estado usando constantemente en el País Miembro y, por efecto de tal uso, el signo ha adquirido aptitud distintiva respecto de los productos o servicios a los cuales se aplica (Los subrayados son míos).

Sobre este artículo se considera que, de acuerdo a lo establecido en el Proceso 242-IP-2015, la letra c) debería modificarse de la siguiente manera:

c) consistan exclusivamente en formas usuales de los productos o de sus envases, o en formas o características impuestas por la naturaleza o la función de dicho producto o del servicio de que se trate; debiendo entenderse el término "formas" en sentido amplio cuando se trate de signos no visibles, abarcando dentro de dicho concepto a los sonidos, texturas, olores o sabores.

Asimismo, se considera que la redacción de la letra f) solo incluye a los signos visibles, cuando en doctrina hemos visto que no pueden registrarse signos no visibles 
que sean genéricos del producto o servicio de que se trate. En ese sentido, sugerimos modificar el antedicho texto de la siguiente manera, en arás a que sea aplicable a estos tipos de signos:

f) consistan exclusivamente en un signo o indicación que sea genérico o técnico del producto o servicio de que se trate

Por último, en la Decisión 486 debe señalarse en los artículos 138, 139 y 140 que el tipo de marca a registrar debe indicarse, en áras de saber si consiste en un signo visible o en un signo no visible, como el sonido, textura, olor o sabor. Asimismo, se cree conveniente que en estos artículos se exprese de manera clara que deben adjuntarse, en el caso de signos no visibles, la reproducción y/o muestra del signo la cual deberá ser complementada con una descripción y/o dibujo o fotografía según corresponda.

En cuanto al Decreto Legislativo 1075, recordemos lo que se establece en su artículo 45:

Artículo 45.- Determinación de semejanza

A efectos de establecer si dos signos son semejantes y capaces de inducir a confusión y error al consumidor, la Dirección competente tendrá en cuenta, principalmente los siguientes criterios:

a) la apreciación sucesiva de los signos considerando su aspecto de conjunto, y con mayor énfasis en las semejanzas que en las diferencias;

b) el grado de percepción del consumidor medio;

c) la naturaleza de los productos o servicios y su forma de comercialización o prestación, respectivamente;

d) el carácter arbitrario o de fantasía del signo, su uso, publicidad y reputación en el mercado; $y$,

e) si el signo es parte de una familia de marcas (Los subrayados son nuestros)

Respecto a la letra a) consideramos que debería reemplazarse el término "aspecto" por "percepción", pues recordemos que el término "aspecto" hace referencia solamente a signos visibles. En ese sentido, este extremo del artículo podría redactarse de la siguiente manera: 
(...) a) la apreciación sucesiva de los signos considerando su percepción en conjunto y con mayor énfasis en las semejanzas que en las diferencias.

Asimismo, sobre la letra d) se piensa que podría añadirse el término "novedoso", pues al igual que una marca de fantasía, que tiene mayor grado de protección, se considera que un signo no visible novedoso (si bien no es un requisito que exige la norma) tiene mayor grado de distintividad en el mercado y, por ende, se piensa que la protección debería ser mayor a comparación de uno ya existente.

Sobre la letra e) se piensa que podría ser aplicable a los signos no visibles toda vez que si un empresario desea, por ejemplo, utilizar la misma fragancia para todos sus productos y, los registra como marcas, podrían convertirse en una familia de marcas. Esto también podría ser completamente viable para los signos sonoros, táctiles y gustativos. 


\section{CONCLUSIONES}

1. Conclusiones generales:

$\checkmark$ Si bien en el artículo 134 de la Decisión 486 se establece expresamente que los sonidos y los olores pueden constituirse como marcas, y de su lectura se infiere que los demás signos no visibles como los gustativos y los táctiles también, en el Perú no existen solicitudes ni registros de marcas olfativas, gustativas o táctiles, solamente de marcas sonoras, habiéndo sido las demás marcas no tradicionales no visibles un tema poco estudiado en el Perú.

El requisito de la representación gráfica no ha formado ni forma parte de la definición de marca; sin embargo, ha devenido en un requisito indispensable para que un signo pueda ser registrado como marca, tema que ha sido muy discutido para el registro de marcas no tradicionales no visibles.

$\checkmark$ Si bien en el tema de las marcas no tradicionales no visibles se ha discutido principalmente el requisito de la representación gráfica para que puedan acceder al registro, el tema de su distintividad también ha sido, aunque en menor medida, cuestionado.

$\checkmark$ Tanto de la lectura del artículo 134 de la Decisión 486 así como de los antecedentes historicos expuestos en el capítulo I, sobre la influencia del ADPIC en la elaboración de las normas andinas luego de su suscripción por parte de los Países Miembros, puede desprenderse que los expertos de propiedad intelectual al momento de la elaboración de la Decisión 486 consideraron que los signos olfativos y sonoros poseen aptitud para distinguir productos o servicios en el mercado y, por ende, para poder constituirse como marcas.

$\checkmark$ En el Proceso 242-IP-2015, el Tribunal de Justicia de la Comunidad Andina aceptó el registro de todos los signos no visibles como marcas - incluyendo el 
de los signos táctiles y gustativos - y, por ende, su aptitud para distinguir productos o servicios en el mercado.

$\checkmark$ Actualmente, en la Unión Europea no se cuestiona la aptitud distintiva de las marcas no tradicionales no visibles para que puedan acceder al registro.

$\checkmark$ Es en los Estados Unidos en donde más se ha discutido la aptitud distintiva de las marcas no tradicionales no visibles, primando la posición de que tendría que demostrarse en la mayoría de casos distintividad sobrevenida, pues no poseerían comúnmente distintividad inherente.

$\checkmark$ Si bien hay posiciones en contra del registro de signos no visibles por considerar que los consumidores no estarían acostumbrados a percibirlos como marcas, puede decirse que los usos y costumbres de los empresarios harán que los consumidores puedan percibirlos de tal manera, variando la figura de la marca a la situación tanto social, económica y comercial que vivimos actualmente.

$\checkmark$ El registro de una marca otorga a su titular el derecho de uso exclusivo sobre dicha marca, y la protege contra usos no autorizados por parte de terceros, no regulando el Derecho de Propiedad Intelectual la forma de uso en el mercado de este signo distintivo.

$\checkmark$ Sin perjuicio de lo expuesto en el inciso anterior, es posible que el consumidor pueda percibir las marcas no tradicionales no visibles antes de realizar la compra de los productos o servicios; sin embargo, sobre las marcas gustativas, se considera que habrían inconvenientes prácticos para que cumplan con la función principal de la marca.

Se considera que es más complicado, a comparación de lo que sucede en el caso de las marcas tradicionales, que pueda demostrarse distintividad sobrevenida de las marcas no tradicionales no visibles. 
Se considera que las marcas no tradicionales no visibles pueden poseer mayormente distintividad inherente $\mathrm{y}$, por ende, no debe exigirse ningún requisito adicional para el registro de este tipo de marcas.

La marca no tradicional no visible deberá añadir un elemento extra al producto, y no ser el producto mismo o una característica intrínseca a él.

$\checkmark$ Respecto a las marcas gustativas, es usual que no puedan disociarse del producto al cual pretenden distinguir en el mercado.

$\checkmark$ Respecto a las marcas olfativas, se considera que los Unique Scents Marks y, siempre que el signo olfativo sea novedoso y creativo, los Secondary Scents Marks, pueden ser registrados como marcas. Por el contrario, se considera que los Primary Scents Marks no pueden registrarse como marcas.

No se encuentran argumentos sólidos que puedan demostrar que la percepción de los sentidos humanos distintos de la vista sean subjetivos $\mathrm{y}$, por ende, que hagan imposible que estos puedan cumplir la función de identificar y distinguir productos o servicios en el mercado.

La prohibición absoluta del artículo 135, inciso c), también será aplicable al registro de signos no visibles como marcas.

$\checkmark$ En el régimen andino no se prohibe el registro de marcas no tradicionales no visibles que otorguen un valor sustancial a los bienes a los que se aplican, a diferencia de lo que sí sucede en la Unión Europea.

$\checkmark$ La denegaciones de registros de signos no visibles como marcas, al igual que para todo tipo de marcas, deben basarse en las prohibiciones absolutas y relativas indicadas en los artículos 135 y 136 de la Decisión 486, y no en otras adicionales. 
$\checkmark$ No debe exigirse que los signos no visibles deban ser novedosos para que puedan ser registrados como marcas, pues a diferencia de la derogada Decisión 85, la Decisión 486 no lo exige como requisito.

$\checkmark$ Debe resaltarse que son los signos no visibles los que deben poseer aptitud distintiva para que puedan acceder a registro como marcas, y no las representaciones que puedan utilizarse con el objeto de su publicación; es decir, son los sonidos, olores, sabores y texturas los que deberán ser aptos para distinguir productos o servicios en el mercado, y no los pentagramas, descripciones, dibujos, entre otros, para que puedan admitirse o no en el registro.

La mayor parte de la doctrina considera que el aroma posee un gran poder evocador y, que la memoria olfativa suele ser más poderosa a comparación de la de los demás sentidos, inclusive más que de la memoria visual.

Carece completamente de asidero la posición que considera que al permitirse el registro de marcas olfativas se estaría permitiendo la apropiación de uno de los cinco sentidos del ser humano, pues de ser cierta, se podría decir que el registro de un signo visual permitiría la apropiación del sentido de la vista, lo cual no tiene lógica.

$\checkmark$ La Teoría del Agotamiento sobre las marcas olfativas no tiene fundamentos sólidos para obstaculizar el registro de estos tipos de marcas.

$\checkmark$ El hecho de que solo un competidor utilice en el mercado un tipo de signo no visible para determinados productos o servicios no debe ser un referente para admitir o denegar estos tipos de marcas pues lo que se pretende es que la mayoría de los competidores puedan utilizar las marcas no tradicionales no visibles.

$\checkmark$ El hecho de que el requisito de la representación del signo deba ser gráfico necesariamente requiere que deba ser visible; es decir, que pueda ser 
representado mediante lineas o dibujos, por lo que no podría representarse gráficamente a cabalidad a las marcas no tradicionales no visibles.

$\checkmark$ El requisito de la representación gráfica es importante para proporcionar seguridad jurídica al sistema marcario, pues facilita el examen y publicación por parte de las Oficinas Nacionales Competentes de los signos que pretenden registrarse como marcas, y a los terceros interesados de saber los signos que estan disponibles o no. Es decir, es el Principio de Seguridad Jurídica del Sistema Marcario el fundamento del requisito de la representación gráfica.

$\checkmark$ Para el registro de signos visibles como marcas, el exigir el requisito de la representación gráfica (el cual vendría a ser la reproducción del signo) es eficaz para otorgar seguridad jurídica al sistema marcario; por el contrario, esta misma seguridad no se la otorga cuando consisten en signos no visibles, pues no permite reproducirlos de manera exacta; es por esto que la marca no tradicional no visible nunca va a poder ser representada de manera completa en sí misma, fácilmente accesible, clara, precisa, inteligible, comprensible y duradera, si se exige que su representación sea gráfica.

La única forma de representar de manera completa en sí misma, fácilmente accesible, clara, precisa, inteligible, comprensible y duradera a las marcas no tradicionales no visibles es con la reproducción o muestra de estos signos, pues debe recordarse que es la aptitud distintiva del signo lo que determina si puede constituirse como marca o no.

$\checkmark$ Debe eliminarse el requisito de la representación gráfica para el registro de signos no visibles como marcas; asímismo, tampoco basta con interpretar este requisito en sentido amplio, pues lo que debe predominar son sus muestras y/o reproducciones, pues son los únicos medios que otorgan seguridad al sistema marcario; las representaciones gráficas de estos signos, como las descripciones, por ejemplo, solo son meras aproximaciones de los signos que se pretenden registrar, pudiendo solo servir como complementos a efectos de las publicaciones en las Gacetas Oficiales. 
$\checkmark$ La eliminación del requisito de la representación gráfica en la Unión Europea sólo ha favorecido al registro de marcas sonoras, mas no al registro de marcas táctiles, gustativas y olfativas, pues tanto el Reglamento de Ejecución, así como la Decisión EX17-1, dejan en claro que estos tipos de marcas no pueden registrarse por no existir aún tecnología que permita representarlas; por lo que no debemos tomar como referencia el tratamiento legal actual de las marcas no tradicionales no visibles en la Unión Europea.

Se considera que para el registro de marcas sonoras, los solicitantes deberán presentar la reproducción del audio, no siendo necesario presentar otra representación adicional, pues la tecnología de hoy en día permite reproducir el sonido de manera electrónica, tanto para efectos de su consulta y para las publicaciones, tal como se hace en la USPTO. Sin embargo, mientras no se implemente la posibilidad de acceder al audio de manera electrónica, se considera que los sonidos deberán depositarse en el INDECOPI, debiendo permitir el acceso a los terceros interesados; y para efectos de la publicación, los solicitantes deberán presentar, como mero complemento, una descripción del sonido.

Se considera que para el registro de marcas táctiles, los solicitantes deberán presentar la muestra de la textura, debiendo permitir a los terceros interesados el acceso a esta; y una descripción, fotografía y/o dibujo del mismo para efectos de su publicación.

Se considera que para el registro de marcas olfativas y gustativas, los solicitantes deberán presentar la muestra del aroma o sabor, debiendo permitir a los terceros interesados el acceso a estos, y pudiendo los solicitantes reemplazar dichas muestras cada cierto tiempo. Asimismo, para efectos de las publicaciones, se considera que deben presentarse las descripciones de estos signos como complementos. 
$\checkmark$ Respecto a la representación de las marcas olfativas, debe tenerse en consideración que actualmente ya se esta trabajando en el desarrollo de tecnologías que permitan transmitir olores a través de medios digitales.

$\checkmark$ Es deber de las Oficinas Nacionales Competentes cerciorarse que el solicitante cumpla con representar de manera adecuada a la marca no tradicional no visible, y no deber del solicitante.

$\checkmark$ Es necesario ajustar algunos artículos de las Decisión 486 y del Decreto Legislativo 1075 para que puedan adecuarse al registro de marcas no tradicionales no visibles, pues algunos solo se han redactado bajo el supuesto de que las marcas a registrar consisten solamente en signos visibles.

\section{Conclusiones específicas}

Se considera que los signos no visibles pueden poseer usualmente distintividad inherente $\mathrm{y}$, por el contrario, resulta más complicado que se configure el secondary meaning para que puedan ser registrados como marcas. En efecto, la presente tesis descarta la hipótesis según la cual los signos visibles deberán demostrar mayormente distintividad sobrevenida para poder acceder al registro.

$\checkmark$ Para el registro de marcas tradicionales, el exigir el requisito de la representación gráfica (la cual viene a ser la reproducción del signo) es eficaz para otorgar seguridad jurídica al sistema marcario; por el contrario, esta misma seguridad no se otorga cuando consisten en marcas no tradicionales no visibles, pues nunca van a poder ser representadas de manera completas en sí misma, fácilmente accesibles, claras, precisas, inteligibles, comprensibles y duraderas, si se exige que su representación sea gráfica. En ese sentido, la presente tesis descarta en parte el extremo de la hipótesis de que el requisito de la representación gráfica deberia ser eliminado por no satisfacer las nuevas demandas del mercado y no hacer posible el registro de marcas no tradicionales no visibles. 
En efecto, la única forma de representar a una marca no tradicional no visible es con su muestra y/o reproducción. En ese sentido, debe eliminarse el requisito de la representación gráfica sólo para el registro de signos no visibles.

$\checkmark$ Es necesario modificar algunos artículos de las Decisión 486 y del Decreto Legislativo 1075 para que puedan adecuarse al registro de marcas no tradicionales no visibles, pues algunos solo han sido redactados bajo el supuesto de que las marcas a registrar consisten solamente en signos visibles, corroborándose una de nuestras hipótesis. 


\section{BIBLIOGRAFÍA}

Acuerdo Asociación Transpacífico (2016). Recuperado del Portal Web del Ministerio de Comercio Exterior y Turismo, en Acuerdos Comerciales del Perú http://www.acuerdoscomerciales.gob.pe/index.php?option=com_cont ent $\&$ view $=$ category $\&$ layout $=$ blog $\& i d=188 \&$ Itemid $=207$.

Acuerdo de Promoción Comercial Perú - EE.UU. (2006). Recuperado del Portal Web del Ministerio de Comercio Exterior y Turismo en Acuerdos Comerciales del Perú http://www.acuerdoscomerciales.gob.pe/index.php?option=com_cont $\underline{\text { ent } \& \text { view=category } \& \text { layout }=\text { blog } \& i d=55 \& \text { Itemid }=78}$.

Acuerdo Comercial entre Perú y la Unión Europea (2010). Recuperado del Portal Web del Ministerio de Comercio Exterior y Turismo, en Acuerdos Comerciales del Perú http://www.acuerdoscomerciales.gob.pe/index.php?option=com_cont $\underline{\text { ent } \& \text { view }=\text { category \&layout }=\text { blog } \& i d=50 \& I t e m i d=73}$.

Acuerdo sobre los aspectos de los derechos de propiedad intelectual relacionados con el comercio - ADPIC. (1994). Recuperado de https://www.wto.org/SPANISH/DOCS_S/legal_s/27-trips.pdf.

Arias, J. (26, 27 y 29 de agosto de 2015). La registrabilidad de las marcas no tradicionales. Simposio sobre el Régimen de Propiedad Industrial Comunidad Andina. 15 años Decisión 486. Recuperado de https://issuu.com/quioscosic/docs/simposio_versionweb.

Ávila, J. (2016). Reconocimiento de "marcas nuevas" o "no tradicionales": Tipologías, retos y desafíos. Universidad Nacional Autónoma de Honduras. Recuperado de http://studylib.es/doc/6082139/reconocimiento-de\%E2\%80\%9Cmarcas-nuevas\%E2\%80\%9D-o-\%E2\%80\%9Cnotradicionales\%E2\%80\%9D--t.

Baylos, C. H., Baylos, M. M., \& Bercovitz, R.-C. A. (2009). Tratado de derecho industrial: Propiedad industrial, propiedad intelectual, derecho de la competencia económica, disciplina de la competencia desleal. Cizur Menor (Navarra: Aranzadi). 
BBC News Mundo (2017). Donald Trump retira a Estados Unidos del TPP, el Acuerdo Transpacífico de Cooperación Económica. Recuperado de http://www.bbc.com/mundo/noticias-internacional-38723381.

Bercovitz, R. (2014). Marca renombrada y vulgarización: ¿Dos caras de una misma moneda? Oficina Española de Patentes y Marcas (OEPM). Recuperado de http://www.oepm.es/export/sites/oepm/comun/documentos_relaciona dos/Ponencias/78_02_La_proteccion_de_la_marca_renombrada_frent e_a_la_vulgarizacion.pdf.

Bertone, L., \& Cabanellas, G. (2003). Derecho de Marcas: marcas, designaciones y nombres comerciales. Buenos Aires. Heliasta. 2da Edición.

Campillo, S. (2016). La ciencia del “olor a nuevo”. Hipertextual. Ciencia. Recuperado de https://hipertextual.com/2016/05/olor-a-nuevo.

Casado, A. (2009). Marca y publicidad comercial (un enfoque interdisciplinar.). Martínez - Echevarría, Pérez \& Ferrero Abogados. Editorial La Ley. 1era Edición.

Castro, J. (2012). Marcas no tradicionales. Universidad Externado de Colombia. Recuperado de http://uexternado.metarevistas.org/index.php/propin/article/viewFile/3 $\underline{273 / 2922}$

Cheilan, M. (2014). "El olor de la marca exitosa en el mundo empresarial japonés". Observatorio Iberoamericano de la Economía y de la Sociedad del Japón. Vol. 6, $\quad \mathrm{N}^{\circ} \quad 20 . \quad$ Recuperado de http://www.eumed.net/rev/japon/20/marca-japon.pdf.

Chijane, D (2007). Derecho de Marcas. Función y concepto - Nulidades, Registro Representación gráfica, Derecho Comparado. Editorial Reus. España.

Código Orgánico de la Economía Social de los Conocimientos, Creatividad e Innovación. (2016). Recuperado de la Página Web de la Organización Mundial de la Propiedad Intelectual - OMPI http://www.wipo.int/wipolex/es/text.jsp?file $\mathrm{id}=439410$.

Comité Permanente sobre el Derecho de Marcas, Diseños Industriales e Indicaciones Geográficas de la Organización Mundial de la Propiedad Intelectual - 
OMPI (2006). Nuevos tipos de marcas. Documento preparado por la Secretaría. Decimosexta sesión. SCT/16/2.

Comité Permanente sobre el Derecho de Marcas, Diseños Industriales e Indicaciones Geográficas de la Organización Mundial de la Propiedad Intelectual OMPI (2007). Relación entre los principios existentes en materia de marcas y los nuevos tipos de marcas. Documento preparado por la Secretaría. Decimoséptima sesión. SCT/17/3.

Comité Permanente sobre el Derecho de Marcas, Diseños Industriales e Indicaciones Geográficas de la Organización Mundial de la Propiedad Intelectual OMPI. (2007). Métodos de representación y descripción de los nuevos tipos de marcas. Documento preparado por la Secretaría. Decimoséptima sesión. SCT/17/2.

Comité Permanente sobre el Derecho de marcas, Diseños Industriales e Indicaciones Geográficas de la Organización Mundial de la Propiedad Intelectual. (2007). Marcas no tradicionales: enseñanzas destacadas. Documento preparado por la Secretaría. Decimoctava sesión. SCT/18/2.

Comité Permanente sobre el Derecho de Marcas, Diseños Industriales e Indicaciones Geográficas de la Organización Mundial de la Propiedad Intelectual OMPI (2008). La representación y la descripción de marcas no tradicionales. Posibles ámbitos de convergencia. Decimonovena sesión. SCT/19/2.

Comité Permanente sobre el Derecho de marcas, Diseños Industriales e Indicaciones Geográficas de la Organización Mundial de la Propiedad Intelectual. (2008). La representación de marcas no tradicionales. Ámbitos de Convergencia. Documento preparado por la Secretaría. Vigésima sesión. SCT/20/2.

Comité Permanente sobre el Derecho de marcas, Diseños Industriales e Indicaciones Geográficas de la Organización Mundial de la Propiedad Intelectual. (2009). La representación de marcas no tradicionales. Ámbitos de Convergencia. Documento preparado por la Secretaría. WIPO/ $\mathrm{Strad} / \mathrm{INF} / 3$.

Comunidad Andina. Documentos Oficiales. Decisiones. Recuperado de http://www.comunidadandina.org/Documentos.aspx?GruDoc=07. 
Comunidad Andina. Notas de Prensa. Secretaría General de la CAN recibió comunicación oficial de retiro de Venezuela. Recuperado de http://www.comunidadandina.org/Prensa.aspx?id=1903\&accion=detal le\&cat=NP\&title=secretaria-general-de-la-can-recibio-comunicacionoficial-de-retiro-de-venezuela.

Comunidad Andina. Relaciones Externas. Chile. Recuperado de http://www.comunidadandina.org/Seccion.aspx?id=189\&tipo=QU\&ti $\underline{\text { tle}}=$ somos-comunidad-andina.

Comunidad Andina. Somos Comunidad Andina. ¿Qué es la CAN? Recuperado de http://www.comunidadandina.org/Seccion.aspx?id=189\&tipo=QU\&ti $\underline{\text { tle }=\text { somos-comunidad-andina. }}$

Constitución Política del Perú (31 de diciembre de 1993). Recuperado del sitio de internet del Sistema Peruano de Información Jurídica - SPIJ: http://spij.minjus.gob.pe/libre/main.asp.

Constitución Política del Perú (31 de diciembre de 1993). Recuperado del sitio del Portal Web del Congreso de la República http://www4.congreso.gob.pe/ntley/Imagenes/Constitu/Cons1993.pdf.

Cornejo Guerrero, C. (2014). Derecho de marcas. Lima. Lex Iuris.

Cornejo Guerrero, C. (2000). Las transformaciones del derecho de marcas y sus relaciones con el derecho de propiedad. Lima. Cultural Cuzco Editores.

Convenio de París para la protección de la Propiedad Industrial (1883). Recuperado de la Página Web de la Organización Mundial de la Propiedad Intelectual - OMPI http://www.wipo.int/treaties/es/ip/paris/.

Decisión 351. Régimen Común sobre Derecho de Autor y Derechos Conexos (17 de diciembre de 1993). Recuperado del Portal Web de la Comunidad Andina http://www.comunidadandina.org/Seccion.aspx?id=83. 
Decisión 85. Propiedad Industrial (27 de mayo a 5 de junio de 1974). Recuperado del Portal Web de la Comunidad Andina http://www.comunidadandina.org/Documentos.aspx?GruDoc=07.

Decisión 311. Régimen Común sobre Propiedad Industrial (07 al 08 de noviembre de 1991). Recuperado del Portal Web de la Comunidad Andina http://www.comunidadandina.org/Documentos.aspx?GruDoc=07.

Decisión 486. Régimen Común sobre Propiedad Intelectual (14 de septiembre de 2000). Recuperado del Portal Web de la Comunidad Andina http://www.comunidadandina.org/Seccion.aspx?id=83.

Decisión $N^{\circ}$ EX16-7 (2017) sobre la aprobación de las Directrices relativas al examen de las marcas de la Unión Europea y los dibujos y modelos comunitarios registrados ante la Oficina de Propiedad Intelectual de la Unión Europea $-=$ EUIPO. Recuperado de https://euipo.europa.eu/tunnel-

web/secure/webdav/guest/document_library/contentPdfs/law_and_pra ctice/decisions_president/ex16-7_es.pdf.

Decisión N EX17-1 (2017) sobre la aprobación de las Directrices relativas al examen de las marcas de la Unión Europea y los dibujos y modelos comunitarios registrados en la Oficina de Propiedad Intelectual de la Unión Europea, que entró en vigencia el 01 de octubre de 2017. Recuperado de https://euipo.europa.eu/tunnelweb/secure/webdav/guest/document_library/contentPdfs/law_and_pra ctice/decisions_president/EX-17-1_es.pdf.

Decreto Legislativo N²95. Código Civil (14 de noviembre de 1984). Recuperado del sitio de internet del Sistema Peruano de Información Jurídica - SPIJ: http://spij.minjus.gob.pe/libre/main.asp.

Decreto Legislativo $N^{\circ}$ 822. Ley sobre el Derecho de Autor (1996). Recuperado de https://www.indecopi.gob.pe/documents/20787/0/DL+822.pdf/f1ed84 16-7438-1ff9-eab6-81fa4dcb7505.

Decreto Legislativo $\mathrm{N}^{\circ}$ 1075. Decreto Legislativo que aprueba Disposiciones Complementarias a la Decisión 486 de la Comisión de la Comunidad 
Andina que establece el Régimen Común sobre Propiedad Intelectual.

Recuperado de

https://www.indecopi.gob.pe/documents/20795/225805/04.+03-

DL1075.pdf/5950edd4-d09c-4347-8d6f-f4f3a6b65d81.

Delgado, A. y, Gastello, R. (2016). Prohibiciones absolutas al registro de marcas.

Escuela Nacional del INDECOPI. Recuperado de http://www.mpfn.gob.pe/escuela/contenido/actividades/docs/4627_pr ohibiciones_absolutas.pdf.

Empresa editora el Comercio S.A (2016). Conoce las 10 marcas más valoradas del mundo según Interbrand. Economía. Recuperado de http://elcomercio.pe/economia/negocios/conoce-10-marcas-masvaloradas-mundo-segun-interbrand-noticia-1936413/10.

Escoffier, L., y Jin, A. (2010). Exhalar o no una fragancia, esa es la cuestión: Un análisis comparativo de las marcas olfativas en la Unión Europea y los Estados Unidos de América como buenas oportunidades de comercialización para las Pymes. Organización Mundial de la Propiedad Intelectual - OMPI. Recuperado de http://www.wipo.int/export/sites/www/sme/es/documents/pdf/olfactiv e trademarks.pdf.

Fernández - Nóvoa, C. (2004). Tratado sobre el derecho de marcas. Gómez - Acebo \& Pombo Abogados. Marcial Pons, Ediciones Jurídicas y Sociales S.A. Madrid, Barcelona.

Ferrero, G. (2009). Nuevas marcas: ¿Algo nuevo bajo el sol? Anuario Andino de Derechos Intelectuales. Año IV, N5, Lima. Recuperado de http://www.anuarioandino.com/Anuarios/Anuario05/art11/ANUARIO \%20ANDINO\%20ART11.pdf.

Giménez, R. (2010). Tipos de Marcas: Marcas Olfativas. Giménez \& Asociados. Recuperado de http://www.registrodemarcas.co/tipos-de-marcasolfativas/.

Holguín, O. (1997). Tratado de Derecho de Propiedad Industrial. Marcas de productos y servicios. Imp. Desa. 
Instituto de Derecho de Autor (2010). Antecedentes históricos de la Propiedad Intelectual. Recuperado de http://hemeroteca.institutoautor.org/story/.php?id=3156.

Instituto de la Propiedad Intelectual de Buenos Aires (IPIBA). (2013). Signos distintivos registrables y no registrables. Recuperado de http://ipiba.org/2013/11/1011/.

Instituto Nacional de Defensa de la Competencia y de la Propiedad Intelectual INDECOPI. (2017). Clasificación Internacional de Productos y Servicios. Clasificación de Niza, 11 Edición, Versión 2017. Recuperado de https://www.indecopi.gob.pe/documents/20795/0/TitulosClasificacion Niza2017.pdf/2ac6ef66-96c8-4d8b-8656-57d749103fa8.

Instituto Nacional de Defensa de la Competencia y de la Propiedad Intelectual INDECOPI. 2014. Resolución 0001391-2014/DSD. 2014. Expediente 442794-2011.

Instituto Nacional de Defensa de la Competencia y de la Propiedad Intelectual INDECOPI. (2007). Resolución 0578-2017/TPI- INDECOPI.

Instituto Nacional de Defensa de la Competencia y de la Propiedad Intelectual INDECOPI. Sistema de Información en línea. Recuperado de http://sistemas.indecopi.gob.pe/osdconsultaspublicas/.

Ishbak, A. (2016). Marcas no tradicionales en los Estados Unidos. Recuperado de http://www.mipatente.com/marcas-no-tradicionales-en-los-estadosunidos/.

Kresalja, R. B. (2004). La propiedad industrial: Evolución y tratamiento normativo en la Región Andina y en el Perú. Lima: Duany \& Kresalja Abogados.

Kresalja, B. (2001). La registrabilidad de las marcas auditivas, olfativas y las constituidas por color único en la decisión 486 de la Comunidad Andina. Revista Themis. Número 42. PUCP. 
Lindley, A. (2013). Cuestionando la existencia de la prohibición absoluta de registro de marcas contrarias a la ley, la moral, el orden públicos o las buenas costumbres. Anuario Andino de Derechos Intelectuales. Año IX-N9. Lima. Recuperado de http://anuarioandino.com/Anuarios/Anuario09/Art09/ANUARIO\%20 ANDINO\%20ART09.pdf.

Liévano, J. (2013). Aproximación a las marcas no tradicionales. Versión actualizada y complementada. Monografía Especialización en Derecho Comercial. Universidad Javeriana. Recuperado de https://repository.javeriana.edu.co/bitstream/handle/10554/14881/Liev anoMejiaJoseDaniel2013.pdf;jsessionid=748368F7D5948EEB724780 F161F90042? sequence $=1$.

Lizano, A. y Pal, A. (2013). Nuevas modalidades de marca: olfativas, táctiles y gustativas. Viabilidad, utilidad y efectos jurídicos en Costa Rica (Tesis para optar por el Grado de Licenciatura en Derecho). Universidad de Costa Rica. Recuperado de http://iij.ucr.ac.cr/wpcontent/uploads/bsk-pdf-manager/2017/06/Nuevas-modalidades-demarcas-olfativas-t\%C3\%A1ctiles-y-gustativas.-Viabilidad-utilidad-yefectos-jur\%C3\%ADdicos-en-Costa-Rica.pdf.

Malacara, N. (2015). Marketing olfativo: Fragancias con olor a nuevo para vender autos usados. Informa BTL. Promociones, activaciones y below the line. Recuperado de https://www.informabtl.com/marketing-olfativofragancias-con-olor-a-nuevo-para-vender-autos-usados/.

Márquez Robledo, S. (2004). Principios generales del derecho de autor (Tesis para optar por el título profesional de abogado). Pontificia Universidad Javeriana.

Recuperado de http://www.javeriana.edu.co/biblos/tesis/derecho/dere6/DEFINITIVA /TESIS23.pdf.

Manual Armonizado en Materia de Criterios de Marcas de las Oficinas de Propiedad Industrial de los Países Centroamericanos y la República Dominicana. Recuperado de https://www.rnpdigital.com/propiedad_industrial/Documentos/Manua 1\%20Armonizado\%20Marcas.pdf.

Northcote, S. C. (2013). Protección de la propiedad intelectual de las empresas. Lima: Pacifico Editores. Primera edición. 
Núñez, S. (2012). El consumidor protegido por el Código de Protección y Defensa del Consumidor. Actualidad Empresarial $\mathrm{N}^{\circ}$ 261. Recuperado en http://aempresarial.com/servicios/revista/261_43_YXPIFCAMSUPU VFIRKNPMVPEWSWBFPVFNSVWYXXKQRZKMFTEQGT.pdf.

Oficina de Armonización del Mercado Interior - OAMI (ahora, EUIPO). 2007. El grito de Tarzán como marca. Departamento de Asuntos Generales y Relaciones Exteriores. Comunicado de prensa CP/07/01. Alicante, 05/11/2007. Recuperado de http://euipo.europa.eu/es/office/press/pdf/051107.pdf.

Oficina de Propiedad Intelectual de la Unión Europea - EUIPO. Nuevo reglamento sobre la marca de la Unión Europea. Recuperado de https://euipo.europa.eu/ohimportal/es/eu-trade-mark-regulation.

Olfabrand ScentAir. (2011). Olfabrand ScentAir - Bloom - Publicidad Exterior con Aroma - Marketing Olfativo.wmv. Video recuperado de https://www.youtube.com/watch?v=Af31dXBG_wk.

Organización Mundial de la Propiedad Intelectual (OMPI). Derecho de Autor. ¿Qué es el derecho de autor). Recuperado de http://www.wipo.int/copyright/es/.

Organización Mundial de la Propiedad Intelectual (OMPI). Marcas. ¿Qué es una marca? Recuperado de http://www.wipo.int/trademarks/es/.

Organización Mundial de la Propiedad Intelectual (OMPI). Modelos de Utilidad. Recuperado de http://www.wipo.int/sme/es/ip_business/utility_models/index.htm.

Organización Mundial de la Propiedad Intelectual (OMPI). 2009. Olfato, oído, gusto Los sentidos de las marcas no tradicionales. Revista de la OMPI. Recuperado http://www.wipo.int/wipo_magazine/es/2009/01/article_0003.html.

Organización Mundial de la Propiedad Intelectual (OMPI). ¿Qué es la Propiedad Intelectual? Publicación de la OMPI $\mathrm{N}^{\circ} 450(\mathrm{~S})$. Recuperado de 
http://www.wipo.int/edocs/pubdocs/es/intproperty/450/wipo_pub_450 .pdf.

Organización Mundial de la Propiedad Intelectual (OMPI). Reseña histórica de la OMPI. Recuperado de http://www.wipo.int/aboutwipo/es/history.html.

Organización Mundial de la Propiedad Intelectual (OMPI). Tratados administrados por la OMPI. Tratados administrados por la OMPI. Partes Contratantes. Arreglo de Niza. Recuperado de http://www.wipo.int/treaties/es/ShowResults.jsp?lang=es\&treaty_id= $\underline{12 .}$

Organización Mundial de la Propiedad Intelectual (OMPI). Tratados administrados por la OMPI. Tratados administrados por la OMPI. Partes Contratantes. Arreglo de Niza. Acta de Estocolmo (1967). Recuperado de http://www.wipo.int/treaties/es/ActResults.jsp?act_id=19.

Organización Mundial de la Propiedad Intelectual (OMPI). Tratados administrados por la OMPI. Tratados administrados por la OMPI. Partes Contratantes. Arreglo de Niza. Acta de Ginebra (1977). Recuperado de http://www.wipo.int/treaties/es/ActResults.jsp?act_id=22.

Osorio, H. (2014). "Marketing olfativo", olores que te recuerdan lugares. Negocios. Video recuperado de https://www.youtube.com/watch?v=yzjHticXH_4.

Otamendi, J. (2010). Derecho de marcas. Buenos Aires: AbeledoPerrot.

Proceso 388-IP-2015. (2015). Tribunal de Justicia de la Comunidad Andina.

Proceso 242-IP-2015. (2015). Tribunal de Justicia de la Comunidad Andina.

Radicación 03087905 de la Superintendencia de Industria y Comercio. (2003). Recuperado de http://www.sic.gov.co/recursos_user/historico/d2011sic9763.htm. 
Ramos, S. (2014). La armonización sobre marcas en el derecho de la Unión Europea y el necesario cambio respecto de las marcas olfativas (Harmonisation on trade in the European Union law and the neccesary change regarding scent marks). IUS Revista del Instituto de Ciencias Jurídicas de Puebla, México. Recuperado de http://www.scielo.org.mx/pdf/rius/v8n33/v8n33a7.pdf.

Real Academia Española. (2014). Aspecto. En Diccionario de la lengua española. (23da ed.). Recuperado de http://dle.rae.es/srv/search?m=30\&w=aspecto.

Real Academia Española. (2014). Decorar. En Diccionario de la lengua españila. (23da ed.) Recuperado de http://dle.rae.es/srv/fetch?id=BymLSuN|BynEFe8.

Real Academia Española. (2014). Gráfico, ca. En Diccionario de la lengua española. (23da ed.) Recuperado de http://dle.rae.es/?id=JPeHrNL.

Real Academia Española. (2014). Intelectual. En Diccionario de la lengua española. (23da ed.). Recuperado de http://dle.rae.es/?id=Lqb2TD7 .

Real Academia Española (2014). Representación. En Diccionario de la lengua española. (23da ed.). Recuperado de http://dle.rae.es/?id=W4VMjJb.

Real Academia Española. (2014). Signo. En Diccionario de la lengua española. (23da ed.). Recuperado de http://dle.rae.es/?id=XrXR2VS.

Real Academia Española. (2014). Susceptible. En Diccionario de la lengua española. (23da ed.). Recuperado de http://dle.rae.es/srv/search?m=30\&w=susceptible.

Reglamento del Tratado de Singapur sobre el Derecho de Marcas. (2011). Recuperado de la página web de la Organización Mundial de la Propiedad Intelectual

OMPI http://www.wipo.int/wipolex/es/treaties/text.jsp?file_id=291575.

Reglamento de Ejecución (UE) 2017/1431 de la Comisión. (2017), por el que se establecen normas de desarrollo de determinadas disposiciones del Reglamento (CE) $n^{\circ}$ 207/2009 del Consejo, sobre la marca de la 
Unión

Europea.

Recuperado

de

https://www.boe.es/doue/2017/205/L00039-00058.pdf.

Reglamento (CE) 207/2009 del Consejo sobre la marca comunitaria. (2009). Recuperado de http://eurlex.europa.eu/LexUriServ/LexUriServ.do?uri=OJ:L:2009:078:0001:0 042:es:PDF.

Reglamento (UE) 2015/2424 del Parlamento Europeo y del Consejo (2015), por el que se modifica el Reglamento (CE) $N^{\circ}$ 207/2009 del Consejo sobre la marca comunitaria, y el Reglamento (CE) N²868/95 de la Comisión, por el que se establecen normas de ejecución del Reglamento (CE) $\mathrm{N}^{\circ}$ 40/94 del Consejo sobre la marca comunitaria, y se deroga el Reglamento (CE) $\mathrm{N}^{\circ} 2869 / 95$ de la Comisión, relativo a las tasas que se han de abonar a la Oficina de Armonización del Mercado Interior (marcas, diseños y modelos). Recuperado de https://euipo.europa.eu/tunnel-

web/secure/webdav/guest/document_library/contentPdfs/legal_reform lregulation_20152424_es.pdf.

Resolución Nº 030868. (2013). Superintendencia de Industria y Comercio de Colombia.

Resolución $\mathrm{N}^{\circ} 3718$ (02 de febrero de 2016), por la cual se modifican unos numerales del Capítulo primer en el Título $\mathrm{X}$ de la Circular Única de la Superintendencia de Industria y Comercio. Recuperado de la página web de la Red de Juristas de Colombia https://www.redjurista.com/Documents/resolucion_3718_de_2016_su perintendencia_de_industria_y_comercio.aspx\#/.

Resolución $N^{\circ}$ 334. (2017). Superintendencia de Industria y Comercio de Colombia.

Resolución $\mathrm{N}^{\circ}$ 423. (2005). Superintendencia de Industria y Comercio de Colombia.

Resolución $\mathrm{N}^{\circ}$ 4282. (2007). Superintendencia de Industria y Comercio de Colombia.

Resolución $N^{\circ}$ 7357. (2006). Superintendencia de Industria y Comercio de Colombia. 
Resolución N 14029. (2005). Superintendencia de Industria y Comercio de Colombia.

Resolución N² 23313. (2002). Superintendencia de Industria y Comercio de Colombia.

Resolución N³3397. (2006). Superintendencia de Industria y Comercio de Colombia.

Resolución N 42107. (2002). Superintendencia de Industria y Comercio de Colombia.

Resolución $N^{\circ}$ 82327. (2015). Superintendencia de Industria y Comercio de Colombia.

Ruiz, S. (2011). La protección jurídica de las propiedades especiales en el mundo. Evolución histórica de la Propiedad Intelectual. Editorial académica española. España.

Saez, K. (2008). Algunos observan un aumento de marcas no tradicionales, pero no aún en las oficinas nacionales de registro. Intellectual Property Watch/ International IP Policy News. Recuperado de https://www.ipwatch.org/2008/06/27/algunos-observan-un-aumento-de-marcas-notradicionales-pero-no-aun-en-las-oficinas-nacionales-de-registro/.

Sáiz, P; Lobato, L. (2012). Breve historia de la propiedad industrial y de su relación con la actividad innovadora. Edición Factoria I+D. Recuperado de http://www.academia.edu/3150570/Breve_historia_de_la_propiedad_i ndustrial_y_de_su_relación_con_la_actividad_innovadora.

Sánchez, L. (2015). Propiedad Intelectual: Derecho de Autor. Oficina de Transferencia Tecnológica y Propiedad Intelectual. Universidad Privada Cayetano Heredia. Recuperado de http://www.upch.edu.pe/faest/images/stories/uict/prop_intelectual/OT TPI-Derecho_de_autor-28012015.pdf.

Schmitz Vaccaro, Christian. (2012). Distintividad y uso de las marcas comerciales. Revista chilena de derecho, 39(1), 9-31. Recuperado de https://dx.doi.org/10.4067/S0718-34372012000100002. 
Standing Committee on the Law of Trademarks, Industrial Designs and Geographical Indications of the World Intellectual Property Organization - WIPO (2010). Summary or replies to the questionnaire on trademarks law and practice (SCT/11/6). Document prepared by the Secretariat. Wipo/Strad/INF/1 Rev.1.

Superintendencia de Industria y Comercio de Colombia. 2007. Resolución 011956 del 30 de abril de 2007. Expediente $\mathrm{N}^{\circ}$ 05-47635.

Superintendencia de Industria y Comercio de Colombia. 2007. Resolución 26779 del 28 de agosto de 2007. Expediente $\mathrm{N}^{\circ}$ 05-47635.

Superintendencia de Industria y Comercio de Colombia. 2009. Resolución 17152 del 2009. Expediente $N^{\circ} 05-47635$.

Superintendencia de Industria y Comercio de Colombia. 2011. Resolución 0001765 del 26 de enero de 2011. Expediente $\mathrm{N}^{\circ} 10-39538$.

Superintendencia de Industria y Comercio de Colombia. 2011. Resolución 20096 del 15 de abril de 2011. Expediente $\mathrm{N}^{\circ} 10-39538$.

Superintendencia de Industria y Comercio de Colombia. 2014. Resolución 00014655 del 03 de marzo de 2014, Expediente $N^{\circ} 10-39538$.

Superintendencia de Industria y Comercio de Colombia. 2016. Resolución 90525 del 29 de diciembre de 2016. Expediente $\mathrm{N}^{\circ} 10-39538$.

Tratado de Singapur sobre el Derecho de Marcas. (2006). Recuperado de la Página Web de la Organización Mundial de la Propiedad Intelectual - OMPI http://www.wipo.int/treaties/es/ip/singapore/.

Tratado sobre el Derecho de Marcas - TLT. (1994). Recuperado de la Página Web de la Organización Mundial de la Propiedad Intelectual - OMPI http://www.wipo.int/treaties/es/ip/tlt/.

Tinoco, J. (2014). 50 años de historia ASIPI. Historia de la Propiedad Industrial. Asociación Interamericana de la Propiedad Intelectual (ASIPI). 
Panamá. Recuperado de http://asipi.org/wpcontent/uploads/2016/05/Libro-Asipi-50-1.pdf.

Tribunal de Justicia de las Comunidades Europeas (2002). Sentencia del Tribunal de Justicia de 12 de diciembre de 2002. Asunto C-273/00. Caso Sieckmann. Recuperado de http://euipo.europa.eu/es/mark/aspects/pdf/JJ000273.pdf.

Tribunal de Justicia de las Comunidades Europeas (2003). Sentencia del Tribunal de Justicia de 27 de noviembre de 2003. Asunto C-283/01. Caso Shield Mark BV. Recuperado de http://euipo.europa.eu/es/mark/aspects/pdf/JJ010283.pdf.

Tribunal de Primera Instancia de las Comunidades Europeas (Sala Tercera). (2005). Sentencia del Tribunal de Primera Instancia de 27 de octubre de 2005 (Sala Tercera). Asunto T-305/04. Recuperado de http://curia.europa.eu/juris/showPdf.jsf;jsessionid=9ea7d2dc30d65b0 4774c996e4f2283aacff4caf6fad0.e34KaxiLc3qMb40Rch0SaxyLbNr0 ?text $=\&$ docid $=58068 \&$ page Index $=0 \&$ doclang $=\mathrm{ES} \&$ mode $=1$ st $\&$ dir $=\&$ occ=first \&part=1\&cid=80506.

United States Patent and Trademark Office - USPTO. Sonido de Intel. Recuperado de https://www.uspto.gov/sites/default/files/75332744.mp3.

United States Patent and Trademark Office - USPTO. Sonido "Doh" de Homero Simpson. Recuperado de https://www.uspto.gov/sites/default/files/76280750.mp3.

United States Patent and Trademark Office - USPTO. La Fanfarria de Twentieth Century / Fox. T Recupetado de https://www.uspto.gov/sites/default/files/74629287.mp3.

United States Patent and Trademark Office - USPTO. Sonido "Rugido de un León" de MGM. Recuperado de https://www.uspto.gov/sites/default/files/73553567.mp3.

United States Patent and Trademark Office - USPTO. (2017). 1202.13 Scent, Fragance, or Flavor. Trademark Manual of Examining Procedure. 
Recuperado

https://tmep.uspto.gov/RDMS/TMEP/Apr2016\#/Apr2016/TMEP-

$\underline{1200 \mathrm{~d} 1 \mathrm{e} 1 . h \mathrm{html}}$

United States Patent and Trademark Office - USPTO. (2017). 904.03(m) Specimens for Scents and Flavor Marks. Trademark Manual of Examining Procedure.

Recuperado

de

https://tmep.uspto.gov/RDMS/TMEP/Apr2016\#/Apr2016/TMEP900d1e994.html.

United States Patent and Trademark Office - USPTO. (2017). 807.09 "Drawing” of Sound, Scent, OR Non- Visual Mark". Trademark Manual of Examining Procedure. Recuperado de https://tmep.uspto.gov/RDMS/TMEP/Apr2016\#/Apr2016/TMEP800d1e1656.html.

United States Patent and Trademark Office - USPTO. Trademark "Sound Mark" Examples. Recuperado de https://www.uspto.gov/trademark/soundmarks/trademark-soundmark-examples.

Valenzuela, I. La incomoda verdad detrás del peculiar aroma de un automóvil nuevo. Vix. Recuperado de https://www.vix.com/es/btg/curiosidades/8267/laincomoda-verdad-detras-del-peculiar-aroma-de-un-automovil-nuevo.

Vallenilla, R. (2009). Marcas genéricas, vulgarizadas $y\langle\langle$ genericidio $\rangle$ ¿Cómo se resuelve el acertijo? Debates IESA. Volumen XIV. Número 2. Recuperado de http://virtual.iesa.edu.ve/servicios/wordpress/wpcontent/uploads/2013/11/02-09-vallenilla.pdf.

Vicente, L. (2014). Introducción al Estudio sobre el Conocimiento Sensible y la Experiencia. Universidad de Murcia. Recuperado de https://books.google.com.pe/books?id=a44eBQAAQBAJ\&pg=PA349 \&lpg=PA349\&dq=percibimos+de+olores+subjetivo\&source=bl\&ots= xhsQwHc11u\&sig=p3HTe5twHjs-LyWA9cgf-

$\underline{\text { Xiz2OM\&hl=es\&sa=X\&ved=0ahUKEwiu_YioibHXAhVBNSYKH }}$ WpbDo8Q6AEILTAC\#v=onepage $\& \mathrm{q}=$ percibimos $\% 20 \mathrm{de} \% 20$ olores $\%$ 20subjetivo\&f=false. 
Vilches, D. (2013). Propiedad intelectual. Fundamento de signos distintivos. Instituto Nacional de Defensa de la Competencia y de la Protección de la Propiedad Intelectual (INDECOPI). Lima.

1 minuto de respiración (Darth Vader). Recuperado en https://www.youtube.com/watch?v=izprRKeQwkA.

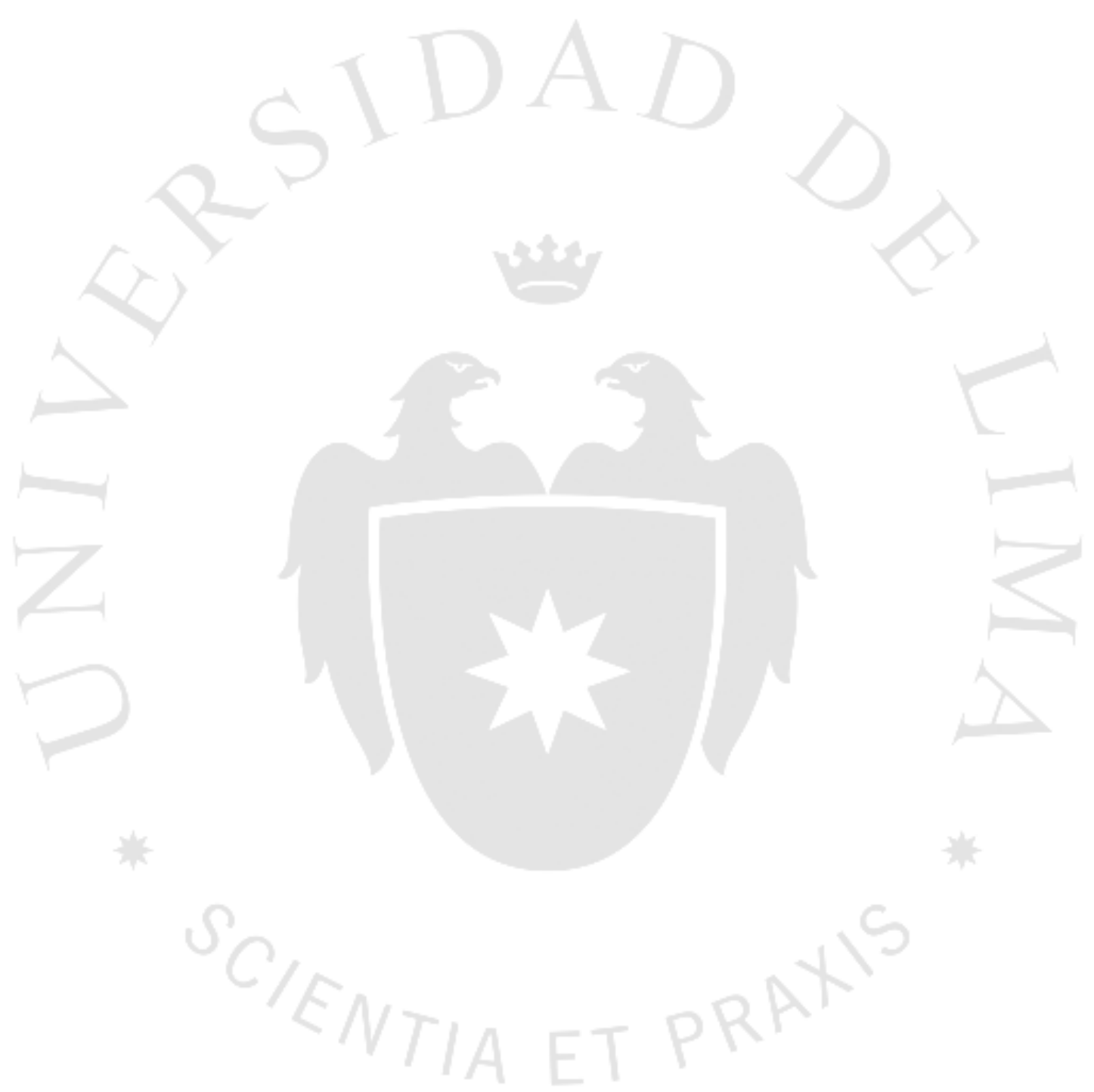

